\title{
Han Dynasty (206BC-AD220) Stone Carved Tombs in Central and Eastern China
}

by

\section{Chen Li}

Merton College

A thesis submitted in partial fulfilment of the requirements for the degree of Doctor of Philosophy

School of Archaeology

University of Oxford

Hilary Term 2015 



\begin{abstract}
This thesis studies Han Dynasty stone carved tombs in Central and Eastern China. These multi-chambered tombs were constructed from carved stone slabs, and were very popular among the Han people. However, such horizontal stone structures were entirely new, and were a result of outside stimuli rather than an independent development within China. The stone carved tombs were a result of imitating royal rock-cut tombs, while the rock-cut tombs were stimulated by foreign examples. Moreover, many details of stone carved tombs also had Western features. These exotic elements were incorporated to satisfy specific requirements of the Han people, and reflected the desire to assimilate exotica within Chinese traditions.

Some details within stone carved tombs showed high level of stone working technologies with Western influences. But in general the level of stone construction of the Han period was relatively low. The methods of construction showed how unfamiliar the Western system was to the Han artisans. Han Dynasty stone carved tombs were hybrids of different techniques, including timber, brick and stone works. From these variations, Han people could choose certain types of tombs to satisfy their specific ritual and economic needs.

Not only structures, but also pictorial decorations of stone carved tombs were innovations. The range of image motifs is quite limited. Similar motifs can be found in almost every tomb. Such similarities were partly due to the artisans, who worked in workshops and used repertoires for the carving of images. But these also suggest that the tombs were decorated for certain purposes with a given functional template. Together with different patterns of burial objects and their settings, such images formed a way through which the Han people gave meaning to the afterworld.

After their heyday, stone carved tombs ceased being constructed in the Central Plains as the Han Empire collapsed. However, they set a model for later tombs. The idea of building horizontal stone chamber tombs spread to Han borderlands, and gradually went further east to the Korean Peninsula. The legacy and spread of the Chinese masonry tradition was closely related to the political circumstances of late Han and post-Han period. The spread of stone chamber tombs in Northeast Asia is presented as a part of a long history of interactions between different parts of Eurasia.
\end{abstract}




\section{Acknowledgements}

First of all, I would like to express my deepest gratitude to my supervisor, Professor Dame Jessica Rawson. Her intellectual guidance has greatly enlarged my understanding of Chinese archaeology. Her suggestions of comparing materials from different cultures have been invaluable. Her thorough reading and editing of my written work has always left me in awe. I am proud to have had her as my supervisor.

I would like to thank Dr. Janet DeLaine, Dr. Frances Wood and Dr. Peter Ditmanson for their insightful suggestions during my transfer and confirmation interviews as well as in the final viva. I am especially indebted to Dr. DeLaine for her one-on-one tutorial on the study of the construction of ancient architecture.

I am also grateful to a number of individuals in China: Professor Wan Shuyuan and Professor Sun Changchu of Tongji University for their continuous support; Dr. Deng Fei of Fudan University for her help and suggestions; Professor Liang Yong of Xuzhou Museum for accompanying me to various sites.

I would also like to express my gratitude to friends and fellow students: To San Han Bang members Chen Xuan and Liu Yan for sharing academic and non-academic interests; To Wu Hsiao-yun, Chen Xin, Chen Yi and Tseng Chin-yin for their invaluable support and advice to survive in Oxford; To Jack Carlson for Roman readings; To Peter Hommel for Russian materials; To Yang Xue and Chen Beichen for offering help when I was in difficulties; To Cao Yecheng for sharing food and laughter in the English sunshine.

This thesis was written under a Merton College Domus A - Chinese Ministry of Education joint scholarship. And travel grants from Merton College, Au-Reyes and Meyerstein foundations allowed my field trips to China.

Last but not least, I would like to thank my wife, Hu Xiujuan, whose love and encouragement comforted me during my writing. This completed thesis would not have been possible without her support. 


\section{Table of Contents}

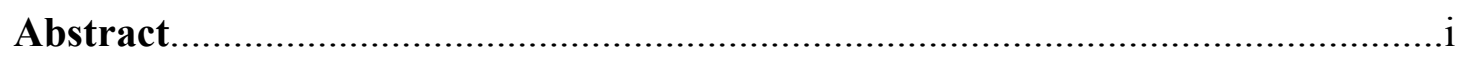

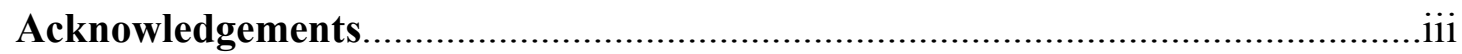

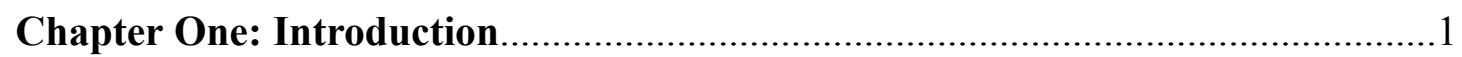

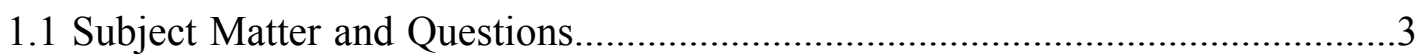

1.2 Literature Review: Primary Sources............................................................ 18

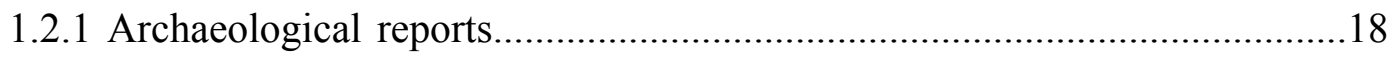

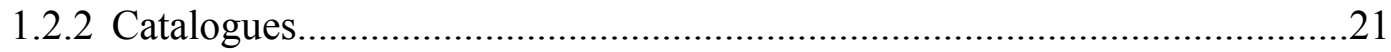

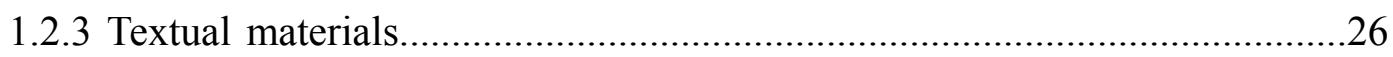

1.3 Literature Review: Secondary Sources..........................................................29

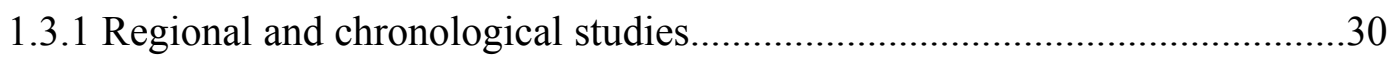

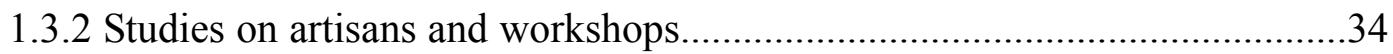

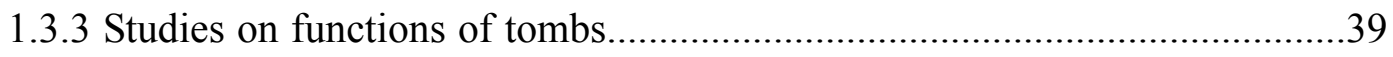

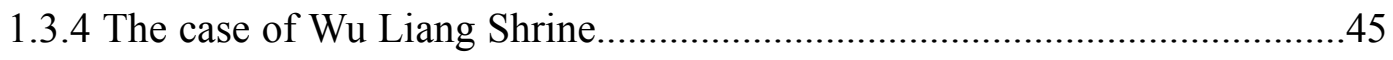

Chapter Two: the Construction of Stone Carved Tombs......................................51

2.1 Comparisons: Timber, Brick and Stone Constructions in the Han.....................53

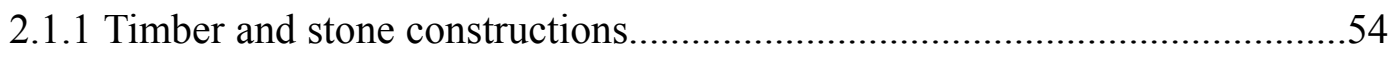

2.1.2 Brick and stone constructions...........................................................61

2.2 The Architectural Processes of Stone Carved Tombs........................................67

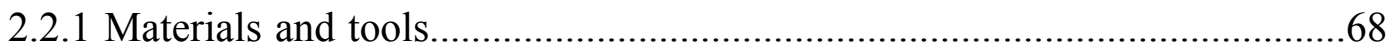

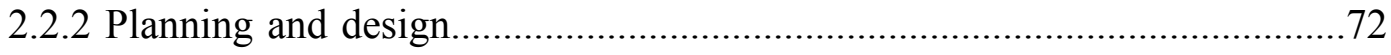

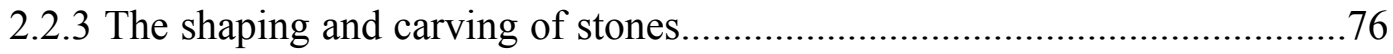

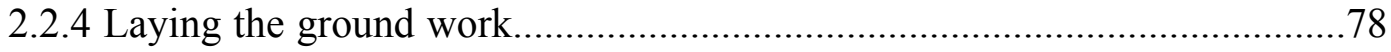

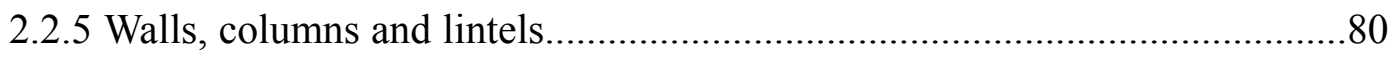

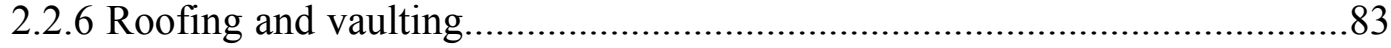

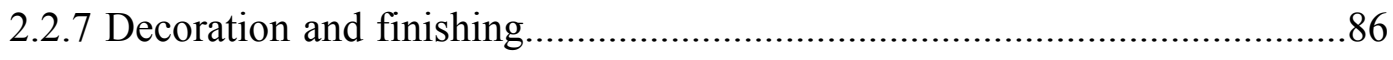

2.3 Case study: the construction of the Chefushan tomb No. 2.............................91

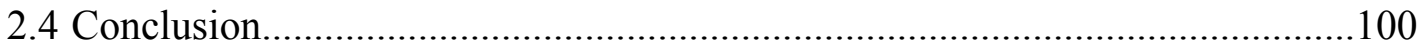


3.1 The developments of burial images in early China........................................105

3.2 Carved images within Han period stone tombs.............................................. 109

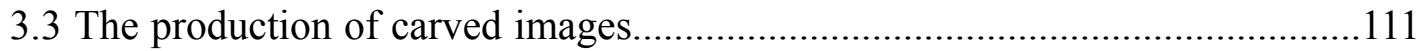

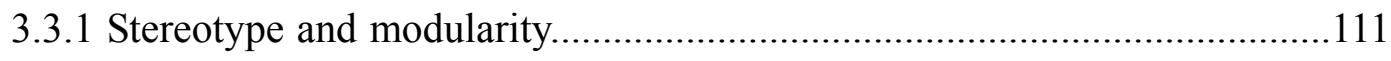

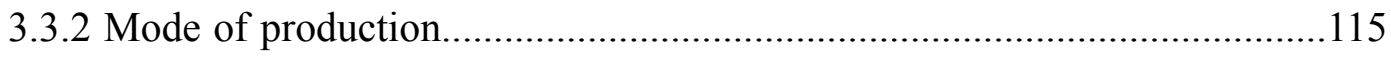

3.4 Understanding images within stone carved tombs.........................................119

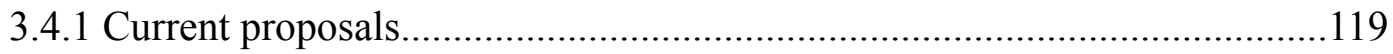

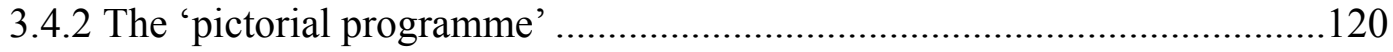

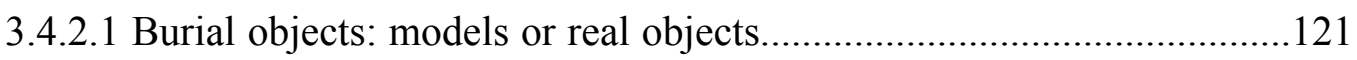

3.4.4.2 Images as models: substitutions or equivalences..............................124

3.5 Case studies: the pictorial programmes of stone carved tombs........................126

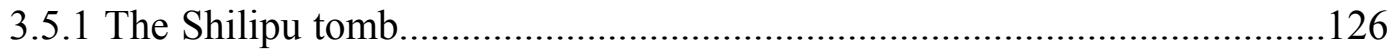

3.5.3 Comparisons: Western Han and Eastern Han kingly tombs........................129

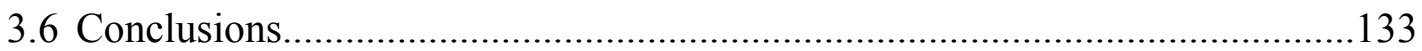

Chapter Four: the Origins of Stone Carved Tombs..........................................135

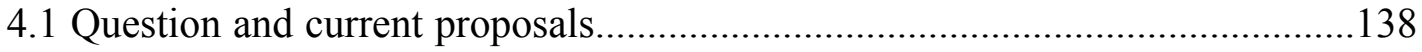

4.2 Independent development or outside stimuli? ................................................. 141

4.2.1 The use of stone in pre-Han China..........................................................141

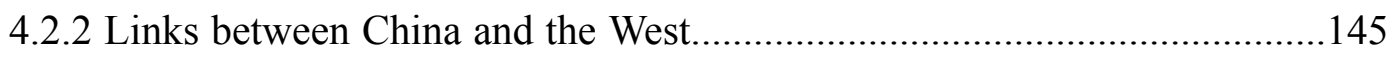

4.3 The introduction of rock-cut tombs: from India or Iran? ..............................147

4.4 From rock-cut tombs to stone carved tombs...................................................154

4.5 Exotic elements in stone carved tombs............................................................ 164

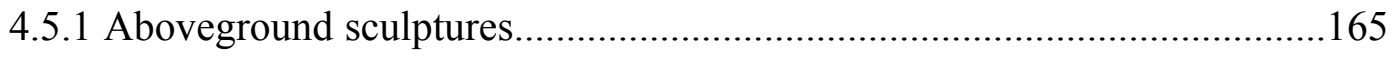

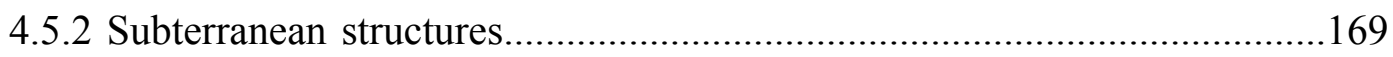

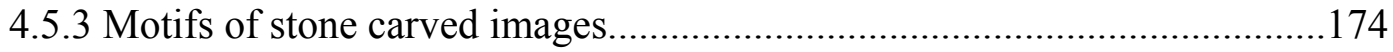

4.5.4 The assimilation of outside elements within China..................................180

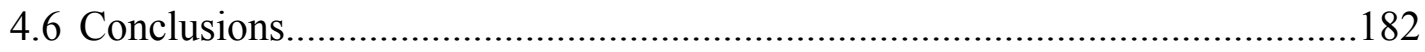


5.1 Late Han and post-Han political geography..................................................190

5.2 Late Han stone carved tombs in Han borderlands............................................197

5.2.1 The Northwest: Northern Shaanxi and Western Shanxi............................197

5.2.2 The Southeast: Zhejiang Province.........................................................202

5.2.3 The North: Beijing and Tianjin area.......................................................208

5.3 Post-Han masonry tombs in Han borderlands...............................................212

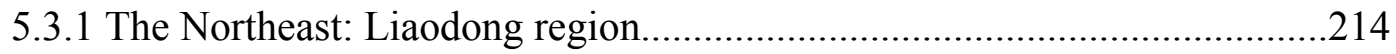

5.4 Further Northeast: the Koguryo Kingdom.................................................218

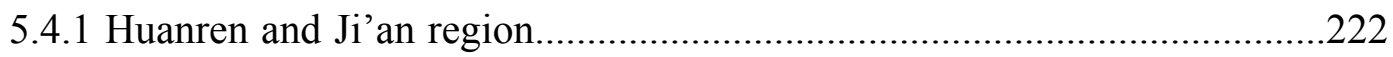

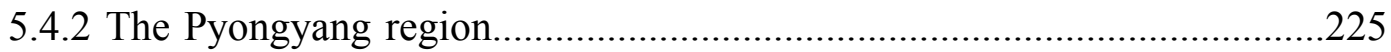

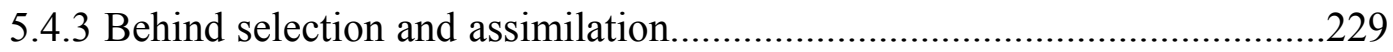

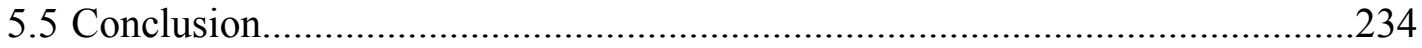

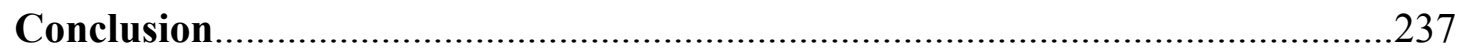

\section{Appendices}

Catalogue of Examined Stone Carved Tombs........................................................241

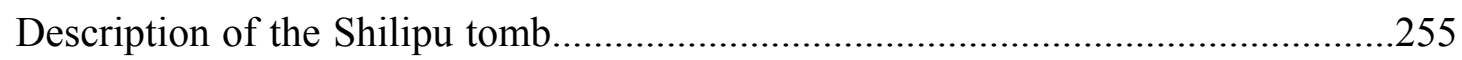

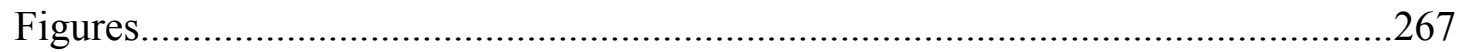

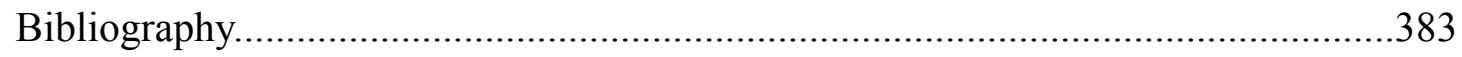




\section{Chapter One: Introduction}

孝文皇帝居霸陵, 北臨廁, 意悽愴悲懷, 顧謂厗臣曰: “嗟乎! 以北山石為槨, 用紵絮 斮陳漆其間, 豈可動哉!”

When the Emperor Xiaowen of Han (r. 180-157BC) was at the Baling Mausoleum, facing northwards by the Ba River, he had a bleak and mournful feeling, and thus turned around and looked at his ministers, saying 'Alas! If I could use stone from the northern hill to build my outer coffin, with finely tailored cloths and lacquers inside, how could it be disturbed!'

\section{-Hanshu 漢書: biography of King Yuan of Chu 楚元王傳 ${ }^{1}$}

Well before his death, The Xiaowen 孝文 Emperor $^{2}$ of Western Han 漢 (206BC-AD9) had decided to construct a safe and luxurious tomb for himself to enjoy in the afterlife. The historical text, the Hanshu 漢書, records that, later, he took one of his ministers' advice, and built a relatively simple tomb instead. But his mausoleum, the Baling 灞陵, as can be seen today, is not by any means a simple one. Located near the Ba River in the southeast suburbs of the capital city of Chang'an 長安, the Baling Mausoleum was constructed in an existing mountain rather than an earthen mound, as was chosen for other Western Han imperial tombs. The Baling has not been excavated, so that exact details, especially the interiors, remain unknown, but its appearance is impressive enough, indicating how important it was to the Emperor.

The Xiaowen Emperor was not alone. In fact tombs and burials have been

\footnotetext{
${ }^{1}$ Hanshu: p. 1951. Translated by the author.

${ }^{2}$ Xiaowen is the emperor's posthumous title, also translated as Emperor Wen or Wendi. In this thesis he will be referred to as Emperor Xiaowen.
} 
essential to Chinese people of all social status, at all times. Since as early as the Shang 商 period (c.1500-c.1050BC), starting from when the Central Plains of modern China could first be understood as 'China', it had been very common for the elites to bury whatever they could afford in their tombs. One of the well known examples is the tomb of Fuhao 婦好 (d. c.1200BC), who was one of the wives of King Wuding 武 丁 (r. 1250-1192BC) of the Shang. This is one of the best preserved Shang royal tombs and was not disturbed before excavation. Large numbers of artefacts, including jades, bronzes, potteries and cowry shells, have been excavated. Remains of sacrificial dogs and even human sacrifices have also been found. Fuhao's lacquered coffins, as well as numerous burial objects, were all buried within an earth pit, which is 5.6 metres long, 4 metres wide and 8 metres deep. ${ }^{3}$ Such tomb structure became standard, and was used by the elites through the Zhou 周 period (c.1050-221BC) to the Han Dynasty (206BC-AD220).

However, there was a major change in the Western Han period, when the Chinese people changed from one type of tomb, namely the vertical shaft tomb, to a variety of tomb types, including but not limited to rock-cut tombs ${ }^{4}$, stone carved tombs and brick chamber tombs. How did this happen? Why were stone tombs built at all? What are the consequences? A key issue that will be examined to answer these questions is a brand new and extremely interesting tomb type: the stone carved tombs

\footnotetext{
${ }^{3}$ For the excavation report see Anyang 1980.

${ }^{4}$ In this thesis 'rock-cut tombs' include tombs that belonged to princes or kings of minor semi-autonomous kingdoms of the Han Empire. Such tombs were built by cutting several linked rooms on a horizontal axis into small rock mountains. Most of the tombs have long access passages with small chambers either side. For references see Mancheng 1980, Yongcheng 1996, 2001, Guangzhou 1991 and footnote 31 of this chapter.
} 
in Central and Eastern China, the subject matter of this thesis.

\subsection{Subject Matter and Question}

In this thesis, the term 'stone carved tomb' includes multi-chambered tombs that were constructed from carved stone slabs or a combination of moulded bricks and carved stones. Most of such stone slabs are highly decorated with carved bas-relief images of banqueting, chariot excursions, music and dance, exemplary portraits, buildings and deities. ${ }^{5}$ To build such tombs, first an earth pit was dug into the ground, and then prepared stone blocks were put together to form house-like chambers, in which the coffins and burial objects were placed. Finally the entrance was sealed and earth was piled up over the tomb to form a mound. In some areas a stone or wood offering shrine was built in front of the tomb. Other above ground structures, such as stone animals, steles and pillars, were sometimes erected. But only a few of these have survived. Such stone tombs appeared in late Western Han, namely the second half of the first century $\mathrm{BC}$, and gradually became popular, disappearing at the beginning of the third century AD, when the Han Empire collapsed.

In 1965, an example of such a tomb was found in the village of Baiji 白集 near Xuzhou 徐州 in Jiangsu 江蘇 Province. The multi-chambered tomb is neatly constructed from stone slabs, and has an entrance hall, a main room, two rear rooms

\footnotetext{
${ }^{5}$ In Chinese language archaeological reports and academic works, these stone tombs are usually referred to as huaxiangshi mu 畫像石墓, or literally pictorial stone tombs, simply because the stone slabs (huaxiangshi) are decorated with images. Also the slabs and their rubbings have been collected and studied as important works of Han dynasty art history, though they were not created for such connoisseurship.
} 
and two side chambers (Fig. 1-1a). Many of the slabs carry carved images with multiple motifs, such as buildings and figures, music and dance, as well as supernatural animals. There are features suggesting a house, for instance, a window indicated by vertical slats in stone, and facetted columns (Fig. 1-1b). Moreover, remains of a stone offering shrine have been found in front of the tomb. The gables of the shrine were also highly decorated with carved images of horses and chariots, exemplary portraits, auspicious animals and deities (Fig. 1-1c). This tomb dates to the late second century $\mathrm{AD}$, and is one of the most complete examples of Han stone carved tombs. $^{6}$

Such stone carved tombs were primarily distributed in the most densely populated areas of the Han Empire. However many of their tomb occupants are not known, as most of the tombs were looted many times before archaeological excavation. Those occupants who have been identified were mainly landowners, official scholars, and occasionally nobles. The stone carved tombs can be divided into five groups according to their distribution and characteristics, such as carving techniques and construction types (Map 1-1). The first group includes tombs from the Qi-Lu 齊魯 Region in present-day Shandong 山東, Northern Jiangsu, Northern Anhui 安徽 and Eastern Henan 河南 provinces. $^{7}$ The second region is the Nanyang 南陽 Basin, including the area around the present-day Nanyang city in

\footnotetext{
${ }^{6}$ For the archaeological report and more pictures see Kaogu 1981.2: 137-150.

7 These tombs are distributed in a vast area that does not coincide with political boundaries, neither modern provincial borders nor Han period administrative boundaries. However, this region roughly covers the territories of Qi and Lu Kingdoms of the Warring States period (475-221BC). Therefore it is referred to as 'the Qi-Lu Region' in this thesis.
} 
Henan Province and a small part of Northern Hubei 湖北 Province. The third region is the Capital Region around Luoyang 雒陽, ${ }^{8}$ capital of the Eastern Han (AD25-220), and is surrounded by the other four regions. The fourth group includes tombs of Northern Shaanxi 陝西 and Western Shanxi 山西 provinces, while the fifth region is the Sichuan 四川 Basin. ${ }^{9}$ This thesis deals with the first three regions which are referred to as 'Central and Eastern China' in the thesis title. ${ }^{10}$ Such masonry tombs in different regions of China were built in various ways and thus had diverse local structures.

${ }^{8}$ The Chinese characters for the modern city of Luoyang are 洛陽, but in the Eastern Han period Luoyang was written as 雒陽.

${ }^{9}$ Stone tombs from the fourth and fifth regions are very different from the central and eastern ones in terms of tomb construction and imagery motifs. They were developed later than, and may have been influenced by the central and eastern ones, which will be discussed in Chapter Five. Stone tombs in the fourth and fifth region appeared in early or middle Eastern Han, and disappeared even earlier. For instance, in North Shaanxi Province, the Han people retreated from this area around AD140, consequently Han tombs ceased to be constructed in this region. Han stone tombs of this area were located in the Wuding 無定 River and the Tuwei 秃尾 River valleys, which were the borders and trade routes between the Han and their neighbours, the Xiongnu 匈奴. Thus they contain an array of special decorative motifs associated with, or influenced by the Xiongnu peoples. For a discussion of stone carved tombs in this region see Wallace 2010. Moreover, in some cases, several family members might have been buried in the same multi-chambered tomb, which may also occur in the Nanyang Basin but was otherwise rare in Eastern China.

In the Sichuan Basin, the Han stone tombs are mainly cliff tombs, namely rock-cut tombs, which are located in the Jialingjiang 嘉陵江 and Minjiang 峮江 River Valleys. Such tombs were constructed by cutting into mountains to form a corridor, then cutting sideways to create tomb chambers. Normally, they have structures that imitate above-ground buildings, while in Central and Eastern China the Han stone tombs are only partially like buildings. In Sichuan sarcophagi were also used within these cliff tombs. For an intensive study of tomb structure, pictorial carvings and burial objects on stone tombs in Sichuan, See Chen Xuan 2014.

${ }^{10}$ Martin Powers called a similar region 'Northeastern China' in his Art and Political Expression in Early China, see Powers 1992. It is true that geographically this area is in the northeast part of the Han Empire, but generally it has never been referred to as 'Northeastern China' in any academic work. More commonly it is called Zhongyuan 中原 in Chinese, literally the Central Plains. As one of the most populated areas in the Han (Map 1-5), it is fair to call this region 'Central and Eastern China' though it is not geographically central. 
The first area, the Qi-Lu Region, has the largest number of excavated stone tombs of the three regions (Map 1-1). The most elaborate stone carved tombs were mainly found in this region, and many of them were carved with the most advanced techniques of the three regions. Such multi-chambered tombs were constructed from stone slabs and sometimes stone columns, with varieties of carving techniques and roof types. However, not all masonry tombs in the Qi-Lu region were made from stone alone. Small moulded bricks of different shapes were also used, especially for the building of roofs, most of which were supported by stone walls. In many cases, a stone offering shrine was built in front of the tomb mound. Other above ground structures, such as stone animals, steles, and pillar gates, were sometimes also erected. Chronology and typology of tombs in this area is very complicated, and one of the most elaborate examples is the Baiji tomb described above. This late Eastern Han tomb has almost all the principal features of tombs in this region: it is a multi-chambered pure stone tomb; most of the stone slabs are highly decorated with carved bas-relief images, using a wide range of carving techniques (Figs. 1-1a, b). ${ }^{11}$ In some major chambers, there are stepped caisson roofs (Fig. 1-1d). Moreover, it has several faceted columns, one of which stands on the back of an animal, placed

\footnotetext{
11 The carving techniques of the pictorial stones are very diverse. In addition to some strongly cut low relief, high relief and sculpture, which were used on columns and architectural structures, most of the stone slabs were carved with bas-relief. On the surface of the smoothed stone, the design might be executed in line engraving only; the background might be cut away to a slight depth, leaving the figures in flat relief; sometimes the designs were engraved and the background might be textured with vertical striations to create a stronger contrast; the figures might be cut in intaglio with slightly bevelled edges against a plain background or on a striated background; and again the background might be cut away to the depth with the contours of the figures slightly rounded. For details of the chronology and typology of carving techniques see Xin Lixiang 1982.
} 
between chambers. These features were popular and can be found in many tombs of this area. Such tombs differ from each other in terms of size, number of chambers, number of columns, and carving techniques.

The Yinan 沂南 tomb No. 1 in Yinan county of Shandong is one of the biggest and most complex stone carved tombs of the Eastern Han period. ${ }^{12}$ It has nine chambers covering an area of 88 square metres (Fig. 5-21a). There are many elements, for instance stone doors, columns, lintels and even a lavatory, suggesting a house. Two roof types have been used for the chambers, stepped roof and caisson roof, which were also used in many other tombs in the Shandong area. ${ }^{13}$ It dates to the late second century AD. Another elaborate example has been found at Mengzhuang 孟莊 near Ji'nan 濟南, capital of Shandong Province. ${ }^{14}$ The tomb was built from 161 stone slabs and was accessed by a passage way (Fig. 2-4). It has a rectangular rear chamber, and a square front chamber divided into six parts by a series of columns. Each of the seven rooms is paved with polished stone slabs, and each has a sloping roof, made by four trapezoidal stone slabs to form a vault, with a rectangular slab as the key stone. All the stone slabs were put together with a structure similar to that of mortise and tenon joints of woodwork, and the junctures of the stone sections were mortared. This form of construction suggests that the artisans were not very familiar with using stone, but had some sort of timber box construction in mind. All columns and lintels are decorated with relief images. It is dated to the second half of $2^{\text {nd }}$ century $\mathrm{AD}$ by the

\footnotetext{
${ }^{12}$ For the archaeological report, see Yinan 1956. For an intensive study on the Yinan tomb, see Thompson 1998.

${ }^{13}$ Details of such stone roofs will be discussed in Chapter Two.

${ }^{14}$ For the report see Wenwu 2002.2: 38-52.
} 
excavators, according to its planning, structure, carving techniques used and coins unearthed.

Some of the earliest Han stone tombs were found in the second region, the Nanyang Basin. Most Han tombs in this region were constructed from a combination of carved stones and moulded bricks, mostly for vaulted roofs. The stone slabs formed the chamber walls or tomb doors, while the bricks formed the vaulted roofs, sometimes decorated with images of celestial bodies. Such stone-brick combinations were common in the Nanyang Basin and in the Capital Region, and were occasionally found in the Qi-Lu region. Two types of construction have been applied in Nanyang. The first type of tombs were multi-chambered, but their plans are slightly different from those in the Qi-Lu Region, where normally the whole plan of a tomb looks like a cross (Fig. 1-2). In the Nanyang Basin, the tombs normally have a front chamber and two or three back chambers in parallel. Sometimes they also have a back chamber or a corridor. Altogether the tomb plan forms a shape of a rectangle (Figs. 1-3 and 1-4). So far there is no archaeological evidence indicating that there used to be shrines erected in front of such tombs.

The Chenpeng 陳棚 tomb in Nanyang is one of the best examples among Nanyang tombs. ${ }^{15}$ This tomb dates to the Xin 新 period (AD9-23), ${ }^{16}$ and has most

${ }^{15}$ For the excavation report with coloured photographs see Kaogu xuebao 2007.2: 233-266, plates 5-16.

${ }^{16}$ The Xin period, also known as the Xin Dynasty, lasted from AD 9 to 23. Its only Emperor, Wang Mang 王莽 (c.45BC-AD23), rose to power as the nephew of an Empress Dowager of the Western Han Dynasty. Wang finally proclaimed himself emperor in AD9. The usurper was however an incompetent ruler and died during peasant rebels in AD23. The Han dynasty was 
of the features described above (Fig. 1-4). Colour painting remains are found on the surface of the carved stones. Moreover, just like many other stone tombs in this area, though it has been robbed, many burial objects still survived. They have supplied extra information for the dating of the tomb, and for the function of the tomb as a whole.

The Qilingang 麒麟崗 tomb at Nanyang is another good example. ${ }^{17}$ Like most typical tombs in this area, this tomb had a square plan and was constructed from a combination of bricks and stone slabs (Fig. 2-1a). Altogether 111 stones were used for its construction. It had one front chamber facing west, and three parallel rear chambers. Each chamber had a flat roof, which was made from a row of stone slabs laid upon the stone walls. Above each flat roof, a brick barrel vault was also constructed. The barrel vault bricks were laid in separate rows with mortar between them. The whole structure was constructed in an earth pit dug into the ground, with the roof slightly lower than the ground level. The floors of the tomb chambers were paved with small bricks. In the front chamber and the south rear chamber, a brick-lined drain was also built. When the tomb was excavated, the central parts of its foundation had sunken slightly beneath its original level, disturbing the tomb structure. As a result several lintels and slabs were cracked (Fig. 2-1b). It is dated to early Eastern Han, according to excavators' analysis based on carving techniques used and burial objects unearthed from the tomb. ${ }^{18}$

restored, known as the Eastern Han, after the overthrow of Wang Mang.

${ }^{17}$ For the archaeological report, see Nanyang 2008.

18 Nanyang 2008: 32-33. 
Apart from the square ones mentioned above, tombs in the Nanyang Basin were also built according to other plans, with different types of roofs. One of the examples is the tomb belonging to Feng Rujiu 馮孺久 in Tanghe 唐河 County of Nanyang. ${ }^{19}$ Accessed by a passage way, it had a front chamber, two side chambers, and two rear chambers surrounded by a tunnel (Fig. 2-2a). The side chambers had brick barrel vaults, and main chamber's roof was a domed brick vault (Fig. 2-2b). The tunnel had a flat stone roof (Fig. 2-15a), and was merely 1.34 metres high, which means that people could not stand or walk easily through it. It used 154 stone slabs, 22 for the flat roof, 34 for flooring, 26 for door posts, 10 for doors and 62 for walls. Its date is AD17 according to inscriptions on the middle door post of the main chambers. ${ }^{20}$

In the Capital Region around Luoyang, large numbers of Han tombs have been excavated, most of which were constructed from moulded bricks or decorated with murals. However, a few stone chamber tombs have also been found. Among the stone tombs, the Dahuting 打虎亭 tombs in Xinmi of Henan Province are the best examples (Fig. 1-5). ${ }^{21}$ Dahuting tomb No. 1 has a relatively unusual plan compared to the ones in Nanyang and Qi-Lu. It is accessed by a twenty-metre long passage way, and has a main chamber with five side chambers surrounding it (Fig. 2-3a). Each side

\footnotetext{
${ }^{19}$ For the report, see Kaogu хиеbao 1980.2: 239-262.

${ }^{20}$ The inscription carved on the central column of the main chamber reads: ‘鬱平大尹馮君 孺久始建國天鳳五年十月十七日癸巳葬千歲不發 Prefect of the Yuping Commandery, Mister Feng Rujiu, buried on the seventeenth day of the tenth month, fifth year of the Shijianguo Tianfeng era (AD17). This tomb will not be opened in a thousand years.' For a rubbing of the inscription see Kaogu хиеbao 1980.2: p. 248, Figure 14.

${ }^{21}$ For the report see Mixian 1993. Mixian 密縣 (Mi County) was name of Xinmi shi 新密 市 (county-level city of Xinmi) before 1994.
} 
chamber is linked to the main chamber with short passageways. Big stone blocks, rather than stone slabs, were used to construct the tomb walls and barrel arches. Small bricks were used to line the outer side of the tomb structure and to construct the facade of the tomb (Fig. 2-3b). All the stone blocks were very carefully carved and dressed, and were put together with white clay mortar. Roofs of all the chambers were barrel vaults, which were constructed from carefully cut voussoirs. Most chamber walls were decorated with relief carvings, except the central chamber. Surfaces of its walls were polished, but not carved. Instead, slots were carved into the cornerstones on the floor. In the slots, remains of decayed timber have been found, indicating that wooden boards were probably fixed in the slots. It is very likely that murals were painted on the wooden surfaces. Tomb No. 2 is similar to No. 1 in terms of planning, structure and carving techniques. The interiors of Tomb No. 2 were decorated with both stone carvings and murals. The excavators believe that both Dahuting tombs date to late Eastern Han. ${ }^{22}$

Although the Dahuting tombs and the Qilingang tomb all had barrel vault roofs, they are of very different types. In the Dahuting tombs, barrel vaults were built right above the chambers, creating high-ceiling spaces, while in the Qilingang tomb and many others in the Nanyang basin, such spaces were separated off by stone slab roofs. The functions of Nanyang brick barrel vaults above flat stone roofs are not clear, but one of the key reasons is probably mechanical. Flat roofs were not strong enough to endure the weight of the rammed earth mound burying the tomb, and vaulted roofs

${ }^{22}$ Mixian 1993: 349-357. 
were obviously more stable. Indeed many flat tombs were found cracked while excavated, while those covered by barrel vaults were more likely to have survived.

Apart from the Dahuting tombs, most other Eastern Han masonry tombs in the Capital Region, especially the ones around Luoyang, were generally constructed from small moulded bricks. Many of them had stone doors, and sometimes stone posts and lintels. However, it seems that stone carving techniques in this tomb and even in this third region have no special local style; instead most of them have many features that can be found in other regions. Located on the crossroads of Han Empire's most developed areas and surrounded by the other four stone tomb distribution regions, stone tombs in the Capital Region showed features of other regions, and were probably influenced by works in other regions at different periods. Such local variations are thus essential to the study of chronological and typological differences of Han stone tombs.

This thesis covers a broad area of Han stone tombs rather than concentrating on a few tombs for the following reasons. First of all, Western scholars started looking at such stone tombs and shrines in the $1880 \mathrm{~s},{ }^{23}$ but most of their works were limited to a few specific examples. There has not been a comprehensive discussion of Han funerary monuments in Western languages. ${ }^{24}$ Secondly, most of the extensive works

\footnotetext{
${ }^{23}$ In 1881, Stephen Bushell for the first time brought several rubbings of Han pictorial stones to Europe. See Bushell 1910 (vol. 1): 26.

${ }^{24}$ Martin Powers asserts that the distinctions between Han stone tombs from different regions are 'commonly known to undergraduates in Chinese art survey courses' (Powers 1992: 113). But I do not think this is the case, as there is no book from which Westerners could easily get the background knowledge of Han stone carvings. Thus there is a gap between textbooks and
} 
in Chinese or Japanese have their own constraints. For instance, they tend to look at the individual stones separately. Little attention has been paid to the tomb as a whole, or to the people who were engaged with the tombs. Examples of these approaches are discussed in the literature review. Moreover, most of the works are now more than a decade out of date; thus they have not benefited from the most recent archaeological discoveries of stone tombs and relevant Han materials.

So far hundreds of major Han stone tombs and countless individual stone slabs have been excavated, and these tombs are distributed in most of the densely populated areas of the Han Empire, thus demonstrating that they were widely accepted and used by Han people. However, such masonry structures were entirely new in the Han period, as was their figural decoration. Many scholars have written on stone tombs, but few of them have paid attention to this issue. Why and how did stone tombs appear and become popular in the Han?

Therefore, a major topic of this thesis is the source of this new trend. Chinese scholars have generally set all tomb structures into a single developmental series within the area of China. Such arguments are obviously unsatisfactory and are discussed in the literature review. However, Chinese scholars have supplied illuminating ideas about the emergence of stone carved tombs. They argue that the rise of economy and prosperity of both Western and Eastern Han made the construction of stone tombs possible and popular. ${ }^{25}$ It is true that dates of the major stone carved tombs are mainly Eastern Han, when the number of landowners and the 
size of their wealth had increased. However, these can not explain why stone tombs appeared during the Han, as carving techniques and mass production for hard materials, such as jade, had been used since a very early period, when stone tombs were not built. It is more likely that the wide expansion of stone funerary monuments was not due to technical but religious reasons. ${ }^{26}$ On the other hand, the decline of the Eastern Han may have also stimulated the further development of stone tombs. The collapse of the imperial economy, plagues and uprising in the second century AD may have significantly affected the beliefs that pressured people to seek for eternity. ${ }^{27}$

Many scholars working in English have suggested outside stimuli for the origin of stone funerary monuments. Ann Paludan and $\mathrm{Wu}$ Hung have argued that stone structures were introduced to China during $2^{\text {nd }}$ century $\mathrm{BC}$, when rock-cut tombs appeared in China, firstly as princely tombs. ${ }^{28}$ Following this development, brick tombs and later stone carved tombs became popular lower down the social scale. Jessica Rawson has suggested that the workers who created the rock-cut tombs and smaller stone built tombs may have borrowed features from Western Asia by way Central Asia or Siberia. ${ }^{29}$ More importantly, she has pointed out that scholars have overlooked the role of rock-cut tombs as providing an impetus for an entirely new tomb structure at all levels of Han society. ${ }^{30}$

\footnotetext{
${ }^{26}$ Paludan 1991: 15-16.

27 See Twitchett and Fairbank 1987: Chapter 5 for details of the fall of the Han dynasty, details include court disorder, uprisings and rebellions; see Chapter 11 for Han economics, such as the increase of landowners' wealth, as well as elite officials and eunuchs.

${ }^{28}$ See Paludan 1991 and Wu Hung 1995.

29 This is reflected in a series of papers. See Rawson 1999a: 24-25, footnote 71; Rawson 2010a: 79-88; and Rawson 2012.

${ }^{30}$ Rawson 1999a: footnote 8.
} 
This thesis will assess how the use of stone spread from the imperial family down to the commoners, by examining the relationship between smaller stone tombs and princely tombs. The Xuzhou region will be explored as a case study. In this region there are several princely rock-cut tombs ${ }^{31}$ and many stone carved tombs, among which there are two unusual examples, the Lalishan 拉犁山 tomb $\mathrm{M1}^{32}$ and the Jiunüdun 九女墩 tomb ${ }^{33}$. They are similar to other stone carved tombs in terms of structure and decoration, but remains of jade suits have been found in these tombs, which shows that the tomb occupants were probably princes or at least nobles of high social status. Thus these may illustrate the possible link between royal tombs and commoners' stone tombs. Another related question concerns the routes by which the structures and motifs of stone carved tombs were influenced by foreign examples. Specific characteristics of stone tombs will be considered.

A further aspect of developments in China is the regional diversity. Stone carved tombs in the separate regions are very different from each other in terms of carving techniques, construction methods, and sets of images, as is mentioned above. Thus

\footnotetext{
${ }^{31}$ Xuzhou was the seat of the Chu 楚 Kingdom during the Western Han and was ruled by relatives of the royal family. So far at least sixteen rock-cut tombs at eight sites have been found in the hills around the city and have been identified as tombs that belong to the $\mathrm{Chu}$ kings. Major tombs have been excavated and published, for the Guishan 龜山 tombs, see Kaogu xuebao 1985.1: 119-137, and Kaogu 1997.2: 36-46; for the Beidongshan 北洞山 tomb, see Wenwu 1988.2: 2-18, 68, and Xuzhou 2003; for the Shizishan 獅子山 tomb, see Kaogu 1998.8: 1-20, Wenwu 1998.8: 4-33 and Xuzhou 2012.

32 Two stone carved tombs have been excavated at Lalishan in Xuzhou. For short excavation reports see Xuzhou 1986: 123-124 and Xuzhou 1990: 208-209. Jade suit remains have been found in M1.

${ }^{33}$ For the archaeological report and pictures see Kaogu tongxun 1955.2: 31-33, plates 8-12. Jade plaques that are believed to be jade suit remains have been excavated. See Kaogu tongxun 1958: 57-59 for discussions of the jade plaques.
} 
another group of major questions include what and why are there these regional differences? Many Chinese scholars have distinguished regional and chronological varieties of carving techniques, but the differences in tomb structures and image sets have been overlooked. Thus this thesis will divide excavated stone tombs into groups according to their distribution and look at their regional variations, focusing on types of construction and sets of images. Other relevant issues will also be discussed, such as the construction process for a tomb, considering how the patrons may have ordered them and masons built them. Lastly, the relationship between stone tombs and other kinds of tombs will be discussed, including brick tombs and tombs decorated with murals. The reason for considering these is that, the distinction between stone tombs, brick tombs and mural tombs is not clear cut. ${ }^{34}$ From such comparisons it is possible to get a better idea of the characteristics of stone tombs, and the reason why people chose certain types of tombs.

Having considered the regional varieties of stone tombs, some other questions arise: Do the different types of tombs (and their decorations) function in the same way? What are the tombs for? Such questions are important because, by focusing on them, it is possible to consider the objectives of a tomb. One of the striking features of the stone tombs is their highly decorated stone reliefs. Although there are regional differences between the stone tombs, the range of motifs of images is limited,

\footnotetext{
${ }^{34}$ First of all, Han tombs constructed from a combination of stones and bricks are very common. Secondly, examples of combinations of stone carvings and murals within one tomb can also be seen, for instance the Dahuting tombs, see Mixian 1993. A recent archaeological find, the Han Dynasty stone tomb in Dongping County of Shandong, even shows us examples of tomb murals painted on the surface of smoothed stones (Fig. 1-6), for the report see Dongping 2010.
} 
including the tomb occupants' activities, exemplary portraits, supernatural deities and architectural decorations. These suggest that the tombs were decorated for certain purposes within a given functional template. Thus this thesis will examine how such templates were achieved by using pictorial programmes together with the house-like structure of the tombs, and the objects buried with the dead. On the other hand, in Han stone tombs, a variety of images are arranged within different pictorial programmes, and sometimes a higher percentage of certain motifs can be seen in tombs from certain regions. For instance, in the Nanyang Basin and the Capital Region, motifs of celestial bodies or supernatural forces were often arranged on the ceilings of stone tombs. This phenomenon is rare in other regions. Consequently this thesis will also look at how the tomb functions were achieved diversely in different regions.

After their heyday in the Eastern Han, stone carved tombs ceased being constructed in Central China as the Han Empire collapsed. It seems obvious that, as some scholars have observed, the stone tombs disappeared simply because of the times of turbulence at the end of the Han, when people could no more afford expensive and labour intensive stone tombs. ${ }^{35}$ Yet the question is, did such stone tombs really disappear? Archaeological evidence shows that similar structures have been found in tombs of borderlands of the Han Empire, in tombs of the following Chinese dynasties, as well as in tombs of the Koguryo 高句麗 Kingdom (traditional dates 37BC-AD668) of the Korean Peninsular. Thus this thesis will also examine the legacy and spread of this masonry tradition, to see how and why people from later

\footnotetext{
${ }^{35}$ For such discussions see Xin Lixiang 2000: 19-20; Li Falin 1982: 50.
} 
Chinese periods and other areas of Asia chose a similar structure. As a result the significance of Han stone tombs in relation to the broader concerns of Chinese funerary practice will be discussed, as well as the tombs' influence on other regions of the world.

\subsection{Literature Review: Primary Sources}

\subsubsection{Archaeological reports}

To date, around 200 Han stone tombs have been excavated in central and eastern China, and large numbers of archaeological reports have been published. ${ }^{36}$ Most of the reports are in short articles. These reports are written by local archaeological teams who conducted the excavation, and normally consist of the following parts: an account of tomb structure and plan, a list of burial objects, long paragraphs of detailed description of pictorial stones and illustrations of stone rubbings, and a short conclusion with a basic discussion on tomb dating, stylistic analysis and tomb occupants if applicable. Sometimes they also have charts or photographs. The report of the previously discussed Chenpeng tomb in Nanyang is a typical one. This report consists of four main parts: 1 , an account of tomb structure, with drawings of tomb plan, side view, front view and descriptions. 2, a list of burial objects, with photos, line drawings, and descriptions of their distributions with in the tomb. 3, detailed descriptions of positions and contents of the pictorial stones, with a chart and many

\footnotetext{
${ }^{36}$ For a full list of tombs and their archaeological reports, see Part I of Bibliography and Appendix 1.
} 
rubbings as well as coloured photographs of stones. 4, a short conclusion about the tomb's date and occupants. ${ }^{37}$ For some well preserved big tombs or closely related tomb groups, monographs are compiled and published in addition to the short report, most of which are of high quality. ${ }^{38}$

Such reports supply the most important and direct resource for the study of Han stone tombs, but the weaknesses of most of the archaeological reports are obvious. First of all, too much attention is usually paid to the carved decoration on the stones, ${ }^{39}$ and the illustrations are mainly low quality rubbings. Where line drawings of the stones are provided, it is difficult to recognise the carving techniques or even the content of images. Often one has to rely on the descriptions, since there are no photographs. Of course, images in reports of later dates are normally of better quality (Fig. 1-4). But because of the limit of publication formats, rubbings are always unsatisfactory in almost all the article reports.

Secondly, the reports on tombs from different regions have different problems.

\footnotetext{
${ }^{37}$ For more details see Kaogu xuebao 2007.2: 233-266, plates 5-16.

${ }^{38}$ For instance, after the archaeological excavation of the Dahuting tombs at Xinmi, the team published a short report in Wenwu 1972.10: 49-62. But after that they gradually put together more information, made rubbings of all the stone carvings, drew all the murals, and arrived at some new conclusions on major issues like tomb occupant and dating. Consequently in 1993 they published a new monograph with maps, line drawings, coloured photographs and an English abstract (see Mixian 1993).

Another example is the Yinan tomb report monograph, though it was published in the 1950s, its quality is still better than some recent ones (see Yinan 1956).

Also in Xiaoxian 蕭縣, Anhui Province, the local museum excavated hundreds of Han tombs of different sizes and types from several highway construction sites. Then they published a monograph of a group of tombs, several of which are stone tombs (see Xiaoxian 2008).

39 The main reason is the tradition of cataloguing stone carvings. These will be discussed in sections below. Another reason is probably that most of the tombs have been robbed many times before scientific excavation, thus there is not too much to say except to list the pictorial stones. However, the archaeologists usually fail to discuss the construction of the tombs.
} 
In the Capital Region near Luoyang, as discussed above, large numbers of many kinds of tombs from all periods of Chinese history have been excavated. However, it seems that the local archaeological team pays more attention to bigger and more luxurious ones, such as imperial tombs. Ordinary Han stone carved tombs have long been ignored. Thus their reports are relatively short and simple, if there are any.

In the Qi-Lu region, which includes present-day Shandong, Northern Jiangsu, Northern Anhui and Eastern Henan provinces, the reports bring another problem, which is that most of the tombs were excavated by local provincial archaeological teams. Thus the excavators tend to emphasise local features of the tombs to distinguish them from those in neighbouring areas. However, such descriptions sometimes cause confusion. For instance, there are large numbers of Han stone tombs in the area around modern city of Xuzhou. But today the tombs are separated by provincial borders, consequently they are excavated and published by different archaeologists from Jiangsu, Shandong, Henan and Anhui Provinces, each stressing local features, while the links between the tombs are rarely mentioned. ${ }^{40}$ But in fact, it is clear that the tombs are not far from each other and most of them can be put into the same group in terms of features such as tomb structure and carving techniques.

Relevant tombs will be divided into groups according to their geographical

\footnotetext{
${ }^{40}$ In fact such regionalism is a general trend in all aspects of Chinese archaeology. Lothar von Falkenhausen discusses the 'regionalist paradigm' in Chinese archaeology. He argues that as a result of administrative reorganizations, many articles published in the regional journals concentrate on cultural phenomena within their provinces, stressing those features that distinguish them from neighbouring provinces. He concludes that regionalist supremacism is merely because Chinese archaeologists have had to adapt to gain official support and legitimation. See von Falkenhausen 1995: 198-217.
} 
distributions, so as to carry out further studies. However, the groups do not have to coincide with political boundaries, neither modern provincial borders nor Han period boundaries. Therefore, it is essential to avoid this modern-day regional bias. The idea of 'economic macro-regions' will be adopted. This idea is developed by G. William Skinner, who divided late imperial China into nine units of economic analysis he calls macro-regions. ${ }^{41}$ Likewise, the Han Empire can also be divided into several different economic macro-regions, based on watersheds, population densities, natural resources, extent of rural peripheries, and trading patterns. The regions often cross both Han period and modern political boundaries, as they follow their geographic and economic determinants. This approach is very helpful to underpin the groups of stone carved tombs, for their distribution often coincides with the economic macro-regions.

\subsubsection{Catalogues}

Scholarship on Han funerary stones started in the Song 宋 dynasty (AD960-1279) and was revived during the Qing 清 period (AD1644-1911). The main interest of these antiquarians was to collect rubbings of pictorial stones or inscriptions. Due to the long history of studies on the stone tombs, there is a tradition of scholars making rubbings of the funerary stones, both for scholarship and for connoisseurship. ${ }^{42}$ It is possible that the famous Northern Song (AD960-1126)

\footnotetext{
${ }^{41}$ Skinner 1977: 211-252, 275-352.

${ }^{42}$ In China there is a long history of making rubbings of inscriptions and carvings, which is to lay a piece of paper over a carved object, for instance a carved stone slab, and to apply ink using small silk wads to the paper to register the entire surface of the object, then the image shows up on the paper for connoisseurship or antiquarian studies.
} 
scholars, Ouyang Xiu 歐陽修 (AD1007-1072) and Zhao Mingcheng 趙明誠 (AD1081-1129), compiled rubbings of Han stone carvings in their works Jigu lu 集 古錄 and Jinshi lu 金石錄, according to the records in the books, but unfortunately just the texts have survived. A Southern Song (AD1127-1279) scholar, Hong Kuo 洪 适 (AD1117-1184), compiled inscriptions on Han stone carvings in his book Li shi 隸釋 and woodcut illustrations of relevant stone images in $L i x u$ 隸續, where he made commentaries, which can be regarded as the earliest research on Han stone carvings. ${ }^{43}$ Such collections provided the only way for such scholars to 'possess' this material. The process incidentally proved a good way to preserve and circulate images of stone carvings, which were difficult to move. Qing scholars published many compilations of Han stone carvings, ${ }^{44}$ but most of them are simple records without illustrations. In 1821 Feng Yunpeng 馮雲鵬 and Feng Yunyuan 馮雲鵷 published their index to antique bronzes and stone carvings, Jinshi suo 金石索, in which they illustrated many individual images drawn after Han stone carvings. ${ }^{45}$ The commentaries concentrated on analysing them based on received early texts (Fig.

\footnotetext{
${ }^{43}$ All of the mentioned works have been compiled and photocopies of early editions have been published in Shike shiliao xinbian 石刻史料新編, see Lin Ronghua 1957, 1979, 1982 and 1986. Modern printed and edited versions with punctuation of some of the above books have also been published.

44 In 1789, Weng Fanggang 翁方綱 (AD1733-1818) published his Liang Han jinshi ji 兩漢 金石記 on bronzes and stone carvings of the Han. In 1797, an even more detailed book Shanzuo jinshi ji 山左金石記 was compiled by Bi Yuan 畢沅 (AD1730-1797) and Ruan Yuan 阮元 (AD1764-1849), concentrating on antiques from Shandong. For compiled early editions in Shike shiliao xinbian 石刻史料新編 see Lin Ronghua 1957, 1979, 1982 and 1986.

45 The first editions of this book are now very rare. Photocopies of late Qing editions have been published. For an 1821 edition, see Beijing 1996.
} 
1-7). ${ }^{46}$ Unfortunately, as this work was published before the invention of photography, illustrations in the catalogue are woodcut prints, not rubbings. Thus, they do not show the original appearance of the stones accurately. However, some of the illustrations are now the only available resource of specific pieces of stone, as the original stones are lost or weathered beyond recognition.

The Song and Qing cataloguing tradition has influenced the interests of modern Chinese scholarship. In the past decades, many catalogues of the funerary stones have been published. Most of such catalogues are compilations of rubbings of stones, with a general introduction and description of contents of images. These hardly differ from the traditional cataloguing approach.

Among the most typical ones is the eight volumes of Zhongguo huaxiangshi quanji 中國畫像石全集. ${ }^{47}$ This work compiles rubbings of stones from important tombs and individual stones that have survived. Sometimes the editors provide photographs for high reliefs and sculptured stones. Unsurprisingly, the tomb stones are compiled and divided into groups in different volumes according to regional distributions based on current provincial boundaries. Moreover, there are also rubbing catalogues of stones from particular regions published by local institutions. ${ }^{48}$ The contents of these books are generally organised according to themes of images, as

\footnotetext{
${ }^{46}$ On two pages of this Qing dynasty work, the authors wrote their commentary on the three edges of the images: the right one tells the images' position in the shrine; the bottom captions describe figures in the images; while the left one is an explanation based on received texts.

47 Shandong and Henan 2000.

48 In the Qi-Lu Region, many such catalogues have been published, see Shandong 1982, Xuzhou1959, 1985 and 1995, Shangqiu 1991, Huaibei 2002. Catalogues of stone tombs of the Nanyang Basin include Nanyang 1981, 1985, 1988 and 1990. In the Capital Region, as discussed above, stone tombs have received little attention, thus there is no regional catalogue. For a full list of catalogues, see Part II of Bibliography.
} 
they are mainly compiled for connoisseurship.

The collection of rubbings as seen in most of the above catalogues is a traditional Chinese approach to gathering information. This interest derives from the importance of cast bronzes and carved bone and stone inscriptions. It was early found to be possible to do rubbings of these inscriptions and thus make them available to scholars. Such catalogues provide a good resource of images of stone tomb decorations, as the rubbings are of relatively better quality than the ones from archaeological reports. But the problems of such catalogues are as obvious. Firstly, in almost all the catalogues, stones from tombs are separated and put together in a new order. Thus the purposes arising from the positions of stones are lost. The stones are considered as individual items rather than as sets of stones, therefore their pictorial programmes are ignored. Secondly, the catalogues also have the same kind of regional bias as the archaeological reports, stressing local features and ignoring links between the tombs from neighbouring areas. Moreover, the regional catalogues are normally edited by local scholars, archaeologists or museum curators, so that they are likely to overvalue local material and thus it is difficult to gain a balanced view from the catalogues. $^{49}$

\footnotetext{
${ }^{49}$ In one of the regional small catalogues of stone carvings found around Shangqiu 商丘, a city of Eastern Henan, the editors are aware that this area borders Northern Jiangsu and Northern Anhui, but still emphasise that stone carvings in this area have many differences from the ones in Xuzhou (Northern Jiangsu) and have an obvious local style for which they give superficial reasons. (Shangqiu 1991: 1 and 11) In fact these tomb stones can be seen as part of a big group with the ones of the neighbouring areas though they are separated by modern provincial boundaries. Moreover, the editors have praised the 'artistic representation' of Shangqiu stone carvings after a comparison between the ones from Shandong, Nanyang, Northern Shaanxi and Northern Jiangsu (Shangqiu 1991: 1), which is disingenuous, as they have obviously excessively praised everything.
} 
Catalogues of the pictorial stones have also been compiled by Japanese and Western scholars. Because of a long-standing Japanese interest in Chinese artefacts and the influence of traditional Chinese scholarship on Japanese academics, there is rarely any deviation in Japanese catalogues from the Chinese model. One of the benefits of works in Japan is that some museums and universities generously publish their collection of photographs or rubbings online, which are of high quality and very convenient for scholars around the world. ${ }^{50}$

Käte Finsterbusch's immensely useful catalogues are some of the few Western compilations of Han funerary stones. ${ }^{51}$ Her earlier volumes in 1966 and 1971 include a volume of texts and a volume of pictures and rubbings of tomb murals, pictorial stones and moulded bricks. The text volume includes and classifies excavated artefacts according to their regional distribution. Again she relies on modern provincial boundaries. One of the main advantages of this compilation is that each stone is discussed with references to archaeological reports, which enables the readers to trace its origin. The volumes also have well organised appendixes, including a collection of inscriptions from stone tombs and stone offering shrines, and a clear map of archaeological sites' distributions. In 2000 and 2004 Finsterbusch published similar new volumes, which include new archaeological finds made since the 1970s. The new text volume has even better appendixes than the old one, including a list of stone

\footnotetext{
${ }^{50}$ For example, collections of rubbings of Kyoto University are available at its official website: http://kanji.zinbun.kyoto-u.ac.jp/db-machine/imgsrv/takuhon/ (Retrieved 1 August 2014). However, just like the Chinese models, these Japanese collections are compiled and divided into groups according to regional distributions based on current provincial boundaries.

${ }^{51}$ Finsterbusch 1966, 1971, 2000 and 2004.
} 
carvings with dated inscriptions. The purposes of these catalogues are no more than to supply visual information for further studies. They made no attempt at analysis or synthesis of the materials.

\subsubsection{Textual materials}

A wide range of primary textual materials is relevant. Such texts may be in many different forms: texts inscribed in tombs, the standard histories and other ancient texts that may have been relevant to customs, beliefs and activities of Han people.

Although the reliability and authenticity of historical texts have always been questioned, ${ }^{52}$ one can not avoid making judicious use of such texts in archaeological research. Many standard texts written during the Han or about the Han contribute to the study of beliefs and images relevant to stone tombs.

Several early texts, the san $L i$ 三禮 (The Three Rites Canons) are anthologies of ancient rituals. ${ }^{53}$ It is probable that they were used during the Eastern Han as sources for the principles of mortuary ritual practice. ${ }^{54}$ According to the Eastern Han dynastic history, in AD79 Emperor Zhang 章 (r. AD75-88) convened and took part in a conference, after which scholars' attention was directed to the Classical Texts. ${ }^{55}$ The Baihu tongyi 白虎通義 (General Significance of the White Tiger Discussions), the

\footnotetext{
${ }^{52}$ For one of the examples see von Falkenhausen 1993: 839-849.

53 The Three Rites Canons include Liji 禮記, Yili 儀禮 and Zhouli 周禮.

${ }^{54}$ However the date, origin and authenticity of each book are still subjects of dispute, see Nylan 2001: 168-201.

${ }^{55}$ Hou Hanshu: 137-139.
} 
proceedings of this conference, were obviously influential, as they cited many classical texts. The text also offers a rich collection of Eastern Han beliefs and practices. For instance, it has a whole chapter discussing funerary rituals and practices. A similar work, the Lunheng 論衡 (Disquisitions) by Wang Chong 王充 (AD27-97), offers a collection on Han religion, thought and folklore. Another work, the Fengsu tongyi 風俗通義 (General Significance of Customs), which was completed during late Eastern Han, also describes contemporary beliefs and cults. Moreover, several books of southern China origin should not be neglected, such as Shanhai jing 山海經 (Classic of the Mountains and Seas) and Huainan zi 淮南子 (The Masters of Huainan), as they addressed beliefs about the living and the dead as well. Their contents also may have contributed certain motifs found on stone carvings. The standard dynastic histories such as the Hanshu 漢書 (History of the Former Han) and the Hou Hanshu 後漢書 (History of the Later Han) do not have much information that is directly relevant to Han funerary customs and beliefs, but are still useful because detailed records in the works supply abundant resource on funerary practices. ${ }^{56}$ Some texts compiled later than the Han period are also useful sources as they record Han sites that could no longer be seen today. ${ }^{57}$

Indeed, the problems of texts should not be ignored. Textual evidence

\footnotetext{
${ }^{56}$ For one of the most typical academic works, see Yang Shuda 1933. Yang's book discusses wedding and funerary customs in the Han, which is mainly a compilation of records on wedding and funerary activities from all kinds of Han texts including the dynastic histories.

${ }^{57}$ One of the most useful later texts is the Shuijing zhu 水經注 by a Northern Wei (AD386-534) scholar Li Daoyuan 麗道元 (AD466-527). This work is mainly about major rivers and their tributaries, but many ancient monuments near such rivers have also been referred to. Some of the mentioned monuments are Han funerary sites.
} 
contributes to the archaeological evidence available. But ancient texts often do not fully reflect the situation in burials. First of all, texts were written for different reasons and often have particular biases. Moreover, the authors were clearly not involved in the masonry work, nor do such texts give detailed information on actual burial rituals. It is unlikely that texts match up well with Han tombs. Thus texts must be examined very carefully. Lothar von Falkenhausen has pointed out that, archaeology is enmeshed in an old and continuous tradition of national history and historical texts in China. He argues that archaeology should be liberated from its present narrowly historiographical agenda. ${ }^{58}$

In the case of activities of patrons and artisans of stone tombs, even standard texts are not available, as the relatively lower ranked patrons and masons are not normally recorded in standard histories, nor were scholars interested in recording their activities. Thus surviving inscriptions on stone carvings are essential for dating tombs and for learning about their patrons, whether they are texts about the contents of images, or inscriptions relevant to tomb construction, or an epitaph of the tomb occupant. ${ }^{59}$ These texts appear on stones in tombs, on offering shrines, or on Que 閶 pillar gates ${ }^{60}$. Such inscriptions are immensely helpful for research on the contents of images, pictorial programmes and activities of patrons and artisans associated with stone tombs.

\footnotetext{
58 von Falkenhausen 1993: 839-849.

${ }^{59}$ Such inscriptions have been found in all the five distribution areas of stone carved tombs. Some texts are dated some are not, but most of them are believed to be inscribed during the Eastern Han.

${ }^{60}$ Que pillar gates are the two tower-shaped pillars that were set up to mark the entry to the burial ground and to memorialise deceased family members.
} 
For instance, there is a famous stone slab carrying more than 300 engraved characters in the Cangshan 蒼山 tomb in Shandong Province. ${ }^{61}$ The text describes in general terms all the images inside the tomb and their positions, which is very helpful in studying the pictorial programme of this tomb and other similar tombs. Among the texts on shrines, inscriptions on the doorpost of the Xiangtajun 薌他君 Shrine from Shandong are the best preserved ones and can be easily identified (Figs. 1-8a, b) ${ }^{62}$ They record issues relevant to the deceased. Most importantly, they also describe the general process of how the patrons and masons built the tomb and shrine. Thus the inscriptions have supplied information about Han stone tomb construction. Moreover, among all the surviving inscriptions, there are many dated texts: either long ones like the Cangshan tomb inscription, or short ones, such as captions of images. ${ }^{63}$ These dated stones are extremely helpful for chronological studies of carving techniques and tomb structures. However, stone inscriptions, just like other historical texts, can be corrupted over time, with interpolations or loss of characters. Thus texts on stone carvings should also be treated with care.

\subsection{Literature Review: Secondary Sources}

Han dynasty stone tombs have always attracted academic interests. In China relevant research goes back to the antiquarians of the Song dynasty, while Western

\footnotetext{
${ }^{61}$ For the archaeological report of the Cangshan tomb, see Kaogu 1975.2: 124-134. For relevant discussions see Wu Hung 1995: 240-250 and Wu Hung 1994b: 81-104.

62 Punctuation and explanations of the inscriptions have been published in Chinese, see Luo Fuyi 1960, Chen Zhi 1988 and Sun Guanwen 2006.

${ }^{63}$ Sometimes carved images have identifying captions supplying names of figures or objects. See Fig. 1-7 for such an example.
} 
scholars started to pay attention to such materials from the 1880 s. Thus secondary discussions on the stone tombs are abundant in various languages including Chinese, Japanese, English and other Western languages. In this section secondary works are divided up according to different categories, in terms of their interests and their relevance to questions raised in this thesis.

\subsubsection{Regional and chronological studies}

Modern comprehensive studies on Han stone carved tombs are mainly undertaken by Chinese archaeologists. Most of their studies concentrate on typological and chronological studies following the mainstream Chinese tradition of archaeology. The most typical and also the best ones are works by academics such as Xin Lixiang 信立祥 and Li Falin 李發林. Xin, based on his master thesis, has built up a typological series in terms of carving techniques, image motifs and image compositions. ${ }^{64}$ Such work supplies a good basis for the study of Han stone tombs, and Xin's typological distinctions have been widely cited by other Chinese scholars. In his 2000 book he examines the ways in which images are arranged within a tomb, ${ }^{65}$ which is rare among Chinese scholars. However, in this book, little attention has been paid to the regional differences in the ways images were put together. On the other hand, Xin divides Han stone tombs into five groups according to their geographical distribution and builds up a chronological series within each group. ${ }^{66}$ His division of

\footnotetext{
${ }^{64}$ Xin Lixiang 1982: 234-306.

${ }^{65}$ Xin Lixiang 2000: 235-271.

${ }^{66}$ See Xin Lixiang 1982 and 2000. In the 2000 book he includes new materials excavated since 1982, and then modifies typological and chronological discussions to make them more
} 
the stone tombs is based on their distribution and characteristics rather than ancient or modern political boundaries (Map 1-1). Such a division is an improvement on other Chinese archaeologists' works, in which it is common to see regional bias.

Li Falin has also worked on the typology and chronology of Han funerary stone carvings. His typological study is based on carving techniques, while his chronological part examines nineteen funerary stones with inscriptions of precise dates from Shandong province. ${ }^{67}$ His results are satisfactory although they refer only to tombs in Shandong and neighbouring regions. Such discussions supply good summaries of excavated materials down to the 1980s. The problem, of course, is that these works are now thirty years old and much new material has been excavated since then.

Moreover, scholars from different regions have also published a series of articles discussing chronology and typology within their regions. For instance, Jiang Yingju 蔣英矩 and $\mathrm{Wu}$ Wenqi 吳文祺 have worked on Shandong stone carvings, ${ }^{68}$ Henan Museum has published pictorial stones from Nanyang; ${ }^{69}$ Xuzhou Museum has published an article analysing funerary stones in their area; ${ }^{70}$ and Guo Xiaochuan 郭 小川 has rebuilt the chronology of the Qi-Lu Region stone carvings. ${ }^{71}$ Most of such discussions are based on carving techniques.

Some Chinese archaeologists have also written on the development of Han stone

abundant and accurate.

67 Li Falin 1982: 42-51.

68 Jiang Yingju and Wu Wenqi 1980.

69 Wenwu 1973.6: 16-25.

70 Wenwu 1980.2: 44-55.

71 Guo Xiaochuan 1997: 171-195. 
tombs. At the end of his book Xin Lixiang talks about the communication and influential relationship between different regions, establishing how such tombs appeared and spread across the Han Empire. ${ }^{72}$ However, this chapter is rather short and unsatisfactory, and Xin ignores all outside influence on the Han stone tombs in this part. Instead he simply assumes that everything was developed within the territory of Han China.

This trend is quite common among Chinese scholars. Most of them have simply conceptualised all tomb structures as arising in a linear development within the area of China. For instance, Huang Xiaofen 黃曉芬 analyses Han tombs, including stone carved tombs, based on intensive archaeological data. She examines almost all known tombs dated from as early as the Qin 秦 Dynasty (221-207 BC) to the end of the Han period, to establish an evolution of tomb types over this period. ${ }^{73}$ She argues that Han multi-chambered tombs were developed from guomu 槨墓 (casket graves), which were tombs with a box-like timber structure buried at the bottom of a vertical pit. Other scholars have even traced the origin of casket graves to the single coffin tombs of the Neolithic Yangshao 仰韶 Culture. ${ }^{74}$ These arguments are obviously too narrow in approach, as they treat China as a region whose culture had no contact with wider activities in Eurasia. Firstly, the Han multi-chambered tombs may have been influenced by multiple sources including stimuli from Inner Asia. Secondly, varieties of tombs observed may not belong to a single line of development. These may be

\footnotetext{
${ }^{72}$ Xin Lixiang 2000: 353-358.

${ }^{73}$ Huang Xiaofen 2003.

${ }^{74}$ For discussions on the development of casket graves, see Huang Xiaofen 2003: 26-93 and Wenwu 2006.6: 49-55.
} 
different regional types rather than different developmental stages. Indeed casket graves and multi-chambered tombs have been used by both upper class and commoners through much of later Chinese history.

Scholars working in English have also interpreted the Han reliefs in their chronological and geographical aspects based on stylistic analysis. Hsio-yen Shih in her $\mathrm{PhD}$ thesis attempts to illustrate 'early Chinese pictorial style', including Han arts through examining the funerary stones on a stylistic basis. ${ }^{75}$ By investigating various issues such as carving techniques, her conclusions on regional chronologies differ from those of Chinese scholars. As an art historian, Shih concentrates on the carved stones. She argues that all stones from different regions and periods can be put into a single developmental series. She takes the Shandong ones as the earliest development, which subsequently influenced Henan. Then, in her view, the Henan masons gradually generated a new style. Similarly, she suggests that early Shaanxi and Sichuan styles were based on those from Shandong and Henan. By contrast, Chinese archaeologists such as Xin Lixiang argue that from the late Western Han to the middle Eastern Han, stone carvings of Nanyang were the most developed among all the regions. He suggests that Nanyang's carving techniques and styles then influenced the Luoyang area, going also as far as Sichuan and even Beijing. In the late Eastern Han, the Qi-Lu region took Nanyang's place, becoming the most advanced and influential region in terms of carving techniques and styles. ${ }^{76}$

Although Shih and Xin end up with different conclusions as art historians and

\footnotetext{
75 Shih Hsio-yen 1961.

76 Xin Lixiang 2000: 353-358.
} 
archaeologists respectively, the discussions about carving techniques are informative.

Such works supply a reasonable basis for later studies on Han stone tombs. However, regional varieties and chronological developments are not just about stylistic elements such as carving techniques. In this thesis, in addition to carving techniques, more attention will be given to tomb structures, tomb plans and pictorial programmes.

\subsubsection{Studies on artisans and workshops}

Carving techniques and tomb construction need to be examined in terms of regional and chronological differences. Thus it is also essential to examine the activities of Han dynasty masons and the operation of their workshops, as after all the tombs were carved and built by them. ${ }^{77}$ Unfortunately, as is discussed in section 1.2.3 of this chapter, textual resources on Han masons and their workshops are very limited, thus such studies have to depend on texts surviving in tombs as well as traces of working practice left in tombs by the masons.

Several views about construction have also been suggested in previous scholarship. Xin Lixiang, whose work is widely accepted and cited within Chinese scholarship, mainly concentrates on the carving of stones that were used to build tombs. Xin summarises the carving of pictorial stones in six steps based on inscriptions on stones from tombs or shrines. According to him the steps are: 1,

\footnotetext{
${ }^{77}$ It is true that the tombs were directly built by stone artisans, but sometimes they have to work according to patrons' requirements, the deceased people's descendants or even the deceased himself could have engaged in the designing and construction of his tomb before his death. Consequently to some extent the patrons might also be regarded as tomb builders. See Section 2.2.2 of Chapter Two for more discussion.
} 
patrons seek out artisans; 2, masons quarry raw stones from hills; 3 , masons smooth and polish stones; 4, draftsmen make sketches for carving; 5, masons carve the stone according to original drafts; 6 , artisans finish the project by adding colours to the carvings. ${ }^{78}$ As Xin has worked in the Chinese tradition, focussing on the subject matter of the images, he only discusses the carving of pictorial stones, without saying anything about how they were used as materials to construct a tomb. He also points out that few academic works have been undertaken on the fifth and sixth steps. Hsing I-Tien 邢義田 approaches the topic in a similar way, with more comments on the social status of Han masons and the use of stencils and patterns to maintain their level of quality ${ }^{79}$ but again he makes no comment on tomb construction. Xin and Hsing merely concentrate on carving techniques of tomb stones, with limited comments on the activities of masons and workshops.

Based on previous scholars' work, Lillian Tseng greatly improves the study of Han stone tomb construction. ${ }^{80}$ She focuses on artisans' workshops, repertoires and the regional visual traditions of the manufacture of Han funerary stones by analysing traces found in the Anqiu 安丘 tomb in Shandong. ${ }^{81}$ The importance of her work is that firstly, she develops the discussion on the use of 'patterns' using a new term getao 格套 (repertoires) ${ }^{82}$. Secondly, she discusses the construction of tomb

\footnotetext{
${ }^{78}$ Xin Lixiang 2000: 22-26.

${ }^{79}$ Hsing I-Tien 1996: 44-59.

80 Tseng 2000: 33-86.

${ }^{81}$ For the archaeological report see Wenwu 1960.5: 55-59, Wenwu 1964.4: 30-40 and Anqiu 1992.

${ }^{82}$ Getao means stone carvings presented by artisans from specified repertoires, usually in alternation. Hsing's approach is similar to that of Lothar Ledderose, as is proposed in Ten Thousand Things: Module and Mass Production in Chinese Art. In Chapter Three of this
} 
chambers, which is rare among other scholars. Moreover, her analysis on regional visual differences is persuasive. Although she just concentrates on tombs of the Qi-Lu area, such methods can be extended in further studies of examples from other regions.

Martin Powers in his book Art and Political Expression in Early China mainly discusses the interaction of Han art and politics, but he also works on the operation of mason workshops by looking at the engraving industry in the area of present-day Shandong. He examines the size of the market, the consistency of market preferences, and the competition between workshops. ${ }^{83} \mathrm{Wu}$ Hung in a chapter of his book Monumentality in Early Chinese Art and Architecture discusses the construction of funerary monuments. ${ }^{84}$ Apart from his discussion on different kinds of patrons, $\mathrm{Wu}$ Hung worked on the Cangshan tomb inscription, establishing a relationship between the inscription which described the images in the tomb and the images themselves. $\mathrm{He}$ also points out that the images are viewed by the artisans and the patrons in very different ways. ${ }^{85}$

Anthony Barbieri-Low has done intensive works on Han masons in his book Artisans in Early Imperial China,${ }^{86}$ although he does not consider the ways in which a whole tomb was built. Barbieri-Low has paid detailed attention to reconstructing the process by which the stones were carved, and he raises several new points, including the use of 'customisable prefabrications', a system used by masons and workshops

thesis both approaches will be incorporated to the study of the imagery of stone carved tombs.

${ }^{83}$ Powers 1992: 110-128.

${ }^{84}$ Wu Hung 1995: 238-250.

${ }^{85}$ Wu Hung 1995: 249-250.

${ }^{86}$ Barbieri-Low 2007: 67-152. 
that allowed most elements of a monument to be constructed off-site using standardised modules. ${ }^{87}$ Barbieri-Low also examines the activities of the stone carving artisans, such as their marketing techniques. His most significant point is the idea of 'economic macro-regions' as discussed above. Although this concept was not developed by Barbieri-Low, he applies this division to the study of Han stone carvings for the first time. Compared with other provincial divisions mentioned above, this approach is much more helpful for the study of Han stone tombs. Barbieri-Low divides the Western Han Empire into six macro-regions. Then he concentrates on activities of masons within the Qi-Lu region, by looking at their work for both royal and private funerary monuments. He concludes that normally the masons travelled no more than 500 kilometres, and operated within one macro-regional area. ${ }^{88} \mathrm{He}$ mentions that this factor probably explains the clear boundaries between regional styles of Han stone carvings, though it seems that such regional boundaries are not clear cut.

Lukas Nickel has worked on Han period brick tombs around Luoyang. He reviews the development of bricks as building materials in early China, and also discusses brick technologies of the Han. Nickel argues that large hollow bricks have been used since the Western Zhou (1046-771BC), and became the preferred building material for tombs in the Yellow River basin. Hollow bricks were no longer used for building tombs from the Xin period, when small bricks became popular. He believes that small bricks were used in China only at the end of the third century BC. They

\footnotetext{
${ }^{87}$ Barbieri-Low 2007: 93-96.

${ }^{88}$ Barbieri-Low 2007: 131-142.
} 
were probably introduced to China rather than an independent invention. The reason is that, at the beginning, small bricks were employed on a large scale, but full knowledge of brick technology remained unknown to builders. ${ }^{89}$

Nickel has also discussed the development of domed and vaulted roofs of tombs around Luoyang. The earliest type, according to him, includes simple barrel vaults that consist of bricks laid out in rows, which were used throughout the Western Han. Then in the first century AD, four-sided domes were developed. During the late first century $\mathrm{AD}$, artisans learned to build barrel vaults with bonded bricks that formed an interlocking pattern. Finally in the late second century $\mathrm{AD}$, alternating rows of voussoir-shaped bricks were lined up to form a more stable type of barrel vault. ${ }^{90}$ Such studies on the development of brick roofs are important to the understanding of stone carved tombs, as in many cases such stone tombs were built from a combination of stone slabs and moulded bricks, and it is very likely that their roofs borrowed features from brick tombs in Luoyang.

However, none of the above authors have really examined the actual building process of stone tombs. Recent archaeological finds and some re-examination of old data will make a study of the construction of stone tombs possible. For instance, a Han dynasty quarry has been discovered in the city of Xuzhou, ${ }^{91}$ though it is the only excavated Han quarry. Thus it is now more feasible to reconstruct the actual building

\footnotetext{
${ }^{89}$ Nickel 2010: 184-191.

${ }^{90}$ Nickel 2010: 189-191.

${ }^{91}$ For the archaeological report see Kaogu 2010.11: 28-39. Traces of masonry workshops, iron tools and abandoned quarry pits have been found. It is very likely that this quarry is relevant to several nearby Han stone tomb sites.
} 
process of Han stone tombs. ${ }^{92}$

\subsubsection{Studies on functions of tombs}

From as early as the Song and Qing dynasties, Chinese scholars have focused on identifying and explaining the themes represented by the images in the tombs. ${ }^{93}$ They treated the stone carvings as individual items, rather than as elements of a complex tomb, but their works are to some extent helpful to the understanding of tomb functions. Even today, the majority of Chinese scholars working on Han stone tombs still concentrate on the interpretation of specific subjects. Among the large numbers of works, Li Falin's book is the most typical one. ${ }^{94}$ Almost all the book is devoted to classifying images on stones into many groups. Then based on a wide range of ancient texts, he analyses different stones carrying similar images. Li provides a good summary of motifs, which is helpful for further research, as his work covers almost all known themes on Han pictorial stones. But surprisingly not a single illustration is offered in this book of pictorial analysis, and again the role of sets of stones and their joint significances are ignored. Moreover, even the explanations of the images are controversial, as his studies are highly dependent on ancient texts, some of which even postdate the Han period. ${ }^{95}$ As discussed above, it is unlikely that texts match up well with Han tombs. Many other issues, such as artisans' activities, should be

\footnotetext{
92 Such studies will be carried out in Chapter Two.

${ }^{93}$ For an early example see Fig. 1-7 and footnote 46.

${ }^{94}$ Li Falin 2000.

${ }^{95}$ For instance, he used the Taiping yulan 太平御覽 to explain images of Queen Mother of the West on Han carved stones, while it is obvious that the Taiping yulan was compiled in the tenth century AD, which was hundreds of years later than the Han.
} 
examined to analyse meanings of images. For instance, the artisans are more likely to be influenced by conventions and patron requirements rather than texts which they are unlikely to have read.

Studies on specific types of images have also been undertaken by Chinese scholars. Most of these works explore meanings and functions of certain motifs of images on the funerary stones. For instance, a collection of essays called Research of Nanyang Astronomic Pictorial Stones has been published to celebrate the $60^{\text {th }}$ anniversary of the Nanyang Museum of Han Stone Carvings ${ }^{96}$. Most articles in the compilation have investigated funerary stones with motifs of celestial bodies or supernatural forces. ${ }^{97}$ Other authors use the stone carved images as illustrations of their texts, to demonstrate other interests such as agriculture, handicraft, and astronomy. For example, stone carvings of scenes of weaving and farming have been widely used to demonstrate developments in Han society. Both types of research are of course limited, and too many assumptions have been made.

Japanese scholars have also written many articles and books on comprehensive studies of Han stone tombs or relevant topics, most of which discuss meanings or understandings of images. Doi Yoshiko 土居淑子 in her book briefly considers the contents of reliefs and the interpretation of images through representation of the dead and the world of the dead, during which she raises the idea of 'time in the images' for

\footnotetext{
${ }^{96}$ Located in Nanyang, central city of the Nanyang Basin, this museum is one of the largest museums for collections of Han stone carvings. Its display of stone slabs is, however, deeply influenced by the Chinese tradition. Individual stones are divided according to their motifs of image. Very few of them are put together in their original sequence in a whole tomb.

97 See Han Yuxiang 1995.
} 
interpreting images. By investigating seasonal time and linear time, she concludes that such funerary reliefs testify to the existence of both views of time in the Han. ${ }^{98}$ Hayashi Minao 林已奈夫 has discussed Han pictorial stones in his book Ishi ni kizamareta sekai 石に刻まれた世界 (The World Carved on Stone). ${ }^{99}$ Just as the book title shows, Hayashi's approach consists in classifying and arranging excavated stones according to the categories of their themes. In many articles Hayashi has also discussed Han funerary arts, ${ }^{100}$ but he is more interested in the life and thought of the Han period reflected on the stones rather than in the tombs as a whole.

Scholars working in Western languages have made many proposals about the styles and functions of Han stone tombs. Martin Powers' work Art and Political Expression in Early China has combined and balanced previous studies on styles and functions of Han stone carvings. Powers discusses the literary, intellectual and social implications of the Han tombs. ${ }^{101} \mathrm{He}$ argues that Han art and politics were both shaped by the rise of the Confucian literati. By considering the construction of funerary monuments, he distinguishes three major traditions of taste and places each of them within a narrative of political conflict. For instance, the Wu Family shrines ${ }^{102}$

\footnotetext{
98 See Doi Yoshiko 1986. She also in her appendix lists relevant tombs with concentration on numbers of carved and raw stones, which is rare among other scholars. She collects a larger number of dated stone pieces than Li Falin does, which is valuable for chronological studies though she does not do so.

99 Hayashi Minao 1992.

${ }^{100}$ For one of the examples see Hayashi Minao 1974: 223-306.

101 Powers 1992.

${ }^{102}$ Details of these shrines are discussed in section 1.3.4 of this chapter.
} 
reflect tastes and ideology of scholar-officials, while the Zhu Wei 朱鮁 shrine ${ }^{103}$ and the Dahuting tomb murals are the artistic expression of luxurious trends among land owners or eunuchs. Then he concludes that the contrast between different traditions of art can be characterised in terms of taste of political and social expression. Thus his work bridges the gap between visual form and social meaning, and finds a balance between artistic analysis and exploration of meaning.

Kim Dramer in her $\mathrm{PhD}$ thesis studies the functions of images on Han dynasty stone carved tomb doors and the functions of the doors themselves. ${ }^{104}$ She argues that, as a result of mortuary innovations during the Eastern Han period, tomb doors and the neighbouring area in a tomb were organisational keys to the tomb structure and pictorial programme, as well as to the performance of ritual necessary to link and transform between the worlds of the living and the dead. Dramer carries out case studies of three tombs from Shandong and Henan. Focusing on tomb doors, she argues that all these structures ensured the link and the transformation through the ritual procession where the doors are integrated into their original architectural setting. In chapters two and three she investigates the structure of a tomb and concludes that the function of a tomb is to act both a space of transition, and a point of transformation in terms of social contexts. Dramer indeed looks at the pictorial programme of a tomb to analyse its functions. Dramer also bridges Han religious contexts and this specific tomb. In her detailed discussions in chapters four and five,

103 See Fairbank 1942: 52-88 and fig. 15 for relevant information.

104 Dramer 2002. 
she argues that the imagery arrangements within the Yinan tomb ${ }^{105}$ resonate with the Han views of cosmology, and images in different chambers have different meanings and functions. ${ }^{106}$ She also considers the dead, the mourners and the public as observers or viewers, to examine their reception of the monument's images.

To get a better understanding of images' functions within tombs, Western scholars such as Jean James explore the study of iconographic programmes of Han stone tombs and offering shrines in a series of works, which supply possible new trends. In her $\mathrm{PhD}$ thesis her most important point is that similar motifs of images are given different meanings in different complexes, and thus have different functions. ${ }^{107}$ In the 1985 article on Han funerary art, she has once again raised the importance of 'context'. ${ }^{108}$ In the 1988 article James focuses on what she calls the 'iconographic program' of the Wu Family offering shrines; her arguments are about finding the pictorial programmes and functions of the shrines. ${ }^{109}$

In fact the study of pictorial programmes of stone tombs had been started much earlier than James' work. Wilma Fairbank in her 1941 article attempts to reconstruct the famous Wu Family Shrines in southwest Shandong Province. She points out that the structural meanings of funerary monuments have been neglected. Then she argues that 'positional significance' rather than individual stones or rubbings should be

\footnotetext{
105 For the archaeological report see Yinan 1956.

106 She argues that within the Yinan tomb, the mingtang 明堂 bright hall, Kunlun 崑崙 mountain and the pillar form the symbolism of the centre; the funerary rites in the front chamber provide for the occupant; and funerary rites of the central chamber representing the journey of the soul.

107 James 1983.

108 James 1985: 283-292.

109 James 1988: 39-72.
} 
considered in order to understand tombs or shrines. The importance is two-fold:

'First, the interrelationships and positional significance of the engraved stones is lost when they are studied as scattered slabs or rubbings. A grasp of this positional significance will be shown to illuminate subject matter at present obscure. Second, the ritual purpose of the buildings as a whole, and the architectural form which expresses it, must continually be kept in mind in any study of the individual parts. ${ }^{110}$

Though these comments are made to support her reconstruction of the offering shrine, such methods remain essential for the study of funerary monuments whether they are tombs or shrines or both.

Until now, however, while certain tombs have been examined and many subjects have been discussed, it is rare for any major academic work to consider the pictorial programme in a tomb as a whole. There is such a study for a Han stone tomb by Lydia Thompson. In her PhD thesis she focuses on the Yinan tomb in Shandong, but raises also a wide range of topics. First of all, she comments on Fairbank's admonition as regards the positional significance of Han pictorial stones in an architectural structure. Then her arguments are directed to investigating the narrative structure of the pictorial stones and reconstructing the pictorial programme in conjunction with the tomb's structural components. Firstly, the architectural structure of this tomb is demonstrated to have cosmological significance, which is to place the dead in an auspicious position. ${ }^{111}$ Secondly, the horizontal structure of the tomb is presented as a journey, incorporating participants including the mourners and the deceased. ${ }^{112}$ Moreover, she

\footnotetext{
${ }^{110}$ Fairbank 1941: 3.

111 Thompson 1998: 152-184.

112 Thompson 1998: 185-247.
} 
also explored questions in a broader sense about the functions of imagery in Han stone carved tombs and in ritual performances. ${ }^{113}$

\subsubsection{The case of Wu Liang Shrine}

Among all the Han dynasty funerary monuments, the Wu Liang Shrine 武梁祠 is probably the most frequently described and published. Thus relevant scholarship will be reviewed so as to show the general situation of studies on specific Han funerary monuments. The $\mathrm{Wu}$ Liang Shrine was erected in AD151 in front of $\mathrm{Wu}$ Liang's tomb near the Wuzhaishan 武翟山 hill in present-day Jiaxiang 嘉祥, Shandong Province. The interior of the walls, gables and ceiling of the shrine are vividly decorated with stone carvings, which makes it famous. ${ }^{114}$ In the Song period, antiquarians recorded images of the site. For a long time it was almost the only group of available images of Han funerary monument. In 1786, Huang Yi 黄易 (AD1744-1802) led probably the earliest archaeological excavation of the collapsed stones, after which it has been well preserved down to today and has always attracted academic interest. ${ }^{115}$

Edouard Chavannes was perhaps the first Western scholar who visited the $\mathrm{Wu}$

113 Thompson 1998: 303-353.

114 In fact the $\mathrm{Wu}$ Liang Shrine is just one of the shrines that belong to members of the $\mathrm{Wu}$ family, and is a part of the buildings of the Wu Family Cemetery, which has stone lions, pillar gates and steles. But because the Wu Liang Shrine is the most famous one, for a long time this term was also used to refer to the whole cemetery. Wu Hung in his $\mathrm{PhD}$ thesis supplies a detailed historiography of the study of the Wu Family Shrines, see Wu Hung 1992a: 38-70. 115 Descriptions and drawings of stone reliefs from the shrines can be found in most of the early publishing mentioned in footnote 43 of this chapter. 
Family Shrines and published relevant academic studies. ${ }^{116}$ In these, he reviewed previous studies on the shrines, and carefully recorded relevant information. He even reviewed previous scholarship on Han funerary art. After that nothing special appears in the list of academic works on the Wu Liang Shrine until 1941, when Fairbank visited the site and afterwards reconstructed all the shrines in her article. ${ }^{117}$ As mentioned above, she drew people's attention to the 'positional significance' of the stones.

Wu Hung in his $\mathrm{PhD}$ thesis goes further, as he compiles and reviews all the available academic works on the $\mathrm{Wu}$ Liang Shrine, and then, not only discusses the pictorial programme of the shrine, but also explores the ideology of the shrine, to show how the images of heavenly omens, immortality and human history created a 'pictorial universe'. ${ }^{118}$

According to $\mathrm{Wu}$ Hung, past studies on stone tombs are either broad studies, to examine the general development of pictorial styles and their relationship with social and religious contexts, or detailed studies, to examine styles or meanings of particular images. ${ }^{119}$ As an alternative, he concentrates on typical tombs, shrines or other sites to analyze relationships between motifs and meanings. In this way he sets out a balance between general social trends, hierarchy, and the ideology of specific tomb

\footnotetext{
116 The French scholar visited China including the Wu Family Cemetery twice in 1891 and 1907, and published two books talking about Han stone carvings, La Sculpture sur pierre en Chine au temps des deux dynasties Han in 1893 and Mission archeologique dans la Chine septentrionale in 1913.

117 See Fairbank 1941. Although she made some mistakes during the reconstruction, her ground breaking work and her method are still useful today.

118 Wu Hung 1992a.

119 Wu Hung 1992a: 70 and Wu Hung 1994a: 48.
} 
occupants. Wu Hung in his $\mathrm{PhD}$ thesis launches this 'balance' and works on a single stone monument, the $\mathrm{Wu}$ Liang Shrine, linking images with the occupant and his social status and ideology. He concludes that the Wu Liang Shrine reflects an early stage of scholar-officials' participation in the creation of artefacts. They regarded, he argues, choosing and arranging images as a means of self expression.

In 2005, an exhibition of the rubbings of Wu Family Shrines was held in Princeton University Art Museum, after which two catalogues Recarving China's Past and Rethinking Recarving were published. ${ }^{120}$ The books are collections of images and essays by relevant scholars, with the purpose of examining the traditional views of the Wu Family Shrines. They reveal certain problems that have been neglected by previous studies, not only in the aspect of Wu Family Shrines studies, but also in the broader field of Han funerary practice and architecture. These problems are following: First, because of the restricted access to the site, scholars have been over-dependent on transmitted texts or rubbings. The lack of fieldwork and close investigation is criticised. Secondly, questions about the textual bias have been raised. Most importantly, funerary practice and architecture have been analysed. For instance, Michael Nylan discusses the above-ground worship halls (offering shrines), as well as their literature and archaeological evidence. ${ }^{121}$ She has raised questions regarding the lack of understanding of the worship halls erected by wealthy commoners, which are also important factors to understand the Wu Family Shrine as a whole. Beyond the Han period and the Wu Family Shrines themselves, their meanings in later periods, for

\footnotetext{
${ }^{120}$ Richard 2005 and 2008.

121 Richard 2008: 196-231.
} 
instance their representation in the Qing dynasty, have also been discussed.

Such academic debates are very beneficial to the promotion of this field. However, there are still several points that have long been neglected. Firstly, two multi-chambered stone tombs associated with the Wu Family shrines were excavated in 1981. But these tombs have never been mentioned in any academic work, though an archaeological report was published in $1995 .^{122}$ Wu Hung was aware of this, but in his book developed from his thesis, he just mentioned the excavation without any discussion, concentrating on the shrine, ignoring the tombs, probably because at that time relevant materials were not available. But today the tombs are still ignored, both academically and materially. The Wu Family Shrines became very famous and a museum was built in as early as 1961 to protect the stone pieces. But it seems that the curators did not pay any attention to the tombs. After the excavation in 1981, everything was just left in situ without any shelter. Now they are filled with sewage and garbage (Fig. 1-9). The tombs have been overlooked by many scholars, probably because of the unusual fact that, by comparison with the elaborately designed and constructed shrines, the associated tombs were barely decorated. However, this is also the reason why they should not be neglected. This material is essential to the study of the Wu Family Shrines, and to explore meanings and functions of this cemetery as a whole. The Wu family spent much money on above ground buildings of their family cemetery, leaving the tombs with only basic decoration. Apparently, functions of these tombs and associated funerary buildings need re-examination.

\footnotetext{
122 See Jiang Yingju and Wu Wenqi 1995: 119-127.
} 
Another issue is the study of Han stone offering shrines in a broader sense. Previous Western studies on Han offering shrines are abundant, but most of them are limited to several specific shrines, including the Wu Family Shrines. Jean James in her general study on functions of Eastern Han shrines argues that such shrines are symbolic structures expressing the need to mourn and to memorialise the dead. ${ }^{123}$ However, the Wu Family Shrines show that, they were primarily built for the living, and only secondarily for the dead. Analysis in later chapters will be based on surviving inscriptions on stone offering shrines, as well as the contrast between tomb chambers and shrine image sets.

123 James 1998: 16-29. 


\section{Chapter Two: the Construction of Stone Carved Tombs}

以其餘財，造立此堂。募使名工高平王 $\square$ 王堅江胡， $\square$ 石連車，菜石縣西南小山陽山。 溷㾖摩治, 規柜施張, $\square$ 帷反月, 各有文章, 調文刻畫, 交龍委虵, 猛虎延視, 玄蝯登 高, 師熊 $\square$ 戲, 眾禽群聚, 萬狩雲布, 台閣參差, 大興舆駕。上有雲氣與仙人, 下有孝 子賢仁。遵者儼然, 從者肅侍, 煌煌濡濡, 其色若 $\square$ 。作治連月, 功扶無亟, 賈錢二萬 七千。

They exhausted all their savings in order to construct this shrine. They invited famous artisans Wang Shu, Wang Jian and Jiang Hu from Gaoping County. The craftsmen carted stone quarried from a small hill called Yangshan in the southwest of the county. Then they dressed and carved the stones, using rulers and compasses. Many of the stones carry drapery and semi-circular decorations. In addition to these, the masons also carved various images: there are interlocking dragons and fierce tigers gazing into the distance; black apes ascend heights; lions and bears roar - animals and birds strewn everywhere like clouds. There are towers and pavilions of different heights; great excursions of chariots. Above, there are clouds and immortals; below, there are figures of filial piety, excellent virtue, and benevolence. Superiors are obedient and look agitated as well as joyous. The craftsmen spent several months to finish the project, which was a great effort. The cost of the shrine is 27,000 qian coins.

- Inscriptions on the An Guo Offering Shrine, AD157 (Eastern Han) ${ }^{1}$

In 1980, archaeologists excavated two stone tombs at Songshan 宋山, Jiaxiang 嘉祥 of Shandong Province. They are both double-chamber tombs constructed from stone slabs with flat roofs. On one of the slabs was carved the above inscriptions, from which we can learn that this slab was originally part of an offering shrine dedicated to An Guo 安國. An's shrine was for some reason torn down in Late Eastern Han, for the construction of the relatively simple tombs at Songshan. The date

\footnotetext{
${ }^{1}$ For the archaeological report of the stone slab carrying the inscriptions see Wenwu 1982.5: 60-70. Inscription translated by the author.
} 
of the An Guo Shrine is AD157 according to the inscriptions, which also recorded the process of how An's tomb and shrine was constructed, saying that the shrine took the craftsmen several months and cost 27,000 qian coins (equals 604.8 grams of gold). Many more such inscriptions have been found within stone carved tombs and other stone offering shrines. ${ }^{2}$ But most of them were about filial piety or the biography of the deceased; obviously it was not their intention to describe the detailed construction process. Very few scholars have worked on the process either - when intensive studies have been undertaken on the relief images of stone carved tombs, few to date have been written on the construction of such tombs. ${ }^{3}$ Some scholars have indeed undertaken studies on the carving of stones, or the activities of artisans and workshops, or case studies, but none of the authors have really looked at the actual building process of tombs. ${ }^{4}$ Therefore major questions remain, what are the characteristics of Han stone buildings? How in general were stones carved and fitted together to build a tomb?

It is probably not that earlier scholars simply overlooked this topic of research, but rather that relevant information, especially archaeological evidence on the

\footnotetext{
${ }^{2}$ See section 1.2.3 of Chapter One.

3 The regionality of Han dynasty stone carved tombs have been noticed and described mainly by Chinese scholars. Examples include Xin Lixiang 2000 and Li Falin 1982. These works are widely accepted and cited by Chinese scholars, but only concentrate on the carving techniques of stones that were used to build tombs.

${ }^{4}$ Several views about construction have been suggested in previous scholarship. Tseng 2000 focuses on the manufacture of Han funerary stones by analysing traces found in the Anqiu tomb in Shandong. Anthony Barbieri-Low raises several new points, including the use of 'customisable prefabrications', a system used by masons and workshops that allowed most elements of a monument to be constructed off-site using standardised modules. He also discussed activities of artisans. See Barbieri-Low 2007. Powers 1992 discusses the operation of mason workshops by looking at the engraving industry in the area of present-day Shandong. For more details see section 1.3 of Chapter One.
} 
construction of Han Dynasty stone tombs, has so far been too limited to support any intensive study. ${ }^{5}$ Beyond the field of Han Chinese buildings, scholars have undertaken many studies of stone construction. In the Roman world, for instance, Jean Pierre Adam has produced an admirable study on Roman architecture, emphasising the process of building through every stage. ${ }^{6}$ This exhaustive study provides rich knowledge of the materials and techniques of Roman building construction, incorporating archaeological finds and other scholars' interpretations. Janet DeLaine has produced an intensive study on the construction of large-scale buildings in Imperial Rome, focusing on the architectural process and the economic implications of the Baths of Caracalla. ${ }^{7}$ Their methods as well as descriptions of Roman construction are helpful to the topic of this chapter.

However, it is not wise to presume that analysis of Han stone carvings even approaches the Western Classicists' studies, as information on Han construction, especially stone structures, is relatively rare. Yet it is not impossible to discuss the actual construction of tombs, if other alternatives are taken into account. Recent archaeological finds and some re-examination of old data have made a study of the construction of stone tombs feasible.

\subsection{Comparisons: Timber, Brick and Stone Construction in the Han}

\footnotetext{
5 The lack of published archaeological evidence probably indicates that the Chinese archaeologists were not interested in such questions, thus did not record relevant information. For reviews of Chinese archaeological reports, see section 1.2.1 of Chapter One.

${ }^{6}$ Adam 1994.

${ }^{7}$ DeLaine 1997.
} 
The following section will propose comparisons between buildings of different materials and dates, for instance timber construction, brick laying, and stone masonry in the Han as well as in later Chinese periods. Such comparisons will be treated as supplementary evidence in addition to limited archaeological evidence, so as to obtain a better understanding of the actual building process of Han stone tombs and its particular characteristics.

\subsubsection{Timber and stone construction}

\subsubsection{Timber construction in Han China}

The main material for all buildings above and below ground in the Central Plains of China had, from a very early period, been wood. But wood is vulnerable to fire and is likely to decay, so that no above-ground timber architecture dating to before the Tang 唐 Dynasty (AD 618-907) has survived. For the appearances of Han wood buildings we have to rely on contemporary literary descriptions and pictorial representations, as well as wall paintings, pottery models, or ironically stone carvings. ${ }^{8}$

\footnotetext{
${ }^{8}$ Many literary works of the Han, for instance the very popular $f u$ 賦 odes, have described the appearances of Han wood architecture. See Quan Han fu: 527 - 533 for one of the examples. In this long ode Wang Yanshou 王延壽 describes the structure, appearance and murals of Lingguang Palace 靈光殿, which belonged to a king of the Lu 魯 Kingdom of the Western Han period in present-day Shandong Province. Above-ground timber buildings have also been depicted on wall paintings (Fig. 2-5a). Pottery models of houses and manors were often made and buried in Han tombs (Fig. 2-5b). For more pottery examples see Guo Qinghua 2010. Architecture was a popular motif of the relief images in Han stone carved tombs. Not only appearances, but also details were represented on such stone carvings (Fig. 2-10a).
} 
Fortunately details of Han carpentry have been preserved underground, in the form of wooden coffins buried in mortuary pits, being the traditional early Chinese form of burial. ${ }^{9}$ One of the best examples is the Mawangdui 馬王堆 tomb M1, which belonged to the wife of a marquis of the Han period, and is dated to 175-145BC. ${ }^{10}$ Buried at the bottom of a pit was a box-like timber structure, which consisted of an inner coffin and several outer coffins. These burial caskets were very neatly constructed from 70 pieces of fir board, the heaviest one of which is 4.84 metres long, 1.52 meters wide, 26 centimetres thick and weighs around 1500 kilograms. The boards were fitted together with a variety of mortise and tenon techniques, but without any metal fittings or nails (Fig. 2-6).

Another type of wood construction of the Han was applied in ticou 題湊 tombs, where good-quality timbers were laid upon each other in many layers to form a wall-like barrier (which is called a ticou) for the inner coffins. Two of the most elaborate examples are the Dabaotai 大葆台 tombs in Beijing. ${ }^{11}$ In tomb M1 the high grade cypress timbers were hewn to a similar size, and were placed facing inwards to supply a frame-like protection to a set of wooden coffins at the centre of the earth tomb pit (Fig. 2-7). However, such techniques for ticou construction were more similar to brick laying rather than carpentry work. The large quantities of

\footnotetext{
${ }^{9}$ In earlier periods of Chinese history, most elite tombs were shafts with a wood coffin buried at the bottom of a vertical pit. Such vertical earth pit tombs have been standard since the Neolithic period in Central China, both for elites and for commoners. See Chapter Four for more discussion.

${ }^{10}$ For the report see Changsha 1973.

${ }^{11}$ For the report see Beijing 1989. It is believed that tomb M1 belonged to Liu Jian 劉建, King Qing 頃 (r. 73-45BC) of the Guangyang 廣陽 Kingdom, and in tomb M2 buried his consort.
} 
timbers were stacked up without mortise and tenon joinery. As a result the ticou walls are not very stable. ${ }^{12}$

\subsubsection{Carpentry techniques used in stone construction}

Several characteristics of Han masonry indicate that the masons were unfamiliar with the new material of stone. Instead, in many cases, they had carpentry techniques in mind. The following examples show that carpentry construction has obviously influenced stone building in the Han.

A Western Han example, the tomb of Liu Sheng 劉勝 (King Jing 靖 of Zhongshan 中山, d. 113BC) at Mancheng 滿城 of Hebei 河北 Province, is a rock-cut tomb that was cut horizontally into a hill. ${ }^{13}$ It has several crudely dug chambers, and buildings with wooden structures and tile roofs were constructed in such caves (Fig. 2-8a). Moreover, a stone house was built in the rear chamber (Fig. $2-8 b)$, where the corpse was buried. Stone slabs used to build this house were cut into very thin flat boards, and it is believed that wooden frames may have been used to fix the stone panels and to support the stone house. ${ }^{14}$ This shows that the builders of this stone house were more familiar with carpentry techniques, or were probably carpenters.

For Eastern Han kingly tomb construction, sometimes stone was used as an alternative to timber. According to the standard Eastern Han history, King Jian 簡 of

\footnotetext{
${ }^{12}$ See Campbell 2010 for the development of ticou tombs and more examples.

${ }_{13}$ For the report see Mancheng 1980. For more discussions see Wu Hung 1995: 130-133.

14 The excavators made this hypothesis, as nails and wood chips were found in the rear chamber. See Mancheng 1980: 22.
} 
Zhongshan, Liu Yan 劉焉 (r. AD54-90), started constructing his tomb when he was still alive, and wanted counties neighbouring his fief to contribute cypress for the construction of his ticou tomb. But the required amount was so large that the counties were not able to get them prepared. ${ }^{15}$ The Hou Hanshu does not mention how his tomb ended up. Interestingly, when his tomb was excavated in 1959 near Dingxian 定 縣 of Hebei Province, it was found that the king eventually used stone instead of timber. ${ }^{16}$ The structure of this tomb was similar to many timber ticou tombs of the Han, except that the protective ticou barrier was made of hewn stone rather than wood. The reason was that, according to Liu Yan's biography, there was not enough timber.

Moreover, in building Liu Yan's stone tomb, carpenters may have worked together with stone carvers. Names of artisans were inscribed on architectural stones of this kingly tomb, so as to mark the contributors of stones. Among the many names of stone masons, it is noticeable that a carpenter's name was also inscribed (Fig. 2-9b). ${ }^{17}$ This means that carpenters may also have been involved in the construction of this tomb, or at least in the shaping of some stones. ${ }^{18}$

In Eastern Han stone carved tombs, many of the stone blocks have cracked when excavated, especially the overlong ones. One of the examples is the lintel separating

\footnotetext{
15 See Hou Hanshu: 1449-1450 for Liu Yan's biography in which the preparation of construction materials for his tomb was described.

${ }^{16}$ See Kaogu xuebao 1964.2: 127-194 for the report.

${ }^{17}$ For the inscriptions see Kaogu xuebao 1964.2: 161-194, especially p.189, and Barbieri-Low 2007: fig. 4.4. Two stones carry inscriptions of the name of a carpenter.

${ }^{18}$ It is unlikely that the carpenter was the expert to set up scaffoldings or wooden frames for lifting, as in the Roman world where most of the mechanisms were set up by carpenters. The two stones mentioned above both carry inscriptions that read “望都石曲逆木工王季陵”, literally 'Stone from Wangdu, carpenter Wang Jiling from Quni', which means that the carpenter Wang actually cut and contributed these particular pieces.
} 
the front chamber and the rear chambers of the Qilingang tomb at Nanyang mentioned above. In the front chamber, a lintel, which is 4.04 metres long, was cracked when the tomb was excavated (Fig. 2-1b). This failure suggests that the masons were unaware of the different tolerances of stone and wood, and thus used long stone lintels, thinking they were as enduring as similar timber beams. ${ }^{19}$ This is the main reason why the stone lintels did not last a long time. Moreover, in many cases the junctions of stone slabs in stone carved tombs used similar types of mortise and tenon as those for timber construction. ${ }^{20}$

From the above examples one can see that, first of all, stone masonry was thought to be a craft that was not very different from carpentry work. When stone masons were in short supply, carpenters were conscripted for the construction of stone structures. Secondly, the craftsmen were unfamiliar with the characteristics of stone, thus treated stone with similar techniques as timber construction.

\subsubsection{Stone imitations of wood structures}

For the smaller stone carved tombs, which were quite different from kingly tombs, influences from timber on stone construction were mainly reflected in stone imitations of wooden architectural elements.

${ }^{19}$ For instance, pine has better transverse bending strength than limestone, and thus can be loaded continuously as a beam. By contrast, limestone has better compressive strength than pine but is not very tolerant of bending. Thus limestone is ideal as blocks, but cannot withstand too much loading when used as a beam.

${ }^{20}$ See Fig. 2-6a for the mortise and tenon system of the coffins of the Mawangdui tomb and Fig. 2-23 for a carved stone slab with a rabbet joint excavated from Jiaxiang of Shandong Province. Notice the similarities of wooden and stone notches. 
Most stone carved tombs had multi-chamber house-like structures, so that it was quite natural for the tombs to include elements that were used in above-ground architecture. The most distinctive traits that can be seen in both above-ground buildings and tomb structures are columns and the dougong 斗拱 brackets. ${ }^{21}$ Dougong is a Chinese term describing a unique structural element of interlocking wooden brackets in traditional Chinese architecture, especially as part of timber frame structures. It includes a wooden block (dou 斗) sometimes placed on a column to provide a base for the bow-shaped brackets (gong 拱) that support a horizontal beam above it. Its mechanical function is to transfer the weight on horizontal beams to the vertical columns or pillars. Han dynasty wooden dougong brackets have not survived, but were frequently represented in many contemporary stone carvings. On a stone slab excavated from Songshan 宋山, Jiaxiang, Shandong Province, images of a group of women were depicted sitting in a two-storied building. The ceilings of both stories are supported by columns and dougong brackets (Fig. 2-10a). ${ }^{22}$ From a comparison between Fig. 2-10a and Fig. 2-10b we can see that, Han period stone dougong brackets were less elaborate than examples of late imperial China, but had similar structures. Inside an unnamed Han period stone tomb excavated near Xuzhou, the dougong brackets placed between columns and ceilings or supporting beams, were obviously stone reproductions of wooden ones (Fig. 2-10b). The stone dougong in Xuzhou and the imagery representations of wooden dougong brackets at Songshan

${ }^{21}$ See Fig. 2-10c for a typical wooden example of Song Dynasty dougong, as none Han dynasty wooden dougong brackets have survived.

${ }^{22}$ For further discussions and more examples, see Zhou Xueying 2006a: 124-128. 
(Fig. 2-10a) showed a similarity. ${ }^{23}$

Stone imitations of timber buildings were also made and erected above-ground by stone masons. In the Qi-Lu region, large numbers of stone offering shrines have been found in front of stone carved tombs. Some of the shrines are still standing in situ above-ground today. Most other shrines have collapsed, but a large proportion of those excavated have been reconstructed: Wilma Fairbank has proposed reconstructions for the $\mathrm{Wu}$ Family Shrines, ${ }^{24}$ Jiang Yingju reconstructed the Songshan shrines, ${ }^{25}$ and Anthony Barbieri-Low has even made a digital simulation of the Wu Family cemetery, including the offering shrines. ${ }^{26}$ Today the Xiaotangshan 孝堂山 shine still stands in situ in Changqing 長清 of Shandong (Fig. 2-11), supplying the only intact example of Han period offering shrine. On the other hand, timber houses and courtyard have been depicted in mural paintings of the Helinge'er 和林格爾 tomb (Fig. 2-5a), and small pottery houses have been frequently excavated in Han tombs, for instance at Linyi 臨沂 of Shandong (Fig. 2-5b). From a comparison between the reconstruction of stone offering shrines and timber house representations, we can see that, there are not very many differences between such offering shrines and small houses of the Han. Many details of the wooden houses, for instance walls, gables, door posts, and even the projecting tile eaves, were executed in

\footnotetext{
${ }^{23}$ See Zhou Xueying 2006a for more dougong examples and comparisons. On the other hand, faceted columns in stone tombs of the Xuzhou region may have borrowed features from the West, see Chapter Four for detailed discussions. But many other stone columns within tombs have imitated indigenous wooden columns as well.

${ }^{24}$ Fairbank 1941: 1-36.

25 Jiang Yingju 1983: 741-751. The Songshan shrine is displayed in Shandong Museum according to Jiang's reconstruction.

${ }^{26}$ See http://mcis2.princeton.edu/wushrines/interactive.htm. Retrieved 1 August 2014.
} 
stone. $^{27}$

Han period stone pillar gates, which marked the entrance to a cemetery, have also survived in Shandong and Sichuan provinces. Two of the best known examples are the twin towers at the Wu Family cemetery in Jiaxiang (Fig. 2-12b). It is very likely that they were copies of Han wooden prototypes as well. Wooden pillar towers have been represented in wall paintings of the Helinge'er tomb (Fig. 2-5a), and on stone carvings in the Yinan tomb No. 1 (Fig. 2-12a). From a comparison between the stone pillars at Jiaxiang and the wooden towers and the wooden architecture roofs depicted in Han images, we can see that they obviously show a resemblance. The stone eaves of the Jiaxiang stone pillar gates (Fig. 2-12b) clearly imitated projecting tile eaves on timber buildings mentioned above.

Unlike the carpentry techniques used in stone construction, the above examples are just imitations of the shape and appearance of timber architecture. Their building skills are of course related to stone carving rather than carpentry. It is possible that a stone copy of a wood architecture would have raised its status. ${ }^{28}$

\subsubsection{Brick and stone construction}

\subsubsection{Characteristics of bricks and stone}

\footnotetext{
${ }^{27}$ See Fig. 2-11a and 2-11b for projecting eaves of the Xiaotangshan shrine and an unknown Jiaxiang shrine. They are surprisingly similar to tile eaves excavated from Han period building sites.

${ }^{28}$ See Wu Hung 1995 and Paludan 1991 for more discussion. Stone imitations of wood are probably symbols of longevity, considering the very different natural characteristics of stone and timber.
} 
Large hollow bricks had been used for the construction of tomb walls from the Zhou period (c.1050-256 BC). ${ }^{29}$ In the Western Han they became the preferred building material for tombs in the Capital Region. Surfaces of the most elaborate bricks were often decorated with stamped images. Hollow bricks were no longer used for building tombs from the Xin period (AD9-23), when small bricks became popular instead. ${ }^{30}$ During the Eastern Han period, carved stones became the preferred construction material for wealthy patrons. But small moulded bricks were also widely used in combination with stone to construct tombs. Small moulded bricks remained popular after the introduction of stone probably because of their following characteristics.

First of all, unlike stone slabs and large hollow bricks, small bricks could be prefabricated on a large scale in a short period and at relatively low costs. The raw material, loess, could be found in many parts of Central China. Secondly, moulded bricks are more versatile, as similar small bricks can be used for varieties of functions. They can be used to build walls and vaults of different sizes and layouts, and can be used as paving as well. For instance, in the Qilingang tomb mentioned above, all the bricks used for roofing, flooring and drain building are of similar sizes. ${ }^{31}$ It is very likely that they were made by the same workshop. By contrast, stone slabs used in the same tomb were of various sizes and shapes, and had to be carved individually.

\footnotetext{
${ }^{29}$ One of the earliest Zhou period hollow brick tombs has been excavated near Zhengzhou, see Wenwu cankao ziliao 1955.10: 3-24.

${ }^{30}$ Nickel 2010: 188-191. The earliest known small bricks discovered in China were used for floor paving in the terracotta pits of the First Emperor's tomb. But it is not known yet whether small moulded bricks were introduced to or invented in China.

31 See Nanyang 2008: 4-8 and 37.
} 
Therefore brick was obviously cheaper than stone. Moreover, in terms of human effort and logistics, building a brick tomb is doubtless much cheaper than building a similar one with stone slabs or blocks. In Han masonry tombs, moulded bricks were often small enough to be hand-carried, thus were easy to transport and to lay. On the other hand, stones were always shaped into large blocks or slabs for construction; They required lifting devices. For brick construction, these were not necessary. Therefore the use of bricks saved labour as well. Mortar, of course, is essential for brick laying, while in stone construction it is optional. For example, in building the Dahuting tombs mentioned above, mortar was not used for the combination of stone blocks of the barrel vaults.

\subsubsection{The popularity of stone}

In areas where stone resources were not so abundant, rich patrons would choose to build major parts of tombs with moulded bricks. But it seems that important elements, such as tomb doors, were made in stone by preference. ${ }^{32}$ A very interesting example, an Eastern Han tomb at Jianhe 澗河 of Luoyang, is a multi-chamber brick tomb with two stone doors and lintels (Fig. 2-13a). ${ }^{33}$ A pediment, supported by a column, separates the rear chamber and the main chamber (Fig. 2-13b). The appearance of the column is similar to such structures in stone tombs, but in fact it was a ceramic imitation rather than a real stone one. In this way, a solution was found

\footnotetext{
32 In Eastern Han Luoyang, for instance, many tombs of relatively high status and larger size are mainly made of small bricks, as stone is relatively rare in this area. But their tomb doors and lintels are very commonly made of carved stone slabs.

${ }^{33}$ For the report see Kaogu xuebao 1963.2: 1-58.
} 
to deal with the shortage of stone and patron's interest, which supports the view that patrons preferred stone structures. In a word, it seems that Eastern Han well-off patrons would unhesitatingly choose stone as their tombs' building material if they could afford it, and if stone was available, although small bricks have many advantages.

In the Qi-Lu Region, where stone was easily accessible, there were also large numbers of tombs constructed from a combination of stones and bricks. Such tombs were relatively smaller than those built from stone only. One of the reasons for this was probably that bricks were cheap, so that members of the society lower down the social or wealth scales could afford them. The patrons seemed to have preferred carved stone slabs to be included in important parts of their tombs, such as doors, walls or lintels. ${ }^{34}$

There were also practical reasons why Han people preferred stone to bricks. Firstly, stone structures were obviously stronger and more secure against tomb robbers than brick ones. Archaeological evidence indicates that, for instance, many stone roofs have survived, while brick domes were more likely to collapse. Secondly, more complicated imagery could be represented on the surfaces of stone. Generally small moulded bricks found in Central and Eastern China only carry simple patterns. ${ }^{35}$ Although it is true that surfaces of brick laid tomb walls could be plastered and

\footnotetext{
${ }^{34}$ For example, in Xiaoxian County of Anhui Province, large numbers of small masonry tombs, most of which belonged to lower ranked commoners, have been discovered. Though most of their brick chambers only supply space big enough for one or two coffins, stone tomb doors were often used. See Xiaoxian 2008.

${ }^{35}$ In the Sichuan Basin however, more complicated images were depicted on moulded bricks. Those are not relevant to the topic of this thesis and are thus not discussed.
} 
painted, stone carved relief lasts longer than murals. The patrons required decorations to provide auspicious surroundings. It was very common for multi-chamber tombs to be re-opened to bury newly deceased family members. ${ }^{36}$ The patrons would have been very disappointed if everything had faded when they re-entered the tomb. Thus stone was their ideal material.

\subsubsection{Roofing techniques in bricks and stone}

Roofing was obviously the most complex part of a masonry chamber. Bricks and stones played very different roles in the construction of roofs. Different characteristics of each material determined various construction types. Small moulded bricks are versatile and could be used for barrel vaults ${ }^{37}$ and different types of domed vaults ${ }^{38}$. Domes could be built above square chambers, which was difficult to achieve with large stones. Moreover, for the same roof type, bricks could be laid in different combinations and varieties of directions; bricks might or might not have been bound together. ${ }^{39}$ These roof types belong to different stages of development. The earliest type, according to Lukas Nickel, includes simple barrel vaults, which consisted of rows of separately laid bricks. These were used throughout the Western Han. Then in the first century $\mathrm{AD}$, four-sided domes were developed. At that time, during the late first century $\mathrm{AD}$, artisans learned to build barrel vaults with bonded bricks that formed

\footnotetext{
${ }^{36}$ For instance in the Xintun 新屯 tomb excavated at Pingyin 平陰 County of Shandong province, traces of reopening and reburying have been discovered. See Kaogu 1988.11: 961-974.

${ }^{37}$ See Fig. 2-32 for an example.

38 See Figs. 2-2b, 2-14a for two of many examples.

${ }^{39}$ See Figs. 2-14b, c for two types of brick combinations.
} 
an interlocking pattern. Finally in the late second century $\mathrm{AD}$, alternating rows of voussoirs were lined up to form a more stable type of barrel vaults. ${ }^{40}$

By comparison, roofs made from bigger stone blocks and stone slabs are of relatively limited types. Known tombs with stone roofs are of the following types only: flat roofs, caisson roofs, stepped roofs and truncated pyramid roofs. Flat roofs were simple, consisting of rows of stone slabs, and are seen most commonly in the Nanyang Basin. The ceiling of the tunnel in the Feng Rujiu tomb near Nanyang is one of the examples (Fig. 2-15a). A caisson roof consists of layers of overlaid right-angled triangles with a square at the top as the capstone. Surfaces facing the interior space sometimes carry carved images. Plans of such roofs are often in the appearance of several overlaid diamonds, thus they are also called overlaid diamond roofs. ${ }^{41}$ Surfaces facing the interior space sometimes carry carved images. Such roofs were often used in the Qi-Lu region. A stepped roof comprises layers of undecorated stone bars and a square or rectangular key stone, sometimes carrying carved images. In profile, the space between tomb walls and the ceiling is stepped, thus the whole structure is called a stepped roof. ${ }^{42}$ Stepped roofs were popular in the Qi-Lu region as well, and were sometimes constructed in combination with overlaid diamond ceilings, for instance in the middle and rear chambers of the Yinan tomb. A truncated pyramid

\footnotetext{
${ }^{40}$ See Nickel 2010: 184-191 for discussions on the development of domed and vaulted tomb roofs in the Han period around Luoyang. Though Nickel's studies concentrate on the development of brick tomb roofs in Luoyang, his ideas also apply in the Qi-Lu region and Nanyang Basin for the following reasons. Firstly, in many cases stone carved tombs were built from a combination of stone slabs as walls and moulded bricks as roofs; secondly it is very likely that the roofs of stone carved tombs have borrowed features from brick tombs in Luoyang.

${ }^{41}$ See Figs. 2-15b, 2-18, 5-23a, c and 5-24a for examples.

42 See Figs. 4-30a and 2-15c for two of many examples.
} 
roof consists of four trapezoidal stone slabs making a sloping type of vault, with a rectangular slab as the key stone. ${ }^{43}$ All known tombs with such roofs were excavated in Shandong. Stone barrel vaults were similar to the bricks ones, except that they were constructed from stone blocks instead of moulded bricks (Fig. 2-15e). Such roofs were quite popular in the Capital Region. Details of roofing and vaulting will be discussed in section 2.2.6 of this chapter.

\subsection{The Architectural Processes of Stone Carved Tombs}

This part of chapter will concentrate on the actual construction of stone tombs and related issues. Analysis will be based on inscribed texts, and traces within tombs, together with other information from the above comparisons. Each stage of the construction process will be documented with descriptions of different funerary structures. In order to undertake a study on the actual process of stone tomb construction, old materials need to be re-examined. Examples from Western stone masonry are used here to fill out the limited Han archaeological and textual evidence. ${ }^{44}$ Stone construction of later periods in China will also be taken into account, as it is possible that some aspects of these techniques were developed out of earlier practices in the Han. Many of the architectural processes of later China have been recorded in texts and in paintings, and are thus easier to reconstruct.

\footnotetext{
${ }^{43}$ See Fig. 2-15d and Anqiu 1992 for two of many examples

44 The wider contexts of exchanges with the West are not clear yet, nor are the ways by which the Han people took over Western methods and their motivations. But it is very likely that similar methods have been used in stone working. For instance in the construction of arches, centrings must have been used in Rome and in Han China.
} 


\subsubsection{Materials and tools}

Unlike the Classical world where marble and granite were favoured, stone tomb construction in the Han employed varieties of limestone and sandstone rather than marble or granite. ${ }^{45}$ Obviously limestone was the best stone resource available in Han period Central China, where marble was probably not known or used. In the three distribution areas of stone carved tombs mentioned in Chapter One, most tombs were built from limestone, and only a small proportion used sandstone. ${ }^{46}$ Both limestone and sandstone were available locally from the hills. Han masons were free to choose stones according to their qualities or patrons' requirements.

In the Qi-Lu region, for example, it is true that principal stone resources include limestone, sandstone and granite. ${ }^{47}$ And indeed the stone industry of today's Shandong exploits limestone and granite. However, in Han period Qi-Lu region, most of the stone carved tombs were distributed in areas where the major resource was limestone. Archaeological reports of tombs have also recognised that they were constructed from limestone, with a small proportion of sandstone. In only one case was granite used for tomb building. ${ }^{48}$ This is probably because granite was relatively difficult to shape and to carve with Han technologies and tools. Other known Han

\footnotetext{
45 It is true that in the Classical West limestone and sandstone were also the principal stones for construction, but in Han China marble was never used, and the use of granite was very limited.

${ }^{46}$ Wang Jianzhong 2001: p. 50.

${ }^{47}$ For geological studies of Shandong Province, see Zhongguo dizhi tuji: 221-228.

48 The only granite slab with relief images is now in a museum in Lianyungang, Jiangsu Province. Unfortunately relevant materials have not been published yet.
} 
dynasty granite sculptures, for instance those at the tomb of General Huo Qubing 霍 去病 (140-117BC), were rather crudely shaped. ${ }^{49}$

Many Han masonry tombs used mortar for the junction of stones or bricks, most of which are natural mud, white clay, and occasionally mixtures of lime and plaster. ${ }^{50}$ However it is not known what exactly Han mortar was made from, as very few scientific analyses have been undertaken. Also in many cases the stone blocks were simply placed one on top of each other without any mortar.

Donald Wagner argues that, in the Central Plains, iron implements appeared in the sixth century $\mathrm{BC}$ and developed into a flourishing industry by the third century BC. ${ }^{51}$ Iron tools were, therefore, available for stone masons in the Han, making stone working much easier to accomplish than had been the case with bronze. Basic tools for shaping the stone were varieties of hammers and chisels, dependant upon the function for which they were being used, for instance, for removing large amounts of material or for putting a fine finish on the surface. Archaeological evidence shows that chisels used by Han masons were of diverse sizes and shapes (Fig. 2-16). ${ }^{52}$ The principal tools of the stonemason remained similar from the Han period down to the twentieth century, both in China and the West. ${ }^{53}$

\footnotetext{
${ }^{49}$ For discussions on his tomb and relevant stone sculptures, see Paludan 1991: 17-27 and Paludan 1994: 109-116.

${ }^{50}$ For instance, the Dengmiao tomb in Dong'e of Shandong was constructed from limestone slabs, and the junctions were mortared with plaster, see Kaogu 2007.3: 32-51. Similar mortars have also been used in the Mengzhuan tomb and the Anqiu tomb, both in Shandong Province. See Wenwu 2002.2: 38-52 and Anqiu 1992.

51 Wagner 1993: 247-265.

52 See Kaogu 2010.11: 28-39 for the report of a Han dynasty quarry site near Xuzhou, where varieties of tools were excavated.

${ }^{53}$ For discussions on modern stone working tools see Rockwell 1993: 31-54. See Figs. 2-17a,
} 
To extract stones from the quarry face, the mason directed a hammer at a chisel to open a slot in the rock. Then iron wedges were hammered into the crevice to cleave off the required stone block. Wedged sockets can still be seen on the roof stones of one of the Wu Family tombs in Jiaxiang (Fig. 2-18). Similar methods were used in the Roman world and are still being used today across the world. ${ }^{54}$ The stones were then crudely dressed near the quarry and were ready for transportation.

How stones were transported for short distances in the Han is unknown. But in later imperial China and in contemporary Roman world, wooden rollers were used to move large stone blocks, and shoulder poles and ropes were used to carry relatively small ones. ${ }^{55}$ According to inscriptions on Han stone carvings, for instance inscriptions on the An Guo shrine mentioned at the beginning of this chapter, stones were quarried from a nearby quarry site and were transported overland by carts to the construction site. In some other cases, for instance the Huaiyang 淮陽 tomb in Henan Province,${ }^{56}$ the tomb was located in a broad plain where no limestone hills or other stone sources were available. Stones for construction and stone sculptures found in this tomb must have been transported from other sites, which were probably more than 150 kilometres away, though how stones were transported such great distances is unknown. But in the Shandong area, prefabricated stone carvings were transported

$\mathrm{b}$ for mason tools of late imperial China and principle stone tools in Europe of the $20^{\text {th }}$ century.

${ }^{54}$ For methods of stone extraction in the Roman world, see Adam 1994: 21- 32. For modern quarrying see Rockwell 1993: 156-165. Also see Fig. 2-19 for a modern example.

55 See Adam 1994: 32-36 for Roman stone transportation and Adam 1994: fig. 31 for wooden rollers. For stone transportation in late Imperial China, see Liu Dake: 273-275.

${ }^{56}$ For the report see Wenwu 1991.4: 34-46. 
from workshops to tomb sites by carts or by boat along rivers, as suggested by Barbieri-Low. ${ }^{57}$

Lifting devices must have been used to hoist large stone slabs or blocks into place. Such mechanisms may have included cranes and pulleys. Pulleys are a different class of devices to cranes. They are never alone, always used together with cranes. Cranes usually employ pulleys to transfer more force to the block. Pulleys have been recorded in texts as early as the Warring States period, ${ }^{58}$ thus it is probable that people in the Han knew about using pulley systems. Moreover, the use of pulleys and combinations of pulleys and cranes are depicted on Han Dynasty stone carvings ${ }^{59}$ as well as pottery models ${ }^{60}$ excavated from Han tombs. In the depictions, such devices were used for lifting heavy tripods or a bucket of water, but they must also have been ideal equipment for hoisting stone as well. Two bronze pulleys with iron hubs have been excavated from the Mancheng tomb M1 (Fig. 2-20c), and are two of the few

${ }^{57}$ Barbieri-Low 2007: 86. His analysis is based upon inscriptions of stone carvings, and archaeological reports of certain tombs, together with reconstructed Han maps.

${ }^{58}$ See Mozi: 533-534 for some of the earliest description of pulleys: “彗有力也, 引無力也。 不心所挈之止於施也, 繩制挈之也, 若以錐刺之。挈, 長重者下, 短輕者上, 上者愈得, 下下者愈亡。繩直權重相若, 則正矣。收, 上者愈喪，下者愈得，上者權中盡，則遂挈”, For the English translation see Johnston 2010: 498-499. 'Lifting up, there is force; drawing down, there is no force. It is not necessary that what raises it stops in action (is direct or oblique). The rope restrains raising it, like by an awl piercing it. In lifting, what is long and heavy descends, what is short and light ascends. What ascends increasingly gains, what descends increasingly loses. If the rope is straight and the counterweight and weight are alike, then it is in balance. In lowering, what ascends increasingly loses, what descends increasingly gains. Ascending involves the counterweight, the weight then completely falling.'

${ }^{59}$ In the Qi-Lu region, scene of the story of Emperor Qin Shihuang 秦始皇 (r. 220-210BC) dragging a tripod from the Si River 泗水 was frequently carved on funerary reliefs. The First Emperor's men always used a pulley system for the tripod lifting. See Fig. 2-20a for one of many examples.

${ }^{60}$ In Han period tombs ceramic models of wells were often buried. Pulley was often depicted, which was used for lifting the bucket from the well. See Fig. 2-20b for an example. 
known actual Han pulley examples. ${ }^{61}$ They were used for pulling and placing coffins of the tomb occupant, but it is fair to suggest that similar pulleys were used by Han artisans for construction as well. It is not known yet how the pulley system was used together with cranes for stone building projects, but reconstruction of later Chinese pulleys and cranes may supply some evidence (Fig. 2-21a).

In the Roman world, lewis irons were used to attach stones to ropes, so that they could be hoisted by mechanics. ${ }^{62}$ A lewis iron is a dovetailed iron tenon made of several parts and designed to fit into a dovetail mortise in a large stone so that it can be lifted by a hoisting apparatus. Lewis irons have been used in the West through the medieval period up to the present. ${ }^{63}$ However, it is unlikely that the lewis iron was used in Han China. Firstly, no lewis holes or sockets have been found on stones that were used to construct Han tombs. Secondly, there were no depictions of lewises in contemporary literature or pictorial representations. Lewis irons were not used in later periods of China either. The reason for the lack of the lewis irons was probably that in China, stones used for construction were not as big as Western ones, thus ropes were adequate. A simple but very possible method of lifting was to use ropes looped or tied around stone blocks (Fig. 2-21b).

\subsubsection{Planning and design}

Generally speaking, the construction of stone carved tombs and related buildings,

\footnotetext{
${ }^{61}$ See Mancheng 1980: 36.

62 See Adam 1994: 80-87.

${ }^{63}$ See Adam 1994: 80-87 and figs. 102, 103, 104, 105.
} 
such as offering shrines, were started after the prospective occupant's death. It was very rare that ordinary people built their tombs well in advance of their death. ${ }^{64}$ The construction process of the whole tomb would normally take a long time, and obviously needed careful planning and design beforehand. For instance, according to inscriptions on the doorpost of Xiangtajun Shrine mentioned in Chapter One, it took the sons more than two years to build a stone tomb and a stone offering shrine for the deceased parents. ${ }^{65}$ The first part of the overall planning strategy was to choose a proper tomb site. Surviving literature seems to record the fengshui 風水 approach for the choice. ${ }^{66}$ Fengshui, including principals of choosing a tomb site, had been fully developed by the Han period. Moreover, a literary work describes the process of choosing a tomb site in the Han. ${ }^{67}$ Though the text is not necessarily relevant to stone

${ }^{64}$ It is common enough for the emperors or kings to start building tombs before their deaths. For one of the examples see Miller 2011: 181-229 for construction of the Baling, mausoleum of Emperor Xiaowen (r. 180-157BC) of the Han. But for commoners it is not the case, though there were occasional exceptions. For instance, an Eastern Han official-scholar Zhao Qi 趙歧 made (or at least designed) himself a tomb with murals in advance of his death. For his biography see Hou Hanshu: 2121-2125. In the field of stone funerary monuments, Wu Hung argues that another Eastern Han official-scholar Wu Liang 武梁 arranged the stone carvings in his offering shrine beforehand, see Wu Hung 1992a for relevant discussions.

${ }^{65}$ See Luo Fuyi 1960, Chen Zhi 1988 and Sun Guanwen 2006 for punctuation and explanations of the inscriptions. The relevant inscription reads “堂雖小, 經日甚久。取石南 山, 更逾二年, 這今成已 Although the offering hall is small, it took a long time to construct. We quarried stones from the South Hill, and the hall is finally completed after two year.'

${ }^{66}$ Fengshui is a Chinese system of divination which was widely used to orient dwellings or tomb sites in an auspicious manner. It was believed that their locations and orientations were of great importance. Such rules have been recorded in texts, for instance the Kaogongji, since the Zhou period.

${ }^{67}$ See the Zhong Fu 冢赋, literally the Ode of Tombs, by an Eastern Han astronomer and literati Zhang Heng (AD78-139). See Quan Han fu: 470 - 471. The first sentences of the ode reads ‘載輿載步, 地勢是觀。降此平土, 陟彼景山。一升一降, 乃心斯安。爾乃陵巍山, 平險陸, 刊叢林, 鋀磐石, 起峻壟, 構大槨。Firstly by carriage, then on foot, I came to investigate the topography of this region. I came down to the plains, went up to the mountains, did not feel relieved until I found a proper site. Then we modified the landscape, chopped 
carved tombs, it is not too far-fetched to suggest that the choice of a site for a stone tomb must have followed a similar procedure.

However, it seems that the stone carved tombs are not always located at places that had the best fengshui. In many cases other factors were taken into account in addition to the fengshui. Also the orientation of tombs was not fixed either, unlike the above-ground buildings, most of which faced south. It is very likely that site logistics were considered when choosing a tomb site. Most of the excavated tombs are located in plains not too far away from limestone hills, so that it was convenient to transport materials, tools and labour to the site and to start the construction there. On the other hand, the tomb sites might have already been decided by ancestors, who had set up a family cemetery. The newly deceased were assigned a place within the cemetery, either sons buried next to their father, or a couple's tombs lying next to each other. Within a family cemetery, the tombs of different family members were arranged according to different rules. Seven chambered tombs dated to between AD126 to AD226 have been excavated at Tongguan 潼關 of Shaanxi Province. The excavators believe that they belonged to a group of scholar-officials, all of whom were members of the local Yang 楊 Family. ${ }^{68}$ These seven tombs were arranged in a row one next to another (Fig. 2-22a). At Changli 昌梨, Donghai 東海 County of Jiangsu Province, six stone carved tombs have been excavated, and all of them were located within the same family cemetery. ${ }^{69}$ The six tombs were arranged on an axis one behind another down inauspicious woods, chiselled the rocks, dug the pit, so that the burial chambers could be placed.'

${ }^{68}$ For the report see Wenwu 1961.1: 56-66.

${ }^{69}$ See Wenwu cankao ziliao 1957.12: 35 for the excavation report. More details of the 
(Fig. 2-22b). In other cases, such as that of the Wu Family tombs, no clear strategy can be seen in the tombs' arrangements (Fig. 2-22c) ${ }^{70}$ But at least the burials were not far from each other, or were probably in the same cemetery, as they shared the twin pillar gates and stone lions, which marked the entrance to a cemetery.

The design of a tomb was complex, including the plan, structure, materials, pictorial programmes and many other elements. The general design was standard, and may have been decided by the artisans. But the details were more complex, and the artisans needed to confer with the patrons, sometimes considering the last wishes of the deceased. The artisans probably had standard basic designs from which the patrons could choose, and the designs were then adjusted according to patrons' requests, for instance by the creation of one more tomb chamber, or specific roof types, or some extra pictorial representations. As a result, no stone carved tombs discovered so far are identical. Similar plans, pictorial themes and structures have, however, been used frequently in different tombs. The Dahuting tombs M1 and M2 mentioned above, were built according to similar plans and structures, and had seven chambers each. It is quite obvious that the stone carvings and tomb construction were executed by the same workshop. These examples reflected the method of modular design, which was a principal feature of China. ${ }^{71}$

Changli tomb No. 1 will be discussed in Chapter Four.

${ }^{70}$ See Jiang Yingju and Wu Wenqi 1995: 1-6.

71 See Ledderose 2000 for such ideas. These issues are more related to the production of carved images. Therefore further discussions on modularity will be carried out in Chapter Three. 


\subsubsection{The shaping and carving of stones}

Once the general plan had been agreed, artisans would start quarrying, shaping and carving stones, if they had not already been prepared. After the stones were extracted and transported to work sites, as discussed above, they would be cut and shaped to form the different structural elements. The working site was normally the tomb site, as this was the most direct way of building a tomb. In many cases, stone chips, the quality of which are the same as tomb stones, have been found in piled earth burying the tomb, which means that the tomb stones were shaped and carved at the tomb site, and finally the leftovers of carved stone were mixed with earth and were used to bury the tomb. ${ }^{72}$ Barbieri-Low has argued that, sometimes stone slabs may have been well prepared and carved at workshops, thus are ready for ordering. However, it seems unlikely that patrons were able to order prefabricated stones 'off the shelf' ${ }^{73}$

Most stones were shaped to rectangular slabs to form footings ${ }^{74}$ or walls of tombs. They were also carved to other shapes, for instance for the construction of stone offering shrines, two stones had to be carved as triangles for gables. ${ }^{75}$ For the construction of tomb roofs, stones were cut into various shapes. At the entrance of the

\footnotetext{
${ }^{72}$ For instance in the tomb belonged to Miao Yu 繆宇 (d. AD151) excavated near Pizhou 䂙州 of Jiangsu Province, stone fragments have been found in its earthen mound. See Wenwu 1984.8: 22. In the passage tunnel of Dahuting tomb No. 1, stone fragments carrying wrongly carved reliefs were buried together with earth. Both the quality of the stone and its carving techniques are similar to those used within the tomb chambers. See Mixian 1993.

${ }^{73}$ See Barbieri-Low 2007: 83-96. This issue will be discussed in detail in Chapter Three.

${ }^{74}$ In this thesis 'footing' or 'sockle' of Han period stone carved tombs refers to a very low wall serving as a foundation on which walls or columns stand.

75 See Jiaxiang 1996: figs. 40, 41, 43 and 44 for two pairs of gables of the Wu Family Shrines.
} 
Anqiu tomb, stone was shaped as a semicircular piece, so that it fitted well to the barrel vault. ${ }^{76}$ Also in the Anqiu tomb, all of the major chambers were covered by truncated pyramid roofs. Such roofs needed a combination of four trapezoidal and one square slabs, which were fixed together with the mortise and tenon system. ${ }^{77}$ In the Qi-Lu region, different types of mortise and tenon, or sockets and slots, were often executed for better junctions to other stone blocks. ${ }^{78}$ These facts have indicated the influence of carpentry techniques on stone carving.

Many of the principal stones were to be decorated with carved relief. Carving techniques of stones have already been intensively studied by Chinese scholars in terms of 'artistic style', although nobody seems to have written anything about tools. ${ }^{79}$ For those that were only carved on one side, the rear side would be roughly cut and shaped. Sometimes, even quarrying sockets can still be seen, for instance, on the rear side of the roof stones of the Wu Family tombs in Jiaxiang (Fig. 2-18). The surfaces to be decorated would be very carefully dressed with a hammer and a flat-edged chisel. Sometimes parallel lines were executed on the surface before images were carved on it (Fig. 2-10a).

All the carved stones would become different structural elements within a tomb. Were the images firstly carved on stones, and then the stones were put together, or was the process the other way round? An examination of more complicated cases will

\footnotetext{
76 See Anqiu 1992: Plate 71.

77 See Anqiu 1992 and Kaogu 2007.3: 32-51 for the Dengmiao tomb which had similar truncated pyramid roofs to those of the Anqiu tomb.

${ }^{78}$ See Fig. 2-23 for an Eastern Han example unearthed in Jiaxiang of Shandong.

${ }^{79}$ Such examples include Xin Lixiang 2000, Li Falin 2000 and Wang Jianzhong 2001.
} 
help answer the question. In the Dahuting tomb No. 1 mentioned above, images may have been executed on separate stone blocks, and then put together to form a whole scene for the wall decoration (Fig. 2-3c).$^{80}$ First of all, most images within the tomb No. 1 were low-reliefs with lines depicting details. Thus it is extremely difficult for the craftsmen to deliver such lines in already constructed tomb chamber, which would be dark. Secondly, marks and numbers have also been carved on these separate stones. This indicates that they were carved and marked first, and then put together according to a plan. Moreover, on the interior of barrel vaults in many tomb chambers, cloud scrolls were carved. However, scrolls on some adjacent stones do not run consistently, indicating that artisans made mistakes while prefabricating such blocks. Lastly, on the rear side of the stone door in the eastern side chamber of Dahuting tomb No. 2, the carved images are upside-down. If these images were carved after the tomb had been constructed, such mistakes could have been avoided. Therefore, although it is really difficult to carve the stones separately and then put them together, it seems impossible that the stone blocks were put together and then carved.

\subsubsection{Laying the ground work}

Perhaps at the same time when masons were quarrying and shaping stones, other members of the workshop would start to prepare the ground work. In order to construct a stone carved tomb, an earth pit had to be dug into the ground. In some areas, for instance the Qi-Lu region, the pit was not deep and the finished tomb

${ }^{80}$ Mixian 1993: p. 336 and Plate IX. 
structures were not completely underground. Instead, in many cases the tombs were merely half-underground, namely they were built in a shallow earth pit, and the upper parts of the tomb chambers were above the ground level before earth was piled up over the masonry structure to make a mound. For instance, the structures of the Mengzhuang tomb mentioned above lies at the bottom of a shallow pit around 2.5 metres deep, and the roofs are roughly one metre higher than the modern ground level, presumably higher than the Han period ground level. ${ }^{81}$ In some cases, for example the Lalishan tombs in Xuzhou, the tomb structures were built completely above-ground, and earth would be piled over the finished structure to form very big mounds. $^{82}$

One of the reasons of constructing tombs in shallow pits or above--ground was that this position may have made the construction work easier to accomplish than with deep pits. Another reason was that groundwater levels of tomb sites in the Qi-Lu region were relatively high, as most tombs were built on the plain rather than among hills. Thus people had to refrain from digging too deep so as to avoid waterlogging. The artisans have also made other efforts to deal with humidity caused by underground water, for instance, laying many kinds of materials under the floor pavements of tombs. Such materials included charcoal, lime and gravel. For instance, beneath the tiled floor of Miao Yu's tomb near Pizhou of Jiangsu Province, charcoal, lime and stone chips have been found. ${ }^{83}$

\footnotetext{
${ }^{81}$ Wenwu 2002.2: p. 38.

${ }^{82}$ For short excavation reports see Xuzhou 1986: 123-124 and Xuzhou 1990: 208-209.

${ }^{83}$ See Wenwu 1984.8: 22-29. Examples in other regions include, the Houshiguo tombs of Mixian, Henan Province, see Huaxia kaogu 1987.2: 96-240; the Dianchang tomb of Tanghe,
} 
Once the earth pit was ready and the stone blocks were prepared, the ground work would be laid. Traces of rammed earth have frequently been found at the bottom of tomb pits. ${ }^{84}$ This indicates that the bottom of the pit, or at least places where footing stones were positioned, was rammed to form a solid foundation for the whole structure. Secondly, the footing stones would be fixed in place according to the tomb plan. ${ }^{85}$ Such stones are normally flat and squat, and are occasionally decorated with relief images if they were not hidden. ${ }^{86}$ These stones would work as the foundations of the whole tomb structure, carrying all the weight. Finally the tomb floors were paved with either dressed stone slabs or tiles. Sometimes drainage was used. In the Qilingang tomb, for instance, drainage was created from small bricks beneath the floor in the front chamber. ${ }^{87}$ In some other cases, grooves were carved on the surfaces of paved floors, which may have worked as drainage. ${ }^{88}$ Flooring and such drainage may have been put in place after the whole tomb structure was finished. The floor pavements do not normally serve any mechanical functions, so that they do not have to be built beforehand.

\subsubsection{Walls, columns and lintels}

\footnotetext{
Henan Province, see Zhongyuan wenwu 1982.1: 5-11.

${ }^{84}$ Once the tombs have been excavated, they were often dismantled and stones were removed to be stored in museums, thus exposing the bottoms, showing remains of rammed earth. The Qilingang tomb is one of the many examples, see Nanyang 2008.

${ }^{85}$ See Fig. 2-26 for footing stones as of the original tomb plan newly excavated near Baiji of Xuzhou.

${ }^{86}$ See Huaxia kaogu 2003.3: 87-95 and fig. 6 for images carved on footing stones of the Chefushan 車夫山 tomb No. 1 near Pizhou of Jiangsu Province.

${ }^{87}$ See Nanyang 2008: 8 and plate 13-15.

${ }^{88}$ See Xuzhou 1986 and Xuzhou 1990.
} 
Once the stone blocks were set in place at the bottom of the pit as a foundation, stone slabs would be built as walls, creating separate spaces. The tomb chambers were either separated by walls, or divided by a series of columns, depending on the size of the tomb, and patrons' requirements. ${ }^{89}$ For middle-sized tombs, for instance the Chefushan tombs near Pizhou, the stone walls simply rested on footing stones, and then the roof was constructed directly on the walls without the support of lintels (Fig. 2-32). ${ }^{90}$ In smaller tombs, even the footings were sometimes omitted, and the walls were directly placed on the prepared groundwork. ${ }^{91}$

For bigger tombs, the structures were accordingly complicated. Not only were footing and walls or columns included, but also lintels were employed. Such horizontal beams were placed on columns or walls to provide a base for roof structures. Mechanically, the weight of the roof is transferred from horizontal lintels to the vertical columns or walls. The combination of lintels and columns also made it possible to construct a higher ceiling, supplying more interior space for the tomb chambers. Moreover, the broad surfaces of lintels provided extra space for relief images. For instance in the middle chamber of the Baiji tomb, lintels were placed between the walls, columns and the roof. On surfaces of such lintels images of supernatural animals were carved (Fig. 2-24), while in relatively small tombs for

\footnotetext{
89 The use of columns differs from region to region. In the Qi-Lu region, chambers of the Dongjiazhuang tomb and the Mengzhuang tomb were separated by stone columns, while the roofs of Yinan tomb No. 1, Changli tomb No. 1 and the Baiji tomb were supported by both faceted columns and stone walls. However, in the Nanyang basin and the capital region, very few columns were used in stone carved tombs.

${ }^{90}$ For the archaeological report see Huaxia kaogu 2003.3: 87-95, Dongnan wenhua 1999.2: 18-21 and Dongnan wenhua 2006.2: 26-32.

${ }^{91}$ For an example see Xiaoxian 2008: 144-145.
} 
instance the Chefushan tombs, such decoration was omitted. In the Qi-Lu region, especially areas around Xuzhou, stone carved tombs often included features suggesting a house, for example, a window indicated by vertical slats in stone, and facetted columns. ${ }^{92}$

The stone footings, walls and lintels were joined together in several ways. Most commonly the junctions of stone or brick sections were mortared. Sometimes they were joined together with mortise and tenon, or sockets and dowels..$^{93}$ It is also very common that when walls were built, the stones were simply stacked up without any cement. For example in building the Dahuting tombs mentioned above, mortar was not used for the combination of stone blocks of the barrel vaults. ${ }^{94}$

On the other hand, unlike Roman columns which were created with a base-and-shaft system, usually, in Han stone tombs, the columns simply stood on a base without such intermediaries. For instance, a stone carved tomb has been newly excavated near Baiji of Xuzhou, Jiangsu Province. On one of the footing stones, imprints of a faceted column could be seen (Fig. 2-27). This suggests that the column was placed directly on the footing, and the junction was not even mortared. But in most cases, Han stone columns would be placed on a plinth, both for stone offering shrines and underground tomb structures. ${ }^{95}$ Moreover, in the Baiji tomb and

\footnotetext{
${ }^{92}$ See Fig. 2-24 and Fig. 1-1b for such architectural elements in the Baiji tomb. Windows indicated by vertical slats were also carved in the Chefushan tombs, the Maocun tomb and many other similar ones near Xuzhou.

${ }^{93}$ See Fig. 2-23 for a carved stone slab with a rabbet excavated from Jiaxiang of Shandong Province.

94 See Mixian 1993.

95 See Fig. 2-11a for the column of the Xiaotangshan shrine in Changqing of Shandong Privince; see Fig. 2-15d for structure of the Dengmiao tomb in Dong'e mentioned above.
} 
occasionally in other Eastern Han stone carved tombs, columns were placed standing on animals such as rams. ${ }^{96}$

\subsubsection{Roofing and vaulting}

The construction of tomb roofs, namely stone or brick arches and vaults, was the most complex but most interesting part of the whole process. As mentioned above, six types of roofs have been used in the construction of Han period stone carved tombs, including flat roofs, truncated pyramid roofs, domed vaults, barrel vaults, caisson roofs and stepped roofs. Han domed vaults were all constructed from small bricks; barrel vaults could be constructed from either stone or bricks; while flat roofs, truncated pyramid roofs, caisson roofs and stepped roofs were all constructed from stone only.

Flat roofs were simple, thus were the easiest to construct. ${ }^{97}$ The stone slabs were lifted by cranes with pulleys or similar devices, and were then placed in the right position. The stone slabs had to be carefully prepared, with carved images in the centre facing the interior and roughly dressed edges to bind with the stone walls. Similar methods must have been used in the construction of caisson roofs ${ }^{98}$ and stepped roofs ${ }^{99}$. A caisson roof consists of layers of overlaid right-angled triangles

\footnotetext{
Note that stone columns in both cases had plinths and capitals, though very simple.

96 This combination certainly refers to a Western Asian practice according to Rawson 1999 and 2010.

${ }^{97}$ See Fig. 2-15a for an example, flat roof of the tunnel in Feng Rujiu's tomb at Nanyang mentioned above.

98 See Fig. 2-15b for roof of one of the tombs belonged to the Wu Family in Jiaxiang.

${ }^{99}$ See Fig. 1-1d for roof of the middle chamber in the Baiji tomb, Fig. 4-30a for roof of Baiji tomb's rear chamber. See Fig. 2-15c for ceiling of the rear chamber in Yinan tomb No. 1.
} 
with a square at the top as the capstone, while a stepped roof comprises layers of undecorated stone bars and a square or rectangular key stone. The lower layers could stand freely before the whole structure was finished; therefore for the building of both roof types, support was not necessary. Also cranes might be omitted, as stones may have been hand-carried by masons, especially for the building of smaller tombs. But lifting devices would obviously make the work easier and more accurate.

Supporting devices must have been used for the construction of some other types of roofs, for instance truncated pyramid roofs ${ }^{100}$, as such roofs could not stand freely before the construction was completed. In terms of supporting systems, the construction of stone tombs was similar to the construction of above-ground timber buildings, for which the use of scaffolding was essential. The truncated pyramid roof was a combination of four trapezoidal and one rectangular slab, which were fixed together with the mortise and tenon system. Bracings, or at least simple supporting beams, were needed for its construction, as the trapezoidal stone slabs would not have stood freely before the ceiling key stone was placed.

For the construction of barrel vaults ${ }^{101}$ and brick domed vaults ${ }^{102}$, bracing

Such structures might have derived from the West, see discussions in section 4.5.2 of Chapter Four. The fact that these roof types were constructed with mature techniques without simpler prototypes in China supplies extra evidence of outside stimuli.

${ }^{100}$ See Fig. 2-15d for structure of the Dengmiao tomb at Dong'e, Shandong. All the Dengmiao tomb chambers have truncated pyramid roofs. Such roofs were also used in the Dongjiazhuang tombs at Anqiu mentioned above. So far truncated pyramid roofs were only found in the Qi-Lu region.

${ }^{101}$ See Fig. 2-15e for the barrel vault of the Xingyuan tomb near Luoyang, Fig. 1-3 for the barrel vault of the Zhaozhai zhuanwachang 趙寨磚瓦廠 tomb in Nanyang, Fig. 1-5 for barrel vault of Dahuting tomb No. 2, Fig. 2-14b for the barrel vault of side chamber of Feng Rujiu's tomb, Fig. 2-32 for the roof of the Chefushan tomb No. 2. Barrel vaults were constructed in all three major regions of stone carved tombs. 
(centring or temporary supporting structure) was essential. However, details of supporting systems for the construction of vaults in the Han are unknown. In the case of masonry construction of middle and late Imperial China, two methods were used. The first method was to provide a robust support with the outline of the proposed arch by setting up scaffolding that was made of wooden framework, in the West called centring. ${ }^{103}$ Alternatively, earth, sand or pebbles were piled up to create the shape of the proposed arch, above which bricks or stones were laid to form a real $\operatorname{arch}^{104}$ Piling up earth was obviously not feasible for the construction of underground tombs, as their interiors were of great importance. In practice, earth piles were mainly used for small scale arched bridge construction. On the other hand, in the Roman world, centring (Fig. 2-29) was used for the construction of different kinds of buildings. ${ }^{105}$ Construction of arches in later periods all over the world also used this kind of standard scaffolding generally, even though the materials and dimensions vary. ${ }^{106}$

Although no actual Han examples survive, we can presume that similar supporting systems must have been employed in the construction of Han tomb roofs, as it would be impossible to build arches or vaults without scaffolding and centring.

\footnotetext{
${ }^{102}$ See Fig. 2-2b for dome of the front chamber in Feng Rujiu's tomb, Fig. 2-14a for dome in the Jianhe tomb at Luoyang. Domed vault was relatively rare in the Qi-Lu region. Domed brick vaults in Luoyang have been studied by Lukas Nickel, though he does not mention details of construction. See Nickel 2010 and Nickel 2012.

${ }^{103}$ See Fig. 2-28 for centring used for arched bridge construction of the Wenchang 文昌 Bridge in Jiangxi 江西 Province, later Imperial China.

${ }^{104}$ For descriptions of this type of vault construction, see Mao Yisheng 1986: 200-201. Liu Dake 1993: 118-120 and 331.

105 The centring is made up of two or more arcs of a circle made of wood and solidly braced, joined by the formwork of a moulding of the arch. See Adam 1994: 357.

${ }^{106}$ See Fig. 2-30 for centring used in the construction site of the gate of Sichuan Fine Arts Institute, Chongqing, China.
} 
Centrings could be reused, which may have resulted in similar sized barrel vaults. For instance, in the Qilingang tomb mentioned above, all three barrel vaults of the rear chambers were of the same diameter.

The stone blocks or small bricks used for vault construction were either mortared or laid together without any cement. Moreover, for brick barrel vaults, the small moulded bricks could be laid in different combinations and varieties of directions; bricks might or might not have been bound together. ${ }^{107}$ Sometimes a brick vault may have multiple layers of moulded bricks with each having a socket and a dowel. ${ }^{108}$ Such structures were quite common near Eastern Han Luoyang, for instance in the Jianhe tomb mentioned above.

Generally speaking, underground vaults and domes did not require buttress supports, as used in Western above-ground buildings, since they were held in place by earthen pits. But when such structures were half above-ground, some efforts had to be made. For instance, in the Chefushan tomb No. 2, the upper edges of the supporting stone walls at both sides of the barrel vault were sloped, so that the arch was held in place (Fig. 2-32). ${ }^{109}$

\subsubsection{Decoration and finishing}

Generally speaking, no more decoration was needed once the major structure of

\footnotetext{
107 See Figs. 2-14b, c for two types of brick combinations. Bonded bricks may have formed an interlocking pattern.

108 See Fig. 2-31 for a brick vault in the Jianhe tomb. Note the sockets and dowels that were used to combine the bricks.

109 For the archaeological report and more details see Dongnan wenhua 2006.2: 26-32. See section 2.3 of this chapter for more discussions.
} 
a stone carved tomb was finished, as the stone surfaces already carried relief images.

But in many cases, some extra decoration might be applied. In the Nanyang Basin, pigment remains have been found on the carved stone surfaces in many of the tombs. ${ }^{110}$ This phenomenon suggests that colour was applied on the stone carvings, though the colours were generally simple. On stone carvings in the front chamber of the Chengpeng tomb at Nanyang, red was applied on a bear's mouth, three figures' clothes, as well as the mouths of dragons. The decorative patterns were also painted red, white and green. ${ }^{111}$ In the Capital Region, most masonry tombs were made from a combination of stones and bricks. And the interiors of such tombs often carried mural paintings, motifs of which were similar to the ones within stone tombs. At Zhucun 朱村 village near Luoyang, a multi-chamber tomb constructed from a combination of stones and bricks has been found. On the walls of the main chamber, murals of banqueting, chariot excursions and auspicious animals were painted directly on the surfaces of bricks. ${ }^{112}$ In the Xingyuan 杏園 tomb also at Luoyang, murals of horses and chariots were found on brick walls that were plastered and then painted. ${ }^{113}$ The interiors of Dahuting tomb No. 2 were decorated with both stone carvings and murals. In many chambers both the stone barrel vault and the stone walls were

${ }^{110}$ See Kaogu хиebao 2007.2: 233-266, plates 5-16 for examples in the Chenpeng tomb of Nanyang.

111 See Kaogu xuebao 2007.2: 233-266, plates 10-16.

112 Wenwu 1992.12: 15-20.

113 See Kaogu 1985.1: 18-22 for the archaeological report of the Xingyuan tomb, see Luoyang 1995 for more pictures of the murals. See also Fig. 2-5a for another example of murals painted on plastered brick walls, the Eastern Han tomb at Helinge'er of Inner Mongolia. 
plastered and then painted. ${ }^{114}$

In the Qi-Lu region, several unusual examples, namely the Houtun 後屯 tombs, unearthed in Dongping 東平 County of Shandong Province, ${ }^{115}$ were built from polished stone slabs, and coloured paintings were applied directly on the smooth stone surfaces (Fig. 1-6). Murals could be easily damaged when the stones were put together, so that such decoration must have been painted after the tomb structure had been finished. Scaffolding may have been used for the painters, especially for work on the relatively high ceilings.

Once the tomb roofs were finished, earth would be filled in the gap between the outer tomb walls and the earth pit, and was then piled up above the roofs to form a mound. The earth may have been rammed layer by layer. At Miao Yu's tomb site mentioned above, earth and occasionally stone fragments were piled up to form the burial mound, and traces of rammed earth have been found. ${ }^{116}$

When the earth mound was piled up and properly shaped, the bottom edges of the mound would be lined with stone blocks or bricks to supply protection for the mound. However, very few lined stone protections survive. At the bottom of the burial mound of Dahuting tomb No. 1, stone blocks were lined to form a circular protection for the mound. ${ }^{117}$ For the mound of the Baiji tomb, three layers of stone slabs were piled up as a low wall in order to supply protection, though the overall plan is

\footnotetext{
114 Mixian 1993.

115 See Dongping 2010 and footnote 33 of Chapter One.

116 Wenwu 1984.8: p. 12.

117 See Mixian 1993 and Fig. 2-35a.
} 
rectangular. ${ }^{118}$ The sequence of construction may have been the other way round. Namely a low stone wall was perhaps built first, and then earth was piled and rammed within the wall to form a mound. Finally, trees might be planted on top of the mound. Such activities are recorded in the Ode of Tombs by Zhang Heng mentioned above, ${ }^{119}$ and trees planted on top of mounds were also represented on stone carvings excavated in Jiaxiang, Shandong. ${ }^{120}$

Within one cemetery, above-ground stone sculptures and pillars might have been carved at the same time when the tomb was being built. In front of the famous $\mathrm{Wu}$ Family cemetery in Jiaxiang, twin pillar gates and a pair of lions were erected facing northwest. On the lower part of the southwestern pillar gate is a carved inscription, and a part of it reads “建和元年…石工孟孚、李弟卯造此閶, 直錢十五萬; 孫宗作 師子，直四萬。During the first year of the Jianhe Reign (AD147), ... mason Meng Fu and Li Dimao made the twin pillar gates which cost 150,000 qian coins (equals 3,660 grams of gold); Sun Zong carved the lions which cost 40,000 qian coins (equals 976 grams of gold)'. ${ }^{121}$ The inscription indicates that the carving and erection of above-ground stone sculptures and pillars involved division of labour, though we have no clear evidence on details of such process. The offering shrines usually included one

\footnotetext{
${ }^{118}$ See Kaogu 1981.2: 137-150 and Fig. 22-35b. Note that some of the stone slabs carry wrongly carved reliefs, which indicates that they may have been leftovers of stones that were used for the tomb construction. Zhong Fu 冢赋, literally the Ode of Tombs, by an Eastern Han astronomer and literati Zhang Heng

119 The original text reads '乃樹靈木, 靈木戎戎 Then spiritual trees were planted (on top of the burial), and the trees were flourishing.'

${ }^{120}$ See Jiaxiang 1992: p. 38, Fig. 45 for registers of images carved on a stone slab found at Songshan of Jiaxiang. A burial mound with trees is depicted.

${ }^{121}$ See Jiang Yingju and Wu Wenqi 1995: p. 11 for full text of the inscription.
} 
chamber only, and carried similar carved images to that of stone carved tombs. Moreover, the structure of stone shrines also had stone footings, walls and roofs, most of which were used in tomb structures as well. Therefore we can presume that the stone offering shrines were carved and erected in a similar way to that of tombs.

The tombs and offering shrines of the Wu Family cemetery may have been surrounded by walls, ${ }^{122}$ but unfortunately none of these survive. Miao Yu's tomb mentioned above is probably the only Eastern Han stone carved tomb that has surviving cemetery walls. The cemetery fenced by stone walls covers an area of roughly 250 square metres. The southern part of the plan is rectangular, and the northern part is trapezoidal, with the tomb structures buried inside (Fig. 2-36) ${ }^{123}$. The northern walls have been examined and partially reconstructed by the excavators. We can learn that the basement of the stone wall was firstly rammed, and then footing stones were laid. Afterwards four layers of stone slabs were piled up to form the wall. The top of the walls were carved into the shape of eaves, and even include images that were commonly seen on roof tiles of Han period above-ground buildings. The reconstructed wall is 1.35 metres high.

When all the tomb chambers, mounds, offering shrines, stone animals, cemetery walls and other above-ground buildings had been finished, the tomb doors, however, would remain open, accessed by a sloping passage way, until the deceased was buried in the tomb chamber. Many of the stone carved tombs were big ones with high ceilings, especially those had domed vaults, stepped roofs or caisson roofs. These high

\footnotetext{
${ }^{122}$ See Jiang Yingju and Wu Wenqi 1995: 1-3 and Fig. 2-22c.
}

${ }^{123}$ See Wenwu 1984.8: 22-29 for the report of Miao Yu's tomb. 
roofs together with square chambers supplied spaces large and high enough for several persons to stand inside a tomb. Such structural innovations of the Han have also indicated changes of funerary rituals. During the funeral, mourners may have entered the tomb at the same time burial objects were interred and when sacrificial rituals took place. In the front chamber of Miao Yu's tomb, the skeleton of a kneeling dog has been excavated. This indicates that sacrifice of animals took place during the process when the tomb occupant was buried. ${ }^{124}$ Once the funeral had taken place and the deceased had been buried, the tomb doors would be closed, and the passage way would be filled with rammed earth. ${ }^{125}$ The masons who engaged in tomb construction may have also served as an integral part of the funeral.

\subsection{Case study: the construction of the Chefushan tomb No. 2}

Not only the construction process, but also the economics of Han stone carved tombs have not been mentioned in previous scholarship. However, it is important to evaluate the relative economic implications of Han stone tomb constructions, especially with respect to manpower and logistics of construction, which should be discussed in quantitative terms. This would allow a more firmly grounded evaluation of the impact of works for various tombs, so as to understand the tombs better, in their proper social and economic context. Therefore, case studies are provided, to include worked examples from the published data, allowing the discussion to move from the

\footnotetext{
${ }^{124}$ See Wenwu 1984.8: p. 23.

${ }^{125}$ However, it not uncommon that one chamber of a stone carved tomb was left empty, and later the tomb was re-opened to bury another newly deceased family member. See footnote 36 of this chapter.
} 
purely qualitative to the quantitative. There is clearly the evidence to do this for selected examples, and it would add a new element to the study of this material.

A group of stone carved tombs have been excavated at Chefushan in Pizhou of Jiangsu Province. ${ }^{126}$ Both tombs were located at the foot of a limestone hill called Bushangshan 埠上山. Among them, the tomb No. 2 is a good example to illustrate the details of construction, as its structure is well preserved and documented, though it has been looted many times thus has very few surviving burial objects.

The whole tomb structure is semi-subterranean, constructed from a combination of stone slabs and small moulded bricks. It consists of a rear chamber and a front chamber with two side chambers, and the tomb door is accessed by a ramped passage way which remains unexcavated. The plan of the tomb resembles a cross o north, and is about 6.3 meters long, and 5 meters wide at its widest point (Fig. 2-40). A total number of 45 stone slabs have been used for the construction. 23 of them, all carrying relief images, serve as columns, lintels, or doors, and they are distributed in every chamber of the tomb. Motifs of the relief carvings include images of daily life, the world of deities, as well as supernatural and auspicious animals. All the tomb walls were placed upon 22 footing stones, which are of similar sizes. Footing stones in the front and side chambers are 0.35 -metres-wide and 0.2-metres-thick, while those in the rear chamber are 0.35-metres-wide and 0.35-metres-thick. The lengths of such footing stones are the same as the wall stones above them. The faces of the stones on the interior of the tomb carry carved geometric patterns and drapery images. The

${ }^{126}$ For the archaeological report of tomb No. 1, see Dongnan wenhua 1999.2: 18-21 and Huaxia kaogu 2003.3: 87-95. For tomb No. 2, see Dongnan wenhua 2006.2: 26-32. 
background of such surfaces were cut away to a slight depth, leaving the images in relief with slightly bevelled edges. Most of the stone slabs are intact, and the material is limestone. Two types of moulded bricks have been used: cuboid bricks were used for paving floors of the tomb chambers, while voussoir bricks were used for constructing the barrel-vaulted tomb roofs (Fig. 2-41). The tomb is dated to mid-late Eastern Han (the end of the second century AD).

In order to get some idea of the possible means of the relative economic impact of the quarrying, transporting, carving and construction for various tombs, it is helpful to use the available data on the dimensions of such stone slabs, and then calculate their volumes and weights. Consequently the degree of working of the blocks, including man hours and the possibly hypothetical work requirements should become clearer. 


\begin{tabular}{|c|c|c|c|c|}
\hline \multicolumn{5}{|c|}{ Chart 2-1 stone walls, doors and lintels of the Chefushan tomb No. 2} \\
\hline Serial No. & function & Size (metres) & $\begin{array}{l}\text { Volume } \\
\qquad\left(\mathrm{m}^{3}\right)\end{array}$ & Weight (tons) \\
\hline 1 & left door & $1.22 \times 0.50 \times 0.21$ & 0.126 & 0.290 \\
\hline 2 & right door & $1.20 \times 0.52 \times 0.21$ & 0.131 & 0.301 \\
\hline 3 & wall & $1.21 \times 0.55 \times 0.34$ & 0.226 & 0.520 \\
\hline 4 & wall & $0.91 \times 0.83 \times 0.23$ & 0.174 & 0.400 \\
\hline 5 & lintel & $0.32 \times 2.59 \times 0.50$ & 0.414 & 0.953 \\
\hline 6 & wall & $0.91 \times 0.80 \times 0.23$ & 0.167 & 0.384 \\
\hline 7 & wall & $1.16 \times 0.30 \times 0.21$ & 0.073 & 0.168 \\
\hline 8 & wall & $1.23 \times 1.21 \times 0.23$ & 0.342 & 0.787 \\
\hline 9 & wall & $0.86 \times 0.81 \times 0.27$ & 0.188 & 0.433 \\
\hline 10 & lintel & $0.29 \times 2.53 \times 0.50$ & 0.367 & 0.844 \\
\hline 11 & wall & $0.88 \times 0.83 \times 0.24$ & 0.175 & 0.403 \\
\hline 12 & wall & $1.23 \times 1.08 \times 0.20$ & 0.266 & 0.611 \\
\hline 13 & wall & $0.85 \times 1.44 \times 0.22$ & 0.269 & 0.619 \\
\hline 14 & wall & $0.85 \times 0.98 \times 0.20$ & 0.167 & 0.383 \\
\hline 15 & wall & $0.85 \times 1.60 \times 0.24$ & 0.326 & 0.751 \\
\hline 16 & wall & $0.88 \times 1.22 \times 0.23$ & 0.247 & 0.568 \\
\hline 17 & wall & $0.86 \times 0.96 \times 0.13$ & 0.107 & 0.247 \\
\hline 18 & wall & $0.87 \times 1.12 \times 0.19$ & 0.185 & 0.426 \\
\hline 19 & wall & $1.04 \times 3.70 \times 0.35$ & 1.347 & 3.098 \\
\hline 20 & wall & $1.04 \times 3.70 \times 0.35$ & 1.347 & 3.098 \\
\hline 21 & wall & $1.14 \times 1.62 \times 0.22$ & 0.406 & 0.934 \\
\hline 22 & wall & $1.07 \times 3.72 \times 0.35$ & 1.393 & 3.204 \\
\hline 23 & wall & $1.07 \times 3.72 \times 0.35$ & 1.393 & 3.204 \\
\hline & tal volume & weight & 9.836 & 22.623 \\
\hline
\end{tabular}


The limestone used for the construction of the Chefushan tomb No. 2 was very likely quarried at the Bushangshan hill nearby. The density of such compact limestone is roughly 2.3 tons per cubic metre. Given the dimensions of the stone slabs, their volumes and weights have been calculated in Chart 2-1. Since the tomb is located at the foot of the Bushangshang hill, where the stone slabs were quarried, it is not too difficult to imagine the transportation of such slabs - they may have been transported by ox-carts or even on wooden rollers. On the other hand, Chefushan tomb No. 1 is only approximately ten metres away, and has a structure similar to that of tomb No. 2 , decorated with similar images carved with similar techniques. ${ }^{127}$ Therefore presumably they were carved and constructed by the same group of artisans, and it is very likely that they belonged to members of the same family. Thus the construction process and relevant logistics were similar as well. But it is not easy to calculate the logistics of quarrying, dressing, carving and the actual construction of the Chefushan tombs. Making comparisons with other documented tombs is one solution.

The Dahuting tombs M1 and M2 mentioned above, were excavated in the 1960s, and after the excavation, the archaeologists interviewed several contemporary stonemasons about their construction. ${ }^{128}$ More than 5,000 stone slabs, around 1,000 cubic metres of stone, were used for the construction of both tombs. According to the suggestions of the masons, about 2,500 gong 工 man-days was required for quarrying. Roughly shaping these stones required around 5,000 man-days, while

\footnotetext{
${ }^{127}$ See Dongnan wenhua 1999.2: 18-21 and Huaxia kaogu 2003.3: 87-95.
}

128 Mixian 1993: p. 337. 
detailed dressing and image carving would take about 10,000 man-days. Therefore, quarrying and finishing the stone slabs for the two tombs required around 17,500 man-days, excluding labour required for stone piling and brick roof construction.

Another famous stone carved tomb, the Yinan tomb also mentioned above, was excavated in 1954, and its report was published in 1956, with a very brief interview of stonemasons. ${ }^{129}$ A total number of 280 stones, 42 decorated with carved images that measure over 440 square metres, were used to construct the Yinan tomb. The interviewed mason believed that, using modern techniques, more than 4,700 man-days would have been needed need for the quarrying, transportation, dressing and carving of stones together with the construction process. According to the Dahuting masons, the labour would double if the same work was done by traditional methods. ${ }^{130}$ Therefore, at least 9,400 man-days was required to construct the Yinan tomb in the Eastern Han period.

Small moulded bricks were used for constructing the tomb chamber roofs and for paving the floors of the Chefushan tomb No. 2. To examine their production, the Dahuting tombs can again be used for comparison. For the Dahuting tombs, around 120,000 moulded bricks, each measuring $0.44 \times 0.24 \times 0.10$ metres, were used. According to contemporary artisans interviewed by the archaeologists, ${ }^{131}$ mud digging, screening, moulding would have taken more than 3,000 man-days, while firing needed another 2,500 man-days; A total 8,500 man-days was required to

\footnotetext{
129 Yinan 1956: p. 11

130 Mixian 1993: p. 337.

131 Mixian 1993: p. 335.
} 
produce the 120,000 bricks, including the preparation of brick-making tools and the construction of kilns. Moreover, 250,000 kilos of coal or 350,000 kilos of timber would have been needed for the firing. The roofs of the Chefushan tomb No. 2 have collapsed, but from their structures and surviving bricks it can be learnt that, around 3,000 bricks have been used for the roofs and the floor. As a result, presumably, 213 man-days were needed to produce the Chefushan bricks.

According to Chart 2-1, a total number of 45 stone slabs were used to construct the Cheufushan tomb, and the total volume is around $13.793 \mathrm{~m}^{3}\left(9.836 \mathrm{~m}^{3}+3.957 \mathrm{~m}^{3}\right)$. If we presume the stonemasons' hypothesis were accurate, the numbers would make it possible to conclude the logistics for the construction of the Chefushan tomb. Based upon the Yinan masons' assumption, 1,510 man-days would be needed to finish the whole construction of the Chefushan tomb. On the other hand, according to the Dahuting masons, either 158 man-days (stone structures only), or 234 man-days (including brick works), or 371 man-days (brick works included but counted in a different way) were required to finish the masonry works at Chefushan. Obviously, the margin of error is very big to discuss logistics only according to contemporary masons' hypothesis.

To conduct more precise calculations and to get more reliable conclusions, other ideas and new approaches should be experimented. However, there is no previous scholarship on ancient Chinese stone works, nor are there any literary sources on the details of such construction, as mentioned above. Therefore, it is helpful to borrow a series of approaches proposed by Western scholars, especially these working on 
Roman architecture. ${ }^{132}$ According to Barker and Russell, many studies on the construction of ancient buildings has made use of a nineteenth-century manual by Giovanni Pegoretti, which provides labour constants for a variety of stone types and stone carving projects, to calculate the labour involved in the construction. ${ }^{133}$

As for the construction of Han stone carved tombs, the stone working can be divided into the following main categories: 1, quarrying and rough shaping at the quarry; 2, transporting; 3, dressing, carving and possible polishing with various types of chisels; 4, the actual construction. The stone slabs of the Chefushan tomb No. 1 were quarried from a nearby hill, as mentioned above. Most of the slabs are less than a ton, thus can be transported with ox-carts. Stone slabs No. 19, 20, 22 and 23 are roughly 3 tons each, thus may have been moved to the construction site with wooden rollers, as they are too heavy for an ox-cart. But it is not easy to work out the exact manpower needed for the quarrying and transporting, as too many details are unknown.

For the construction process, evidence of cooperation between artisans could be seen. As mentioned above, in the rear chamber of the Chefushan tomb No. 2, the upper edges of the supporting stone walls at both sides of the barrel vault were sloped, so that the bricks were held in place (Fig. 2-32). There was a possible link between brick laying and stone carving and laying. This has shown a division of labour, namely the organisation and cooperation of different types of artisans on site and in

132 This is reflected in a series of books and articles, see DeLaine 1997, Barker and Russell 2012 and Russell 2013.

${ }^{133}$ See Barker and Russell 2012. 
workshops, making the evaluation of manpower even more difficult.

On the other hand, it is possible to calculate the cost of labour times for stone carving, if we make use of Pegoretti's figures. Take stone No. 21, which is the southern wall of the rear chamber, for example. It is 1.16 metres long, 1.14 metres wide, and 0.22 metres high. One side of the slab was decorated with relief image (Fig. 2-42). From the tool marks we can learn that, the carved side may have been worked with point chisels and claw chisels, while the other five sides of the slab involved rough plain work with medium chisels. Therefore, the amount of rough plain worked area is $1.16 \times 1.14+1.16 \times 0.22 \times 2+1.14 \times 0.22 \times 2=2.3344$ square metres. Relief-decorated area is $1.16 \times 1.14=1.3224$ square metres. According to Pegoretti, labour required for rough plain work on soft white marble, presumably similar to the limestone used at Chefushan, is 8.9 man-hours per $\mathrm{m}^{2}$; while labour required for smooth plain work on soft white marble, presumably similar to the carving on Chefushan slabs, is 22.24 man-hours per $\mathrm{m}^{2}$. Therefore, the labour required for finishing stone No. 21 at Chefushan is roughly $29.41+20.78=50.19$ man-hours.

However, as Barker and Russell have mentioned, the reliability of Pegoretti's figures has never been tested, and they have tried to resolve this problem. ${ }^{134}$ There are also other available manuals, but they are very different from each other. On the other hand, relevant figures in Han China must have been different from that of the Roman world and nineteenth-century Europe. The characteristics of Chinese limestone and sandstone have rarely been examined by architecture historians. As a

\footnotetext{
${ }^{134}$ See Barker and Russell 2012.
} 
result, at this stage, it is nearly impossible to work out precise logistics of Han stone tomb construction, due to the limitation of available materials and the lack of previous scholarships. This chapter only provides the background and preliminary research for a series of questions that awaits further studies. Discussion of the subject shows that there is much more potential and reveals a series of interesting possibilities that could lift the argument in future studies. It may deserve another thesis-scale research, which may be accomplished by making comparisons between data, including Western figures, possible Chinese antique manuals, as well as discussions with modern masons.

\subsection{Conclusion}

The construction process discussed in this chapter covers some of the more complex stone carved tombs. Many of these stages were omitted in relatively simple and small tomb construction. In general, however, the construction process shows that, the Han dynasty was a period of experiment for constructing stone tombs. First of all, different regions tried various approaches. Such experiments include, for example, in Shandong stone slabs, where people could execute relief images, and stone imitations of timber structures were popular. In the Capital Region sometimes stone blocks were used. As a result of the lack of stone in Luoyang, brick tombs were used as an alternative. The brick walls were then plastered and decorated with mural paintings, or sometimes directly painted. Combinations of carved stone slabs with brick vaults were used in Nanyang. Secondly, such regional variations are not clear cut, as similar 
plans, combinations and techniques were used in different areas. Different construction styles and techniques could be seen sometimes in the same tomb, indicating the cooperation of artisans, sometimes from different workshops. Some details within stone carved tombs, for instance the Classical columns, stepped roofs and caisson ceilings, indicate Western influences and show a high level of stone working technologies. ${ }^{135}$ But in general the level of stone construction of the Han period was relatively low. The methods of construction shows how unfamiliar the Western system is to the Han artisans. Probably that is why Han craftsmen frequently incorporated carpentry techniques in stone construction.

Han Dynasty stone carved tombs were thus hybrids of different techniques, including timber construction, stone working and brick laying. From these variations, Han people could choose certain types of tombs to satisfy their specific ritual and economic needs. The patrons of different types of stone carved tombs must have considered prices of different materials and their combinations, as well as styles of construction, so as to find a balance between their ritual needs and economic situations.

${ }^{135}$ See Chapter Four for detailed discussions on this issue. 
Chapter Two: the Construction of Stone Carved Tombs Chen Li, Hilary Term 2015 


\section{Chapter Three: the Imagery of Stone Carved Tombs}

元嘉元年八月廿四日, 立郭畢成, 以送貴親。魂靈有知, 怜哀子孫, 治生興政, 壽皆萬 年。薄疎郭内畫觀: 後當朱雀對遊戲仙人, 中行白虎後鳳皇。中直柱, 雙結龍, 主守中 $\square$ 辟邪央。室上央, 五子舉, 僮女隨後駕鯉魚。前有青龍白虎車, 後 $\square$ 被輪雷公君, 從 者推車, 乎梩冤廚。上衛橋, 尉車馬, 前者功曹後主簿, 亭長騎佐胡使驽。下有深水多 魚者, 從兒刺舟渡諸母。使坐上, 小車軿, 驅馳相隨到都亭。游徼候見謝自便。後有羊 車橡其櫘。上即聖鳥乘浮雲。其中畫, 橡家親, 玉女执尊杯桉柈, 局 $\square \square$ 抗好弱貌。堂 央外, 君出游, 車馬道從騎吏留。都督在前後賊曹。上有虎龍銜利來, 百鳥共持至錢財。 其央內, 有倡家, 生汗相和仳吹盧, 龍爵除央鶮噣魚。堂三柱, 中直 $\square$ 龍 $\square$ 非詳, 左有 玉女與仙人, 右柱 $\square \square$ 請丞卿, 新婦主待給水將。堂蓋花好, 中瓜葉 $\square \square$ 包, 未有䀒。 其當飲食就太倉，飲江海。學者高遷宜印綬，治生日進錢萬倍。長就幽冥則決絕，閉曠 之後不復發。

On the twenty-fourth day of the eighth month, in the first year of the Yuanjia reign period (AD151), we completed the construction of this tomb chamber, to send you, the honourable member of the family, off on your journey. If your soul has consciousness, please take pity on your descendents, let them prosper in their livelihood and achieve longevity. (Allow us) to list and explain the pictures inside the tomb.

The rear wall: The Red Bird encounters a roaming immortal. Phoenixes trail after the White Tiger who is strolling in the middle.

The central column (in front of the rear section): Here a pair of intertwining dragons, guard the tomb's heart and ward off evil.

The ceiling of the (rear) chamber: A wuzi carriage is followed by servant girls who are driving carps; the chariot of the White Tiger and the Azure Dragon runs ahead; the Duke of Thunder on wheels brings up the rear; and those pushing the vehicle are the assistants - foxes and mandarin ducks.

(The lintel above the west chamber): Ascending the bridge over the Wei River, here appear official chariots and horsemen. The Head Clerk is in front, and the Master of Records is behind. Together with them are the Chief of a Commune, the Assistant Commandant of Cavalry, and a barbarian drawing his crossbow. Water flows under the bridge; a crowd of people are fishing. Servant boys are paddling a boat, ferrying (your) wives across the river.

(The lintel above the east niche): (The women) then sit in small ping carriages; following one another they gallop to a ting station. The awaiting officer youjiao pays them an audience, and then apologizes for his departure. Behind (the procession), a ram-drawn carriage symbolises a hearse; above, divine birds are flying in drifting clouds.

The Portrait inside (the east niche) represents you, the member of the family. The jade maidens are holding drinking vessels and serving boards - how fine, how fragile, and how delicate! 
The face of the door lintel: You are now taking a tour. Chariots are guiding the retinue out, while horsemen remain at home. The dudu commander is in front, and the zeicao officer is at the rear. Above, tigers and dragons arrive with good fortune; a hundred birds fly over bringing abundant wealth.

The back of the door lintel: Here are the musicians and singing girls playing the wind-instruments of sheng and $y u$ in harmony, while the sound of a lu pipe strikes up. Dragons and birds are driving evil away; cranes are poking at fish.

The three columns of the front hall: In the middle, dragons ward off evil; at the left, are the Jade Fairy and immortals; and on the right column (two characters missing), the junior master is called upon, and drink is served by his newly wedded wife.

The ceiling of the front hall is decorated beautifully: Surrounding a round protrusion, melon-leaf patterns are added to the tips of the leaves.

(All the figures and animals,) when you eat and drink, may you eat in the Great Granary, and may you drink from the rivers and the seas. You who devote yourselves to learning, may you be promoted to high rank and be awarded official seals and symbols. You who devote yourselves to managing your livelihoods, may your wealth increase 10,000-fold in a single day. (But you, the deceased,) have entered the dark world, completely separated from the living. After the tomb is sealed, it will never be opened again.

- Inscriptions in the Cangshan tomb, Shandong Province ${ }^{1}$

In 1973, archaeologists excavated a stone tomb in Cangshan, Shandong Province. Similar to most other Han stone carved tombs, the Cangshan tomb was constructed from around 60 limestone slabs, and includes one front chamber with stepped roof, two side niches, and two rear chambers (Fig. 3-1b). As usual, many of the stone slabs carry carved images. But what is unusual is that, a long inscription of more than 200 characters was carved on the post of the western chamber. (See above) Many scholars, including Wu Hung, have studied the inscription and the tomb itself. Now most scholars believe that the inscription was authored by the artisans who designed and constructed the tomb, and it describes images carved in the tomb in

\footnotetext{
1 Translation of inscription adapted from Wu Hung 1995: 240-244. See Fig. 3-1a for rubbings of the inscriptions. For the archaeological report of the Cangshan tomb, see Kaogu 1975.2: 124-134.
} 
great detail, as well as designs that were for some reason not executed. ${ }^{2}$ The images described and carved in the Cangshan tomb are common enough among other Han stone carved tombs. Although there are differences between these stone carved tombs, the range of motifs of images is quite limited. Carved images include tomb occupants' activities, exemplary portraits, supernatural animals, banqueting, chariot excursions, music and dance, buildings and deities, similar to those of the Cangshan tomb. Similar motifs can be found in every region and almost every tomb.

Pictorial decoration of stone carved tombs was an innovation of Han China, as will be discussed in Chapter Four: the concept and technologies of constructing masonry tombs represented a major move away from the shaft tomb tradition of Central China. Han stone carved tombs were constructed from stone slabs, and most of the stone slabs were elaborately decorated with carved bas-relief images. However, there was no history of using such imagery within tomb complexes in Central China before the Han. Therefore a major question is, why are such stone carved images adopted at all, and what were the major functions?

\subsection{The development of burial images in early China}

To examine the driving forces of creating carved images, the development of pictures applied in early Chinese burials should be considered first. Burial images ${ }^{3}$ in

\footnotetext{
2 See Li Falin 1982, Wu Hung 1994b and Wu Hung 1995.

${ }^{3}$ Images, or decoration, within the burial context, traced back to as early as the Neolithic period in Central China, in the forms of painted pottery, jade carvings, decorated bronzes and textiles, as well as ornaments on other materials. But this chapter only discusses images on burial receptacle, namely tomb walls or coffins, not those on burial objects.
} 
pre-Han China were significantly different from Han period stone carvings or murals, if they existed at all. The earliest mural known so far in the Central Plains was found in a tomb at Xiaotun 小屯 village near Luoyang of Henan Province. This tomb was buried in an earth pit that is ten metres long, nine metres wide and twelve metres deep, and is dated to the Warring States period (475-221BC). Remains of red, white, yellow and black pigments were found on its earth pit walls, which the excavators believe were originally wall paintings. ${ }^{4}$ This is the only known example of Warring States tomb mural in the Central Plains.

More burial paintings of the Warring States period have been found in South China. One of the most famous examples is the tomb of the Marquis Yi of Zeng 曾侯 乙 (d. 433BC) found in Suizhou 隨州 of Hubei province: buried at the bottom of a rock pit were the outer and inner lacquer coffins both with painted geometrical patterns and supernatural figures (Fig. 3-2). ${ }^{5}$ Similar paintings have also been found in a number of Warring States tombs of the Chu Kingdom. ${ }^{6}$ This tradition continued to develop down to the Western Han period, for example in the Mawangdui tomb M1 mentioned above, the lacquer coffins were painted with abstract and supernatural motifs (Fig. 3-3a). Moreover, a T-shaped silk banner has been found in the tomb, with three registers of paintings of the underworld, this world, and the heaven (Fig. 3-3b). The silk banner draped the innermost of the coffins, and might have served a similar

\footnotetext{
${ }^{4}$ For the archaeological report see Kaogu 1959.12: 653-657. Unfortunately no photographs or line drawings are included in the report, therefore details remain unknown.

${ }^{5}$ See Suizhou 1989. The tomb is dated to 433BC.

${ }^{6}$ For some of the examples see Baoshan 1991; Xinyang 1986: p. 18, plaques 1, 2 and figures 5,6 and 7.
} 
function as that of murals.

All the above early examples of burial paintings were in fact painted on burial receptacles, not on tomb structures; therefore it is not correct to call them murals or to link them with Han period stone carvings. The first example of true mural known so far was discovered in the Shiyuan 柿園 tomb near Yongcheng 永城 of Henan Province. ${ }^{7}$ It is a rock-cut tomb cut horizontally into a small hill, and has a long passageway and several chambers (Fig. 4-21), like many other kingly rock-cut tombs mentioned in previous chapters. What is different from most other kingly tombs is that, murals were painted on the ceiling, the southern wall and the entrance walls of the main tomb chamber, which is 9.2 metres long, 5.2 metres wide with a 3.1-metre-high ceiling. The ceiling painting is the best preserved, and it depicts cloud scrolls, the lingzhi 靈芝 magical fungi, a dragon, the zhuque 朱雀 vermilion bird, the white tiger and other supernatural creatures (Fig. 3-4). Other murals in the main chamber were not very well preserved, but recognisable motifs are mainly decorative patterns and supernatural creatures as well. Because the Shiyuan tomb is a rock-cut tomb, the stone surfaces were first sanded down and then smoothened with a layer of greyish white plaster before being painted. The colours of the mural are red, white, black and green. According to the archaeological report, the red pigment is cinnabar $(\mathrm{HgS}){ }^{8}$ Moreover, some of the earliest know stone carved images have also been discovered

\footnotetext{
${ }^{7}$ For details of the Shiyuan tomb, which belonged to one of the kings of the Liang 梁 Kingdom of Western Han, see Yongcheng 2001: 81-247. 95-99. More details of this tomb will be discussed in Chapter Four.

${ }^{8}$ Yongcheng 2001: p. 120.
} 
in side chamber No. 8 of the Shiyuan tomb. ${ }^{9}$

Painting has also been found in a contemporary tomb in south China. The tomb which belonged to King Wen 文 of the Nanyue 南越 Kingdom, Zhao Mo 趙昧 (r. 137-122BC), was excavated in Guangzhou in 1983, and on the walls of the front chamber, traces of floral scrolls were found painted on the polished surface (Fig. 3-5). ${ }^{10}$ In some of the Chu King tombs at Xuzhou, for instance the Beidongshan tomb, cinnabar was painted on many dressed stone tomb walls. We are not sure whether such fragments of cinnabar were originally murals that later decomposed. But excavators of this tomb believe that the painting of cinnabar was part of religious practices rather than remains of decoration. ${ }^{11}$

From the above examples we can see that, most early Han burials had no murals at all, and pre-Han murals were mainly relatively simple geometrical or scroll patterns. In fact murals painted on house walls had developed during the Warring States period, and were frequently used in royal palace buildings of the Qin and Han period, which were mainly wooden. ${ }^{12}$ The reason that they were not widely used within contemporary tombs was probably that early tomb structures restricted the use of wall paintings. Most early tombs were coffins buried in earth pits, and it is relatively difficult to plaster earth surfaces and apply paintings. When stone chamber tombs were developed in the Western Han period, supplying reasonable surfaces for murals,

\footnotetext{
${ }^{9}$ See section 4.4 of Chapter Four for detailed discussions.

${ }^{10}$ For the archaeological report see Guangzhou 1991.

11 Xuzhou 2003: p. 46.

12 This is intensively supported by textual and archaeological evidence. For a listing of examples see Hsing I-Tien 2011: 1-46.
} 
wall paintings began to be employed. ${ }^{13}$

\subsection{Carved images within Han period stone tombs}

As previously discussed, although there are regional differences between Han stone carved tombs, the range of motifs of images is quite limited. Li Falin has worked on the typology and chronology of Han funerary stone carvings in his 1982 work. ${ }^{14}$ In 2000, Li finished even more intensive studies on Han stone carvings, supplying good summaries of excavated materials down to the late 1990 s. $^{15}$ In his work carved images were classified into groups according to their motifs. The first category is motifs of material life, for instance agricultural and handicraft works, everyday life including hunting, horses and chariots excursions, music and banqueting and so on. The second major category includes mythological motifs, with two sub-categories of deities and supernatural animals. Auspicious images are in the third category, while the fourth category includes historical figures, such as ancient sages, filial sons, assassins and men and women with virtue. The last category embraces natural scenes, such as astronomic images, landscape scenes, birds, animals, and fish as well as trees. Since the publication of Li's work, large numbers of stone carved tombs and countless individual stones have been excavated, but very few of them carry images that are outside Li's classification.

\footnotetext{
${ }^{13}$ However, it is odd that very few Western Han rock-cut tombs deployed murals. The Shiyuan and Nanyue tombs were probably the only two kingly rock-cut tombs that have wall paintings. This phenomenon will be discussed later in this chapter.

${ }^{14}$ Li Falin 1982: 42-51.

${ }^{15}$ Li Falin 2000: 133-406.
} 
Not only was the range of motifs limited, but the stone carved tombs were also very similar in content. Similar motifs can be found in every region and nearly every tomb. The best examples are stone doors used within tombs. Nearly all stone carved tombs had at least two stone doors, but their decorations are surprisingly similar to each other. Stone doors excavated from all the major regions of stone carved tombs, for instance at Dongjiazhuang of Shandong (Fig. 3-10a), ${ }^{16}$ at Tangsimen 唐寺門 of Luoyang (Fig. 3-10b), ${ }^{17}$ at Chenpeng of Nanyang (Fig. 3-10c), ${ }^{18}$ at Santaizi 三台子 of Beijing (Fig. 5-17), ${ }^{19}$ are all very much alike. From a comparison of figures, we can see that, all the stone doors had images of pushou xianhuan 舖首銜環 a beast head bearing rings in the mouth, with minor variations. For instance, at the Chenpeng tomb doors auspicious animals were carved above the beast head; and at the Santaizi tomb the composition has three registers with extra images of auspicious animals and a warrior.

Such similarities of images as well as combinations are of course partly due to artisans, who worked in well organised workshops and used well-prepared repertoires of stencils and patterns for the carving of images. But this also suggests that the tombs were decorated for certain purposes with a given functional template. Therefore, this chapter explores the production and the function of carved images within Han period stone carved tombs.

\footnotetext{
16 Anqiu 1992.

17 The date of the Tangsimen tomb is the first year of the Yuankang 元康 Reign (AD167).

${ }^{18}$ Kaogu xuebao 2007.2: 233-266.

19 Wenwu 1966.4: 53-54.
} 


\subsection{The production of carved images}

\subsubsection{Stereotype and modularity}

When Han period artisans undertook to carve images on stone slabs, they did not start with reality, even if they were carving realistic motifs, for instance a ram, but rather with an idea or concept in mind..$^{20}$ They selected from their mental stereotypes an appropriate pattern for the motif, and then adapted it by adding distinctive features of the required motif. For instance, at the rear chamber door of Miao Yu's tomb mentioned above, images of a qilin 麒麟 unicorn and a fudeyang 福德羊 goat of fortune and virtue were carved on the stone slab (Fig. 3-11). From the picture we can see that, the qilin and the goat are nearly identical except that the goat has two spiral horns, while the qilin has one straight horn between its ears. The reason for the similarities between the unicorn and the goat is probably that the carver had no idea about the appearance of a qilin, but had some experience of goats. Therefore he created his own qilin by adding a horn between a goat's ears, so that it accord with characteristics of qilin. ${ }^{21}$ Finally with a caption of 'qilin', the figure is no longer a

\footnotetext{
${ }^{20}$ In his groundbreaking work Art and Illusion, Ernst Gombrich illuminates how artists produce works of art. To be very straightforward, an artist goes to nature to look for material for painting, and he chooses and organises elements into his works of art. However, that is the very basic situation. Not all the paintings come from nature. When artists start to paint pictures, they start with what Gombrich calls a 'schema'. The schema, he argues, is "the first approximate, loose category which is gradually tightened to fit the form it is to reproduce." Without a medium and without a schema which can be moulded and modified, no artist could imitate reality. See Gombrich 1961: 63-92. A similar process could have happened in the carving of Han period stone slabs, though the carvers were artisans rather than artists. ${ }^{21}$ In a Han period dictionary, the Shuowen jiezi 說文解字 Explaining and Analyzing Characters, it is recorded that '麒麟, 仁獸也。麇身、牛尾、一角。Qilin is the animal of virtue, it has the deer's body, cattle's tail, and a single horn.'
} 
goat but a unicorn of virtue. Captions were important in Han stone carvings. That is probably why in many cases captions were wrongly carved by artisans with little knowledge, ${ }^{22}$ and that is also why nowadays some Han images, especially supernatural motifs, are so difficult to identify. Modern scholars have lost the Han context, as without captions or reliable texts, those images could be anything.

Moreover, there is almost no doubt that, even the image of the goat was not created after a live goat. Artisans learned skills from each other, and they tended to copy each other. As Gombrich states, 'you cannot create a faithful image out of nothing. You must have learned the trick from other pictures you have seen. ${ }^{23}$ It is easier to learn the carving of something from an existing pattern than from nature. And also, it is always more difficult than one can imagine to paint or carve anything without a familiar starting point. If one mason succeeded in innovation, for instance some kind of carving techniques or imagery motifs, the next craftsman needed no special insight; all he needed to do was to copy his predecessor. As argued by Gombrich, it is always easier to copy than to innovate in nearly all forms of art, including stone carved images of the Han period.

In addition, in carving stone slabs that were used for the construction of stone chamber tombs, the Han masons developed a 'modular system' similar to the one proposed by Lothar Ledderose:

\footnotetext{
${ }^{22}$ On one of the stone slabs in the Yinan tomb No. 1 for example, two figures are depicted in the same scene and seem talking to each other, with captions of ‘藺相如 Lin Xiangru’ and '孟賁 Meng Ben' respectively. However, it is impossible that these two figures had ever talked to each other. Therefore it is very likely that the masons carved the captions wrongly. See Yinan 1956.

${ }^{23}$ Gombrich 1961: p. 68.
} 
'The Chinese devised production systems to assemble objects from standardised parts. These parts were prefabricated in great quantity and could be put together quickly in different combinations, creating an extensive variety of units from a limited repertoire of components. $^{24}$

These components are called modules in his book. The author argues that modularity is inherent in all variety of Chinese art forms, from Chinese characters to bronze ritual vessels to funerary sculptures. These individual examples are presented by him as practices of the 'modular' system. Han period stone carvings were no exception: The modular system made it possible for the Han masons to assemble countless combinations from a limited repertoire of motifs and images. They had a repertoire of distinct motifs, including animals, birds, figures, chariots and excursions, as well as geometric and abstract motifs, as mentioned above. Such motifs could be combined into very complicated patterns, generating countless variations of compositions. Typically the motifs fit into registers, compartments of stones, resulting an interplay between decoration and overall tomb plan.

Within the same pattern, the composition might be created by combining different motifs from a given repertoire. One of the best examples of this is the so called 'shuixietu 水榭圖, the image of waterside pavilions' motif which was commonly depicted on stone slabs that were used for the construction of stone carved tombs, particularly in the Qi-Lu region. Figs. 3-12 (a-f) shows a group of shuixietu carvings excavated from different sites in Zoucheng 鄒城, Tengzhou 滕州 and Weishan 微山 counties in Shandong Province. These scenes all have a bridge

${ }^{24}$ Ledderose 2000: p. 1. 
connected to a pavilion, both supported by dougong brackets, ${ }^{25}$ with two figures sitting in the pavilion and more figures walking on the bridge. The inclusion of other elements seemed quite casual: birds or monkeys sitting on top of the pavilion roof, different kinds of fish, turtles, dragons and other supernatural animals, birds poking at fish, figures paddling boat and so on, might or might not have been carved on the different shuixietu scenes. All these elements were quite common in Han stone carvings. For example, according to the inscription at the beginning of this chapter, motifs like fish, dragons, birds catching fish, figures paddling boat were also depicted in the Cangshan tomb. ${ }^{26}$ It is possible that, in creating the shuixietu pattern, the Han masons first represented the pavilion and bridge combination, which were the basic standard elements, and then threw in other relevant motifs according to patrons' requirements, or even randomly. ${ }^{27}$ Like that, varieties of patterns were created from a limited range of motif and images.

\subsubsection{Mode of production}

There was a way of high-efficiency production in the carving of images within Han period stone tombs. The production of stone carved images was compartmentalised into different steps. These steps and units can also be viewed as

\footnotetext{
${ }^{25}$ See section 2.1.1.3 of Chapter Two for descriptions of Chinese dougong brackets.

${ }^{26}$ See Kaogu 1975.2: 124-134 for images of carvings within the tomb, which roughly accords with descriptions in the inscription.

${ }^{27}$ For more examples and a different argument, see You Yifei 2009: 159-160. You Yifei argues that the different combinations of images had specific meanings; while I believe they were nothing more than random combinations of various auspicious motifs and images.
} 
modules, as suggested by Ledderose. ${ }^{28}$ First of all, carving images on stone slabs involved division of labour. However, there are very limited contemporary written sources showing how the Han period stone carving workshops were organised. Yet the carved stones themselves and occasional inscriptions on them allow us to do some examinations.

On the doorpost of the Xiangtajun Shrine in Dong'e of Shandong mentioned in Chapter One, inscriptions were carved recording issues relevant to the deceased, as well as the process of how the tomb and shrine were carved. A part of the inscription reads, ‘使師操家、山陽蝦丘榮保、畫師高平代盛、邵強生等十餘人。(The patron) employed more than ten craftsmen, including master Cao Yi, artisan Rong Bao from Xiaqiu County of the Shanyang Commandery, painter Dai Sheng and Shao Qiangsheng from Gaoping County.' According to the inscription, apart from masons, painters were also engaged in the carving of the shrine. Indeed, from details of such carved stones we learn that sometimes artisans first sketched on the stone surface and then carved, as occasionally line drawing remains are found on some tomb stones. ${ }^{29}$ Sometimes the masons carved directly into the stones without sketching, probably in order to save time. On a stone excavated in Xuzhou, overconfident artisans have left examples with clear errors (Fig. 3-20). In this scene the horse was supposed to raise its front leg, but actually it was blocked by the decorative frame. This indicates that

\footnotetext{
${ }^{28}$ Ledderose discusses the division of labour in Chinese bronze casting, stating that the production is compartmentalised into single steps and units, which can be viewed as modules of work in a system of production. When the entire set of bronze vessels was cast, many workers could make the necessary moulds simultaneously. Each of the specialists was responsible for a standardised part of the process. See Ledderose 2000: 48.

${ }^{29}$ For one of the examples see Anqiu 1992.
} 
the masons carved the frame before carving the horse. Such mistakes could have been avoided if they had sketched beforehand. In the cases where there were preliminary sketches, while the painter was sketching on the dressed stone surfaces, the carvers were chiselling those already sketched stones. This must have been a timesaving process.

Moreover, the carving of different stones could be completed simultaneously, very likely on site, in large numbers, as the arrangements of motifs and their positions within a tomb could have been determined before work began. The Cangshan tomb inscriptions cited at the beginning of this chapter were actually masons' formulae, describing frequently used repertoires, as argued by Wu Hung. ${ }^{30}$ In the Anqiu tomb, different carving styles and traces of unfinished projects shows that the tomb was built in a relatively short time, and it was possible that artisans from several workshops have cooperated in carving and constructing. ${ }^{31}$

Different stones with similar compositions have also been found. On two stone slabs excavated in Xuzhou, three similar registers of images were carved; even the motifs in each register of both stones were nearly identical (Fig. 3-21). This suggests that there must have been some kind of album or formula containing varieties of motifs and compositions. Masons must have been presented carving patterns from specified repertoires. ${ }^{32}$ Furthermore, sometimes identical images can be seen on

\footnotetext{
${ }^{30}$ See Wu Hung 1995: 240-244.

31 See Tseng 2000: 33-86 for detailed discussions. Apart from research on the cooperation of workshops, Tseng has also examined repertoires and the regional visual traditions of the manufacture of funerary stones in Han period Shandong.

32 This approach of pattern production is called getao 格套 (repertoires) by Lillian Tseng, see Tseng 2000: 33-86. See also Hsing I-Tien 1996: 44-59 who calls this 'pattern' as a way to
} 
several tomb stones surfaces. For instance, on a pair of stone doors excavated from a tomb in Suide 綏德, Shaanxi 陝西 Province, images of deer, bird catching fish, dragons, winged tigers, double-headed beast and many other supernatural animals were depicted (Fig. 3-22). More importantly, many of the images carved on the doors are identical. This means that templates or stencils may have been employed. The artisans simply put a template, probably in wood, against the stone surface, and then drew along the border of the template so as to create a silhouette of the figure, before carving the stone.

Anthony Barbieri-Low has done intensive works on Han masons in his book Artisans in Early Imperial China. ${ }^{33}$ He has reconstructed the process of stone slabs being quarried, carved, transported and fixed. Also he incorporates several new points, including tools, traces of tool marks, activities of artisans, precision and labour saving devices, in his research. He describes the use of 'customisable prefabrications', a system used by masons and workshops that allowed most elements of a monument to be constructed off-site using standardised modules, arguing that stone slabs may have been well prepared and carved at workshops, thus are ready for ordering. ${ }^{34}$ Barbieri-Low's primary example is the homage scene depicting the male deceased seated in a pavilion, with his mourning wife and concubines seating upstairs. $\mathrm{He}$ notices that different versions of this scene portray from one to six mourning females. He then argues that the stone carvers anticipated this variable situation and maintain the level of quality.

33 Barbieri-Low 2007: 67-152.

${ }^{34}$ Barbieri-Low 2007: 83-96. 
prefabricated at least six versions of the homage scene (Fig. 3-23). This way patrons were able to order prefabricated stones 'off the shelf', picking the one that had the right number of wives. ${ }^{35}$

I agree with Barbieri-Low that there were formulae for certain patterns, for instance the homage scene he mentioned. But it would be farfetched to suggest that such stones, or any other stone slabs used for funerary monument construction, were carved at workshops before being ordered. First of all, such stone slabs were not individual ones as seen today. They were created for the building of specific tombs or offering halls, and needed to be combined with other stones. Prefabricated ones might not fit with others in construction, or might not fit into the required tomb and shrine planning. Secondly, stone work was expensive in the Han period. ${ }^{36}$ The required amount was not that big, while there was fierce competition between different workshops. Therefore, preparing six versions of the homage scene is not feasible; it would be a great waste if they were not sold. Lastly, the most time-consuming and labour intensive part of tomb or shrine construction was quarrying, transporting and the actual construction. Image carving is relatively fast, given formulae and stencils. The artisans did not have good reason to carve images beforehand at their workshop. Indeed, as suggested in Chapter Two, most of the Han funerary stones were carved at the tomb site. The reason of Barbieri-Low's point of view is probably that, he did not manage to jump out of the tradition that he criticised, ignoring the fact that such stone

\footnotetext{
35 Barbieri-Low 2007: p. 94.

${ }^{36}$ For instance, An Guo's shrine erected in Shandong in AD157 cost the patrons 27,000 qian coins (equals 604.8 grams of gold).
} 
slabs were not separate pieces of works of art, but were integral parts of stone carved tombs or stone offering shrines.

\subsection{Understanding images within stone carved tombs}

\subsubsection{Current proposals}

Many scholars have worked on the carved images of stone carved tombs. In mainland China, the study of Han stone carvings has even become a dominating subject in archaeology and art history. Most Chinese scholars simply concentrate on typological and chronological studies within the mainstream Chinese tradition of archaeology, treating the stone reliefs as individual images. Following the antiquarian tradition, they use ancient texts to explain the meanings of such images. ${ }^{37}$ Although such works are helpful to further research, the conclusions are fragmentary. Such traditions have even influenced early Western scholars, many of whom have also talked about single images or motifs. One example is the debate on a commonly seen motif of Han stone carvings, the bridge battle scene. ${ }^{38}$ Now most scholars have abandoned the view that motifs such as bridge battle reflects specific events related to the tomb occupant. Most of the scenes are, in fact, related to the afterlife belief, or simply a result of masons carving what they could carve based on their templates. The misunderstanding of images by early scholars was partly due to the way that they treated the stone carvings as individual items, rather than as elements of a complex

\footnotetext{
${ }^{37}$ See section 1.3.1 of Chapter One for comments on this approach.

${ }^{38}$ See Berger 1976 and James 1982 for two of many examples. Many earlier scholars believed that the battle at the bridge scene carved on the Wu Liang Shrine was related to Wu's experiences.
} 
tomb.

In her 1941 article, Wilma Fairbank insightfully raises the 'positional significance' of carved stone images, pointing out that their structural meanings have been neglected. ${ }^{39}$ However, except for her own work on the reconstruction of a stone offering shrine using fragmentary images, Fairbank's approach was not taken up until the $1980 \mathrm{~s},{ }^{40}$ and its importance is still not realised by Chinese scholars. Moreover, Fairbank's method has its flaws: she merely concentrated on carved images of stone funerary structures, while other elements such as burial objects were ignored. An improved approach to examining tombs and burials can be deduced from works by Jessica Rawson, who sees tombs and their furnishings as correlative embodiments of deeply held beliefs about the structure of the cosmos. As she shows, the designs, furnishings and decoration were deployed to create a microcosm of the universe, to provide the underground chambers as a place within which the departed soul would happily dwell. ${ }^{41}$ Bearing the above ideas in mind, a clearer picture has emerged: to fully understand the meanings and functions of stone carved images, it is useful to look at their pictorial programmes, in a new way.

\subsubsection{The 'pictorial programme'}

\footnotetext{
${ }^{39}$ Fairbank 1941: 3.

40 See James 1983, 1985 and 1988 for Jean James' study on the iconographic programmes of Han stone tombs and offering shrines; see Wu Hung 1992 for his ideas of the 'pictorial program' of the Wu Liang Shrine. See section 1.3.3 of Chapter One for full references and comments.

${ }^{41}$ These views are reflected in a series of articles on burials and afterlife, see Rawson 1996, 1998, 1999, and 2002.
} 
Undoubtedly the meanings and functions of carved images will be better understood if we take the complete group of images within a particular tomb, illuminating their positional significance within the arrangement of the pictorial programme of a stone carved tomb. The discussion of 'pictorial programme' should include not only carved images on stones, but also the tomb structures as well as burial objects within tombs. Although the architectural features of tombs, as well as the figurines, paintings, stone carvings and other artefacts they contained, have been the subjects of many studies, ${ }^{42}$ few scholars have treated these as closely interrelated elements.

Construction creates space, which is the key element for above-ground architecture and within tombs. It is in this space that the occupant was buried, and numerous objects were interred. It is also the architectural structure that supplies surfaces and made it possible for ornaments to be applied, be it stone carvings or wall paintings. On the other hand, it is the burial objects and images that supplied contents for the space, making it a meaningful complex for the occupant, either by offering models for the afterlife, or by creating a model universe. Examining the interactions between different subjects within a tomb, including the structure, the objects, the images and the body, is key to understanding what the tomb was expected to achieve.

\subsubsection{Burial objects: models or real objects}

\footnotetext{
${ }^{42}$ For examples, see Guo Qinghua 2010 for a study on Han period ceramic models of buildings, see section 1.3 of Chapter One for large numbers of works on studies of stone carvings within Han tombs.
} 
Archaeological evidence indicates that, not only real objects, but also replicas of real objects were buried within Han tombs. This reveals a change of burial practices: from the Shang and Zhou periods, bronze ritual vessels, real weapons and chariots were buried, while in the Qin and Han dynasties replicas of real objects generally took their place. ${ }^{43}$ In northern China, terracotta figures or pottery models of building complexes were frequently interred. Wooden replicas might have also existed, but very few have survived as they have perished. Wooden models of figurines are sometimes preserved in tombs in the South, partly because many tombs were very well sealed, partly because the wooden models were lacquered, thus preventing from decay.

One of the examples is the Fenghuangshan 鳳凰山 tomb No. 168 excavated in Jiangling 江陵 County of Hubei Province, which is a traditional tomb with timber coffins buried at the bottom of an earth pit. ${ }^{44}$ The tomb was found intact, thus numerous burial objects have been excavated. Among them a bamboo tablet that is 23.2 centimetres long, 4.1-4.4 centimetres wide and 0.3 centimetres thick has been found (Fig. 3-24), and it carries ink inscriptions which reads:

十三年五月庚辰。江陵丞敢告地下丞: 市陽五夫（大夫）遂，自言與大奴良等廿 八人、大婢益等十八人、軺車二乘、牛車一兩、 $\square$ 馬四匹、䭹馬二匹、騎馬四匹。 可令吏以從事。敢告主。

(This tomb was buried) on the day of gengchen (fifteenth day) of the fifth month in the thirteenth year (of Emperor Wendi's reign, 167BC). The minister of Jiangling dares to

\footnotetext{
${ }^{43}$ Rawson 1996: 42-49. It is true that in the Han period, as well as in later periods of Chinese history, some real objects were still buried within tombs, especially in kingly tombs, for instance the Mancheng tomb mentioned above, but the trend was that replicas generally took the place of real objects.

${ }^{44}$ Kaogu xиebao 1993.4: 455-513.
} 
inform the underground minister: the tomb occupant is Sui, with the wudafu title, originally from Shiyang, is saying by himself that he is accompanied by: twenty-eight excellent male servants, eighteen fine servant girls; two yao chariots, one ox-cart, four (unidentified) horses, two liu horses, four ridden horses. Please deal with these according to regulations of the underground world. I dare to inform you this. ${ }^{45}$

It is quite obvious that, the cited texts were written to communicate with an underground lord, which reveals that the afterlife bureaucracy existed in people's minds in early China. ${ }^{46}$ Together with this bamboo tablet, sixty-six bamboo slips were also found, listing burial objects buried within the tomb: chariots and drivers, male and female servants, ox-carts, boats, numerous lacquer wares, textiles, bronze coins and so on. The inventory may have been a convenient ritual or bureaucratic device for the preparation of the tomb, addressed not to living people, but to officials in the afterlife. Therefore, a list of a collection of burial goods had been transmitted to the underground lord of funerary goods. Indeed, lacquer wares, textiles and coins excavated from the tomb accord with what has been listed on the bamboo slips. Moreover, wooden models of chariots and servants were found, the numbers of which approximately accord with the bamboo tablet records. However, very interestingly, what was recorded in the inventory was not 'twenty-eight models of servants', but was 'twenty-eight servants'. They were understood not as replicas of servants, but as functional real servants, as if they would attend the deceased in the after world.

The Fenghuangshan tomb No. 168 is not the only such example. Large numbers of similar tombs, which include wooden and bamboo inventories recording how many servants were buried but where in fact models of servants were buried, have been

\footnotetext{
45 Kaogu xuebao 1993.4: 499. Translated by the author.

${ }^{46}$ See Harper 1985 and Seidel 1987 for relevant studies.
} 
discovered. ${ }^{47}$ These indicate that in the Han period, models buried within tombs were treated as real objects rather than merely replicas. The Han people must have an understanding that models and objects of daily life were equally functional. Therefore in the Han period, burial models quickly developed, nearly everything that one had used in the life could be replicated in wood or terracotta and interred. The varieties of models kept growing, and became systemised in the Eastern Han period. ${ }^{48}$ It is important to bear in mind that, the models were all equivalents rather than substitutes of the real objects. ${ }^{49}$

\subsubsection{Images as models: substitutes or equivalents}

The burial practices in the Han period did not only change from real objects to models, but also from real objects to images, ${ }^{50}$ for instance relief images carved within stone tombs. The fact that the carved images were executed on the inside of the house-shaped tomb chambers, which were sealed and buried underground, and that the motifs of images consisted of musicians and dancers, clearly suggest that they were intended for the enjoyment of the tomb occupants, not meant to be viewed by an outsider. ${ }^{51}$ What are the images for? Jessica Rawson has suggested that, unlike the

\footnotetext{
47 The famous Mawangdui tombs mentioned above have such inventories as well. See Changsha 1973.

${ }^{48}$ Details of models specifically made for burials, especially pottery models, will be discussed later in this chapter.

49 Similar ideas have been proposed in Hayashi Minao 1992 and Rawson 2002.

${ }^{50}$ Rawson 1996: 42-49.

${ }^{51}$ It is possible that tomb images have been viewed during funerals before being sealed, but that was not as important as functions for the occupant. A Han period mural tomb has been frequently cited by scholars because it has inscriptions saying “諸觀者皆解履乃得入 those who intended to view (the murals) should not get in unless they take their shoes off'. See
} 
occident where pictures mainly served as architectural ornaments, the purpose of images in China was different. ${ }^{52}$

To some extent the carved images within stone tombs had the same function as that of pottery models. Firstly, stone carvings supplied another medium for the reproduction of real objects: there are large numbers of relief images depicting similar activities or objects as that of pottery models. For instance, pottery models of architectural complexes were frequently found in Han tombs in Central China, and in the same area carved images and murals of buildings were as popular (Fig. 1-1b and Fig. 2-5). Moreover, everyone wished to have horses and chariots, but not everyone could afford burying them in the tomb for the afterlife. Therefore they found it practical to use models instead, either in the form of carved images of horses (Figs. 3-20 and 3-21), or smaller lead models of chariots, ${ }^{53}$ which would be functional in the afterlife as well. The carved images were a pictorial representation of certain objects, just as pottery models were material representations of such objects.

Secondly, carved images could represent a variety of motifs that was difficult to achieve with pottery models, for instance supernatural animals, deities, celestial beings, constellations. It is more convenient to use images to represent a heavenly world, while pottery figures were mainly models of the human world. According to

Kaogu yи wenwu 2002.3: p. 76. But in fact the tomb is too small to be stepped in, therefore meanings of this inscription is debatable. For a discussion on the viewers of images in Han tombs, see Zheng Yan 2006: 39-55.

52 Rawson 2006b: 380-389.

${ }^{53}$ Lead was a cheaper material than bronze, which was used by the upper class to produce parts of chariots. Sometimes in commoners' tombs model chariots smaller than life size have been found, and many were made of lead. For such an example see the Shilipu 十里鋪 tomb, which will be discussed later in this chapter. 
the Cangshan inscription cited at the beginning of this chapter, the artisans treated relief carvings in the tomb as hua 畫 images, but not merely images by themselves: A pair of intertwining dragons at the central column would ward off evils; the combination of tiger and dragon would arrive with good fortune, and the birds would fly over to bring wealth. Such images would be equally functional as the auspicious animals they represent. No matter whether it was objects that existed in reality or imagination that were depicted, the carved images were all understood by the Han people as equivalents rather than substitutes of the real objects, or the proposed supernatural creatures. Just as Rawson has argued, proper provision of the appropriate functions was important, and the means by which they were supplied, either as ceramic figures or as carved images on stone, were less important. ${ }^{54}$

\subsection{Case studies: the pictorial programmes of stone carved tombs}

\subsubsection{The Shilipu tomb}

The Shilipu 十里鋪 tomb found in the southern suburbs of Xuzhou, Jiangsu Province in 1964 is a good example to illustrate the interrelationships between the pictorial programme, the burial objects and the tomb structure. ${ }^{55}$ Though it was

\footnotetext{
${ }^{54}$ Rawson 1999: p. 11.

55 The Shilipu tomb is chosen for case study because of the following reasons. Firstly, the plan of the tomb could represent most cases in this specific distributional area, the Qi-Lu region. Secondly, it is a relatively small tomb, and the tomb structure is not too complicated. Bigger tombs tend to be too sophisticated, thus must have included more variations, many of which might have been personalised creatures that could not reflect the general trend. Thirdly, a large proportion of burial objects have been preserved when the tomb was excavated, and many of the objects were not disturbed until the excavation, so that their original places can
} 
excavated and published in the 1960s, the archaeological report is surprisingly detailed and of high quality. ${ }^{56}$

The whole tomb structure is semi-subterranean, constructed from a combination of stone slabs and small moulded bricks, and was buried within un-rammed earth. It consists of a rear chamber, a middle chamber, and a front chamber with two side chambers, as well as an entrance chamber accessed by a ramped passage way. The plan of the tomb resembles a cross facing south, and is about 15 meters long, and 5.5 meters wide at its widest point (Fig. 7-10). Eighteen stone slabs, all carrying relief images, have been used for the construction; and they are distributed in every chamber of the tomb, serving as columns, lintels, or doors. Motifs of the carved images include images of daily life, the world of deities, as well as supernatural and auspicious animals. Burial objects include lead models of chariots, ceramic models of lamps, plates, tables, stoves and architecture, pottery animals as well as ceramic models of foreign-looking male and female servants. ${ }^{57}$

From the tomb structure and the range of images and burial objects we can learn that, the primary purpose of the Shilipu tomb was to create a house-like structure, providing living space for the afterlife of the tomb occupants. This purpose is achieved through carved images together with the burial objects, be they real objects be identified. This way their functions and relationships with carved images can be precisely illuminated. Almost all currently know stone carved tombs have more or less been looted, some more than once in historical and modern times. None of the tombs were found intact at the time of excavation, therefore I have chosen the Shilipu tomb within which larger numbers of objects have survived.

${ }^{56}$ Kaogu 1966.2: 66-83 and 91.

${ }^{57}$ See Appendix II for full description of the carved images and burial objects within the Shilipu tomb. 
or models. Many of the buried models, for instance architecture, foreign servants, and chariots, were also carved on stone slabs, which indicate that the only difference between the two is the medium of representation. Everything interred within the house-like tomb structure was important for the material life of the deceased.

Moreover, the tomb chambers were obviously not intended for the living, as many of the chambers are not high enough for a person to stand in (ceiling height: front chamber: $1.5 \mathrm{~m}$; western chamber: $1.08 \mathrm{~m}$; eastern chamber: $1.06 \mathrm{~m})$, except the middle and the rear chambers (ceiling height: middle chamber: $2.44 \mathrm{~m}$; rear chamber: $1.96 \mathrm{~m})$. The middle and rear chambers are important, because they were supposed to be the tomb owners' dwellings. This assumption can be supported by inscriptions found in Feng Rujiu's tomb mentioned above. ${ }^{58}$ At the lintel or door post of each chamber of Feng's tomb, the function of the chamber was inscribed. Inscriptions include 'zhong damen 中大門 the central gate', 'cheku 車庫 chariot storage', 'xifang neimen 西方內門 the western inner door', and 'cangge 藏閣 storage room'. It is quite obvious that the purpose of the tomb was to reconstruct the occupants' everyday dwellings in the underground world.

In fact the purpose of the Shilipu tomb is two-fold: Apart from providing a living space for the afterlife of the occupants, imagery of spaces, deities, celestial bodies and supernatural beings were also depicted in the Shilipu tomb, picturing a universe for the occupants. In the middle chamber a very complicated sculpture in the shape of a pedestal or a vessel was found. It is 35.5 centimetres high, and its diameter

58 See Kaogu xuebao 1980.2: 239-262 for the archaeological report. 
is 41 centimetres (base) and 29 centimetres (top) respectively. Among its mountain-like knobs, there are many smaller figures including winged horses, sheep, fourteen dancing figures and musicians many of which might be foreigners, and the siling 四靈 animals. A pottery millstone was placed in its top opening (Fig. 7-19e). The excavators believe that this sculpture depicts a ceremony praying for a bumper harvest of crops. ${ }^{59}$ Therefore, the tomb occupants were provided with all necessities, especially for feasting and sleeping, for chariot excursions, for the performance of ceremonies and rites, and for a world of immortality. Just as Rawson has argued, the stone carved tombs were complete settings for the afterlife. Each tomb was an entire universe centred on its occupants. ${ }^{60}$

\subsubsection{Comparisons: Western Han and Eastern Han Kingly tombs}

In different periods of the Han dynasty, tombs that belonged to the kings were constructed, decorated and equipped differently. A group of kingly tombs found in the suburbs of Xuzhou will be examined because of the following reasons. All three tombs, although some are rock-cut tombs some are stone carved tombs, belonged to nobles of the Chu or Pengcheng kingdoms, the seat of both was modern Xuzhou. Therefore, the examination of three tombs in chronological order shows how the kings' choices of tomb structures changed in the wake of their changes in status and power. But on the other hand, the functions of their tombs remained unchanged, though achieved in different ways.

\footnotetext{
${ }^{59}$ Kaogu 1966.2: 66-83 and 91.

${ }^{60}$ See Rawson 1999: p. 13.
} 
The Shizishan 獅子山 tomb was found at Xuzhou, and was cut horizontally into a limestone hill. ${ }^{61}$ It was cut according to a south-north axis, and is 117 metres long, 13.2 metres wide at the widest point. The Shizishan tomb has twelve burial chambers covering an area of 851 square metres (Fig. 3-30). Although it was once looted in antiquity, more than two thousand burial objects were excavated, including jade, gold and silver vessels, bronze vessels, pottery, seals and bronze coins. The tomb occupant was probably Liu Yingke 劉郢客 (r. 178-175BC), the third Chu King of the Western Han period, and his consort. ${ }^{62}$ The structure of contents, most of which are real objects rather than models, of the Shizishan tomb are impressive, but it is interesting that no carved images or murals were found in the tomb. ${ }^{63}$

The Woniushan 臥牛山 tomb excavated near Xuzhou in 1980 is another kingly rock-cut tomb. It was cut horizontally into the Woniushan hill following a natural cave; therefore we can presume that it was much easier to carve than the Shizishan tomb. It has three burial chambers, covering an area of roughly 100 square metres (Fig. 3-31). ${ }^{64}$ It is very likely that it belonged to Liu Yu 劉紆 (r. 2BC-AD8), the last Chu King of the Western Han period, and his consort. ${ }^{65}$ This tomb was looted many times in antiquity. Surviving burial objects include bronzes, an iron sword, ceramic jars and basins, models of dogs and chickens, a pottery model of a pigpen as well as

${ }^{61}$ For the archaeological report, see Kaogu 1998.8: 1-20, Wenwu 1998.8: 4-33 and Xuzhou 2012.

${ }^{62}$ Liang Yong 2001: p. 79.

${ }^{63}$ The only two Western Han kingly tombs that had murals or carved images are the Shiyuan tomb and the Nanyue tomb mentioned above. See section 3.1 of this chapter and Fig. 3-4, Fig. 3-5.

${ }^{64}$ The archaeological report of the Woniushan tomb has not been published yet. For a brief description see Zhou Xueying 2001: 134-141.

${ }^{65}$ Liang Yong 2001: p. 77. 
models of architecture. These reflect that, at the end of the Western Han period, the kings no longer had real power, and thus could not maintain lavish lifestyles and burials. ${ }^{66}$ Therefore, they buried models of real objects in their tombs, believing that such models had the same function as real objects, providing for the afterlife.

The Lalishan 拉犁山 tomb No. 1 was one of the unusual examples. ${ }^{67}$ It is similar to other stone carved tombs in terms of structure and decoration, but the remains of a jade suit have been found in this tomb, which show that the tomb occupant was probably a king or at least a noble of high social status. Other burial objects include ceramic models of pigpens, wells, stoves and buildings. Motifs of carved images include auspicious and supernatural animals such as dragons, zhuque vermilion bird, nine-headed beast, lotus images, pushou xianhuan as well as decorative patterns. These indicate that, in the Eastern Han period, powers of the kings and nobles were indeed further reduced as described in historical texts. ${ }^{68}$ Therefore, the kings introduced not only models of real objects, but also carved images, to achieve the functions of the tomb. But for key elements where the material matters, for instance the jade suit, real objects were retained. Generally, stone carved tombs were more richly decorated but less equipped with real objects than the kingly rock-cut tombs, while very few rock-cut tombs have murals or carved images, but have abundant burial objects.

\footnotetext{
${ }^{66}$ See Chapter Four for detailed discussions.

${ }^{67}$ Two stone carved tombs have been excavated at Lalishan in Xuzhou. For short excavation reports see Xuzhou 1986: 123-124 and Xuzhou 1990: 208-209. Jade suit remains have only been found in tomb No. 1.

${ }^{68}$ See section 4.4 of Chapter Four for further discussions on the change of status and power of Han kings.
} 
The development of Han period kingly tombs in Xuzhou supplies further evidence for the argument that, the purpose of Han period tombs was two fold: firstly providing material life for the afterlife of the occupants, secondly creating an entire universe centred on its occupants. For these purposes, images and modelled burial objects were understood as equivalents of real objects. For instance, in the Eastern Han, real chariots and horses and other burial objects were replaced by images or models of the burial objects, which were cheaper but could achieve the same function for the afterlife. The reason for this is that, Eastern Han kings and other well-off patrons were not as rich and powerful as the Western Han ones. On the other hand, the function of imagery of spaces, seasons, celestial bodies and supernatural beings is picturing a universe. Murals excavated from Western Han kingly rock-cut tombs were all about supernatural motifs, something difficult to approach with burial objects, therefore murals were painted.

In conclusion, the above comparisons indicate that, stone carved tombs are a result of relatively simple burial customs rather than lavish burial customs as is widely argued. ${ }^{69}$ Such stone carved tombs seem labour intensive and expensive, but they were relatively cheap compared to previous elite tombs, for instance ticou tombs and rock-cut tombs mentioned above. The change from human sacrifice to sculptural figurines in the Qin as well as the Han, was one development of Chinese burial custom. ${ }^{70}$ The change from real objects to models and images was a further

\footnotetext{
${ }^{69}$ See Xin Lixiang 2000 and Li Falin 1982 for such views. Both believed that the emergence of stone carved tombs in the Han period was a result of lavish burial customs, and such views are widely accepted.

${ }^{70}$ Although human sacrifice was not completely absent in the Han period. For instance in the
} 
improvement of the Han period. The images, pottery models and real objects simply provide different types of materials for the tomb occupant to construct a continuation of their previous lives in the afterworld. The application of carved image, ceramic models and real objects created three different points of view in how the tomb occupant intended to represent their afterlives. Individuals of different social and economic backgrounds were quite free in choosing particular elements to suit their own needs, according to one's attitude toward death and what the afterlife was supposed to achieve, as well as considering what they could afford. In a word, the choice of stone chamber tombs with relief carvings and models or real objects was a balance between afterlife beliefs and patron's economic situations.

\subsection{Conclusion}

The images carved on stone tombs and offering shrines were not merely images. Together with different patterns of burial objects and their settings, such images formed a way through which people of the Han period attempted to give meaning to their world. Such combinations were also a kind of expression of how the owners saw themselves in the private and public social contexts. Though not necessarily derived from their own experiences, it is in society that people normally acquire and localise their memories. The carved images and combinations of objects preserved a social context within which the tomb occupant's memories as well as the general trend were placed.

Shizishan tomb mentioned above, the king buried two of his concubines and one chef with him. 
Moreover, such sets of images and objects within stone carved tombs have differed considerably across time and space. Such changes should be linked to wider changes and varieties of ritual performances as well as beliefs. Of course, such differences between sets were also partly due to reasons of masons. Organised workshops in different regions must have used different repertoires of stencils and patterns for the carving of images. Apprentices taken by veterans might have developed different tomb designs and carving styles, which would be reflected as chronological differences between image and object sets. Beliefs and ideas about the tomb contents should be taken as part of a pictorial programme, rather than freestanding beliefs. 


\section{Chapter Four: the Origins of Stone Carved Tombs}

孝武之世……下殷富, 財力有餘, 士馬彊盛。故能睹犀布、瑇瑁則建珠崖七郡, 感枸 醬、竹杖則開牂柯、越崔, 聞天馬、蒲陶則通大宛、安息。自是之後, 明珠、文甲、通 犀、翠羽之珍盈於後宮, 蒲梢、龍文、魚目、汗血之馬充於黃門, 鉅象、師子、猛犬、 大雀之蛘食於外直。殊方異物, 四面而至。

In Emperor Xiaowu's time ... the Empire was rich and powerful. Therefore, when the Emperor saw rhinoceros horns and tortoise shells, he was able to set up seven commanderies in the south including Zhuya (Hainan Island). Inspired by the jü berry sauce and bamboo canes, the southwest was opened up. Having heard about Heavenly Horses, he eventually succeeded in establishing relations with Dayuan (Ferghana) and Anxi (Bactria). From that time on, precious articles like shining pearls, rhinoceros horns, tortoise shells and emeralds overflowed in the inner palace, four of the best kinds of horses filled the palace gates, and giant elephants, lions, fierce dogs, and big birds were fed in the Imperial garden. In short, rare things of various places came from all directions.

- Hanshu 漢書: biography of the Western Regions 西域傳 ${ }^{1}$

During the Han Dynasty, Chinese power attained great heights, especially under the rule of Emperor Xiaowu 孝武 (r. 141-87BC). ${ }^{2}$ The Emperor had not only expanded the empire's borders, repelled the nomadic Xiongnu 匈奴 people from raiding north China, but also established connections with the 'Western Regions', including various kingdoms of present-day Xinjiang 新疆 as well as Central and Western Asia. In the wake of the opening up of the Western Regions, a lot of new things emerged in the land of China. One of the rare things that was not seen in

\footnotetext{
${ }^{1}$ Hanshu: juan 66, p. 3928. Translation adapted from Yü Ying-Shih 1967: 192.

${ }^{2}$ Xiaowu is the emperor's posthumous title, also translated as Emperor Wu or Wudi. In this thesis he will be referred to as Emperor Xiaowu.
} 
pre-Han China was the stone carved tomb, which was however very popular in the Han period. However, the masonry structures as well as the stone carved decorations of such tombs were all innovations of the Han period. Are stone carved tombs an independent development within China or a result of outside stimuli?

Before discussing the stone carved tomb, another type of tombs must be examined, namely the rock-cut tombs which belonged to princes or kings of minor Han kingdoms. ${ }^{3}$ They are not the topic of this thesis, but are relevant to the origins of stone chamber tombs. Such tombs were created by cutting several linked rooms on a horizontal axis into small rock mountains. Most of the tombs have long access passages with small chambers either side. Two of the elaborate examples are the Guishan 龜山 tombs near Xuzhou of Jiangsu Province. They are two parallel rock-cut tombs placed in an east-west orientation. Each of the tombs was built by cutting horizontally into the rock hill of Guishan to form two 56-metre-long passageways, and then by cutting sideways to create chambers. The passage ways are around one metre wide, 1.77 metres high, and are both very finely cut and dressed. Altogether there are fifteen stone chambers in the two tombs, and they cover an area of 700 square metres. The main funerary structure lies underneath the centre of the hill, and consists of chambers designed for specific functions, including halls, storerooms, kitchens, wells, carriage houses and even a lavatory. The two tombs are connected to each other through a narrow passageway (Fig. 4-1). It is believed that

\footnotetext{
${ }^{3}$ The lands of the Han Empire were divided into commanderies controlled by the central government and some semi-autonomous kingdoms, which were ruled by members of the royal family, and were located mainly in the eastern part of the empire (Maps 4-1 and 4-2).
} 
these tombs belong to Liu Zhu 劉注, King Xiang 衰 (r. 129-117BC) of the Chu 楚 Kingdom of Western Han, and his consort, because a silver seal of Liu Zhu has been found in one of the tomb chambers. ${ }^{4}$ More than a dozen similar tombs have also been found near Xuzhou as well as Henan, Shandong and Hebei 河北 Provinces (Map 4-3). Their dates are mainly of the middle and late Western Han, namely the first two centuries BC. All of them belong to elites of different kingdoms of the Western Han, which shows that rock-cut tombs were very popular among the kings.

Stone tombs, either rock-cut tombs or smaller stone carved tombs, were widely accepted and constructed by the Han people. However, the use of horizontal stone tombs in Han China is unusually interesting: such structures are entirely new in the Han period, and they were a major departure from previous precedents. In earlier periods of Chinese history, most elite tombs consisted of a wooden coffin buried at the bottom of a vertical pit. Such vertical earth pit tombs had been standard from a very early period in Central China, both for elites and for commoners. One of the best examples is the Mawangdui 馬王堆 tomb M1. Buried at the bottom of a pit is a box-like timber structure, which consists of an inner coffin known as guan 棺 and several outer coffins known as guo 槨. The large tomb pit is accessed by a descending slope from above, the pit walls slope outwards and are stepped at the top probably to avoid soil sliding down during construction (Fig. 4-2). The pit was covered with rammed earth to form a mound. This tomb belonged to the wife of a

\footnotetext{
${ }^{4}$ For the archaeological report of the Guishan tombs, see Kaogu xuebao 1985.1: 119-137, and Kaogu 1997.2: 36-46.
} 
marquis of the Han and its date is about $175-145 \mathrm{BC} .^{5}$

\subsection{Question and current proposals}

The stone carved tombs, rock-cut tombs and earth pit tombs show that a fundamental transformation of ancient Chinese tomb structures took place during the Han period. Horizontal tombs replaced vertical pit tombs to dominate elites' choices of tombs. Another transformation is that the underground structural medium has changed from timber to stone. ${ }^{6}$ There is no history of using stone chambered tombs or large scale stone monuments in Central China before the Han. Therefore, major questions are, what are the sources of this new development? How did it spread?

Several views have been suggested in previous scholarship. The most widely known argument is hypothesised by a Chinese scholar Huang Xiaofen 黃曉芬. She argues that Han masonry chambered tombs were developed from guomu 槨墓 (casket graves), which were tombs with a box-like timber structure buried at the bottom of a vertical pit. According to her, chamber tombs emerged in three developmental stages: stage one, door and windows were opened on walls of inner coffins connecting each other, which was typical in Chu tombs in Southern China during early Warring States period (475-221BC); stage two, an entrance was created

\footnotetext{
${ }^{5}$ For the report see Changsha 1973.

${ }^{6}$ But people in Southern China were relatively conservative. They kept on with traditional wooden chamber tombs until late Han. Moreover, the distinction of timber and stone tombs is not clear cut. In the Western Han period, there were several kingly tombs which were cut into rocks, with wood structure in the bottom. Examples include a group of tombs belonged to the $\mathrm{Lu}$ 魯 Kings in Qufu 曲阜 and Zoucheng 鄒城 of Shandong Province, and a newly excavated tomb burying one of the Jiangdu 江都 Kings in Xuyi 䀒眙, Jiangsu Province.
} 
on the front wall of the outer coffin to connect the tomb's interior with the exterior, which happened during early Western Han; stage three, chamber tombs of various materials were built (Fig. 4-3). ${ }^{7}$ However, no matter how many 'chambers' the coffins have, they were always buried at the bottom of a vertical pit. Huang could not explain why suddenly the tombs were cut into hills along a horizontal axis. Nor did she mention anything regarding why the material has transferred from timber to stone and bricks. The changes at stage three were fundamental but ignored by her.

There are similar arguments by other Chinese scholars. For instance Xin Lixiang 信立祥 has suggested that stone carved tombs were developed from sarcophagi with carved decoration that appeared in late Western Han period, and the carved decoration can be traced to silk paintings buried within tombs of the Warring States period. ${ }^{8}$ Generally most Chinese scholars have seen all tomb structures arising in a linear development within the area of China. Very few of them have realised that stone funerary monuments were entirely new in the Han period.

Scholars working in Western languages have suggested outside stimuli for the origin of stone funerary monuments. Victor Segalen is probably the first scholar who has suggested that the origins of Han dynasty stone monuments, especially rock-cut tombs, could be traced back to similar examples in Iran or even Egypt. Because of limitations of materials available in his age, he was not able to illustrate this in detail, but he was pretty confident about his presupposition. ${ }^{9}$ Ann Paludan has noticed that

\footnotetext{
${ }^{7}$ Huang Xiaofen 2003: 90-93.

${ }^{8}$ Xin Lixiang 2000: 190-198.

${ }^{9}$ In fact Segalen was talking about rock-cut tombs in Sichuan Province of China. Segalen was not aware of similar rock-cut tombs in Central and Eastern China, as none of them had
} 
the use of stone monuments was relatively late in China, since in the Shang and Zhou period, stone, unlike jade or bronze, was considered a less appropriate medium for ritual and sacrificial purposes. Paludan has also pointed out that a change in attitude to the material of stone had taken place at the end of the third century $\mathrm{BC}$, when stone monumental sculpture emerged. Although not having suggested a source of this development, she suggests that the late emergence of stone sculpture can hardly be due to technical reasons, but to religious considerations. ${ }^{10}$

Wu Hung argues that stone buildings were introduced to China during the second century $\mathrm{BC}$, when rock-cut tombs appeared in China as princely tombs. $\mathrm{He}$ believes that this tradition may have been influenced by Indian cave temples. His only example is that, the tomb of Liu Sheng 劉勝, the King Jing 靖 of Zhongshan 中山 (r. 154-113BC), has a similar annular tunnel structure to Indian cave temples, where a stupa was surrounded by the tunnel inside a temple cave. ${ }^{11}$

been scientifically excavated at the beginning of the twentieth century when he visited China. See Segalen 1930: 40-41. Although nowadays most scholars believe that Sichuan cliff tombs were influenced by their precedents in the Central Plains, Segalen was quite right to link Chinese rock-cut tombs with West Asian ones.

${ }^{10}$ Paludan argues that, by the time when stone sculptures became popular, the tools and techniques for working on hard materials such as jade had been in use for over a thousand years, and large-scale production techniques were equally developed. Therefore, the reason for the belated appearance of stone sculpture lies in changing attitudes towards stone as a material. See Paludan 1991: 15-16.

${ }^{11}$ See Wu Hung 1995: 126-142. Liu Sheng's tomb was found at Mancheng of Hebei Province. Like many other rock-cut tombs, the Mancheng tomb was also cut horizontally into a rock hill and has many chambers. But what is unusual is that, the main chamber is surrounded by an annular tunnel (Fig. 4-4a). For the archaeological report, see Mancheng 1980. As suggested and illustrated by Wu Hung, in an Indian rock-cut temple, a stone stupa stood at the rear end of a ceremonial hall and was surrounded by a passageway for the rite of circumambulation (Fig. 4-4b). Wu Hung suggests that 'the builders of the Mancheng tomb must have thought the stupa was a burial device and replicated its features in Liu Sheng' chamber.' See Wu Hung 1995: 133. 
Jessica Rawson has suggested the workers who created both rock-cut tombs and smaller stone built tombs may have learned about features from Western Asian and Central Asian tombs. ${ }^{12}$ More importantly, she has pointed out that scholars have overlooked the role of rock-cut tombs as providing an impetus for an entirely new tomb structure at all levels of Han society. ${ }^{13}$

\subsection{Independent development or outside stimuli?}

Are Han Dynasty stone tombs an independent development within China or a result of outside stimuli? To answer this question, it is necessary to firstly examine the history of the use of stone in earlier periods of China, and the history of interactions between China and the West.

\subsubsection{The use of stone in pre-Han China}

First of all, the emergence of stone monuments in China was relatively late. There was no history of using horizontal tombs or large scale stone sculptures in

\section{Central China.}

Stone was not completely absent in Central China before the emergence of Han dynasty stone tombs, though in the Central Plains wood was the primary material for building. Stone had occasionally been used for a limited range of construction, in both

\footnotetext{
12 This is reflected in a series of papers. See Rawson 1999a: 24-25, footnote 71; Rawson 2010a: 79-88; and Rawson 2012. In the articles she has also mentioned how the import of exotic objects stimulated the ancient Chinese to create new and innovative materials, demonstrating that Han China was part of a world that was entering the early phrases of globalisation. In this chapter I am developing and expanding ideas proposed by Rawson. ${ }^{13}$ Rawson 1999a: footnote 8.
} 
aboveground buildings and subterranean structures.

Perhaps the best known aboveground stone building before the Han was the Great Wall, the construction of which started in the fourth century BC. Many of the walls in the plains were made from rammed earth, but on the northern borders of China a large proportion were indeed constructed in stone, though many were merely unworked gravels. ${ }^{14}$

Stone had also been used to build different kinds of city buildings since the Warring States period. Ruins of a Qi 齊 state fortified city has been excavated in Linzi 臨淄 of Shandong Province. ${ }^{15}$ In the Qi state capital, stone was used to build city walls, to pave roads, and to line the underground drain system. Also at many remains of buildings, though the wooden architecture has long disappeared, the stone bases of foundations have been discovered. Moreover, outside one of the Qi city wall gates, remains of stone platforms on both banks of the moat have been found. Remains of pier-like stone blocks and traces of rammed earth have also been found at the bottom of the moat, which shows that there was a bridge, parts of which were built from stone.

Although there were occasional applications of stone in construction, there were no elite buildings that were constructed from stone in the pre-Han period. ${ }^{16}$ In the

\footnotetext{
${ }^{14}$ For instance in the Yan 燕 State, a kingdom on the northern boarders of the Chinese speaking area of the Warring States period, more than 350 kilometres of walls have survived, and a large proportion of the walls were constructed from stone, mainly by lining bigger natural stones and filling the gaps with gravels. In some cases, the walls were built by piling pounded earth on a stone basement. For more details see Beijing 1981: 6-20.

${ }^{15}$ For the report see Wenwu 1972.5: 45-54.

16 These are also true in post-Han. Buildings for the upper class have never been constructed from stone in Central China.
} 
famous Classical work, Kaogongji 考工記 (literally Records of Examinations of Craftsmen), which includes descriptions of diverse craftsmanship, there were no records of stone masonry at all. ${ }^{17}$ This indicates that stone work in pre-Han China was either not very well developed or thought trivial and thus not worth mentioning.

In terms of underground tombs, stone structures were more common in the north than in the Central Plains. Examples include cist tombs, tomb pits that were dug into rock faces, and tombs dug into earth but lined with stone. ${ }^{18}$ However, it is difficult to claim to what extent these tombs and people associated with them were Chinese. The cairn graves as well as the famous Niuheliang 牛河梁 jades relate more to Siberian practices than to central China. Within the Central Plains, there was no archaeological evidence of stone used in burial contexts until the Warring States period.

One of the most famous examples is the tomb belonged to the Maquis Yi 乙 of Zeng 曾. It has been found at Suizhou 隨州 of Hubei Province and is dated to the

\footnotetext{
${ }^{17}$ It is believe that the Kaogongji was compiled around the end of the Spring and Autumn period (770-476BC) and the beginning of the Warring States period, by an unknown author of the Qi State in present-day Shandong Province. It describes various crafts including carpentry, metallurgy, leatherwork, painting, pottery and jade working, as well as many sub-divisions of the above. But not a single word was about stone masonry. For more details see Kaogongji. ${ }^{18}$ Such tombs have been used since the Neolithic period in present-day Northeast China. Large scale stone cairns and graves have been found at Niuheliang in Chaoyang 朝陽 of Liaoning 遼寧 Province, where stone was used in many forms. For instance, tomb M1 of location 1 was dug into bedrock to form a pit, see Wenwu 1997.8: 4-8. Moreover, at the bottom of the shaft stones were lined to form a cist, in which the body was buried. The pit was covered by stones as well (Fig. 4-5). The Niuheliang site dates to approximately 6000-5000BC. The Jiabang 甲幫 grave site at Fushun 撫順 city of Liaoning Province is an earth pit tomb lined with raw stone slabs. It is covered by stone slabs, while its bottom is not paved, where a body was buried, for the report see Wenwu 1983.5: 44. Similar stone lined tombs have also been found in neighbouring regions. Their dates are contemporary to the Spring and Autumn period of Central China.
} 
Warring States period. ${ }^{19}$ Its enormous tomb pit was dug vertically into bedrock at the top of a small sandstone hill (Fig. 4-6). The multi-chamber timber coffin was placed at the bottom of the pit. A layer of big stones was placed above the earth-sealed pit, and was filled with smaller gravels.

Also in the Qi state capital city mentioned above, a rectangular pit tomb believed to belong to Duke Jing 景 of Qi (r. 547-490BC) has been found. ${ }^{20}$ In the centre of the tomb lies the coffin pit, which was also lined with stone blocks and covered by smaller stones as well (Fig. 4-7). The space between the stone linings and the wooden coffin is filled with pebbles.

More high status tombs which incorporated stone have been found in a number of major states of the Warring States period. ${ }^{21}$ Such application of stone might be regarded as early stages of the development of stone work in China. However, in these cases stones have been used merely for paving floors, building walls, or sealing tomb pits. It cannot be said that such structures are stone buildings on the lines of the later stone carved tombs, which had house-like structures.

From the above examples it can be concluded that, there was occasional use of stone in Chinese tombs before the Han, ${ }^{22}$ but they were of small scale. And most of them just used raw stone as building material, they was nothing sculptural or

\footnotetext{
${ }^{19}$ Suizhou 1989. According to inscriptions written on a lacquered chest, exact date of the tomb is around 433BC.

${ }^{20}$ For the report see Wenwu 1984.9: 14-19.

${ }^{21}$ See Miller 2011: 310-311 for a list of stone related tombs in the states of Wei, Jin, Zhao, Song and Zhongshan.

${ }^{22}$ Even these occasional use of stone in pre-Han China were to some extent related to similar practices outside China. For instance all cist and cairn graves in borderlands of China were linked to the steppe. See Rawson 1999.
} 
architectural. Ashlar masonry, which had been developed much earlier in the Western world, was not developed until the Han period. Secondly, Han Dynasty techniques of stone carving were relatively simple by comparison with those of Western cultures. Moreover, stone tombs require a series of manufacturing techniques not generally used in early China, where most architecture was built of timber.

Therefore, it is difficult to suggest that Han period stone tombs were developed from earlier tombs within the land of China. It is unlikely that stone chamber tombs could have been independently invented in China. Consequently we should look outside China.

\subsubsection{Links between China and the West}

There have been continuous traces of routes linking Central China and Western Asia from a very early period. Mobile peoples and nongovernmental merchants had brought Central China and Western Asia into contact with each other through the lands of deserts, steppes and mountains. Jessica Rawson has suggested that, although Central China and Western Asia seem far away from each other, interactions between the two started as early as the third millennium BC, and continued until today. ${ }^{23}$ There have been traces of a route from the Caucasus, across Central Asia through

\footnotetext{
${ }^{23}$ She has discussed carnelian beads which were used in ancient Iraq, Pakistan and India but later appeared in China during the ninth century BC; the introduction of gold to Central China especially gold belt plaques with steppe motifs which were popular among Western Han kings; the Chinese imitation of Achaemenid silver boxes and Central Asian rhytons in the Han period, all of which indicate continuous interactions between Central China and the Western world. See Rawson 2010c and Rawson 2012. Her latest arguments have been presented as part of the 2013-14 Slade Lectures entitled 'Warfare, Beauty and Belief: Innovations from the West that Changed China's Art and Culture, 1500 BC-1000 AD' at the University of Cambridge.
} 
Xinjiang, Gansu 甘肅 and Inner Mongolia. Exotic materials were very popular, especially among the elites, in pre-Han China. ${ }^{24}$

On the other hand, many tombs found in the steppe show Chinese influences and many objects were a mixture of Chinese and Western styles. Some of the most famous and intensively published examples are the Pazyryk burials found in Russia. ${ }^{25}$ They are a number of Iron Age tombs found in the Altai Mountains of Siberia, not far from the Russian borders to China, Kazakhstan and Mongolia. It is believed that these kurgan tombs belonged to nomads that were active between the fifth and the third centuries BC. Many of the tombs were flooded and frozen in ancient times, therefore burial objects were preserved in ice until their excavation. Important findings include chariots, decorated rugs and textiles, silk and embroidery, jewellery, bronze mirrors and gold plaques. Among them two Chinese articles were found: one is a piece of silk that carries images surprisingly similar to another piece excavated from a Chu tomb of the Warring States period (Fig. 4-42a, b); the other is a bronze mirror with 'E' patterns, (Fig. 4-43) which were very popular in China also during the Warring States period. ${ }^{26}$ These indicate that the Pazyryk people must have obtained articles through horse trading with other cultures, including China, that were far away.

Moreover, according to official historical records of the Han, in the second

\footnotetext{
${ }^{24}$ For two of many examples, see Wu Hsiao-yun 2013 for the origins of Shang period chariot, which was closely related to their Steppe associations, see Mei Jianjun 2009 for the existence of early cultural interactions between northwestern China and the Eurasian steppe, and the nature of steppe influence on early metallurgy in China.

25 See Rudenko 1970.

${ }^{26}$ See Chen Jianwen 2010: 921-964 for detailed discussions of interactions between Siberia and China, and the possible carriers and routes of these Chinese style objects.
} 
century $\mathrm{BC}$, because of wars with the Xiongnu, people were sent by the Han court to the West to seek allies. In 139BC, an imperial diplomat Zhang Qian (200-114BC) travelled to Central and Western Asia. He came back to the capital of Chang'an 長安 in $126 \mathrm{BC}$, and brought back reliable information about the West, including Bactria and Parthia, to the Han court. Following that, official and commercial links with the West were established, known as the beginning of the Silk Road. ${ }^{27}$ The main route of Han period Silk Road starts from the capital city of Chang'an, westwards to the Hexi 河西 Corridor of present-day Gansu Province, then through the Tarim Basin of Xinjiang and the Pamir Plateau at the borders of China and Tajikistan, approaching the vast areas of Central Asia, Iran, Iraq and Syria, and finally to the Mediterranean World (Map 4-4). Such flourishing relations kept bringing ideas and objects into Central China, as depicted in the citation at the beginning of this chapter.

Many Han people immersed themselves in trade with the West. Diplomats and large numbers of merchants frequently went to the Western Regions and came back to Central China. As a result, it is quite natural that Western style motifs and objects appeared in Central China, or Chinese styles were found in the West. Therefore, these supplied a possibility that the patrons and artisans of Han stone chamber tombs might have borrowed certain ideas and features from abroad.

\subsection{The introduction of rock-cut tombs: from India or Iran?}

There are two cultures to the west of China, but not very far away, Iran and India,

${ }^{27}$ See Shiji: $3157-3180$ and Han shu: 2687-2705. 
where large scale stone monuments were used from a period much earlier than the Western Han. In Iran, some of the most impressive stone monuments, including palaces and rock-cut tombs, are found at the ceremonial capital of the Achaemenid Empire (c. 550-330BC), Persepolis. The earliest remains of Persepolis date to around $515 \mathrm{BC}$, and the construction of the famous terrace and great palaces began during the reign of Darius I (r. 522-486BC). Although architecture at Persepolis is noted for the use of wooden columns, it is better known for its stone relief carvings and giant stone columns, with special stone bases and capitals (Fig. 4-10). ${ }^{28}$

Famous royal rock-cut tombs have been found near Persepolis (Fig. 4-11a). They are cut into cliffs at a considerable elevation thus difficult to approach. Each of their facades resembles a Greek cross, and is decorated with sculptures and a colonnade. Between the columns is the entrance to the multi-chambered tomb (Fig. 4-11b). In one of the simple cases, the tomb of Xerxes I (r. 486-465BC), behind the ornaments are arched chambers and a deep horizontal recess, where the sarcophagi are buried underground (Fig. 4-12). ${ }^{29}$

In India, the history of stone monuments can be traced back to the third century $\mathrm{BC}$, during the Mauryan period (322-185BC). Following the westward retreat by Alexander the Great's (356-323BC) Greek and Persian armies in 325BC, Chandragupta Maurya (340-298BC) rapidly expanded his power and founded the Mauryan Empire. The empire reached its height in the third century BC, when

\footnotetext{
${ }^{28}$ See Schmidt 1953 for discussions of the structures, reliefs and inscriptions at the ruins of the palaces.

${ }^{29}$ See Schmidt 1970: 90-93 for more details of the tomb of Xerxes. This tomb is also cited in Rawson 2010a and Rawson 2012.
} 
Chandragupta's grandson, known as Ashoka the Great (r. 273-232BC), reigned over nearly the whole Indian subcontinent after a number of conquests. During his forty years of peace and prosperity, Ashoka constructed a number of stone monuments throughout the country.

A series of columns, known as the pillars of Ashoka, were erected in north India, sometimes inscribed with edicts by Ashoka. Most of them are between ten and fifteen metres in height, and weigh up to fifty tons (Fig. 4-13). The Ashoka lion pillar at Sarnath, dating to the third century BC, is probably the earliest surviving example of Indian sculpture. The shaft of the column was polished, and its capital includes a slab decorated with the Wheel of Dharma and animals serving as a base, on which stand four roaring lions, facing the four directions (Fig. 4-14). ${ }^{30}$ The appearance and carving techniques of the capital indicates Persian or more precisely Achaemenid influence. Most details, including flutes, petals, realistic animals, and stylistic lions, are similar to features of carvings at Persepolis.

Very interestingly, the Mauryan Dynasty was established in the wake of the fall of Persepolis, after its conquest by Alexander the Great. Many of the carvers who worked in Persia must have fled to the Mauryan Empire to work in Ashoka's workshops after the fall of the Achaemenids. This is reflected in details of the capital of the Ashoka columns. From this evidence, scholars confidently ascribed Persian-Hellenistic origins to Indian art. ${ }^{31}$ Moreover, according to Roy Craven, the

\footnotetext{
${ }^{30}$ See Mitter 2001: 13-15 for details.

31 This view, although sometimes being challenged, is held by a number of scholars. See Craven 1997: 35-48; Gupta 1980: 1-4, 187-225; and Mitter 2001: 13-14.
} 
extremely mature genre of constructing stone monuments appeared in India all of a sudden, and changed the direction of Indian sculpture. This confirms that such tradition came from outside cultures. ${ }^{32}$

Another type of Indian stone monument is the rock cave temple. The earliest surviving rock-cut temples also date back to the Ashokan period. Such temples were cut horizontally into rock hills, with structures imitating traditional timber buildings. One of the most noticeable and most published temples is the Lomas Rishi grotto, which is probably the earliest example of Indian architecture in stone. The cave faces south, and has two chambers. Its facade clearly indicates an imitation of timber columns and beams (Fig. 4-15a). Within the grotto, the outer chamber is 9.86 metres long and 5.18 metres wide, while the unfinished inner chamber measures 4.33 metres by 5.18 metres (Fig. 4-15b). ${ }^{33}$ Its plan and structure is similar to those of the rock-cut tombs near Persepolis, therefore it is again very clear that early Indian stone buildings were influenced by Persian architecture, as royal rock-cut tombs were well known in Persia centuries before similar structures were created in India.

The stone columns and rock-cut temples were the earliest such examples in India. But in the Mauryan Dynasty, as well as during later periods of Indian history, rock-cut structures were generally used for religious purposes, rather than being constructed as tombs, just as Craven has pointed out:

'These third-century BC rock-cut chambers mark the beginning of a great tradition which would span more than a thousand years and, ... would serve all of India's

32 Craven 1997: p. 46. Craven has also illustrated other capitals which show a mixture of Ionic and Iranian style.

33 See Gupta 1980: 189-190 for more details of the Lomas Rishi grotto. 
religious communities. ${ }^{34}$

Coming back to Han China, it is difficult to argue that Han rock-cut tombs are influenced by Indian cave temples, as Wu Hung suggested. First of all, it has been pointed out that the dates of Indian cave temples are not very much earlier than Han rock-cut tombs. ${ }^{35}$ The rock-cut temple that $\mathrm{Wu}$ Hung mentioned is datable to the second century $\mathrm{BC}$ according to inscriptions on the wooden beam below the vault. ${ }^{36}$ On the other hand, the occupant of the Mancheng 滿城 rock-cut tomb, Liu Sheng (King Jing of Zhongshan, r. 154-113BC) was buried in 113BC. It is more likely that designers of the Mancheng tombs, or the king himself, had been influenced by similar but earlier tombs that belonged to the Chu Kings of the Western Han. ${ }^{37}$

Secondly, in Mauryan India, large scale stone sculptures and monuments are mostly used in Buddhist cave temples rather than tombs, as discussed above. Thirdly, it is widely believed that the Indian cave temples of the Mauryan Dynasty have been influenced by similar ones of the Iranian Empires ${ }^{38}$ Craftsmen of Mauryan India created Buddhist cave temples based on Iranian rock-cut tombs, structures of which are quite similar.

\footnotetext{
${ }^{34}$ Craven 1997: p. 48.

35 Bagley 1998: 243. Bagley suggests, 'The earliest rock-cut sanctuaries anywhere in India, among them the one Wu illustrates are little if any earlier than the time of Emperor Wendi ( $\mathrm{r}$. 180-157BC)'.

${ }^{36}$ See official website of the Archaeological Survey of India, under the Ministry of Culture of the nation: http://asi.nic.in/asi monu tktd maha bhajacaves.asp. Retrieved 1 August 2014. ${ }^{37}$ More than a dozen rock-cut tombs that belonged to the Chu Kings have been found around the city of Xuzhou. Several of them are dated: the Shizishan tomb, 174BC; the Beidongshan tomb, 140-129BC; the Guishan tomb, 117BC. The Chu King tombs, together with some of the Liang Kingdom rock-cut tombs, are all earlier than the Mancheng tomb (113BC), which Wu Hung used as an example.

${ }^{38}$ Gupta 1980.
} 
On the other hand, in ancient Iran, not only stone palaces, temples and other buildings, but also rock-cut tombs had been built since the Achaemenid period. The earliest examples of royal stone tombs are dated to the sixth century $\mathrm{BC}$. The popularity of such tombs was to last until the seventh century AD, the Sassanian Period (AD224-651). One of the elaborate examples of Persian rock-cut tombs belonged to Darius I at Nakhsh-i-Rustam, twelve kilometres northwest of Persepolis. Like most other rock-cut tombs, it was cut into the cliff. The general appearance resembles a Greek cross which is around 23 metres high, and the distance from the ground of the floor is about fifteen metres. The facade is decorated with registers of sculptures and a colonnade, and in between the columns is the entrance to the multi-chambered tomb (Fig. 4-11b). Behind the ornaments are burial chambers, including one vestibule, and three vaulted chambers with nine burial cists (Fig. 4-16). The axis of the vestibule is parallel to the facade of the tomb and is 18.72 metres long and 2.13 metres wide. The three vaults are of similar sizes, around 4.5 metres long and 3 metres wide. Each of the vaults includes three cists. ${ }^{39}$ All the Achaemenid rock-cut tombs are generally of the same type, except that they are of different sizes and have different numbers of tomb chambers and cists.

As suggested by Jessica Rawson, the idea of carving rock-cut tombs is very likely to have been borrowed by the Han people. ${ }^{40}$ Indeed most Han period kingly rock-cut tombs had similar structures to those of Persian rock-cut tombs. Chinese examples include the Shizishan 獅子山, Beidongshan 北洞山, and Guishan tombs in

\footnotetext{
39 See Schmidt 1970: 80-89 for more details.

${ }^{40}$ See Rawson 1999a: 24-25, footnote 71; Rawson 2010a: 79-88; and Rawson 2012.
} 
Xuzhou, the Mancheng tombs in Hebei, and the Liang 梁 Kingdom rock-cut tombs in Henan mentioned above, though they had even more functional chambers and sometimes were on larger scales than the Persian ones. The differences between Chinese and Iranian rock-cut tombs are that, entrances of Han rock-cut tombs were always blocked with giant stones and then buried, while the facades of Achaemenid rock-cut tombs were decorated and presented as symbols of power. It seems that only the idea of carving horizontally into live rock was borrowed by the Chinese.

Large numbers of burial objects, including exotic articles, have been excavated from Han rock-cut tombs, which have illustrated the kings' interests in exotica and their contacts with the Western borders. A large proportion of them have features borrowed from Iran as well. Examples include a pair of sculptures of crouching felines each with a ring on its collar excavated from the Shizishan tomb ${ }^{41}$ (Fig. 4-17a), boshanlu 博山爐 incense burners that have been discovered in nearly every kingly tomb and some commoner tombs ${ }^{42}$, as well as silver boxes with Achaemenid designs found in a number of kingly tombs ${ }^{43}$. Apart from these Persian styles, a number of

${ }^{41}$ As suggested by Rawson, prototypes of these pieces include a gold weight discovered at Xuyi 盯眙 of Jiangsu Province (Fig. 4-17b) and common bronze weights from Iran in the shapes of crouching lions, with loops on their backs (Fig. 4-17c). See Rawson 2012.

${ }^{42}$ The so-called boshanlu hill censer was a particular type of incense burner which had a conical cover in the shape of a mountain sitting on a bowl in which the incense was placed and burnt. Rawson has suggested that the Han incense burners was stimulated by the example of censers employed in the Achaemenid Empire. The Han Chinese only adopted the exotic shape for their censers, and had added Chinese interpretations of its usage. See Rawson 2006a: 75-86.

${ }^{43}$ Lukas Nickel has investigated a group of silver boxes dated between the third and the second centuries BC, which were found in Han elite tombs. The material of silver and the lobed decoration of the boxes show traces of foreign traditions. Nickel argues that although the design of such silver boxes is based on Achaemenid wine vessels, they were made in China rather than imported. See Nickel 2012: 98-107. 
exotic objects from kingly tombs also had prototypes that can be traced to the Xiongnu peoples, the Siberian Steppes, and Central Asian. ${ }^{44}$ The above objects excavated from Western Han kingly tombs all have exotic appearances. However, they were made in China rather than imported. This indicates that the kings had adopted exotic styles, especially Iranian styles, on purpose. Therefore, it is quite natural for them to follow Persian examples to carve rock-cut palaces for the afterlife.

By comparison, there is no exact evidence that any of the objects had features borrowed from India. Therefore, the argument is strengthened that the contacts of Han were with Iran rather than India. Indian and Chinese people seem to have taken over and interpreted stone monuments in different ways, and consequently created cave temples and rock-cut tombs separately.

\subsection{From rock-cut tombs to stone carved tombs}

The Han was a period of experiment in creating stone tombs. After the introduction of rock-cut tombs, traditional burial types were not completely abandoned, with old and new tomb structures used in parallel for a long time. Vertical earth pit tombs, rock-pit tombs, rock-cut tombs, timber ticou 題湊 tombs ${ }^{45}$, stone ticou tombs, hollow brick tombs, stone carved tombs and other masonry tombs were constructed over different time periods and in various regions. Therefore, it is

\footnotetext{
${ }^{44}$ See Rawson 2012 for more examples.

${ }^{45}$ Within a ticou tomb, good-quality timbers were laid upon each other in many layers to form a wall-like barrier (which is called a ticou) to protect the inner coffins. The whole structure is usually buried in an earth pit under an earth mound. For an intensive study on ticou tombs see Campbell 2010.
} 
necessary to examine several major tomb types so as to illuminate the transformation of tomb structures (from vertical to horizontal) and materials (from timber to stone).

When the idea of building rock-cut tombs in small hills was introduced into China, it not only inspired the kings to create their palaces for the afterlife, but also provided an impetus for an entirely new tomb structure at all levels of Han society, as suggested by Rawson. Following this development, stone and brick chamber tombs became popular lower down the social scale. I would like to expand this argument, to suggest that the stone carved tomb was a result of imitating royal rock-cut tombs. Both types of tombs were constructed by similar groups of artisans.

Archaeological and textual evidence shows that, it was quite common in the Han period for the commoners to imitate imperial practices and objects. One of the best examples is the production and popularity of bronze mirrors. The changing styles of inscriptions on bronze mirrors during the Western and Eastern Han periods indicate that, the bronze mirrors were gradually becoming popular commodities, instead of being imperial products only. ${ }^{46}$ The Han government established official workshops

${ }^{46}$ The earlier inscriptions, for instance the poetic rhyming sentences “見日之光, 長樂未央 As brilliant as the sunshine, eternal happiness without end’, “內清質以昭明, 光輝象夫日月 The internal limpidity makes it shiny and brilliant; its splendour symbols the sun and the moon', seem to have been more literary in style, which indicates that bronze mirrors were some sort of luxury for the upper class. Later on in the Eastern Han, however, inscriptions were increasingly replaced by stereotyped popular expressions of good fortune, which tend to demonstrate that they had fallen into the public domain had found its way to the commoners. Typical later inscriptions include ‘長宜子孫 May your descendents prosper’, ‘君宜高官 May you be promoted to high rank' and alike. Occasionally some characters were written incorrectly, for example ‘買此竟(鏡)者家昌富 For one who buys this mirror, may his family become rich and prosperous'. The bronze mirrors seem to have been fully transformed into a kind of common commodity that could be produced and purchased by commoners during the Eastern Han. For detailed discussions and more examples of Han bronze mirrors and inscriptions see Sun Ji 1991: 264-276. 
in various places for the making of fine articles, including bronze mirrors. At the capital, such workshops located within the palace were under the control of two offices known as Shangfang 尚方 and Kaogong 考工 respectively, and were responsible for making productions for imperial use. It was the imperial workshop, Shangfang, that produced refined bronze mirrors, and indeed according to archaeological discoveries, many inscriptions on Han mirrors begin with the name of Shangfang, claiming that the inscribed mirror was produced at the imperial workshop. However, many of such inscribed mirrors are of relatively low quality, thus it is unlikely that they were produced in the Shangfang. ${ }^{47}$ Moreover, in the Eastern Han period, the Shangfang was divided into three departments, zuo 左 left, zhong 中 middle and you 右 right. According to current knowledge, the production of bronze mirrors was supervised by the Right Department of Shangfang. As a result inscriptions on genuine imperial mirrors should have included the specific department where they were made, rather than generally 'made by the Shangfang'. Clearly most of the mirrors whose inscriptions claim they were made by the Shangfang were merely civilian artisans' copies of imperial examples. ${ }^{48}$ Of course not all the craftsmen would have cheated their customers. A number of genuine inscriptions have been found on Han bronze mirrors as well, for example, ‘劉氏作竟 mirror made by Liu’, ‘王氏作竟 mirror made by Wang’, ‘會稽師鮑作明鏡 bright mirror made by

\footnotetext{
${ }^{47}$ For one of many examples see Sun Ji 1991: 270.

48 See Barbieri-Low 2007: 142-147 for more discussions on how Han artisans claimed their products to have been made at imperial workshops of textiles and bronzes. Barbieri-Low believes that the imperial factory names had fallen into the public domain and had become merely illustrious words and slogans with which to imbue a product with greater snob appeal and greater marketability.
} 
Artisan Bao from Kuaij'. These indicate that there were a number of artisans active all over the empire, sometimes in remote places, like the Kuaiji Commandery in present-day southeast China. Bronze mirrors had indeed in the Eastern Han become a kind of common product rather than a privileged article for nobles only. Therefore, it was also quite natural for the commoners to follow imperial examples while constructing their tombs.

If we compare the planning of both kingly and commoners' stone tombs, we can see that the stone carved tombs have very similar functional structures to those of the rock-cut tombs. For instance, the Tuolanshan 䭾籃山 tombs, which belonged to one of the Chu Kings and his concubine, were two typical rock-cut tombs, both carved in to the rock hill of Tuolanshan on a south-north axis, and each has many functional chambers on two sides of a corridor, including storage rooms, chariot chamber, kitchen, lavatory and many other chambers (Fig. 4-20a, b). ${ }^{49}$ Most of such features can also be seen in Eastern Han stone carved tombs. Although a single stone carved tomb did not necessarily include all the possible function chambers, it would at least include one main burial chamber and several storage niches. ${ }^{50}$ Moreover, most of the ceiling types of kingly rock-cut tombs were taken over by stone carved tombs, for instance the truncated pyramid ceiling used in the Tuolanshan tombs can be seen in

\footnotetext{
49 For the archaeological report see Xuzhou 1991: 173-174; for a more detailed description see Zhou Xueying 2001: 72-83. The tomb occupants of the Tuolanshan tombs are debatable, but most scholars believe that tomb M1 belonged Liu Wu 劉戊 (d. 154BC), third king of the Chu Kingdom and in M2 buries his concubine.

${ }^{50}$ For instance in tombs mentioned above, the Yinan tomb has a lavatory; the Shilipu tomb obviously have one chariot chamber; one of the chambers in Feng Rujiu's tomb even carries inscriptions saying ‘車庫”, literally chariot storage room.
} 
the Dengmiao 鄧廟 tomb, the structure of which is similar to that of Tuolanshan tombs as well (Fig. 4-20c). The biggest differences between the two types of tomb structures are that stone carved tombs had fewer side chambers, shorter passage ways, and are on smaller scales. They were constructed from stone slabs instead of being cut into limestone hills.

Another similarity between the two types of tombs is that, the burial objects cover the same range of types, all providing for the afterlife of the tomb occupants. In the kingly Shizishan tomb mentioned above, jades, chariots, large number of coins, bronze vessels and even skeletons of a sacrificed chef and concubines have been excavated from the tomb chambers. On the other hand, tomb occupants of Eastern Han stone carved tombs were mainly well-off elites, but they were not as rich and powerful as the Western Han kings, thus their burial objects, even if of similar types, were not as abundant as those of the kingly tombs. In most stone carved tombs, small numbers of coins, bronze vessels, pottery vessels, pottery models of servants and musicians, and models of buildings are frequently found. ${ }^{51}$ However, images and models of jades, chariots, and other luxurious articles were used instead of real objects in stone carved tombs, as a result of the tomb occupants' social status and economic situations. The idea of building stone tombs and the arrangements of tomb chambers as well as burial objects went lower down the social scale, from kings to elites and commoners during the Han period.

More importantly, from traces in the princely tombs it can be detected that

\footnotetext{
${ }^{51}$ See Chapter Three for detailed discussion on images and burial objects within Eastern Han stone carved tombs.
} 
imperial tombs have been built by similar groups of artisans as the stone carved tombs. Some of the earliest stone carved images were discovered in the 1980s in the Shiyuan 柿園 tomb near Yongcheng 永城 of Henan Province. It is a rock-cut tomb cut horizontally into a small hill, and has a long passageway and several chambers (Fig. 4-21), like many other kingly rock-cut tombs mentioned above. The excavators believe that the occupant is Liu Mai 劉買, King Gong 恭 of Liang (r. 144-136BC) of the Western Han period. ${ }^{52}$ In side chamber No. 8, which served as the bathroom, stone carved images have been found. On one of the carved surfaces, the upper part of the composition depicts three so-called evergreen trees, with two diamond patterns between them and a bird standing on top of them looking backwards. The lower part includes decorative patterns of diamond, triangle and circular lines (Fig. 4-22a). The other carved stone has a two-part composition as well, and the upper part includes an evergreen tree surrounded by triangular and diamond patterns, above them is a pavilion. The lower part is broken, but its images are quite similar to the first piece (Fig. 4-22a). Both of them are around 40 centimetres high and 15 centimetres wide, much smaller than most Eastern Han carved stones, but they are so far the earliest known stone carved images found in Han tombs, also the only example of carved images found in kingly tombs. These images are surprisingly similar to relief images on Western Han sarcophagi, which belonged to commoners. For instance, on one of the slabs of a sarcophagus discovered at Qingyunshan 慶雲山 of Linyi 臨沂 in

\footnotetext{
${ }^{52}$ The Shiyuan tomb is one of many kingly rock-cut tombs of the imperial family members who ruled the Liang Kingdom in present-day eastern Henan Province. Most of the tombs were found in the hills near Yongcheng. For the archaeological reports see Yongcheng 1996 and Yongcheng 2001. For details of the Shiyuan tomb see Yongcheng 2001: 81-247. 95-99.
} 
Shandong Province, and a sarcophagus excavated at Fanshan 范山 near Xuzhou of Jiangsu Province, similar line carvings of discs, evergreen trees, diamond decoration as well as a pavilion were found (Fig. 4-22b, c). ${ }^{53}$ More importantly, in Xiayi 夏邑 County of Henan Province, which is merely some twenty kilometres away from the Shiyuan tomb, six sarcophagi dated to late Western Han have been excavated. ${ }^{54}$ Among them, three sarcophagi carry simple carved images of a bird sitting on an evergreen tree, and geometrical decoration. The discs surrounded by a ribbon-like pattern are nearly identical to the carved image found in the Shiyuan tomb (Fig. 4-22d). Therefore it is quite clear that such sarcophagi were made by the same group of artisans who took part in the construction of the Shiyuan tomb.

But we have no evidence as to who exactly were the builders of most Han kingly tombs, except in a few exceptional examples. A stone tomb, which belonged to Liu Yan 劉焉, King Jian 簡(r. AD54-90) of the Zhongshan Kingdom, has been excavated at Dingxian 定縣 of Hebei Province. Interestingly, names of craftsmen were inscribed on the stones that were used for the tomb construction, so as to mark the contributors of stones. ${ }^{55}$ In another Eastern Han example, which was discovered at Jining 濟寧 of Shandong Province, masons' inscriptions were found as well. This stone tomb is believed to have belonged to Liu Shang 劉尚, King Xiao 孝 of the Rencheng 任城 Kingdom (r. AD84-101). ${ }^{56}$ More than 174 stone blocks that were

\footnotetext{
${ }^{53}$ For the archaeological report of the Qingyunshan tomb, see Wenwu 1988.10: 68-75. For the Fanshan sarcophagus, see Xuzhou 1985: plate 4.

${ }^{54}$ For the report see Zhongyuan wenwu 1990.1: 308.

${ }^{55}$ See Kaogu xuebao 1964.2: 127-194 for the excavation report, see Chapter Two for detailed discussion on this tomb.

${ }^{56}$ For the archaeological report see Jining 1999.
} 
used to construct the tomb carry inscriptions by masons with their names, native places and sometime sources of the stone. Such groups of masons were simply conscripted for the construction project of the King. We do not know whether they were paid in cash or whether their work was considered tax tribute, ${ }^{57}$ but we can tell from the inscriptions that many of them were indeed professional masons. For instance, a very interesting inscription has been found and it reads “須昌沐孫有大石 十五頭' (Fig. 4-23), literally 'Mu Sun from Xuchang County (in present-day Shandong) has fifteen big blocks of stones'. This Mu Sun did not even forget to promote his business, while working for a king! A large proportion of such masons were from areas in present-day Shandong, where many stone carved tombs for commoners were constructed as well. Therefore, it is very likely the specialised mason communities applied similar construction methods while building commoners' stone tombs.

However, there is an important issue that should not be neglected, the different dates of rock-cut tombs and stone chamber tombs. The kingly rock-cut tombs were mainly created and were popular in the Western Han, while stone chamber tombs appeared in late Western Han, and were popular in the Eastern Han only. Since rock-cut tombs and stone carved tombs were built by similar groups of artisans, as argued above, techniques and ideas of stone tombs may have been borrowed immediately when the masons were employed by non-imperial patrons, but in fact

\footnotetext{
${ }^{57}$ It should be no problem that the masons' works were compensated. In Liu Yan's biography in the Hou Hanshu: 1449-1450, it is recorded that the artisans who worked for Liu Yan were not paid cash but their labour was treated as tax contribute.
} 
stone carved tombs were not developed until early Eastern Han.

It is very likely that during the Western Han, the stone carving industry may have been developed from the construction of rock-cut tombs, but was still in its early stages, and it would take time before a group of trained craftsmen developed. Moreover, as the tomb form was very new, a conservative population might not have wished to follow the new trend. Specialised mason communities just concentrated on the construction of tombs that belonged to the kings. Rock-cut tombs would have taken large numbers of artisans many years to build, sometimes the number of masons was not adequate, even carpenters were conscripted. For example in the tomb of Liu Yan mentioned above, it is noticeable that a carpenter's name was also inscribed (Fig. $2-9),{ }^{58}$ indicating that carpenters involved in the construction of this tomb. Another example is seen in the Mancheng tomb mentioned above: in its rear chamber, a stone house was built (Fig. 4-27), but from every aspect it looks like a timber construction, except that the material medium is stone. All the stone slabs were cut into very thin flat boards, and it is believed that wooden frames may have been used to fix the stone panels and to support the stone house. These indicate that the builders of this stone house were more familiar with carpentry techniques, or were probably carpenters. Therefore, it is reasonable to argue that in the Western Han almost all available masons mainly worked for kings and princes, who were of course given higher priority.

\footnotetext{
${ }^{58}$ For the inscriptions see Kaogu xuebao 1964.2: 161-194, especially p.189, and Barbieri-Low 2007: fig. 4.4. One of the inscriptions reads ‘才工王季陵', literally 'carpenter Wang Jiling', which means that the carpenter Wang hewed and contributed this particular piece.
} 
During the construction of kingly rock-cut tombs, a group of masons were trained and gradually developed their skills. However, the number of masons was obviously inadequate even for the construction of kingly tombs only, which conscripted most of them. As a result, only very occasionally, for instance when the masons were not on royal duty, were they able to work for non-imperial patrons to make a living, creating small scale sarcophagi, which were relatively less labour intensive.

During the Western Han period, the powers of the kings were gradually weakened, especially after $154 \mathrm{BC}$, when the rebellion of seven kingdoms against the Emperor Jing 景 (r. 157-141BC) took place. Once the rebellion had been suppressed, the kings no longer had real power, but still enjoyed lavish lifestyles and burials. ${ }^{59}$ By the Eastern Han, the powers of the kings had been removed, and just their ceremonial status was retained. Therefore, the kings could not afford labour-and-time-consuming rock-cut tombs any longer. On the other hand, in the Eastern Han, landowners, businessmen as well as officials gradually increased in power, gathering more and more wealth. ${ }^{60}$ As a result, the craftsmen who had made masonry their career while constructing kingly stone tombs had to seek new patrons to make their living; hence they switched to creating smaller stone chamber tombs for these well-off commoners.

\footnotetext{
59 According to the Han shu, after the Rebellion of the Seven Kingdoms, the emperor kept repressing the kingdoms, changing the rules. As a result, the kings were merely eligible to receive imperial clothing and food together with local tax, and were no longer allowed to take part in governmental affairs. The original text reads ‘諸侯惟得衣食稅租, 不與政事’, see Han shu: p. 395.

${ }^{60}$ See Twitchett and Fairbank 1987: Chapter 11 for Eastern Han economics, such as the increase of landowners' wealth, as well as elite officials and eunuchs.
} 
In conclusion, Eastern Han stone chamber tombs were a result of imitating Western Han kingly rock-cut tombs.

Some unusual tombs dated to the Eastern Han period have been found near Xuzhou, the Lalishan 拉犁山 tombs $^{61}$ and the Jiunüdun 九女墩 tomb. ${ }^{62}$ They are similar to other stone chamber tombs in terms of structure and decoration, but the remains of jade suits, which were exclusive burial objects for princes and nobles in the Han period, have been found in these tombs. This suggests that the tomb occupants were probably princes or at least nobles of high social status. In the Huaiyang 淮陽 tomb of Henan Province, the remains of jade suit and other jade objects have also been found. ${ }^{63}$ The excavators believe that the tomb occupant is very likely to be Liu Chong 劉崇, King Qing 頃 (r. AD120-125) of the Chen 陳 Kingdom. From the above examples we can see that, by the Eastern Han, rock-cut tombs were abandoned by the kings, as they were not able to afford them any more. The princes and other members of the royal family started using stone chamber tombs as well. These indicate that stone carved tombs became increasingly popular in all of Eastern Han society, and were constructed by both the kings and the well-off commoners.

\subsection{Exotic elements in stone carved tombs}

\footnotetext{
${ }^{61}$ See Xuzhou 1986: 123-124 and Xuzhou 1990: 208-209 for the reports.

${ }^{62}$ For the archaeological report and pictures see Kaogu tongxun 1955.2: 31-33, plates 8-12. Remains of jade plaques have been excavated. See Kaogu tongxun 1958: 57-59 for a discussion which suggests that such plaques were remains of jade suit.

${ }^{63}$ For the report see Wenwu 1991.4: 34-46.
} 
After the opening of the 'Western Regions' and the introduction of stone tombs to China, exotic elements came to China constantly. Therefore, many details of stone chamber tombs also had features borrowed from the West throughout their development, with exotic elements found in aboveground sculptures and subterranean structures, as well as carving motifs that were associated with stone carved tombs.

\subsubsection{Aboveground sculptures}

In terms of above ground sculptures, as mentioned above, in some cases, stone animals, que 閶 pillar gates and columns were erected in front of the tomb, to form the so called spirit road. It is quite obvious that, the que pillar gates were imitations of similar timber structures that were common in the Han period. But placing stone animals and monumental columns in front of tombs was not a tradition in pre-Han China. ${ }^{64}$ Some of the best examples are the pair of stone lions in front of the $\mathrm{Wu}$ Family cemetery (Fig. 4-24a). They stood in front of the pillar gate facing each other with bulging eyes and open mouths, each stepping on a cub. The west lion is female, and is 1.28 metres high, 1.48 metres long. The eastern male lion is of about the same size, with opening mouth and extending tongue, and its mane is vividly carved. According to inscriptions on the pillar, they were carved in AD147, making them two of the earliest stone lions known so far. Some less realistic lion-like feline sculptures have also been found in Central China, some with wings curved backwards, loop-like

\footnotetext{
${ }^{64}$ The earliest example of placing stone sculptures in tombs yard was the tomb belonged to Huo Qubing 霍去病 (140-117BC), a general who was buried within the imperial tomb complex of Emperor Xiaowu. For discussions on his tomb and relevant stone sculptures, see Paludan 1991: 17-27 and Paludan 1994: 109-116.
} 
tail or horn (Fig. 4-24b).

In the Han period there were no lions in Central China, therefore it is quite obvious that such sculptures derived from the West. Lions had been brought to the Han court as tributes by foreign ambassadors by at least the Eastern Han period. ${ }^{65}$ The lions would have been kept in imperial gardens in the capital, and it is not known yet how the artisans learned the appearance of lions and made realistic sculptures. One route is probably that there had been paintings of such exotic animals that were available to anyone. Another possibility is that, carvers of the big stone lions were inspired by similar but smaller stone or jade felines (Fig. 4-24c) that had been made from as early as the Western Han period.

Moreover, stone felines including lions had been placed in front of tombs in the West from a very early period. For example, a stone winged lion seated on a plinth (Fig. 4-24d) was found probably at Vulci, one of the cities of Etruria, where the entrances of tombs were regularly guarded by lions and sphinxes carved from local volcanic stone. It has wings that curve forward, and highly stylised muscles. Its bulging eyes, extended tongue and sharp teeth make a fierce expression, keeping evil spirits away. This tomb monument dates back to the sixth century BC. Such traditions of placing stone felines within the tomb complex spread to the Hellenistic world, and

${ }^{65}$ Lions became known to Chinese when Emperor Wu set up connections with the Western Regions. The Han shu records that '烏式山離國有...師子 lions are found in the Wuyishanli state (one of the small kingdoms probably in present-day Iran)'. See Han shu: 3888-3889. The earliest text about lions being brought to China is recorded in Hou Han shu: 168 and 189. In the second year of Zhanghe reign (AD 88) and thirteenth year of the Yongyuan reign (AD101), ambassadors of Anxi (Parthia) had twice brought lions as tributes to the court. The original text reads ‘（章和二年）...安息國遣使獻師子; ... (永元十三年) 冬十一月, 安息國遺 使獻師子’. 
was used in a broad area from present-day Turkey to Iran. Therefore it is possible that,not only the appearance of lions, but also the idea of placing stone animals in front of tombs in China came from the West as well.

Another type of aboveground tomb monument that has Western features is the stone columns erected in front of tombs as part of the spirit roads. Two of the best known and properly published examples have been found within the aboveground stone monuments attached to the tomb of Qin Jun 秦君 near Beijing (Fig. 4-25a). ${ }^{66}$ Two stone columns and two stone slabs and many other stone fragments have been excavated. One of the slabs carries carved images of guards, dragons and auspicious birds, the other slab has inscriptions, saying that the monuments was created by a mason from present-day Shandong Province in AD105. Both slabs are more than two metres long and were part of two que pillar gates. The two stone columns are quite similar, nearly identical. Each was originally attached to a base and is 2.25 metres high, and the shaft is channelled with many parallel flutes. The capital consists of two tigers supporting a plaque, with inscriptions of “漢故幽州書佐秦君之神道 Spirit road of Qin Jun, the late secretary of Han commandery of Youzhou' (Fig. 4-25b).

Although some Chinese scholars argue that these are imitations of similar wood or bamboo structures, ${ }^{67}$ it is quite clear that they have been influenced by Classical columns, especially in terms of the flutes on the shaft. Moreover, the tongues at the

\footnotetext{
${ }^{66}$ For the report see Wenwu 1964.11: 13-22.

${ }^{67}$ Many Chinese scholars used a fourth century text, the Shujing zhu, to demonstrate that such stone columns were imitations of a type of column that was made by combining and tying up a bunch of bamboo sticks. But the text was around four hundred year later than the stone columns, so that the conclusion was not very reliable.
} 
top of the flutes show a particular feature of Doric fluting that was used in ancient Greece and Rome, while similar decorations were never seen in pre-Han China. Classical orders of architecture originated in Greece, and gradually spread to the Hellenistic east, including present-day Western and Central Asia, which were not too far away and came into contact with China. At Persepolis, for instance at the gate of Xerxes Palace, similar but much bigger stone columns were used (Fig. 4-10). Such classical column orders also spread to Central Asia following the conquests of Alexander the Great. One of the examples is the Ai-Khanoum site located in Kunduz Province of northern Afghanistan, where various unearthed structures were perfectly Hellenistic, while some others integrated Persian elements. ${ }^{68}$ Another example is the Alexandria Eschate, literally 'Alexandria the Farthest', established by Alexander the Great in the Fergana Valley in modern Tajikistan. This Hellenistic outpost was only around 400 kilometres west of Xinjiang, remaining in contact with Hellenistic culture and with the Chinese centres. ${ }^{69}$ Therefore, it is very likely that the shapes of such columns were borrowed by Han artisans, and their features were replicated as tomb monuments.

The Qin Jun columns must have been two of many such monuments of the Han period, rather than solitary examples. On the stone slabs excavated near the columns, two sentences of the inscriptions read ‘匪愛力財, 迫於制度', which means that '(I erected these relatively simple monuments) not because I was reluctant to spend effort and money on them, but because that I had to keep to the regulations'. This indicates

\footnotetext{
${ }^{68}$ See Litvinskij and Pičkjan 2002 for more descriptions.

${ }^{69}$ See Holt 1988 for discussions on this Greek frontier in Central Asia.
} 
that at that time there had already been some regulation regarding the scale of tomb monuments. Erecting columns of different sizes and combinations must have been widely practiced, though nowadays not many examples survive. ${ }^{70}$

\subsubsection{Subterranean structures}

The masonry construction of stone carved tombs involved a package of skills and outcomes, and was descended from the kingly rock-cut tombs, which had features distantly borrowed from the West, as argued above. The underground structures of stone carved tombs had additional exotic elements. Some architectural elements, especially roofs and underground stone columns, are particularly obvious examples of results of outside stimuli.

A total number of six types of roofs were used in the construction of Han period stone carved tombs, including flat roofs, truncated pyramid roofs, domed vaults, barrel vaults, caisson roofs and stepped roofs. ${ }^{71}$ Were these independent Chinese inventions, or were they introduced from the West?

Flat roofs were simple, and their construction did not require any special technologies, thus could be independently invented in any culture. The truncated pyramid roofs were a combination of four trapezoidal and one rectangular slab, which

\footnotetext{
${ }^{70}$ So far only three sets of four fluted columns that are dated to the Han period have been found, including the Qin Jun columns. One column belonged to a Liu Jun 劉君 from Langya 琅㑚 Commandery is now stored in Shandong Museum, but not very well preserved, with unreadable images and inscriptions. Another stone column with flutes is stored in the Qingzhou 青州 Museum of Shandong, see Qingzhou 2003: p. 173. However, the Qin Jun columns are the only two examples known so far that have been scientifically excavated and well preserved.

${ }^{71}$ More details about the styles and construction of such roofs are discussed in Chapter Two.
} 
were joined by mortise and tenon. ${ }^{72}$ Moreover, roofs similar to truncated pyramid roofs had already been used in Western Han kingly tombs. For instance in the Beidongshan tomb where some parts of the roofs were constructed from stone slabs, the combination of stones was some sort of imitation of a timber joinery system. ${ }^{73}$ In the Mancheng tomb, a stone house was constructed in the real chamber. As mentioned above, the builder was unfamiliar with masonry, and the roof of the stone house was pretty awkward (Fig. 4-27). Therefore, the truncated pyramid roof was very likely a Chinese invention as well.

On the other hand, domed vaults, barrel vaults, caisson roofs and stepped roofs require a series of manufacturing techniques not generally used in early China, where most architecture was built of timber. In the Western Han period when rock-cut tombs were introduced to China, the roofs of such tombs were relatively simple, as many of the tombs were merely caves carved into the hill. However, in the Eastern Han period, when stone carved tombs became popular, their roofs were built with mature skills, and a number of roof types and stone combinations appeared. Thus it seems unlikely that they are independent inventions in China. Nowadays most scholars believe that domed vaults and barrel vaults originated in the West, and inspired similar ones in China. ${ }^{74}$

\footnotetext{
72 See Anqiu 1992 and Kaogu 2007.3: 32-51 for two of many examples, see Chapter Two for detailed discussions.

${ }^{73}$ See Xuzhou 2003: p. 46 and Fig. 4-26 for details.

${ }^{74}$ Different kinds of roofing structures were deployed in regions to the west of China from an earlier period. In the vast area between Iran and Rome, various types of masonry roof have been employed. According to Rawson, in West Asia, barrel vaults and domes in brick are features perfected by the Parthians, who ruled present-day Iran between 247BC-AD224. She suggests that this was the model for brick vaults in Central China. See Rawson 2010: p. 84.
} 
The prototypes of caisson roofs and stepped roofs in Han period stone carved tombs have not been discussed in previous scholarship. A caisson ceiling consists of layers of overlaid right-angled triangles with a square at the top as the capstone. Surfaces facing the interior space sometimes carry carved images. Plans of such roofs are often in the appearance of several overlaid diamonds (Figs. 5-23a, c and Fig. 5-24a), thus they are also called overlaid diamond roofs. A stepped roof usually consists of several parallel layers of decreasing square perimeters from lowest to highest, and is covered by a square stone slab. In profile, the space between tomb walls and the ceiling is stepped (Fig. 4-30a), thus the whole structure is called a stepped roof. Stepped roofs were sometimes, for instance in the middle and rear chambers of the Yinan tomb, constructed in combination with overlaid diamond ceilings.

Structures similar to the Yinan tomb have been found in the West. For instance in Milas Province of Turkey, the Gümüşkesen Monument has a rectangular grave chamber with a masonry wall, and an upper storey supported by an open colonnade (Fig. 4-28a). Its roof consists of five layers of stone blocks to form a shallow pyramid. This structure is similar to the Yinan 沂南 tomb, except that the roofs of this tomb are supported by columns and walls, and the tomb was buried underground. Moreover, the keystone of the Yinan tomb's roof has a design of coffers (Fig. 4-28b), which is surprisingly similar to that of the Turkish monument. ${ }^{75}$ Both of them have several

For a discussion on Han period brick and stone vaults, see Chang Qing 1991. Chang believes that the origins of Han masonry vaults should be traced to Central and Western Asia.

${ }^{75}$ On the ceilings of some of the chambers in the Yinan tomb and the Mixian tomb No. 2, ornaments of lotus flowers were applied. Jessica Rawson has pointed out that such tomb 
layers of stones each placed diagonally across the angles of the one below, and a circle in the centre (Fig. 4-28c, d). They are too specialized to have been invented twice. It is true that the Gümüşkesen Monument is merely slightly earlier than the Yinan tomb, but it can be presumed that there are earlier prototypes of such a structure, while the Han tomb roofs are simple, but are the earliest such examples found in China. The Gümüşkesen Monument is most likely a simplified copy of the famous tomb of Mausoleum at Halicarnassus, which was built between 353 and 350BC also in Turkey. ${ }^{76}$ Moreover, prototypes of such caisson ceilings in wood have been found in Central Asia, dated back to the Bronze Age. ${ }^{77}$

Stepped roofs which are commonly seen in Han stone tombs, for instance in the Baiji tomb (Fig. 4-30a), may have also copied early examples from the West. Such roofs as well as stone tomb chambers were buried under Scythian tumuli around 400-350BC near Kerch in the Crimean Peninsula on the northern coast of the Black Sea (Fig. 4-30b) ${ }^{78}$ It is very likely that ideas of such chambers and roofs were spread by mobile peoples across the steppes beyond the mountains to Central China. These similarities between Chinese and Crimean examples are not likely to be coincidences or separate lines of evolution, though Xuzhou and Kerch are very distant from each other. In 1842, Han style damasks were found at Kerch in Crimea. Such textiles are dated to the first century, and Xia Nai 夏鵤 affirms that they were produced in Han

ceiling ornaments with coffers are also details borrowed from further west. See Rawson 2010.

76 See Jeppesen et al. 2003.

77 See Kuz'mina 2007: 43 and 617.

78 These similarities have also been mentioned by Rawson. See Minns 1913 for more examples of stepped roofs of Lydian stone tombs. 
China and then imported to Kerch, according to their decorative designs and weaving techniques (Fig. 4-46). ${ }^{79}$ This discovery indicates that there were connections between Kerch and China during the Han period, and thus strengthens the argument that, stepped roofs which were commonly used in Eastern Han stone carved tombs, might have been a feature borrowed from the Scythian tombs near Kerch. It is not impossible that such ideas, or even artisans or stencils were brought to Central China.

Another exotic feature of stone carved tombs is the use of stone columns. Stone columns were not only erected in front of tombs as spirit roads as mentioned above, but also constructed as an integral part of the underground structure. In many cases the Han stone chamber tombs have spaces separated by columns, which were again foreign features. Internal spaces with stone columns were and are more common in the West, as is shown in the Turkish example above. China had wooden columned buildings before the Han, but not small squat ones with moulded edges. Examples like faceted columns and pilasters in the Baiji tomb (Fig. 4-31), may have been influenced by Hellenistic columns. ${ }^{80}$ Moreover, it would be more reasonable to argue that the idea of erecting columns inside tombs is from the West, if we have a look at some other tomb columns. In the Changli 昌梨 tomb No. 1 excavated in Donghai 東海 County of Jiangsu Province, a faceted column stands in the front chamber. ${ }^{81}$ Two more columns have also been found, one in the shape of a bear holding a beam, the

\footnotetext{
79 Xia Nai 1961: p. 49 and figure 4.

${ }^{80}$ Moreover, in the Baiji tomb and occasionally in other Eastern Han tombs, columns were placed standing on animals such as rams. This combination certainly refers to a Western Asian practice according to Rawson 1999 and 2010. See also Knauer 2006 for examples of animal bases.

${ }^{81}$ For the archaeological report see Wenwu cankao ziliao 1957.12: 35.
} 
other depicts a figure wearing peaked cap embracing a baby (Fig. 4-32a). Both figures were foreign to China. In an unnamed tomb found near Xuzhou, foreign figures standing on each other, playing exotic musical instruments have been carved as part of a column supporting a beam (Fig. 4-32b). Such traditions were not used in China before the late Han.

\subsubsection{Motifs of stone carved images}

Another feature of the stone chamber tombs is that many of them are decorated with relief images that are not commonly seen in China; for instance winged animals, possible Buddhist motifs, and foreign figures, have been noticed and published by scholars. $^{82}$

Some extremely interesting examples of images were executed on column No. 10 of the Mengzhuang tomb in Shandong Province. ${ }^{83}$ It has two registers of imagery, separated by a rope-like decoration. With a rubbing the images can be unrolled in sequence (Fig. 4-33a). Figures of the lower register are standing on the backs of

\footnotetext{
${ }^{82}$ A lot of scholars have worked on foreign images found within stone carved tombs. See Rawson 2010 for studies on lotus flower and scroll patterns within Han tombs. See Wu Hung 1986 for a study of Buddhist elements in Chinese art between the second and the third century $\mathrm{AD}$, with some references of possible Buddhist images in stone carved tombs. See Hsing I-tien 2011 for studies on steppe motifs found in Han period stone carved tombs. A Chinese scholar, Miao Zhe 繆哲, in his $\mathrm{PhD}$ thesis has listed a number of foreign motifs in Han pictorial art, concentrating on stone carvings found in tombs. He has made comparisons of motifs of chariots and horse riding, eagle pecking hare, double-headed creatures, and unicorns in the West and in Han China. However, he did not mention anything about how and why they were introduced to China, which is the more important but difficult part. See Miao Zhe 2007. There are countless more motifs that represented outside stimuli, which deserve another thesis-scale research. Here in this chapter I merely mention several particularly interesting examples, to show how exotic elements were used within Han stone carved tombs.

${ }^{83}$ See Wenwu 2002.2: 38-52 for the archaeological report of the Mengzhuang tomb.
} 
animals like tigers, rams and turtles, and are holding up the separating beam with their hands. Above them stands a similar group of figures and animals, holding up another beam, which is the capital of the column. This sequence of layers of images is an innovation in China. It is very likely that images of small figures holding heavy objects come from the West as well: On the façade of the rock-cut tomb of Darius I near Persepolis, a similar two-layered composition can be seen. In the lower register is a group of figures supporting a beam with their hands, upon which another group of figures are holding up another beam carrying the throne of the king (Fig. 4-34). Moreover, images engaging animals and birds, with humans standing on the back of animals are very commonly seen on cylinder seals from Western Asia (Fig. 4-35). Such seals may have supplied motifs for Chinese artisans.

On column No. 2 in the front chamber of the Mengzhuang tomb, two registers of imagery are separated by cloud scrolls (Fig. 4-33b). Roaming birds and animals, probably dancing figures, and again beam-holding figures are depicted. Occasionally an erotic scene can be seen, with naked or half-dressed men and women (Fig. 4-33). Such scenes have also been found on one of the columns in Anqiu 安丘 tomb also in Shandong Province, but are quite unusual in Han imagery of Central China. ${ }^{84}$ Complex figural scenes are common enough in Western Classical art, and then in Western Asia as well as in India (Fig. 4-36). While the forms may have been introduced from outside, the content and meanings of the image was probably local.

\footnotetext{
${ }^{84}$ In the Sichuan basin, erotic scenes have been depicted in the Pengshan cliff tomb as well as a couple of moulded bricks. Chinese scholars have tried to explain such scenes by exploring all historical texts, but have failed. For one of such studies See Liu Dunyuan 1994. Meanings of erotic motifs within tombs are still debatable.
} 
In the Huaiyang tomb, a sculpture suggesting a double headed lion was excavated (Fig. 4-37a). ${ }^{85}$ It was probably used as the base of screens or columns. Motifs of double headed animals were also new in the Han, but were again very common in earlier periods of the West. In Persepolis, similar double headed lions and other animals, were widely used as capitals of columns (Fig. 4-37b). Moreover, a frequently depicted deity within Han tomb carvings, the Queen Mother of the West, is often represented as seating on a twin headed animal as well, though the heads are not identical, one dragon the other tiger (Fig. 4-38a). Interestingly, this deity was believed to be living in stone chambers in the Kunlun Mountain to the west of Central China. As is argued by Alfriede Knauer, ${ }^{86}$ it is possible that the imagery or even the concept of Queen Mother of the West reflected elements from the West. Indeed some similar images of earlier dates can be found in the Western world, such as a figure sitting on twin animals, and a deity sitting on the back of supernatural animals (Fig. 4-38b, c, d).

These similarities between Chinese and Western Asian examples mentioned above are not likely to be coincidences or separate lines of evolution. First of all, the Western examples mentioned above are relatively early, and had no comparable history in China. Secondly, there have been continuous traces of routes linking Central China and Western Asia, as mentioned earlier in this chapter. However, there are several central questions that are very difficult to answer. The first question concerns the carriers: How did people transmit ideas and imagery? In several cases, the question is not that difficult. Many scholars have worked on the introduction of

\footnotetext{
85 Wenwu 1991.4: 34-46.

${ }^{86}$ Knauer 2006: 62-115.
} 
small objects to China, for instance silver boxes and boshanlu incense burners as mentioned above. These portable articles could be carried by merchants or diplomats and be brought back home, but what about tombs? For rock-cut tombs the answer is quite easy, as mouth to mouth information would be good enough to stimulate the idea of cutting into the hill. But what about the stone carved tombs, which include numerous foreign elements, such as columns and roofs? In later periods of Chinese history, for instance in the sixth century AD, it is known from historical texts and other evidence that, foreign artisans, sometimes even with stencils, moved to China. ${ }^{87}$ But what about earlier ages, for instance the Han period, when textual records and archaeological evidence are relatively inadequate?

Another difficult question is about the actual routes of communication: How were foreign (or not that foreign) materials moved step by step to China? Unfortunately current evidence related to Han stone carved tombs is not enough to draw a clear picture. It is relatively difficult to show the exact routes through which the ideas and imagery were transmitted step by step. What will be shown is a balance of different ideas and possibilities, through a couple of case studies.

The first case study refers to the movement of people, especially possible artisans. An interesting record has been preserved in the chapter on the Western Regions of the Han shu:

罰賓國……其民巧, 雕文刻鏤, 治宮室……自武帝始通䍔賓。

In the Kingdom of Jibin ... the inhabitants are skilful at carving and sculpting (stone) as

${ }^{87}$ See Tseng Chin-yin 2013 for a study on how the construction of Buddhist caves borrowed features from the West during the Northern Wei period (AD386-534). 
well as constructing palaces and houses ... it was since Emperor Wu's reign (141-87BC) when (Central China) was connected with Jibin. ${ }^{88}$

According to Lin Meicun 林梅村, Jibin was the name used by Han period historians referring to the Kingdom of Gandhara in northwest Indian subcontinent in present-day Pakistan and Afganistan, where people were good at stone carving and sculpting. Thus it is obvious that in the texts “雕文刻鏤 sculpting and carving' refers to the working of stone. ${ }^{89}$ There was communication between China and Gandhara from as early as the first century $\mathrm{BC}$, consequently it is not impossible that some of the artisans might have come to central China, engaging in the constructing and carving of stone monuments, through the Eastern Han period. For it is not unusual for artisans to move to different regions. In the Mauryan Dynasty of India, the tradition of making large scale stone monuments was to some extent stimulated by groups of masons who fled to India after the fall of the Achaemenids, where they used to work, as mentioned above.

The second group of case studies concerns the movement of motifs carried by portable materials, for instance textiles, cylinder seals or small jade objects. It has been suggested above that, there are similarities between some Han stone carved images and Achaemenid cylinder seals excavated in Persepolis (Fig. 4-35). Moreover, silk fabrics dated to Eastern Han have been unearthed in 1995 at an elite tomb near the ancient city of Niya 尼雅, which was deserted in the third century AD. Located in present-day Xinjiang, the Niya site is famous for several beautiful pieces of Han

\footnotetext{
${ }^{88}$ Han shu: 3884-3885. Translated by the author.

${ }^{89}$ Lin Meicun 2000: 163-164.
} 
embroidery which were very well preserved because of the dry conditions. On one of the most famous pieces, images of animals roaming among cloud or floral scrolls were embroidered, including a winged unicorn and an ostrich (Fig. 4-44). ${ }^{90}$ Ostriches lived in ancient Iran and Iraq, but were not seen in Han China. Moreover, images of winged unicorn were also depicted on Iranian cylinder seals dated to the fifth century BC. Therefore we can conclude that, these motifs were brought from Iran to China by way of Xinjiang.

Han style embroideries were found not only in Xinjiang, but also further west in Western Asia. Chinese silks were unearthed during in 1933 and 1937 from several tombs datable between AD 83 and 273 in Palmyra in Syria, an ancient trading centre on the Silk Road (Fig. 4-45). Many scholars believe that these silks are of Han origin. ${ }^{91}$ Xia Nai has argued that silks of Palmyra are surprisingly similar to those of Niya in terms of techniques and decorative designs. Several silk fabrics of both places were woven by the same method, and similar elements in motif designs and decorative patterns are presented in both cases. ${ }^{92}$ This indicates that the Palmyra silks may have been brought from Han China to Syria, located within the trade connections between the Occident and the Orient.

Although it is not very likely that Han merchants has ever arrived in Palmyra or Kerch, the above materials are sufficient enough to suggest the existence of prosperous trade links between the Western Regions of Han China and the Roman

\footnotetext{
${ }^{90}$ See Wenwu tiandi 1999.6: 26-30.

91 See Yü Ying-Shih 1967: 163.

${ }^{92}$ Xia Nai 1961: 52-54.
} 
east. Ideas about the afterlife and tomb constructions might have been brought to Central China step by step: from the Roman Orient to Xinjiang, namely the Western Regions, then through the Hexi Corridor to the Central Plains (Map 4-4).

\subsubsection{The assimilation of outside elements within China}

Han people did not merely take over foreign ideas or make identical copies, although they favoured ideas and objects from the West. They also adapted foreign ideas to satisfy their own specific requirements. Many artefacts were incorporated into major ritual activities, and reflected the desire to assimilate exotica within distinct local and ethnic traditions.

Foreign objects were not just transferred, but also changed. If we look at the Beidongshan and other rock-cut tombs again, they reflected foreign characteristics, but are not identical with Western Asian parallels. In the Beidongshan tomb, the main funerary structure consists of a doorway, four side chambers, an ante-chamber, a burial chamber, two lavatories and a gallery. Rooms of the auxiliary complex are designed for specific functions as well: an arsenal, storerooms, a music and dance hall, a kitchen, a firewood store, an ice cellar, a food store room, a lavatory and a well (Fig. 4-40). The tomb was filled with countless symbols of life, as the main structure resembles the residential section, while the auxiliary complex replicates the public and functional sections. Obviously the tomb is designated to achieve a good afterlife for the dead. Once the king had been buried in his tomb, the entrance of the tomb would be sealed with big stone blocks, thus not accessible any longer. The 
underground palace became a dwelling for the afterlife, rather than a symbol of power, as were the Iranian rock-cut tombs. Such tombs were a combination of foreign styles and local beliefs.

Smaller stone carved tombs are hybrids as well, mixing features from the West with Chinese cultural practices and beliefs. The following examples provide an overview of the ways in which the stone funerary monuments were taken over and interpreted by Han Chinese. In front of Qin Jun's tomb mentioned above, classical columns were erected together with Chinese pillar gates to mark the entrance of the tomb, forming a so-called spirit road (Fig. 4-25a). Moreover, the Han artisans added their own creation: capitals of the Hellenistic columns each carry a plaque, with Chinese inscriptions of the name and title of the tomb occupant (Fig. 4-25b). Such a new type of column and the combination of stone columns, pillars and animals set up a new tradition for the Han people, and this style was also adopted and developed by designers of imperial tombs of the Six Dynasties (AD222-589). ${ }^{93}$

In terms of tomb planning and construction, foreign structures were sometimes used in conjunction with traits from traditional Chinese structures. A stone carved tomb belonging to an Eastern Han official Miao Yu (d. AD151) has been excavated near Pizhou of Jiangsu Province. It has only one front chamber and one back chamber covered by stepped roofs, a type that has Western features as argued above. It also has a cloister-like tunnel surrounding the back chamber, with openings towards the front

\footnotetext{
${ }^{93}$ For a study on the origins of stone sculptures along spirit roads of imperial tombs of the Six Dynasties, see Kaogu 2006.8: 74-82 and Paludan 1991.
} 
chamber (Fig. 4-41). ${ }^{94}$ Such cloister structures were not very commonly seen in Eastern Han masonry tombs, but was a type that had been frequently employed in big timber tombs, especially ticou tombs, in the Western Han period. The builders of Miao Yu's tomb have therefore combined new structures and materials with traditional tomb plans.

The form of an object can be directly transferred, while the meaning embodied within the design will more than likely have been redefined by the individual patrons and artisans. In conclusion, the above exotic features were incorporated within the Chinese ritual, ideological and institutional systems, and were given Chinese functions and meanings, to create a good afterlife for the dead. This new burial type, namely the horizontal masonry tomb, was favoured by people of different social rankings and soon became the dominant burial type. The assimilation of stone tombs is just like that of English tea culture. It is obvious that, originally porcelain was introduced from China, and tea was imported from China, but when English people adopted the ideas and objects, Chinese traits disappeared and a new context was developed. The English people enjoyed sitting down with adopted and adapted china sets, socialising over cups of tea and delicate cakes. Consequently tea time became an integral part of English life.

\subsection{Conclusions}

It seems reasonable that, according to previous analysis, the idea of building

\footnotetext{
${ }^{94}$ See Wenwu 1984.8: 22-29 for the report.
} 
horizontal stone tombs comes from Iran. The Chinese adopted exotic burial types to create new forms of burial pattern, namely the royal rock-cut tombs. They were given Chinese functions and meanings, to create a good afterlife for the dead. This new form stimulated a fundamental transformation of ancient Chinese tomb structures (vertical $\rightarrow$ horizontal; timber $\rightarrow$ stone and brick). People lower down the social scale borrowed the idea of stone chambered tombs and built similar, but smaller ones. Such stone carved tombs were constructed from stone slabs or bricks to form a house-like structure, and were directly influenced by kingly rock-cut tombs in terms of tombs structure and planning. Moreover, many details of stone carved tombs, such as certain motifs and specific structures, were introduced from India as well as Central Asia (Chart 4-1). This new burial type was favoured by people of different social rankings and soon became the dominant burial type. Such new tomb structures lasted for the rest of Chinese history.

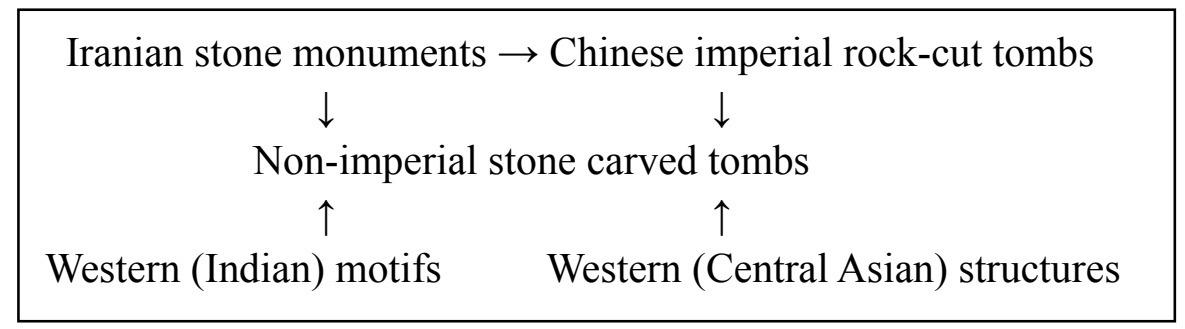

Chart 4-1

However, Chinese people would not have borrowed exotic ideas and objects if they did not need them. Foreign objects can be brought to a place only if they are needed. So why did Han Chinese adopt and adapt foreign structures since they have already had a tradition of building vertical pit tombs?

One possible reason is that changes of afterlife beliefs made the Chinese people 
dependent on good tombs. Wu Hung argues that, prior to the Han, people yearned for longevity in this world. But during the Han, people became concerned with achieving immortality in the afterlife. ${ }^{95}$ Thus it became a widespread practice for people to put great effort into building their tombs; some even started tomb construction well before their death, as tombs were thought to be an important place for the afterlife. Moreover, it was thought that the West Regions were mysterious, so that any information brought back from the West would be taken seriously. ${ }^{96}$ Also some of the deities related to immortality were living in the mountains of the West. For instance the Queen Mother of the West mentioned above was believed by the Han people to be living in stone chambers in the Kunlun Mountain to the West of Central China. This can explain the transformation from timber to stone as well. The natural characteristics of stone, strength and endurance, became metaphors of eternity. Practically, stone is less likely to decay. Timber tombs were well sealed to avoid decaying. But such efforts were not necessary in stone tombs.

Furthermore, the relationships between exotica and power should not be neglected. The rarity, high labour costs and high manufacturing skills of foreign objects resulted in the control of access to exotic materials being seen as an index of power. For instance, all rock-cut tombs dated to the Western Han period belong to different kings who were members of the royal family. The intensive labour and high manufacturing skills required for rock-cut tombs obviously represented the status and wealth of the occupant. These indicated not only shared interests across elites of

\footnotetext{
95 Wu Hung 1995: 124-126.

96 Wu Hung 1995: 127-130.
} 
different kingdoms, but also control of access to exotica. Foreign objects were not like today's imported goods, everyone can buy some if they want. In the Han, distribution of objects was concentrated in the hands of the most powerful elites.

It is quite natural that the adoption of exotic materials began with the elites in Han China, and then spread lower down the social scale to the commoners. Firstly, diplomatic tasks were mainly an official enterprise that was irrelevant to the masses. On the other hand, trade between China and the Western Regions was mainly about luxurious goods. The merchants involved in international trade must have had closer relationships with the upper class than with the commoners. Therefore, the elites were more exposed to influences from the West, as it was they, not the masses, who could afford foreign luxuries. A good example is recorded in several letters from the famous historian Ban $\mathrm{Gu}$ 班固 to his brother, general Ban Chao 班超 in the Western Regions, compiled in the Quan Hou Han wen 全後漢文. We can learn from one of the letters that, a Mr Dou 竇, presumably an imperial in-law, had delivered 800,000 qian coins to buy some dozen pieces of carpets produced in the Western Regions. Another letter tells us that the Mr Dou was planning to forward 700 pieces of silk fabric of different colours and 300 pieces of white silk to the Western Regions, to purchase luxury goods, such as Yuezhi 月氏 horses, Suhe incense 蘇合香, and woollen textiles. ${ }^{97}$ This indicates that first of all, elites of the Eastern Han were extremely interested in foreign products. Secondly, most exotic goods were quite expensive. In the Han period, 800,000 qian equals 19.52 kilograms of actual gold, ${ }^{98}$

${ }^{97}$ Quan Hou Han wen: juan 25: 4a. See also Yü Ying-Shih 1967: 195.

98 According a generally agreed calculation, 10,000 qian 錢 (copper coins) $=1$ jin 斤 $(244$ 
but that could merely buy some dozen carpets.

Merchants, landowners and officials had to be very wealthy to afford these, not to mention commoners lower down the social scale. However, when it comes to business related to their afterlife, it might not be a big problem to construct the already fashionable stone chamber tombs for themselves, and to occasionally bury some exotic objects such as glazed beads with them in the tomb. No matter whether they were aware of this or not, stone chamber tombs were the latest fashion originating from the West, and they were fond of them.

It seems that this tradition has not changed too much in contemporary China. Nowadays, around 150,000 Chinese tourists visit Britain each year, after filling some 30-page visa application form, which makes sure that they could afford to fly more than ten hours overseas. ${ }^{99}$ A large proportion of the affluent Chinese tourists would travel another hour from London to Bicester, where a popular outlet shopping village is located, to spend thousands of pounds on a handbag. Going back home with Western luxurious goods that everyone covets, must be the epitome of fashion on the streets of Beijing or Shanghai. Of course many Chinese shoppers are also buying for their family and friends. Even for the overseas Chinese students, when going back home for holidays, it is common enough for them to bring some exotic objects, which will definitely become perfect presents that everyone likes.

People may have not been aware of this, but it is undeniable that they immerse grams) of gold. See Chang Chun-shu 2006: Equivalents of Weights and Measures.

99 See Tobin, Lucy. 'Chinese pack their suitcases at Bicester', the Independent, 13 Oct 2012 (http://www.independent.co.uk/news/business/analysis-and-features/chinese-pack-their-suitca ses-at-bicester-8209793.html). Retrieved 1 August 2014. 
themselves in exotica. It is not the function, but probably the brand name and the foreignness that really matters. 


\section{Chapter Five: the Legacy of Stone Carved Tombs}

東至樂浪, 西至敦煌, 萬里之中, 相競用之。

From the Lelang Commandery in the east, to the Dunhuang Commandery in the west, within ten thousand li miles, people were all emulously adopting this burial style.

Qianfu lun 潛夫論: Chapter of extravagance 浮侈篇 ${ }^{1}$

In his text criticising contemporary societies, the Eastern Han philosopher Wang $\mathrm{Fu}$ 王符 (c. AD78-163) commented on the luxurious burial customs of his age. Though discussing wooden coffin tombs rather than stone carved tombs, these comments have shown how one type of structure quickly became fashionable across the Han Empire.

After their heyday, as the Han Empire collapsed, stone carved tombs ceased being constructed in the Central Plains. It seems obvious that, as some scholars have observed, the stone tombs disappeared simply because in the times of turbulence at the end of the Han, people could no longer afford expensive and labour intensive stone tombs. ${ }^{2}$ Indeed, most stone carved tombs in the Qi-Lu region and the Nanyang Basin were constructed during the middle and late Eastern Han period, mostly before the start of the Yellow Turban Rebellion in AD184. This argument can be strengthened by dated stone slabs found in these areas. In Qi-Lu and Nanyang, around

${ }^{1}$ Qianfu lun: p. 134. Translation by the author.

${ }^{2}$ For such discussions see Xin Lixiang 2000: 19-20; Li Falin 1982: 50. 
forty stone carvings with dated inscriptions have been found, in tombs, offering shrines and on que pillars. The earliest inscribed stone dates to AD8, while most other stones are dated to between AD61 and AD182. There is only one stone that was carved after the start of the uprisings. This stone was excavated in Tengzhou of Shandong and carries inscriptions stating ‘初平元年 first year of the Chuping reign’, namely $\mathrm{AD} 190 .^{3}$ The above dated inscriptions indicate that, stone carved tombs basically stopped being constructed when the rebellion broke out in Central China.

Yet the question is, did such stone tombs really disappear? Archaeological evidence shows that similar structures have been found in tombs of the Han borderlands, and of later Chinese dynasties. These Han masonry tombs set a model for tomb structures and imagery in later tombs. Thus this chapter will examine how and why people from later Chinese periods and other areas of Asia chose a similar structure. It is very likely that, the legacy and spread of this masonry tradition is closely related to the political circumstances of the late Han and post-Han period. Therefore, it is probably a good solution to start from looking at late Han and post-Han historical geography.

\subsection{Late Han and post-Han political geography}

During Emperor Xiaowu's reign (141-87BC), following a series of conquests and expansions, the Han Empire reached its height. From that time, the Chinese armies pushed farther and farther with a number of campaigns, and the influence of

\footnotetext{
${ }^{3}$ Shandong 1982: p. 2.
} 
the powerful Han Empire rapidly spread into neighbouring border regions, involving expansion of the bureaucratic government as well as the migration of elites and commoners to the remote places, including Sichuan, Northern Shaanxi and Western Shanxi, the Hexi 河西 Corridor, Northeast China, and the South (Map 5-1). Chinese intellectual life and material culture was as active as that in the military and political spheres, both in the Central Plains and in the peripheral areas.

The northwest borders region was very significant for the Han Empire, as it neighbours the nomadic Xiongnu people, the traditional enemy of the Han; and it was in this region that a series of battles were fought between the Han and the Xiongnu. Having expelled the Xiongnu from the Hexi Corridor in $121 \mathrm{BC},{ }^{4}$ the Han court embarked on an expansion westwards through the Hexi Corridor, in order to cut off the Xiongnu's possible connection with its allies, the Qiang 㒸 people who were active in the mountainous areas to the south of the Hexi Corridor. From the fourth year of the Yuanshou 元狩 reign (119BC), the Han court established four new commanderies in this area, namely Wuwei 武威, Zhangye 張掖, Jiuquan 酒泉 and Dunhuang 敦煌, know as the Hexi sijun 河西四郡, the four commanderies of the Hexi Region. ${ }^{5}$ A number of outposts were set up, and large numbers of government-arranged immigrants were moved there. The area from then on became a

\footnotetext{
${ }^{4}$ The Hexi Corridor, also known as the Gansu Corridor, is a historical route in present-day Gansu Province which lies between the Tibetan Plateau and the desert area, and connects Central China with Xinjiang as well as Central Asia. As part of the Silk Route, it runs northwestwards from the bank of the Yellow River, hence its name, Hexi, literally 'to the west of the (Yellow) River'.

${ }^{5}$ For an intensive study on the management of the Hexi region by the Western Han Empire, see Chang Chun-shu 2006. For a discussion on the northeastern frontier of the Eastern Han Empire, see Tse 2012.
} 
more important route for traders and diplomats, and material culture in this region reflects traditional Chinese traits as well as foreign influences.

In 119BC, another new Commandery, Xihe 西河, was established, with its seat at Pingding 平定, near the present-day city of Ordos 鄂爾多斯 of Inner Mongolia. Its territory was a broad area of present-day Northern Shaanxi, Western Shanxi, and the Inner Mongolian borders to Shaanxi and Shanxi, but it was not very well populated. Therefore, in 119BC, around 725,000 Han people were encouraged to immigrate to Xihe and other surrounding commanderies. ${ }^{6}$ Most of the immigrants were either extremely poor people or criminals and their families from Central China. From that time, this area along the Yellow River was occupied by Han Chinese until the fifth year of the Yonghe 永和 reign (AD140), when they had to abandon their land because it finally fell to the Xiongnu. The Han people then had to retreat, and the seat of Xihe Commandery was moved to Lishi 離石 at present-day Lüliang 呂梁 of Shanxi Province. ${ }^{7}$ Around AD184, a further series of raids were carried out by the Xiongnu, consequently all the Han people fled to the south, and the Xihe Commandery was completely abandoned. During the several decades when the Xihe area was occupied by Han Chinese, they managed to develop this region and maintain a moderate Chinese life style, including constructing masonry tombs that were similar

\footnotetext{
${ }^{6}$ See Hanshu: p. 178. The original text reads: ‘四年冬...關東貧民徙隴西、北地、西河、上 郡、會稽凡七十二萬五千口。In the fourth year (of the Yuanshou reign), 725,000 poor people from the Central Plains were immigrated to Xihe and other commanderies.'

${ }^{7}$ See Hou Hanshu: 269-270. The original text reads: ‘五年 $\cdots$ 夏四月 $\cdots$ 南匈奴…圍美稷。… 徙西河郡居離石。In the fourth month of the fifth year (of the Yonghe reign), summer, the Southern Xiongnu sieged Meiji County (of the Xihe Commandery). Later the seat of Xihe was moved to Lishi.'
} 
to those in Central China.

During the late second century $\mathrm{AD}$, trouble was coming from within the borders: the authority of the Eastern Han Empire was seriously challenged by the Yellow Turbans Uprising, causing the downfall of the Han. The rebellion, which got its name because of the colour of turbans that the rebels wore, was a peasant revolt that broke out in AD184 in the Central Plains of China. The rebels were defeated after several years, but at a very high cost: the society and economy of the most populated regions of the empire were destroyed, and many people were left homeless. After the rebellion was suppressed, Central China was divided by autonomous warlords and remained in the state of war and turbulence. After that, especially from AD190, even larger numbers of people moved to remote border areas, including the Youzhou 幽州 Prefecture, the Liaodong 遼東 Commandery, and the Hexi Corridor, the Southeast and the Sichuan Basin, where it was relatively peaceful. These people contributed to the spread of their culture, including funerary customs, tomb construction and pictorial materials.

Immigration to Southeast China in late Eastern Han was largely due to the expansion of one influential warlord, Sun Ce 孫策 (AD175-200). In AD195, Sun crossed the Yangtze 揚子 River, heading to southeast China to establish his new power base, and a number of scholar-officials and commoners followed him. Since Sun was generous and employed people according to their abilities, many officials and scholars from Central China decided to go to the Southeast with him. The Sanguo 
zhi 三國志, official history of the Three Kingdoms (AD220-280), ${ }^{8}$ recorded around sixty names of immigration scholar-officials, many of whom later became important figures for the Sun lineage's expansion as well as ruling of Southeast China. Around forty of them came from the Qi-Lu region or present-day Henan Province. Most of the scholar-officials were not travelling alone, they also brought to Southeast China and to settle their families and attendants, which might number in the hundreds. Moreover, many of them had had very good reputations in their hometowns, and thus a number of people would follow them wherever they went. ${ }^{9}$

On the other hand, many commoners did not migrate voluntarily, but were forced to move. For instance, in the fourth year of the Jian'an 建安 reign, namely AD 199, Sun Ce attacked Wancheng 皖城 in present-day Anhui 安徽 province and captured more than thirty thousand artisans and musicians, who were attendants of another warlord, Yuan Shu 袁術 (d. AD199). Sun then moved all of them to Wu 吳, in present-day Suzhou 蘇州, Jiangsu Province. ${ }^{10}$ Many of these refugees, who wandered from place to place in the Central Plains, finally returned home when it became relatively peaceful. But most refugees who fled to the south of Yangtze

${ }^{8}$ The Three Kingdoms period refers to the period between the foundation of the Wei 魏 Kingdom in AD220 and the fall of the $\mathrm{Wu}$ 吳 Kingdom in AD280. However, the period between AD184 when the Yellow Turbans Uprising broke out and AD220 has been regarded as an 'unofficial' part of the Three Kingdoms period, and the chaotic infighting among warlords in various parts of China has been recorded in the Sanguo zhi as well.

${ }^{9}$ For instance, in the biography of Zhang Zhao 張昭 (AD156-236), a scholar who migrated from Xuzhou to Southeast China and became an important politician of the later Eastern $\mathrm{Wu}$, in the Sanguo zhi, it is recorded that “漢末大亂, 徐方士民多避難揚土, 昭皆南渡江。 Because of the great turmoil at the end of the Han, many elites and commoners in the Xuzhou Prefecture fled to Yangzhou Prefecture to seek refuge. Zhang Zhao arranged all of them to cross the Yangtze River (to Southeast China).' See Sanguo zhi: 1219.

10 Sanguo zhi: 1108. 
eventually settled down, as later the regime of Wu (AD229-280) was established, and the area it ruled remained peaceful for several decades.

In AD188, a diligent official, Liu Yu 劉虞 (d. AD193), was appointed governor general of Youzhou Prefecture. Youzhou Prefecture embraces a broad area of Han Empire's northeast frontier, which includes present-day Beijing, Tianjin 天津, northern Hebei 河北 province and Liaoning 遼寧 province. The prefectural seat was at Ji 薊, in modern Beijing. As Youzhou abutted uncultivated borderlands, the central government had always had to transfer around 200 million qian coins from Qingzhou 青州 and Jizhou 冀州 to Youzhou each year to cover its expenses. But on account of the Yellow Turban Rebellion, roads were blocked and Youzhou was thus isolated from other prefectures. But $\mathrm{Liu} \mathrm{Yu}$ managed to promote agriculture in Youzhou and made good use of the salt and iron industry of Yuyang 漁陽 Commandery, so as to gain wealth for the government. Moreover, Liu Yu practiced a lenient policy toward the non-Han tribes at the border, sometimes bestowing on them money and valuables. Under his rule, the tribes, including the Xianbei 鮮卑, the Wuhuan 烏桓, Fuyu 夫餘 and Huimo 穢腼, did not raid Han borders, and paid their tributes on time. ${ }^{11}$ Liu also encouraged the border market in Shanggu 上谷 Commandery, where the Xianbei and Wuhuan peoples came to trade. The market turned out to be very prosperous and Liu profited. ${ }^{12}$ Later on, when the Yellow Turban rebels threw the Central Plains into turmoil, more than a million people fled to

\footnotetext{
${ }^{11}$ See Hou Hanshu: p. 2353. The original text reads: “鮮卑、烏桓、夫餘、穢貃之輩, 皆隨 時朝貢, 無敢擾邊者。The Xianbei, the Wuhuan, the Fuyu and the Huimo all paid their tributes on time and dared not raid Han border.'

${ }^{12}$ For Liu Yu's biography see Hou Hanshu: 2353-2354.
} 
Youzhou to seek refuge, and the wealth gained proved very helpful to accommodate these refugees. Unfortunately in AD192, Liu Yu was murdered by one of his ambitious subordinates, and Youzhou was then controlled successively by different warlords, until the pacification of North China by Cao Cao 曹操 (AD155-220) in AD207.

The northeastern-most part of the empire, namely the Liaodong Commandery and the lands of former Four Commanderies of the Han, ${ }^{13}$ was only narrowly connected to the Central Plains by land and thus remained relatively peaceful, for an even longer time. The autonomous rules of warlords, the Gongsun 公孫 lineages, were maintained in the Liaodong Commandery until AD238, eighteen years after the fall of the Han. The Liaodong area was always somewhat Chinese in culture and organisation until the fall of the Western Jin 西晉 dynasty (AD265-316). Diverse clans and nomadic tribes such as the Wuhuan, the Xianbei, and the Koguryo 高句麗, remained active along the northeast Han borderlands (Map 5-4). ${ }^{14}$

The Koguryo Kingdom (traditional dates 37BC-AD668) developed from a league of tribes and gradually expanded its power, but did not become a major force until the later years of the Han Empire, when its territories were the mountainous areas of the Yalu 鴨綠 River. Koguryo had been combating the Chinese northeast

\footnotetext{
${ }^{13}$ Emperor Xiaowu (r. 141-87BC) of the Western Han Empire conquered the Wiman Joseon 衛滿朝鮮 (194-108BC), who occupied the northern part of the Korean Peninsula, and set up three commanderies, Lelang 樂浪, Zhenfan 真番 and Lintun 臨屯 in 108BC, and the Xuantu 玄菟 Commandery in 107BC. See Erickson et al. 2010 for a brief history the Four Commanderies and their relevance to the Koguryo.

${ }^{14}$ See Barfield 1989: 104-105 for more information about the political geography of the 'Manchurian borderlands' after the collapse of the Han Empire.
} 
commanderies in their push for expansion, as well as being attacked by surrounding powers, from the first to the fifth centuries. At its peak Koguryo ruled a broad area from northeast China to the northern part of the Korean peninsula. Northeast Asia, including northeast China and the Korean Peninsula, experienced a transformative period, with continuous interactions of people and cultures in the centuries during and after the collapse of the Han Empire. Under such circumstances, archaeological discoveries in the Han borderlands which are dated to this period are as arresting as cultural transformations.

\subsection{Late Han stone carved tombs in Han borderlands}

Late Han and post-Han historical geography and political circumstances are closely related to the legacy and spread of Han Dynasty stone carved tombs. Late Eastern Han stone tombs in Sichuan were followers of tombs of the Central Plains, and often belong to immigrants and were built by immigrant workers. ${ }^{15}$ Similar masonry and mural tombs were also constructed in Han borderlands, including Shaanxi and Shanxi provinces, the Southeast, the North as well as the Northeast.

\subsubsection{The Northwest: Northern Shaanxi and Western Shanxi}

The Xihe Commandery mentioned above is one of the border areas where stone carved tombs have been found. Within the Northern Shaanxi and Western Shanxi

\footnotetext{
${ }^{15}$ For an intensive study on the tomb structures, pictorial carvings and burial objects of Eastern Han tombs in Sichuan, see Chen Xuan 2014. Chen has also worked on the communication between Sichuan and Central China, linking it to the tombs of migrations in Sichuan.
} 
region, tens of masonry tombs and countless individual stone slabs have been excavated. ${ }^{16}$ Among them a large number of tomb stones carry short inscriptions, which sometimes include the dates of the inscribed text, therefore it is possible to date precisely some of the tombs. On the western bank of the Yellow River namely in Northern Shaanxi, such tombs were mainly found near the modern towns of Shenmu 神木, Yulin 榆林, Mizhi 米脂 and Suide 綏德 (Map 5-2). A large proportion of them are located in the valleys of the Wuding 無定 River, tributary of the Yellow River. A total number of eleven tombs that have precise dates have been found in Northern Shaanxi: the earliest one was constructed in the second year of the Yongyuan 永元 reign (AD90), while the latest was finished during the fourth year of the Yonghe reign (AD139).

The Yellow River has another tributary to its east, the Sanchuan 三川 River. In the river valleys lie two modern towns, the city of Lüliang and the Liulin 柳林 County, around which many stone carved tombs have been excavated (Map 5-2). Among them four tombs can be dated again according to inscriptions: the earliest one was constructed in the first year of the Heping 和平 reign (AD150), the latest during the fourth year of the Xiping 喜平 reign (AD175).

From the dates of tombs in both regions it can be seen that, stone carved tombs ceased to be constructed in Northern Shaanxi after around AD139, while very few stone carved tombs in Western Shanxi can be dated to earlier than AD150. This situation perfectly fits the political circumstances in middle and late Eastern Han in

\footnotetext{
${ }^{16}$ For a brief introduction and a compilation of ink rubbings of stone carved reliefs see Shandong and Henan 2000: vol. 5.
} 
this area. As mentioned above, in AD140, the seat of Hexi Commandery was moved to Lishi in present-day Shanxi Province, in the wake of a series of Xiongnu invasions. Han peoples, including officials, soldiers, merchants, peasants and artisans must have all retreated to the east of the Yellow River, as the west bank had already been occupied by the Xiongnu. Moreover, tombs in both Shaanxi and Shanxi are of similar types in terms of planning, tomb structure and stone carving techniques. Therefore I suggest that, stone carved tombs in Western Shanxi were developed by the same group of people, after the relocation of the commandery seat. Around AD184, the Xiongnu invaded Xihe Commandery again, in the wake of the Yellow Turban Rebellion. Consequently the Han people had to flee again, completely abandoning all lands of modern Northern Shaanxi and Western Shanxi. Thus stone carved tombs of course disappeared following the retreat of the Han.

Now most scholars believe that stone carved tombs of Northern Shaanxi and Western Shanxi were developed after such tombs in Central and Eastern China, ${ }^{17}$ and indeed there are a lot of similarities between the two groups of tombs. But tombs in this area still have unique characteristics, probably related to the colonists' life and the natural environment of this region.

The first characteristic is the style of construction. In this area, nearly all tombs were constructed from a combination of stone slabs and small bricks, unlike in Eastern China, where many tombs were built from stone only. One of the examples is the Mamaozhuang 馬茂莊 tomb No. 3, excavated near Lishi. ${ }^{18}$ It is a relatively big

\footnotetext{
${ }^{17}$ Xin Lixiang 1982: 285-288, Xin Lixiang 2000: 353-358 and Wang Jianzhong 2001.

${ }^{18}$ Henan 2000, vol. 5: 3-16.
} 
tomb, with a plan in the shape of a cross, and stone slabs were only used for the construction of tomb doors, columns and lintels in the middle chamber. Small moulded bricks were used for tomb walls and particularly for the dome vaults over the chambers (Fig. 5-1). The reason that the tomb occupant or his relatives employed a lot of bricks is probably not because that he could not afford a tomb built with stone only, but due to reasons of natural resources. Northern Shaanxi and Western Shanxi are both within the Loess Plateau, where stone is not abundant but loess, one of the main materials for moulded bricks, is everywhere.

The natural resources in this area also determined the carving and decoration techniques of stone tombs. Within the Loess Plateau, the main type of stone available is shale, characterised by parallel layers of sediments. Unlike limestone which is commonly seen in Central and Eastern China, shale tends to break into thin layers when intensively carved, thus is not appropriate for the carving of detailed images or line engraving. As a result, stone reliefs in this area were mainly carved with one type of technique only: On the surface of the smoothed stone, the background of the design was cut away to a slight depth, leaving the figures in flat relief. On the smooth surface of figures, it is very rare that line carvings were executed, as in Eastern China. The figures were more often painted instead. For instance, in the Shipan 石盤 tomb of Lishi, ${ }^{19}$ the two slabs used as tomb doors carry common images of auspicious animals, bi discs and floral scrolls. The background was cut away, and ink line drawing with occasional red pigments was applied on the figures to depict details (Fig.

\footnotetext{
${ }^{19}$ For the archaeological report see Wenwu 2005.2: 42-51.
} 
$5-2)$.

Another characteristic is that, located near the borders between the Han and the Xiongnu, stone tombs in this area contain an array of special decorative motifs associated with, or influenced by, the Xiongnu peoples. ${ }^{20}$ Moreover, stone carved tombs in this area tend to carry inscriptions. By 2006, 29 inscriptions had been found in stone carved tombs or on individual tomb stones excavated in the Shaanxi-Shanxi area, and most of them record the name, title and place of origin of the tomb occupants. ${ }^{21}$ Considering the relatively small number of tombs excavated in this area by comparison with that of the Central Plains, 29 inscriptions indicate that a large proportion of stone carved tombs in this area carried inscriptions. Why did this happen? In Central China hundreds of stone carved tombs and countless individual stones have been excavated, but only a few of them have inscriptions.

One of the best examples in the Shaanxi-Shanxi region is the tomb of Niu Chan 牛產, found at Mamaozhuang near Lishi. ${ }^{22}$ It is a single chamber tomb constructed from a combination of stone slabs and bricks. The left column of the tomb door carries inscription which reads “漢故西河回陽守令平周牛公產萬歲之宅兆 Residence for Mr Niu Chan of Pingzhou County, the late chief officer at Yuanyang County of Xihe Commandery. May his residence be preserved for ten thousand years. (Fig. 5-3)’ The right tomb door is inscribed with ‘喜平四年六月 the sixth month during the fourth year of the Xiping reign (AD175)'. From these texts we can learn

\footnotetext{
${ }^{20}$ For an intensive study on tomb reliefs from Shaanxi and Shanxi, especially unique motifs such as the hunting imagery, see Wallace 2010.

${ }^{21}$ See Kaogu yu wenwu 2006.1: 53-69 for a piece by piece analysis of these inscriptions.

${ }^{22}$ For the archaeological report see Wenwu 1996.4: 13-27.
} 
that the tomb occupant, Mr Niu, was originally from Pingzhou County, which was originally located at present-day Mizhi County, and that he had worked for the government of the Yuanyang County which is the modern town of Suide. ${ }^{23}$ Niu's tomb was completed in AD175, when Pingzhou, part of the Xihe Commandery, had already fallen to the hands of Xiongnu, as a result of which he was unable to be buried at his hometown, as most Han people would have expected to be. Therefore, we can presume that the reason why Niu included abundant information in very short inscriptions is that, he had travelled a lot and was buried in what he regarded as an alien land, thus in his tomb he needed to clarify his identity. This also applies to most other inscribed tombs in this area, as the majority of population in the Xihe Commandery were immigrants. By comparison, detailed inscriptions did not seem to have been necessary for tomb occupants in Central and Eastern China, as most of them were locals and were fortunate to be buried at their hometown, where they must have already been known among the locals.

\subsubsection{The Southeast: Zhejiang Province}

In 1973, a stone carved tomb was found at Chang'an 長安 town of Haining 海 寧 county, Zhejiang 浙江 Province of Southeast China. ${ }^{24}$ It is relatively small by comparison with similar tombs in Central China: merely 9.56 metres long, 4 metres

\footnotetext{
${ }^{23}$ See Kaogu yu wenwu 2006.1: 53-69 for a study on the locations of the Pingzhou and Yuanyang counties, which reckon they were located at present-day Mizhi and Suide respectively.

${ }^{24}$ For the archaeological report see Wenwu 1983.5: 1-20. For an intensive study see Huang Yafeng 2009.
} 
wide with 3.1 metre-high roofs. The tomb has a front chamber, a rear chamber and two side niches (Fig. 5-4a). Its foundation and the tomb walls are constructed from stone slabs, and the whole structure is covered by a brick barrel vault (Fig. 5-4b). Fifty-five of the stone slabs carry elaborately carved images of buildings, figures, auspicious omens and tomb occupant's daily life (Fig. 5-4c). Excavators of this tomb have dated it to from late Eastern Han to early Three Kingdoms period (AD220-280), according to analysis of carving techniques and burial objects. ${ }^{25}$

For a long time people thought the Chang'an tomb was the only stone carved tomb in Zhejiang Province or even in the vast region to the south of the Yangtze River. Scholars were surprised at this orphaned tomb found far away from the majority of tombs in Central and Eastern China. In fact, three other stone carved tombs have been excavated in Deqing 德清 County of Zhejiang, only fifty kilometres to the west of Chang'an, in 1963 and 1974 respectively. But they were not known until they were published in 2005. ${ }^{26}$ The Fenghuangshan 鳳凰山 tombs M1 and M2 are nearly identical in terms of scale, plan and methods of construction: both of them are single chamber masonry tombs facing east, and both chambers are roughly 6.6 metres long and 2.8 metres wide (Fig. 5-5d, e). As a result the archaeological report only describes the structure of M1, which is a masonry tomb constructed from small moulded bricks, with stone tomb doors and a brick barrel vault. On the doors, images of servants, zhuque 朱雀 or 'vermilion birds' and other auspicious animals are carved. A variety

\footnotetext{
${ }^{25}$ Wenwu 1983.5: 20.

${ }^{26}$ For the Fenghuangshan tombs see Zhejiang 2005: 439-457, for the Qiushan 秋山 tomb see Zhejiang 2005: 458-462.
} 
of burial objects have been found in both tombs, including common objects, such as bronze coins, a jade pig, cermics and a silver ring. More interestingly, a set of stone furniture, which had not been disturbed, was found in the front chamber of M1 (Fig. 5-5a, b, c): a stone couch, 1.44 metres long, 0.8 metres wide and 0.2 metres high, surrounded by two square screens 0.84 metres wide and 0.08 metres thick. Both stone screens carry carved images of figures, and each has a small stone lion supporting it. A stone low table, 1.5 metres long, 0.43 metres wide and 0.23 metres high, was placed alongside the couch. In M2 similar sets were found, but the stones were too weathered to identify their carvings. Both tombs are dated to late Eastern Han by the excavators. ${ }^{27}$ The Qiushan tomb is not too far away from the Fenghuangshan tombs, and has a quite similar structure. A similar set of stone couch and stone low table has been found in the tomb chamber (Fig. 5-6). The date of the Qiushan tomb might be as late as Three Kingdoms period, as a celadon vessel was buried in it together with many other objects.

A fifth tomb was found at Xifengba 西峰壩 of Changxin 長興 County (sixty kilometres to the north of Deqing), also in Zhejiang Province in $2006{ }^{28}$ It has a square plan, and was constructed from stone slabs only, and includes one front chamber facing east, one rear chamber and one side niche. Both the front and the rear chambers are covered with stepped caisson roofs (Fig. 5-7a), a feature that was used only in the Qi-Lu region in the late Eastern Han. The whole structure is 7.86 metres long, 4.2 metres wide and 2.64 metres high. The tomb is now mostly above-ground

\footnotetext{
27 Zhejiang 2005: 443.

${ }^{28}$ For the archaeological report see Zhejiang 2012.
} 
(Fig. 5-7b), and it is very likely that it was above-ground when built, because of the high underground water level in this area. Earth would have been piled up after the construction was finished. Carved reliefs are only found on the tomb lintel and doors, with images of dragons, tigers, zhuque vermilion birds and deer. It is dated to late Eastern Han by the excavators, according to coins, jade bi 璧 disc and pottery found in tomb chambers. ${ }^{29}$

This group of tombs in Zhejiang is distant from the principle area of stone carved tombs (Map 5-3), namely the Central Plains. Why were the group of tombs built; where were the patrons and artisans from? A Chinese scholar, Huang Yafeng 黃 雅峰, has argued that stone carved tombs in Haining and Deqing were constructed by a group of artisans originally from Luoyang, but this is unlikely. Huang's argument is based on a paragraph of historical texts, saying that the Eastern Han politician Zhu Jun 朱儶 (d. AD195) had once sought out craftsmen in Luoyang and brought them back to his hometown in present-day Zhejiang, to construct his mother's tomb. But Huang has misunderstood some of the text. Moreover, there are some mistakes in this later text:

永興縣東有洛思山, 漢太尉朱售為光祿大夫時, 遭母哀, 欲卜墓此山, 將洛下冢 師歸, 登山相也。

In the eastern part of the Yongxing County (present-day Xiaoshan of Hangzhou), there is a hill called Luosi. When Zhu Jun, the taiwei officer of Han Dynasty, was serving as the guanglu dafu officer, his mother passed away. (He wanted to build his mother's tomb on this hill) and thus would like to evaluate this hill (to see whether it is a proper location for tomb construction). So that he led grave masters from Luoyang, and climbed up the hill to make divinations. ${ }^{30}$

\footnotetext{
29 Zhejiang 2012.

${ }^{30}$ Kuaiji ji, compiled in Taiping yulan: juan 47, cited in Huang Yafeng 2009: 88-89.
} 
The text was written by Kong Lingfu 孔靈符 (d. AD465?), active in the Liu Song 劉宋 Dynasty (AD420-479), and the text was compiled in the Taiping yulan 太平御覽 in the Northern Song 北宋 period (AD960-1127), both much later in date than the Eastern Han. It is always problematic to use later texts, and an inconsistency is indeed clear: Zhu Jun's mother died around AD185 before he was promoted to guanglu dafu 光祿大夫, according to Hou Hanshu, ${ }^{31}$ the official history of the Eastern Han. Moreover, even if the Song text was correct, the men who Zhu Jun had led home were not craftsmen. According to the above translation, the word zhongshi 冢師, literally grave master, does not mean tomb constructors, but refers to fengshui augurs, whose job was to choose an auspicious location for the tomb. ${ }^{32}$ Once they had done their job, they would have gone back to Luoyang with no reason to stay in Zhejiang. What is more, as is mentioned in Chapter One, in Eastern Han Luoyang, most tombs were constructed from small moulded bricks, and only a few of them have stone carved tomb doors. So that it is unlikely that there was a team of masons in Luoyang that were competent to construct relatively complicated stone tombs in Zhejiang. Therefore, it is unlikely that the stone carved tombs in Zhejiang were built by Luoyang masons.

\footnotetext{
Translated by the author.

${ }^{31}$ Hou Hanshu: 2308-2313. The original text reads: ‘(中平二年)封錢塘侯, 加位特進。以母 喪去官, 起冢。復為將作大匠, 轉少府、太僕……復拜儶為光祿大夫。(In AD185) Zhu was conferred the title of Marquis of Qiantang, with a promotion of official rankings. But later he had to resign because of his mother's death, and constructed a tomb for her. After that Zhu held a number of titles including jiangzuodajiang, shaofu and taipu, before he became guanglu dafu officer.'

${ }^{32}$ See section 2.2.2 of Chapter Two for more details about the fengshui approach, which was widely used to orient tombs in an auspicious manner.
} 
It would be a better idea to examine the tombs themselves, to identify their origins. Firstly, the stone carvings of the Zhejiang tombs, especially those at the Chang'an tomb at Haining, are strikingly similar to those in the Qi-Lu region, especially the Yinan tomb stone slabs, in terms of carving techniques. ${ }^{33}$ Moreover, in the Fenghuangshan and Qiushan tombs, two set of stone furniture, including couches surrounded by screens, together with low tables, have been excavated (Figs. 5-5a, b, c and 5-6a, b). Prototypes of such stone furniture have been found in Central China. In the Huaiyang tomb mentioned above, stone sculptures of tigers and lions ${ }^{34}$, a stone table and a fragmentary stone was found (Fig. 5-8). The excavators as well as some scholars believe that the stone tigers and lions were supporting a stone slab, and together they formed a screen. ${ }^{35}$ Although the tomb was severely disturbed, making the original positions of objects unclear, it can still be argued that the set of furniture in the Huaiyang tomb included tables and screens similar to that of the Zhejiang tombs.

Another such example is the Wangdu 望都 tomb No. 2 in Hebei Province, in which a stone low table and a stone crouch were found, together with many other stone sculptures (Fig. 5-9). ${ }^{36}$ Through comparison between the Zhejiang tombs and those in the Central Plains, we can see that the Zhejiang tombs may have been influenced by the ones in Central and Eastern China. It is possible that they were

\footnotetext{
${ }^{33}$ For a comparison of details see Figs. 5-4c, d.

${ }^{34}$ See Fig. 4-37a and section 4.5.3 of Chapter Four for discussions on the sculpture of a double headed lion, which might serve as the seat of screens.

35 See Wenwu 1991.4: 34-46 for the archaeological report; also in Yang Aiguo 2013 it is suggested that the fragmentary stone slabs were part of screens.

${ }^{36}$ For the Wangdu furniture set see Wangdu 1959: 19 and 32.
} 
constructed by artisans who had migrated to Zhejiang, ${ }^{37}$ as there is no history of building stone tombs in this area before late Eastern Han. Han masonry tombs in Zhejiang, other than the ones mentioned above, were all constructed from bricks, according to currently available archaeological materials.

The emergence of stone carved tombs in Zhejiang should be linked with the late Han political circumstances. The hypothesis is that, on account of the Yellow Turban Rebellion, a group of masons who had worked on stone tombs in the Qi-Lu region, had to flee from their hometown. Although many of their countrymen chose to flee northwards, they decided to go to the south. They might have strayed for a while on the Jianghuai 江淮 Plains before being captured and moved to the South by troops of the Sun lineages, who later became rulers of the Eastern Wu. They might also have migrated directly to the south of Yangtze River, either by themselves, or following the renowned scholar-officials like Zhang Zhao mentioned above. Then, the masons settled down in Eastern $\mathrm{Wu}$, under whose rule the vast region to the Yangtze River remained at peace for several decades. Consequently, they were active in the Eastern $\mathrm{Wu}$, promoting and constructing a new burial type, stone carved tombs, in this area, especially at the edges of the plain by the Lake Taihu 太湖, where the limestone hills supplied them with materials (Map 5-3).

\subsubsection{The North: Beijing and Tianjin area}

\footnotetext{
37 Very interestingly the Huaiyang and Wangdu tombs were slightly off the principle areas of stone carved tombs, namely the Qi-Lu region. They might have been constructed by masons from Qi-Lu.
} 
Tombs that are very similar to the Qi-Lu ones have also been found further north, in the area near the modern metropolis of Beijing and Tianjin, which was ruled as part of the Youzhou Prefecture in the Han period. The spread of stone carved tombs from the Central Plains to Youzhou can be divided into two stages. The first stage is the period before AD184, when the Yellow Turban Rebellions broke out. Tombs or related monuments of this period were constructed by masons from the Qi-Lu region. Some may have been migrants; others may have worked on temporary engagements with local patrons. For instance, the above-ground stone monuments attached to the tomb of Qin Jun near Beijing were, according to inscriptions on the pillar gates, executed in AD105 by mason Juyi 巨宜 from Lu 魯 in present-day Shandong Province (Fig. $2-25 a, b) .{ }^{38}$ In this case Shandong masons travelled or migrated to places more than 500 kilometres from their hometown. Another example is the tomb site excavated in Wuqing 武清 of Tianjian. Although this multi-chamber tomb was constructed from small bricks only, a stele was found in front of it. According to the inscriptions, the tomb belonged to a Han official Xianyu Huang 鮮于璜 (d. AD125), and the stele was erected in AD165. ${ }^{39}$ Images of animals of the four directions were carved on the stele above the main texts (Fig. 5-15a), a practice that was very common in the Central Plains. Moreover, a stone box carrying images that are very similar to examples in the Xuzhou region was excavated from the tomb chambers (Fig. 5-15b, c),

38 Wenwu 1964.11: 17. One of the inscription reads: “魯工石巨宜造 executed by craftsman Shi Juyi from Lu'. See section 4.5.1 of Chapter Four for more descriptions of funerary monuments of Qin Jun.

39 The title of the inscription reads: “漢故雁門太守鮮于君碑 Stele of Mr. Xianyu, former Prefect of Yanmen Commandery of the Han'. See Kaogu xuebao 1982.3: 351-365 for the report of Xianyu Huang's tomb and an interpretation of inscriptions on the stele. 
and a fragment that might have served as the roof of a que pillar gate has also been found at the tomb site (Fig. 5-15d). The stone box must have been buried in the tomb not too much later than Xianyu Huang's death in AD125, and the stele was carved and erected forty years later in AD165. These inscriptions indicate that during those decades, stone masons had been available in the Youzhou area, who very likely came from Shandong, as mason Juyi did.

The second stage is the period after AD184, when the peasant revolt broke out in the Central Plains. As a result, larger populations flowed into Youzhou during the Yellow Turban turmoil. Later in AD188, Liu Yu was appointed governor general of Youzhou, and he had to deal with the refugees:

青、徐士庶避黃巾之難歸虞者百餘萬口, 皆收視溫恤, 為安立生業, 流民皆忘其 遷徙。

Because of turmoil caused by the Yellow Turban rebels, more than one million numbers of elite and commoners of Qingzhou and Xuzhou fled to Youzhou to seek refuge under Liu Yu. Liu solicitously accommodated all of them, and all the refugees settled down and managed their livelihoods, reluctant to migrate anymore. ${ }^{40}$

Although the utopian descriptions of Liu Yu's rule of Youzhou is not very reliable and may include exaggeration, we learn that large numbers of refugees had fled to Youzhou, from Qingzhou and Xuzhou Commanderies, where there had been many stone carved tombs. Some of the refugees may have been masons, or patrons who favoured stone carved tombs.

Archaeological discoveries have indicated that tombs of these dates were relatively simple, and many of them were constructed mainly from bricks, but had

${ }^{40}$ Hou Hanshu: p. 2354. Translated by the author. 
stone columns, lintels or doors. For instance, a multi-chamber tomb built from carved stones has been found at Xiaomaozhuang 小毛莊, Jixian, near Tianjin. ${ }^{41}$ The Xiaomaozhuang tomb is constructed from sandstone slabs and small bricks. Buried in a three-metre deep pit are one front chamber, one middle chamber and one rear chamber connected to each other via short passage ways, several niches are also attached to the main chambers (Fig. 5-16a). Stone slabs were mainly used as tomb doors, columns and lintels, and all carry relief carvings of auspicious animals and servant figures. Some of the images were painted with red, yellow and black pigment (Fig. 5-16b). The Xiaomaozhuang tomb is the only intact stone carved tomb found in the Beijing-Tianjin region to date. In addition, two stone slabs together with a number of small bricks were excavated at Santaizi 三台子 village, Fengtai 丰台 District of Beijing. ${ }^{42}$ The stone slabs served as tomb doors of a masonry tomb, but unfortunately the original structures were completely destroyed, thus details of the tomb remain unknown. However, the carving techniques and image composition are quite similar to those of the Xiaomaozhuang tomb (Fig. 5-16b and Fig. 5-17). Presumably both tombs were carved in the same period, or by the same group of masons. It is impossible to date precisely the Xiaomaozhuang and Santaizi tombs, as archaeological evidence is too limited, but it is very likely that they were constructed at the end of the second century, according to their tomb plans ${ }^{43}$ and carving

\footnotetext{
41 Jixian 2005: 118-122.

42 Wenwu 1966.4: 53-54.

${ }^{43}$ The plan of the Jixian tomb is similar to that of the Wangdu tomb No. 2 (Fig. 5-18), except that it had fewer chambers. Wangdu tomb No. 2 was constructed from small bricks and was decorated with murals, but it has stone tomb doors, and a number of stone sculptures have been excavated from the chambers (Fig. 5-9a). This indicates that a number of stone masons
} 
techniques. It is not unlikely that these tombs were built by masons who fled to Youzhou during the time of turmoil. It is also possible that they were built by workshops set up by the group of masons who were already there from the early second century.

\subsection{Post-Han masonry tombs in Han borderlands}

Stone carved tombs and other similar masonry tombs were constructed in the borderlands not only during the late Han, but also in the centuries immediately following the fall of the Han Empire. Masonry tombs constructed in later periods had ground plans, structures, decorative motifs and burial objects similar to those of Han period stone carved tombs. To study post-Han masonry tombs in Han borderlands and further beyond, it is important to start by looking again at Eastern Han stone carved tombs, the arguable sources of later tombs. Some exceptional examples will be introduced and deserve special attention, as their major features were adapted in the post-Han period tombs.

A tomb belonging to an Eastern Han official, Miao Yu, was excavated near Pizhou 䂙州 of Jiangsu Province, bordering Shandong to the south. It has only one front chamber and one back chamber covered by stepped roofs, but it has a cloister-like tunnel surrounding the back chamber, with openings towards the front chamber (Fig. 5-21b). It is securely dated to AD151 according to inscriptions found in 
the tomb. ${ }^{44}$ The tomb in Pizhou carries elaborate relief images on its stone surfaces.

Among the large numbers of stone chamber tombs, there are several unusual examples, for instance the Houtun 後屯 tombs which were excavated in Dongping 東平 County of Shandong. ${ }^{45}$ Amongst the 18 tombs from the same cemetery, M1, M12 and M13 are the prominent ones, all constructed from stone slabs. Houtun M13 is the most complicated. It has a front chamber and two main chambers for the coffins. It also has a cloister-like tunnel enclosing the main chambers, with two openings towards the front chamber (Fig. 5-21c). All three tombs contain images of dancers, literati, and supernatural animals, but these are murals painted on polished stone surfaces, rather than relief images, which were more common in most Han stone chamber tombs (Fig. 5-25 and Fig. 1-6). The tombs date to the early first century AD.

Many of the Han period stone carved tombs have more than five chambers, with which later stone chamber tombs cannot be compared. For instance very few tombs in the Hexi Corridor or the Koguryo Kingdom have more than three chambers. The chambers of Han stone tombs are connected to each other by two methods: either separated by columns or linked with relatively narrow corridors. Moreover, varieties of roof types were used for their constructions. Apart from the simple flat roof, stepped roof and caisson roof, a fourth type, the truncated pyramid roof, ${ }^{46}$ was also popular during the Han, especially in Shandong. Most of the above elements were

\footnotetext{
${ }^{44}$ See Wenwu 1984.8: 22-29 for the report. The earliest known example that has the cloister-tunnel structure is Feng Rujiu's tomb near Nanyang, the date of which is AD18. See Kaogu хиеbao 1980.2: 239-262.

${ }^{45}$ For a detailed report see Dongping 2010.

${ }^{46}$ A truncated pyramid roof consists of four trapezoidal stone slabs to make a sloping type of vault, with a rectangular slab as the capstone.
} 
borrowed by their followers in other regions and in later periods of China, as will be discussed in the following sections.

\subsubsection{The Northeast: Liaodong region}

Liaodong is one area where Han type stone chamber tombs have been found. Tombs excavated in this region have been discussed in other studies. ${ }^{47}$ However, the significance of Liaodong's location has been ignored. Situated at the north of the Yellow Sea and the Bohai 渤海 Bay, Liaodong is narrowly connected to the North China Plain by land, and comes into contact with the Shandong Peninsula by sea. Xiangping 襄平, seat of Liaodong Commandery of the Han at the modern city of Liaoyang, was a transport hub to link central China with Koguryo to the east, and Lelang Commandery to the southeast (Map 5-4). During the Eastern Han period, Liaodong had a population bigger than those of the other northeast commanderies.

To date, around 30 stone chamber tombs have been excavated in the suburbs of Liaoyang, and 20 of them have been published. ${ }^{48}$ The earliest mural tombs near Liaoyang are dated to the early second century, but the number of tombs did not rise until the end of the second century, on evidence that a large proportion of the Liaoyang mural tombs are dated to this period. Most of such tombs are multi-chambered, constructed from shale slabs, with flat roofs supported by stone

\footnotetext{
${ }^{47}$ For two of the examples see Steinhardt 2002 and Jeon 2006. Both scholars have made comparisons between tombs in Central China, the Liaodong area and the Koguryo Kingdom. They have noticed the similarities between those tombs, but did not mention the geographical importance of Liaodong, or its relationship with late Han and post-Han political circumstances.

${ }^{48}$ Liu Wei 2004: 233.
} 
columns. Many of them have a tunnel-corridor surrounding the main chambers (Figs. 5-22a, c). All of these tombs were decorated with murals, which were directly painted on the surfaces of stone slabs. Such stone chamber tombs were popular from the end of the second century and continued down to the end of the Western Jin period (AD265-316), though the sizes of tombs slightly decreased.

The Shangwangjiacun 上王家村 tomb, dated from the late third century to the early fourth century, is relevant to the discussion. ${ }^{49}$ It is constructed from shale slabs, with a front chamber, two side chambers and two rear chambers (Fig. 5-22d). There are two columns inside the doorway, and another column in the right side chamber. The front chamber has a stepped caisson roof, the only known example in northeast China. Mural paintings of banqueting and mounted excursions are painted on the polished stone surfaces of the side chambers. Its date is later than any other mural tombs found near Liaoyang.

From the above examples, we can see that there are characteristics in Liaodong tombs which resemble those tombs of the Central Plains, especially the Shandong area. Plans and structures of most Liaodong tombs are similar to stone chamber tombs in Shandong. ${ }^{50}$ Tombs in both areas are multi-chambered, built from stone, though none of the Liaodong ones match the quality of the elaborate Shandong examples. The tunnel structure surrounding the rear chambers, which was common for Liaodong tombs, recalls examples in central China, such as Feng Rujiu's 馮孺久 tomb in Nanyang, Miao Yu's tomb in Pizhou, as well as Houtun M3 in Dongping mentioned

\footnotetext{
49 Wenwu 1959.7: 60-62.

${ }^{50}$ For a comparison of details see Fig. 5-22 and Fig. 5-21.
} 
above. There are also many similarities in the use of motifs, although in Liaodong tombs murals were painted instead of executing stone carvings. But all tombs near Liaoyang are surprisingly similar to the Houtun tombs in terms of plan, structure and size. More importantly, tombs in Liaoyang and Houtun all include murals painted on polished stone surfaces.

It is relatively clear that the emergence of stone chamber tombs in Liaodong was closely related to the late Han and post-Han political circumstances. When the Han Empire was in turbulence during the last decades of the second century, Liaodong was geographically separated from the Central Plains and thus was relatively at peace. Many refugees, some of whom may have been artisans, came to this region, and may have brought ideas and technologies required for building stone tombs. Consequently various structures and decoration motifs became available for patrons, and more stone chamber tombs were built. However, tombs near Liaoyang were smaller in size than the Shandong examples and had fewer tomb chambers. Probably the reason is simply that the financial situation of patrons in Liaodong was not as good as those of the Central Plains. Even the well-off patrons originally from central China had had to control their expenditure after fleeing to Liaodong because of difficulties in the new circumstances. This could also explain why murals were applied instead of relief images in Liaoyang tombs, as painting was obviously cheaper than carving stone.

The patrons and artisans may have come to Liaodong over land or by sea. Occasional sea links between the Shandong Peninsula and the Liaodong Peninsula started in prehistoric periods, and more proper voyages on the same route had 
flourished from the Warring States period. ${ }^{51}$ During the late Eastern Han, many officials as well as famous literati scholars fled to Liaodong by sea or even settled down according to historical texts. ${ }^{52}$ The artisans may also have come to Liaodong by land. As is mentioned above, some Shandong masons travelled or immigrated to Youzhou, roughly 500 kilometres distant from their hometown, so that it is not impossible for them to have moved slightly further to Liaodong.

In AD238, the Gongsun lineages were defeated by the state of Cao Wei 曹魏 (AD220-265), one of the Three Kingdoms, hence Liaodong became part of Cao Wei, later the Western Jin territories. Rulers of both dynasties advocated simple burials, and as a result, under their control, the Liaodong tombs became even simpler in structure and smaller in size. Shortly after the Jin court's evacuation to the south, in AD334, Liaodong was conquered by Xianbei forces, and in the early fifth century by the Koguryo. Consequently Xiangping was no longer an important Chinese outpost, and fewer Han style stone tombs were built. However, during the centuries of cultural interactions, Han structures and motifs were found in tombs that belonged to the Xianbei state of Yan, as well as those of the Koguryo kingdom who took over Liaodong.

\footnotetext{
${ }^{51}$ For a brief history of sea routes and maritime communications between Shandong and the Liaodong Peninsula, see Liu Fengming 2010.

${ }^{52}$ For instance, several famous scholar-officials, Guo Yuan, Bing Yuan and Guan Ning migrated to Liaodong Commandery during the Yellow Turban Rebellions. This is recorded in Guo Yuan's biography in the Sanguo zhi. ‘國淵…樂安蓋人也。…後與邴原、管寧等避亂遼 東。Guo Yuan was born in Gai county of Le'an Commandery (in present-day Shandong Province). He fled to Liaodong with Bing Yuan and Guan Ning to get away from turmoil of the Central Plains.' See Sanguo zhi: 339.
} 


\subsection{Further Northeast: the Koguryo Kingdom}

Archaeological discoveries within Northeast China and the Korean Peninsula, which are dated from the first to the seventh centuries, are as arresting as the cultural transformations mentioned at the beginning of this chapter. More than ten thousand stone tombs have been discovered on the northern Korean Peninsula, and a large proportion are stone chamber tombs. They are distributed mainly across two areas. The first region is the upper reaches of the Yalu River, near present-day Chinese towns of Ji' an and Huanren 桓仁, in Jilin 吉林 and Liaoning provinces respectively. The second group of tombs is located around the North Korean capital of Pyongyang 平壤, which was the seat of Lelang Commandery in the Han period, and the capital of the Koguryo Kingdom from AD427. ${ }^{33}$ Many of the tombs had one or more burial chambers constructed from stone, and are dated from the fourth to the seventh centuries AD.

The most published and studied tombs are the ones that were elaborately decorated with wall paintings. Up to 2008 , a total number of 115 tombs with murals have been excavated and published, 38 of which are located in present-day China, and the other 77 in North Korea. ${ }^{54}$ Within China, most of the stone tombs are buried under earthen mounds, while a few others have piled stones to form a stepped mound in the shape of a truncated pyramid. Two of the elaborate examples are the Wukuifen

\footnotetext{
53 The Koguryo capital was located at present-day Ji'an, but was later moved to Pyongyang in AD427, according to Samguk sagi: 225. The original text reads: ‘(長壽王)十三年, 移都平 壤。In the thirteenth year (of the reign of King Jangsu, namely AD427), the capital was moved to Pyongyang.'

${ }^{54}$ Geng Tiehua 2008: 7-11.
} 
五盔墳 tombs No. 4 and 5 near Ji'an, capital of Koguryo before AD427. They are both single chamber tombs, accessed by a passage way (Fig. 5-23a). Polished surfaces of granite walls and their ceilings are elaborately decorated with mural paintings of guardians, supernatural animals, lotus flowers and the four directional deities (Fig. 5-26a, b). Both tombs are dated to the sixth century. ${ }^{55}$ Another example is the Changchuan 長川 tomb No. 1 near Ji'an. It is a stone chamber tomb known for its Buddhist wall paintings, and is dated to the middle fifth century. ${ }^{56}$ Most of the well known mural tombs have large earthen mounds in the shape of flat-topped pyramids.

The second group of mural tombs were found in areas near Pyongyang and are all stone chambers buried under earthen burial mounds. One of the best known and most elaborate examples is the Anak 安岳 tomb No. 3, discovered in South Hwanghae Province 黃海南道 to the south of Pyongyang. It is constructed from stone, and has a front chamber, a main chamber with two side chambers, as well as two rear chambers. There is a corridor that surrounds the rear chambers, with one opening towards the corner of the main chamber (Fig. 5-24a). All chambers have caisson ceilings, supported by beams resting on several octagonal columns. On surfaces of most stone walls are paintings of tomb occupants, banquets, horses, excursions and buildings. The tomb is dated to AD357 according to inscriptions found inside it, and the tomb occupant was a Chinese general who spent his final years in Koguryo, according to Su Bai 宿白. ${ }^{57}$

\footnotetext{
${ }^{55}$ Kaogu 1964.2: 59-66 and Kaogu xиebao 1984.1: 121-136.

${ }^{56}$ For the archaeological report see Changchuan 1982. See Steinhardt 2002 for discussions on the North Asian contexts of the Changchuan tomb No. 1.

57 Su Bai 1952.
} 
The above examples are commonly known as Koguryo tombs, ${ }^{58}$ and belonged to elite members of the Koguryo society. But they were new to the Korean Peninsula from the fourth century, and they were also a major departure from the Koguryo tradition. Within the earlier territories of Koguryo, namely regions around Ji'an, traditional burial types were cairn graves. ${ }^{59}$ In areas near Pyongyang, namely the former Han Lelang Commandery, wooden tombs and brick tombs were used before the Koguryo conquest. In both areas, dolmens were erected from as early as the prehistoric period. ${ }^{60}$ Many scholars have worked on the origins of the Koguryo stone chamber tombs. Some argued that they were developed from traditional dolmen tombs or cairn graves ${ }^{61}$ but this is unlikely. The Koguryo tombs represented a transition of structures from vertical to horizontal tombs, thus dependence on earlier cairn tombs does not seem plausible. The emergence of spaces inside tombs for mural decoration is another innovation that was unlikely to be developed from earlier traditional forms.

Now most scholars agree that Eastern Han tombs were the sources for the Koguryo ones. There are indeed similarities between Han and Koguryo stone chamber

\footnotetext{
${ }^{58}$ It is important not to confuse the term 'Koguryo tombs' with 'tombs within Koguryo borders', as some of the tombs to be examined might belong to Chinese immigrants rather than Koguryo people. But in the following text all of them will be referred to as 'Koguryo tombs' for convenience.

59 A cairn grave was constructed by firstly piling gravels or pebbles above-ground to create a burial space, and then covering the whole structure with more rubble to form a pile. See Kaogu 1979.1: 27-32 and Kaogu 1991.7: 600-607 for examples of cairn graves.

${ }^{60}$ A dolmen is a type of stone structure usually constructed from three or more vertical stone slabs supporting one horizontal capstone. Within Northeast Asia, dolmens are found on the Korean Peninsula and coastal provinces of north and east China including Liaoning, Shandong and Zhejiang Provinces. It is often believed that dolmens were erected since the Neolithic period and were used as tombs or for other funerary purposes, though there are still a lot of unknowns, and no absolute chronology has been established.

${ }^{61}$ Kim Byong-mo 1976.
} 
tombs, though the Koguryo ones are much later. Comparisons have been made by scholars in terms of tomb structure and decoration motif. As discussed in works by Steinhardt and Liu Wei 劉未, ${ }^{62}$ stone chamber tombs in both Han and Koguryo had similar tomb structures, for instance many ceiling types and tomb plans of Eastern Han stone chamber tombs are found in Koguryo tombs as well. Jeon argues that tombs of China and the Korean Peninsula also shared many motifs, for example images of tomb occupants, excursions, banquets, dancers and acrobats, scenes of war, celestial bodies, supernatural animals and deities, in their mural decorations. ${ }^{63}$ Moreover, the material of stone used for tomb constructions in both Han and Koguryo is another similarity that seems obvious but should not be ignored, though decorations were represented in Han stone tombs mainly by relief carving, while in Koguryo by wall painting.

It seems fair to argue that, Koguryo tombs borrowed elements from Han tombs. However, the tombs' chronology is still an unsolved problem, as stone chamber tombs flourished on the Korean Peninsula at least a century after the fashion for stone chamber tombs had peaked in Central China. Thus the time gap between the Han and the Koguryo tombs needs to be bridged; therefore this chapter discusses Han tombs' delayed impact on Koguryo. Some other issues that have been neglected include, why did the Koguryo people copy Han tombs at all? The best solution to these questions is probably to start from looking at stone chamber tombs in the two regions.

\footnotetext{
${ }^{62}$ See Steinhardt 2001, 2002 and Liu Wei 2008.

63 Jeon 2006.
} 


\subsubsection{Huanren and Ji'an region}

Before the capital was moved to Pyongyang in AD427, the centre of Koguryo rule was at Ji'an. Traditional burials for the Koguryo people in this area were cairn graves that were constructed by piling up rubble (Fig. 5-27). More complicated forms of cairn tombs include extra stone blocks piled upon the burial, to construct a stepped mound in the shape of a flat-roofed pyramid (Fig. 5-28a, b). Such tomb types already existed probably before the foundation of Koguryo Kingdom.

The earliest stone chamber tombs in the Koguryo territory were something in between cairn graves and the famous mural chamber tombs mentioned above. The Wanbaoting 萬寶汀 tomb No. 242 near Ji'an is such an example. ${ }^{64}$ Its form is a flat-roofed pyramid 45 metres long, 17 metres wide and 1.4-3.5 metres high. Within this stepped stone mound were two cairn graves and two stone chamber tombs. This tomb is dated to the late third century, and marks the beginning of stone chamber tombs in the Ji'an region. From the end of the third century onwards, stone chambers buried within stepped stone mounds became popular, and sometimes remains of wall paintings were found on such tomb walls. Both cairn tombs and stone chamber tombs buried under piled stones were used in parallel until the fifth century.

From the middle fourth century, stone chamber tombs buried under earthen mounds emerged, and continued to be constructed until the early seventh century. Such tombs have been extensively described and studied, but their chronologies are not clear. Unlike the tombs of Central Plains, in this area structures and objects with

${ }^{64}$ Kaogu yu wenwu 1982.6: 16-19 and 28. 
absolute dates are rare, and chronologies are mainly based on stylistic studies. One of the earliest examples, the Tonggou 通溝 tomb No. 12, which is dated to the fifth century, includes two burials under the same tomb mound. The larger one of the two has a main chamber accessed by a passage chamber with two side chambers at both sides (Fig. 5-23b). The main chamber is covered by a stepped roof, which is common among Han tombs in Shandong area. The sixth century tombs Wukuifen No. 4 and 5 mentioned above are both single chamber tombs accessed by passage ways, and each has an overlaid diamond roof (Fig. 5-23a). Many features that are shared in such mural tombs are traced from stone chamber tombs in central China and Liaodong, as discussed above.

Another sixth century tomb that belonged to a member of the Koguryo elite, Ran $\mathrm{Mu}$ 再牟, is one of the double chamber tombs found near Ji'an (Fig. 5-23c). Like many other Koguryo tombs, its rear chamber has a stepped caisson ceiling. The roof of the front chamber, however, is in the shape of a truncated pyramid, which is rare among tombs near Ji'an, but is common enough for Han stone tombs in Shandong. Both chambers are square, constructed from neatly shaped stones, and are connected to each other through a short passage way, which was again popular for Han tombs in the Central Plains. Surfaces of this tomb were plastered, but did not carry wall paintings except inscriptions narrating the life and achievements of the tomb occupant. The Changchuan tomb No. 1 is also a double chamber tomb similar to Ran Mu's tomb, except that both chambers have stepped caisson ceilings instead of truncated pyramid vaults. 
Based on the above descriptions of tombs of different periods we can conclude that, burials for Koguryo elites were transformed from cairn tombs to chamber tombs within stone pyramids, and finally to stone chamber tombs under earthen mounds. It should be pointed out that, the different developmental stages refer to dates when certain types of tomb appeared. After the emergence of stone chamber tombs buried under earthen mounds, cairn graves and stone chambers buried within piled stones were not abandoned. In fact nearly a half of Koguryo tombs near Ji'an are tombs buried within piled stones. ${ }^{65}$ Old and new tomb types were used in parallel until the late fifth century, after which all elite Koguryo tombs were constructed as stone chambers buried under earthen mounds. ${ }^{66}$ And indeed in many cases stone and earthen mounds were piled up within the same cemetery (Fig. 5-30).

It is very likely that, the evolution of tomb structures is again related to the political circumstances of that period. In the fourth century, Koguryo attacked some of the Han commanderies to expand their territory. They raided Xuantu in AD302, conquered Lelang in AD313, and around ten thousand Han people were forced to move to Koguryo (Map 5-5a, b). ${ }^{67}$ Then they continued with the same policy over the following decades: in AD385, Koguryo invaded Xuantu and Liaodong again, ${ }^{68}$ and

\footnotetext{
${ }^{65}$ Kaogu xuebao 1980.2: 166.
}

${ }^{66}$ See Chart 5-1. Chronologies are based on Liu Wei 2008, Wei Cuncheng 2002 and Zhao Junjie 2009 with minor corrections.

${ }^{67}$ Samguk sagi: 216. The original text reads: ‘(烽上王)十四年冬十月, 侵樂浪郡, 虜獲男女 二千餘。In the tenth month of the fourteenth year (of King Bongsang reign, namely AD313), Koguryo invaded Lelang Commandery and captured more than two thousand men and women.'

${ }^{68}$ Samguk sagi: 222. The original text reads: ‘(故國壤王)二年夏六月, 王出兵四萬襲遼東… 陷遼東、玄菟, 虜男女一萬口而還。In the sixth month of the second year (of King Gogugyang, namely AD385), the king led an army of 40,000 to invade Liaodong ... The 
eventually took Liaodong over in the early fifth century. This period was a turning point of the emergence of stone chamber tombs. The Koguryo came into conflict with Han forces, and many times captured Han people, among whom may have been artisans with knowledge of stone chamber tombs or mural paintings. This explains why the transfer of Koguryo tomb structures happened in the fourth and fifth centuries, when there were continuous interactions between Han commanderies and the Koguryo Kingdom.

\subsubsection{The Pyongyang region}

Before the conquest by Koguryo, Pyongyang was very likely the main seat of the Han Lalang Commandery. During the early years of Han rule, major burial types in this region were either wooden coffins or kwitul mudom (Korean language), which were wooden chambers built of angular logs that sometimes contained a double or triple burial. ${ }^{69}$ From around the second century, burial structures changed to brick chamber tombs that were accessed through horizontal tunnels or ramps, and had one or two rooms with side chambers and vaulted ceilings. Such tombs continued to be built after the fall of Lelang, until the mid-fourth century.

Although Koguryo took over Lelang in the early fourth century, lands of this former Han commandery remained culturally Chinese for a long time. Koguryo was stuck in wars with the Xianbei in the north, their capital Wandu 丸都 (Ji'an) was

Koguryo defeated Han forces in Liaodong and Xuantu, capturing ten thousand men and women and then came back.'

${ }^{69}$ Erickson et al. 2010: 139. 
even once sacked in AD342. ${ }^{70}$ Thus Koguryo could not rule Lelang efficiently, and large numbers of Han Chinese remained in Lelang. Most masonry tombs constructed before the fifth century belonged to Chinese, as many of the tomb occupants used official titles of the Eastern Jin 晉 (AD317-420) to show their identity, or used Eastern Jin reign names to record dates. ${ }^{71}$ One of the best examples is the Anak tomb No. 3 mentioned above, which belonged to Dong Shou 冬壽. Its stone chambers and wall paintings resemble Han stone tombs in Liaodong and Shandong. The corridor surrounding the rear chamber is an element that can be seen in many tombs of Liaodong and Central China. The stepped caisson roof, which was used in the Shangwangjiacun tomb near Liaoyang, can be seen in the front chamber, the main chamber and the side chambers of the Anak tomb No. 3 (Fig. 5-24a). Obviously the builders borrowed features from the Liaodong tombs (the date of this tomb is later than the Shangwangjiacun tomb). This view is reinforced by the tomb occupant's background. According to analyses based on ancient texts Jinshu 晉書 and Zizhi tongjian 資治通鑑 by $\mathrm{Su}$ Bai, ${ }^{72}$ Dong Shou was a Chinese general who was originally from Liaodong, but fled to Koguryo in AD336, after the conquest of Liaodong by the Xianbei in AD334. During the years before his death, there were continuous conflicts between Koguryo and the Xianbei state of Former Yan

\footnotetext{
70 ‘(慕容徨)發美川王墓, 載其屍, 收其庫府累世之寶, 虜男女五萬餘口, 燒其宮室、毀 丸都城而還。(Murong Huang, leader of the Xianbei forces) opened the tomb of King Micheon of Koguryo, and took his body out. Murong has also looted reassures in the Koguryo warehouses, captured more than 50,000 men and women, then burnt the Koguryo palaces, destroyed the Wandu city, and returned to the Xianbei land.' See Samguk sagi: 220.

${ }^{71}$ See Zhao Junjie 2009: 113-131 for further discussions on Han communities around Pyongyang after the Koguryo conquest.

${ }^{72}$ See Su Bai 1952.
} 
(AD337-370), during which Koguryo attacked Liaodong several times and seized Han people. It is very likely that Dong Shou was aware of the ideas and technologies of building stone chamber tombs, and thus asked Koguryo craftsmen, or even Chinese masons, to construct a Liaodong style tomb for him.

In the early fifth century, Koguryo took Liaodong from the hands of the Xianbei. And in AD427, the capital of Koguryo was moved from Ji'an to Pyongyang, after which the lower reaches of the Taedong River 大同江 gradually became the centre of Koguryo culture. Consequently, larger numbers of stone chamber tombs were built around Pyongyang. Most of the tomb occupants were Koguryo people, or Han Chinese who had been assimilated within Koguryo society. ${ }^{73}$ Many of the tombs had features that can be traced to tombs in Shandong, Liaodong and the former Lelang commandery, but have Koguryo characteristics as well. A stone chamber tomb found at Sunchon 順川 to the north of Pyongyang, ${ }^{74}$ is one of the many examples of tombs belonging to Koguryo people. It has a front chamber with two tomb doors facing south and two small chambers at both sides, and four back chambers in parallel (Fig. $5-24 b)$. The tomb was constructed from gneiss blocks, and many of the tomb walls carry murals, among which the most important one was painted on the south wall of the front chamber, between the tomb doors. It depicts a walled city with a caption stating Liaodong Cheng 遼東城, literally the city of Liaodong. Here the Liaodong Cheng was actually the former Han town of Xiangping, which was renamed 'Liaodong' after the Koguryo conquest. It is very likely that the tomb occupants were

\footnotetext{
${ }^{73}$ Zhao Junjie 2009: 109-112.

${ }^{74}$ Kaogu 1960.1: 54-58.
} 
closely related to the battles at Liaodong mentioned above. ${ }^{75}$ This tomb was constructed during the middle fifth century, after the Koguryo conquest of China's Liaodong Commandery, and is commonly known as the Liaodong Cheng tomb because of the mural. The plan of the tomb is unusual but can be traced back to the tombs in the Liaodong region. Its ceiling structures and mural motifs have elements borrowed from the Central Plains.

As in the Ji'an region, there are also many single chamber tombs in the Pyongyang area. The Tokhwa-ri 德花里 tomb No. 2 is such an example among the relatively late Koguryo mural tombs. It is one of the three stone chamber tombs excavated in Taedong County 大同郡 to the west of Pyongyang, and has only one chamber accessed by a passage way (Fig. 5-24c). The stepped ceiling of this tomb is probably developed from Chinese examples, but is much more complicated. The lower part of the ceiling is a two-layered stepped corbel, and its upper part is formed by five layers of octagons of decreasing size, covered by an octagonal slab. The ceiling is decorated with paintings of constellations, a motif that was commonly depicted in Han tombs of Henan Province. The whole tomb structure is buried under an earthen mound in the shape of a truncated pyramid. The excavators, cited in Zhao Junjie 2009, believe that it was constructed during the early sixth century. ${ }^{76}$

Most of the stone chamber tombs in the Pyongyang region that dated from the fifth to the seventh centuries have elements borrowed from tombs of Liaodong as well as the Central Plains. After the relocation of the Koguryo capital to Pyongyang, the

\footnotetext{
75 Yu Weichao 1960.

${ }^{76}$ Zhao Junjie 2009: 20.
} 
idea of building stone chamber tombs spread to the northern part of the Korean Peninsula, and they continued to be built until the seventh century, when the Koguryo kingdom was conquered (Chart 5-1).

\subsubsection{Behind selection and assimilation}

Although the Koguryo people took the practice of constructing stone chamber tombs from China and borrowed many features from Chinese sources, the Koguryo also made unique contributions. The Changchuan tomb No. 1 mentioned above is the best example. The stepped ceiling of its back chamber can be traced back to similar Han stone tomb roofs, but the front chamber roof is much more complicated and carries more decoration. It has four parallel layers of decreasing square perimeters as other stepped ceilings, but all four corners of the lower three layers are reinforced with a right-angled triangle (Fig. 5-31). The roof style of the Tokhwa-ri tomb No. 2 may have been developed from the Ji'an examples, but was even more intricate. The lower part of the ceiling is similar to many other tombs in Ji' an and in central China, but the upper part has five layers of octagons, a pattern that had never been used in Han tombs. Another development is that, after the official adoption of Buddhism in AD 375, ${ }^{77}$ more and more Buddhist elements were deployed in Koguryo tombs. For example murals of the Buddha and bodhisattvas were painted in the Changchuan tomb No. 1, and more images of lotus flowers can be seen, especially on tomb

\footnotetext{
77 ‘(小獸林王)五年春二月, 始創肖門寺 $\cdots$ 又創伊弗蘭寺…此海東佛法之始。In the second month of the fifth year (of the reign of King Sosurim, namely AD375), Buddhist temples Xiaomen and Yifulan were established. This marks the beginning of Buddhism in Koguryo.' See Samguk sagi: 221.
} 
ceilings, for instance in the Tokhwa-ri tomb No. 2.

Moreover, though most Koguryo tombs were constructed from stone like the Han ones, there were innovations in building materials. New types of stone, including shale, gneiss and even granite, were used for tomb construction, while in the Central Plains most stone tombs were constructed from limestone or sandstone. The Wukuifen tombs mentioned above were constructed from neatly dressed granite blocks, both for chamber walls and for their high ceilings. This indicates an improvement of masonry tools, given granite is harder and more difficult to carve than limestone and sandstone, which were commonly used by the Chinese. The Koguryo people must have also used better mechanisms to hoist the roof blocks, as granite is relatively dense compared with most other types of construction stone. Lastly, when Koguryo tomb structures were built, they were buried under an earthen mound in the shape of a flat-topped pyramid. This is another unique characteristic of Koguryo tombs. Such mound appearances are similar to the stone truncated pyramids previously used in the Ji'an area, and might be an imitation of traditional Koguryo piled stone tombs rather than Chinese examples: In the Eastern Han period, mounds of most stone carved tombs were round. 


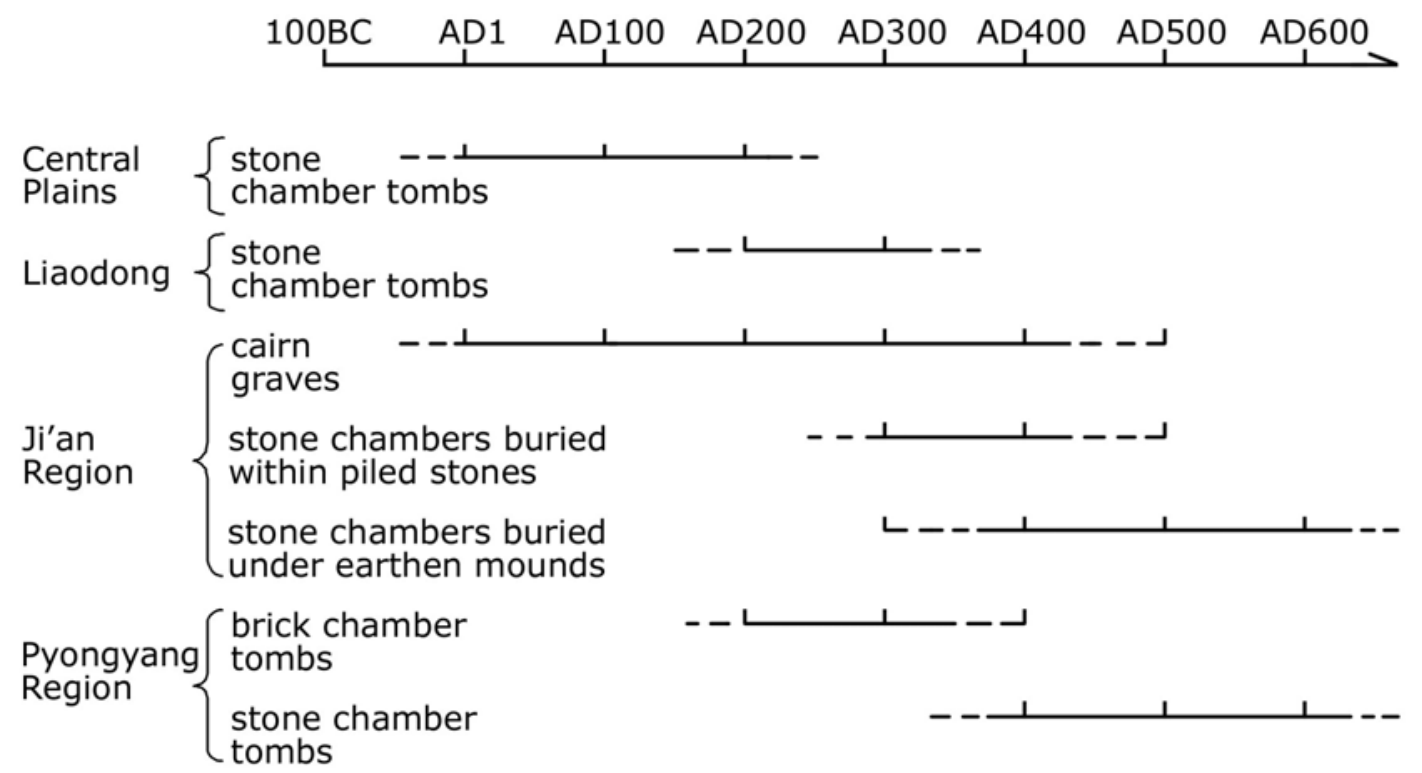

Chart 5-1, chronological development of different tomb types in the Central Plains, Liaodong, Ji'an and Pyongyang areas

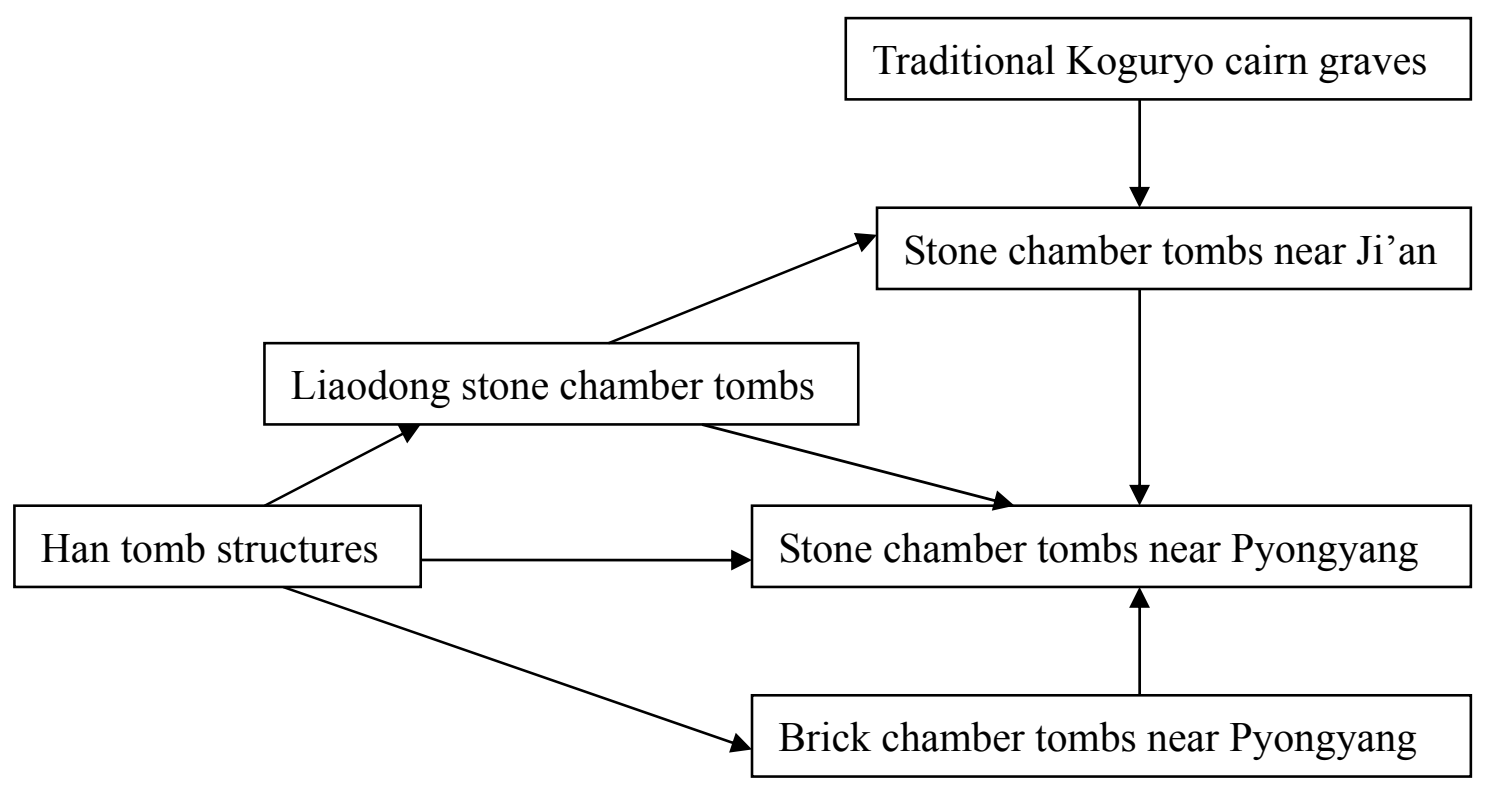

Chart 5-2: possible routes and borrowing relations of the spread of stone chamber tombs in Northeast Asia 
The Koguryo people borrowed features from Han Chinese stone tombs as well as many other ideas that gradually spread to the Korean Peninsula. However, they did not simply make identical copies of outside examples, but added their own creativity, and thus foreign elements were assimilated within the Koguryo system. ${ }^{78}$ More interesting questions are, what do such patterns imply, and what are the causes behind these facts? It is important to find out why the Koguryo people borrowed Han examples at all, and how they choose what to take from the Han.

The spread of stone chamber tombs happened in the process of the foundation of the Koguryo Kingdom, during which Han China played a role, bringing ideas and technologies to the Korean Peninsula. During the conflicts and communication between China and Koguryo, large numbers of Han people moved in, and were engaged in every aspect of the Koguryo society. More importantly, the Koguryo court frequently paid tribute to the more powerful Chinese dynasties ruling central China, ${ }^{79}$ consequently ideas and material cultures, including building stone chamber tombs, were dominant and influential in Koguryo. Before the fourth century, Koguryo people used stone to construct their cairn graves, so that it is not difficult for them to switch to Han style chamber tombs, which were built from stone as well.

Several social and political possibilities may also supply relevant explanation. In many Koguryo cairn graves that are located along the Yalu River, traces of fire are found. Also remains of cremated bones and shrunken ceramics have been discovered

\footnotetext{
78 The possible routes and borrowing relations of the spread of stone chamber tombs in Northeast Asia are shown in Chart 5-2, and chronologies of various tomb types are shown in Chart 5-1.

${ }^{79}$ See Samguk sagi: $192-193$ and 225-244 for a series of records.
} 
among burnt tomb stones. For instance at Dongdapo 東大坡 tomb No. 356 of Ji'an, burnt pebbles were found, and molten bronzes were stuck together with burnt gravels, caused by the shrinkage when the pieces cooled. ${ }^{80}$ Archaeologists believe that these are cremation activities rather than accidents or due to tomb lootings. A more interesting example is the Wanbaoting tomb No. 242 mentioned above, which has two cairn graves and two chamber tombs buried within one rubble mound. Remains of cremated bones together with burnt gravels have been excavated from the cairn graves, while no evidence of firing can be seen in the stone chambers. And indeed in the Ji'an area cremation traces have been found only in cairn tombs, not in stone chamber tombs, which means that cremation was a tradition closely related to cairn graves. This suggests a transition of afterlife beliefs and burial practices, from cremation to body preservation in tomb chambers.

In the Ji'an region, Koguryo people simply switched from cairn graves to stone chamber tombs buried under either stone or earthen mounds, as mentioned above. On the other hand, in the other major distributional area of Koguryo stone chamber tombs, the Pyongyang region, the process of transformation of tomb structures was different. During the Lelang Commandery era, the most important tomb type for Han people around Pyongyang were wooden tombs and brick tombs. But in the early third century, people in this area ceased building brick tombs and started constructing stone tombs instead. Moreover, all of the stone chamber tombs near Pyongyang were buried under earthen mounds, while in the Ji'an region a small proportion was buried under piled

${ }^{80}$ Kaogu 1991.7: 602. 
stones. The fact that Koguryo tombs near Ji'an and Pyongyang developed differently were probably due to other reasons.

Indeed there was a tradition of cairn graves for the Koguryo in their early years, and they started constructing stone chamber tombs within piled stone mounds during their Ji'an period in the late third century. However, burying stone chamber tombs under earthen mounds gradually became standard in the fifth century (Chart 5-1). As a result, when the capital was moved to Pyongyang, the stone chamber and earthen mound tradition was brought to the Korean Peninsula. Such chamber tombs dominated, taking the place of previous brick chamber tombs that were popular among the Han Chinese. Constructing stone chamber tombs with murals may also be a way of representing their Koguryo identity, given that many Han people remained in their former Lelang Commandery and constructed lots of brick tombs which were standard during the Chinese Southern Dynasties.

Koguryo tomb structures changed continuously from the third to the fifth centuries, in the same period when the kingdom was developing, while stone chamber tombs with earthen mounds gradually became popular from the fifth century to the seventh century, when the Koguryo kingdom was at its peak. Such tombs reflected a mixture of characteristics as well as flows of people and culture, and were closely related to political circumstances of that period.

\subsection{Conclusion}

The dominance and influence of Chinese material culture among other East Asian 
states, especially Korea, was significant. Connections between China and the Korean Peninsula from the Warring States period can be supported by textual and material evidence. For instance, well established contacts are evident in bronze mirrors, coins, and fortified cities discovered in both regions. ${ }^{81}$

Chinese influences had a remarkable impact on stone tomb constructions as well. Assimilating West Asian ideas, technologies and motifs, Han Chinese created stone chamber tombs, which set a model for tomb structures and imagery styles of other regions of China and later periods of Chinese history. Such stone chamber tombs with pictorial decorations began at the end of the first century $\mathrm{BC}$, and became mainstream in Northeast Asia during the first two or three centuries AD. Together with other traditions such as cairn graves, brick tombs and timber coffin burials, they supplied all kinds of possibilities. However, every patron and artisan had his own interest and choices, which formed the complexity of the stylistic structures of Northeast Asian tombs. People's requirements in terms of ritual, economy and identity were the leading impetus, and their command of burial knowledge and technologies helped in making choices.

Chinese influences moved further, spreading to not only Koguryo but also kingdoms to its south, such as the Paekche 百濟, where masonry chamber tombs were built from the fifth century, and were favoured by the ruling class of the Paekche until it was conquered in AD660. These tombs show signs of Chinese influences, such as

${ }^{81}$ See Horlyck 2002: 48-53 for the spread and assimilation of Chinese bronze mirrors in early Korea, and Wei Cuncheng 2002: 214-224 for descriptions of Koguryo burial objects, many of which reflected borrowed features from China, or were directly imported from China. 
styles of construction and burial objects including Chinese coins and bronze mirrors.

Moreover, there was a possibility that the styles of Northeast Asian stone chamber tombs were to some extent reflected in the Japanese kofun 古墳 tumuli. ${ }^{82}$ The spread of stone chamber tombs in Northeast Asia is presented as a part of a long history of interactions between different parts of Eurasia.

82 Okauchi 1986. 


\section{Conclusion}

This thesis aims to examine the use of stone in tomb architecture of the Han Dynasty, and raises several questions that no-one has really discussed before. Where this thesis has differed from previous studies is two-fold. Firstly, it argues for a need to look at the stone tombs as a whole rather than as individual decorated stones which have been the focus of much earlier research. Secondly, the emergence of stone tombs in Han China is surprising, since there is no real history of using stone in pre-Han China. As a result, there is a need to cover a broad cross-section of Han stone tombs rather than concentrating on a few, something that has not been attempted previously in Western literature.

Based upon a wide range of textual and archaeological materials, I have reconstructed the construction process of the stone carved tombs. No one has written about this before. Preliminary studies with regard to manpower and logistics of construction have been conducted to illustrate their economic implications. From the creation of such tomb structures, it is possible to understand their characteristics and their meanings to Han people: stone carved tombs were hybrids of different techniques, including timber, brick and stone works. From these variations, Han people could choose certain types of tombs to satisfy their specific ritual and economic needs.

This thesis also examines stone carved tombs as a whole rather than different 
sets of materials in isolation. Pictorial decorations of stone carved tombs were innovations of Han China. Although there are differences between these stone carved tombs, the range of motifs of images is quite limited. Similar motifs can be found in every region and in almost every tomb. Such similarities of images as well as combinations were of course partly due to reasons of artisans, who worked in well organised workshops and used well-prepared repertoires of stencils and patterns for the carving of images. But these also suggest that the tombs were decorated for certain purposes with a given functional template. The images carved on stone tombs were not merely images, but were understood by the Han people as equivalents of real objects. Together with different patterns of burial objects and their settings, such images formed a way through which people of the Han period have attempted to give meaning to their world.

I have presented arguments for Eastern Han stone carved tombs developing in imitation of Western Han kingly rock-cut tombs, which were themselves an introduction from Iran. It is further argued that other Western models influenced the details and development of stone carved tombs, including different forms of roofing and types of columns, and associated decorative elements such as above-ground sculptures as well as some motifs used in interior carvings. Such features were normally adapted rather than adopted wholesale, and they were incorporated into the Chinese ritual, ideological and institutional systems, to create a good afterlife for the dead. It is also argued that exotic elements conveyed power through rarity and difficulty of access. 
After their heyday, stone carved tombs ceased being constructed in the Central Plains as the Han Empire collapsed. However, they set a model for later tombs. Therefore in the final main chapter I have examined the ways how stone carved tombs were carried forward, based upon an integration between the historical situation and the stone tombs. The idea of building horizontal stone chamber tombs spread to Han borderlands, and gradually went further east to the Korean Peninsula. The legacy and spread of the Chinese masonry tradition was closely related to the political circumstances of late Han and post-Han period. The spread of stone chamber tombs in Northeast Asia is therefore presented as a part of a long history of interactions between different parts of Eurasia.

The present research is the first step of my study on the transformation of Chinese tomb structures, as well as interactions between Central China and other parts of Eurasia, during and after the Han period. This is the end of my thesis, but just a beginning of many other questions that deserve another, or several, thesis-scale researches. 


\section{Appendix I: Catalogue of Examined Stone Carved Tombs}

\section{Part I: the Qi-Lu Region}

\begin{tabular}{|c|c|c|c|c|c|c|c|}
\hline Name of Tomb & Location & Dating & $\begin{array}{l}\text { Construction } \\
\text { Material }\end{array}$ & Roof Type & Plan & $\begin{array}{l}\text { Year of } \\
\text { Excavation }\end{array}$ & Source \\
\hline $\begin{array}{l}\text { Dongjiazhuang } \\
\text { 董家莊 tomb }\end{array}$ & $\begin{array}{l}\text { Anqiu, } \\
\text { Shandong }\end{array}$ & Late Eastern Han & Stone & $\begin{array}{l}\text { Truncated } \\
\text { pyramid roof }\end{array}$ & $\begin{array}{l}\text { The figure originally presented here } \\
\text { cannot be made freely available via } \\
\text { ORA for copyright reasons. }\end{array}$ & 1959 & $\begin{array}{ll}\text { Wenwu } & 1960.5 \\
\text { Wenwu } & 1964.4 ; \\
\text { Anqiu } 1992\end{array}$ \\
\hline $\begin{array}{l}\text { Houtun 後 屯 } \\
\text { tomb No. } 12\end{array}$ & $\begin{array}{l}\text { Dongping, } \\
\text { Shandong }\end{array}$ & Early Eastern Han & Stone & Flat roof & $\begin{array}{l}\text { The figure originally presented here } \\
\text { cannot be made freely available via } \\
\text { ORA for copyright reasons. }\end{array}$ & 2007 & Dongping 2010 \\
\hline $\begin{array}{l}\text { Houtun tomb No. } \\
13\end{array}$ & $\begin{array}{l}\text { Dongping, } \\
\text { Shandong }\end{array}$ & Early Eastern Han & Stone & Flat roof & $\begin{array}{l}\text { The figure originally presented here } \\
\text { cannot be made freely available via } \\
\text { ORA for copyright reasons. }\end{array}$ & 2007 & Dongping 2010 \\
\hline
\end{tabular}




\begin{tabular}{|c|c|c|c|c|c|c|c|}
\hline Name of Tomb & Location & Dating & $\begin{array}{l}\text { Construction } \\
\text { Material } \\
\end{array}$ & Roof Type & Plan & $\begin{array}{l}\text { Year of } \\
\text { Excavation } \\
\end{array}$ & Source \\
\hline $\begin{array}{l}\text { Wangdu 望 都 } \\
\text { tomb No. } 2\end{array}$ & $\begin{array}{l}\text { Wangdu, } \\
\text { Hebei }\end{array}$ & AD182 & Stone and brick & Barrel vault & $\begin{array}{l}\text { The figure originally presented here } \\
\text { cannot be made freely available via } \\
\text { ORA for copyright reasons. }\end{array}$ & 1955 & Wangdu 1959 \\
\hline $\begin{array}{l}\text { Yinan 沂南 tomb } \\
\text { No. } 1\end{array}$ & $\begin{array}{l}\text { Yinan, } \\
\text { Shandong }\end{array}$ & Late Eastern Han & Stone & $\begin{array}{l}\text { Caisson roof; } \\
\text { stepped } \\
\text { caisson roof }\end{array}$ & $\begin{array}{l}\text { The figure originally presented here } \\
\text { cannot be made freely available via } \\
\text { ORA for copyright reasons. }\end{array}$ & 1954 & Yinan 1956 \\
\hline
\end{tabular}




\begin{tabular}{|c|c|c|c|c|c|c|c|}
\hline Name of Tomb & Location & Dating & $\begin{array}{l}\text { Construction } \\
\text { Material } \\
\end{array}$ & Roof Type & Plan & $\begin{array}{l}\text { Year of } \\
\text { Excavation } \\
\end{array}$ & Source \\
\hline $\begin{array}{l}\text { Chefushan 車夫山 } \\
\text { tomb }\end{array}$ & $\begin{array}{l}\text { Pizhou, } \\
\text { Jiangsu }\end{array}$ & $\begin{array}{l}\text { Middle to late } \\
\text { Eastern Han }\end{array}$ & Stone and brick & $\begin{array}{l}\text { Barrel vault } \\
\text { and flat roof }\end{array}$ & $\begin{array}{l}\text { The figure originally presented here } \\
\text { cannot be made freely available via } \\
\text { ORA for copyright reasons. }\end{array}$ & 1998 & $\begin{array}{l}\text { Dongnan wenhua } \\
\text { 1999.2; } \\
\text { Dongnan wenhua } \\
\text { 2006.2; } \\
\text { Huaxia kaogu } \\
2003.3\end{array}$ \\
\hline $\begin{array}{l}\text { Cangshan 蒼 山 } \\
\text { tomb }\end{array}$ & $\begin{array}{l}\text { Cangshan, } \\
\text { Shandong }\end{array}$ & AD151 & Stone & Caisson roof & $\begin{array}{l}\text { The figure originally presented here } \\
\text { cannot be made freely available via } \\
\text { ORA for copyright reasons. }\end{array}$ & 1973 & Kaogu 1975.2 \\
\hline
\end{tabular}




\begin{tabular}{|c|c|c|c|c|c|c|c|}
\hline Name of Tomb & Location & Dating & $\begin{array}{l}\text { Construction } \\
\text { Material }\end{array}$ & Roof Type & Plan & $\begin{array}{l}\text { Year of } \\
\text { Excavation }\end{array}$ & Source \\
\hline $\begin{array}{l}\text { Jiunüdun 九女墩 } \\
\text { tomb }\end{array}$ & $\begin{array}{l}\text { Suining, } \\
\text { Jiangsu }\end{array}$ & Late Eastern Han & Stone and brick & $\begin{array}{l}\text { (Probably) } \\
\text { barrel vault }\end{array}$ & $\begin{array}{l}\text { The figure originally presented here } \\
\text { cannot be made freely available via } \\
\text { ORA for copyright reasons. }\end{array}$ & 1954 & $\begin{array}{l}\text { Kaogu tongxun } \\
1955.2\end{array}$ \\
\hline $\begin{array}{l}\text { Tomb of Miao Yu } \\
\text { 繆宇 }\end{array}$ & $\begin{array}{l}\text { Pizhou, } \\
\text { Jiangsu }\end{array}$ & AD151 & Stone & Stepped roof & $\begin{array}{l}\text { The figure originally presented here } \\
\text { cannot be made freely available via } \\
\text { ORA for copyright reasons. }\end{array}$ & 1982 & Wenwu 1984.8 \\
\hline $\begin{array}{l}\text { Mengzhuang } \\
\text { 孟莊 tomb }\end{array}$ & $\begin{array}{l}\text { Pingyin, } \\
\text { Shandong }\end{array}$ & Late Eastern Han & Stone & $\begin{array}{l}\text { Truncated } \\
\text { pyramid roof }\end{array}$ & $\begin{array}{l}\text { The figure originally presented here } \\
\text { cannot be made freely available via } \\
\text { ORA for copyright reasons. }\end{array}$ & 1986 & Wenwu 2002.2 \\
\hline
\end{tabular}




\begin{tabular}{|c|c|c|c|c|c|c|c|}
\hline Name of Tomb & Location & Dating & $\begin{array}{l}\text { Construction } \\
\text { Material }\end{array}$ & Roof Type & Plan & $\begin{array}{l}\text { Year of } \\
\text { Excavation }\end{array}$ & Source \\
\hline $\begin{array}{l}\text { Changli 昌 梨 } \\
\text { tomb No. } 1\end{array}$ & $\begin{array}{l}\text { Donghai, } \\
\text { Jiangsu }\end{array}$ & Late Eastern Han & Stone & Caisson roof & $\begin{array}{c}\text { The figure originally presented here } \\
\text { cannot be made freely available via } \\
\text { ORA for copyright reasons. }\end{array}$ & 1957 & $\begin{array}{l}\text { Wenwu cankao } \\
\text { ziliao } 1957.12\end{array}$ \\
\hline $\begin{array}{l}\text { Lalishan 拉犁山 } \\
\text { tomb No. } 1\end{array}$ & $\begin{array}{l}\text { Xuzhou, } \\
\text { Jiangsu }\end{array}$ & Late Eastern Han & Stone & $\begin{array}{l}\text { Caisson roof } \\
\text { and stepped } \\
\text { roof }\end{array}$ & $\begin{array}{c}\text { The figure originally presented here } \\
\text { cannot be made freely available via } \\
\text { ORA for copyright reasons. }\end{array}$ & 1985 & $\begin{array}{l}\text { Zhongguo } \\
\text { kaoguxue } \\
\text { nianjian } 1986\end{array}$ \\
\hline $\begin{array}{l}\text { Lalishan 拉犁山 } \\
\text { tomb No. } 2\end{array}$ & $\begin{array}{l}\text { Xuzhou, } \\
\text { Jiangsu }\end{array}$ & Late Eastern Han & Stone & Stepped roof & $\begin{array}{c}\text { The figure originally presented here } \\
\text { cannot be made freely available via } \\
\text { ORA for copyright reasons. }\end{array}$ & 1988 & $\begin{array}{l}\text { Zhongguo } \\
\text { kaoguxue } \\
\text { nianjian } 1990\end{array}$ \\
\hline
\end{tabular}




\begin{tabular}{|l|l|l|l|l|l|l|}
\hline Name of Tomb & Location & Dating & $\begin{array}{l}\text { Construction } \\
\text { Material }\end{array}$ & Roof Type & Plan & $\begin{array}{l}\text { Year } \\
\text { Excavation }\end{array}$ \\
\hline Source & Stone and \\
$\begin{array}{l}\text { Shilipu 十里 鋪 } \\
\text { tomb }\end{array}$ & $\begin{array}{l}\text { Xuzhou, } \\
\text { Jiangsu } \\
\text { bricks }\end{array}$ & c. AD167-189 & Barrel vault & $\begin{array}{l}\text { The figure originally presented here } \\
\text { cannot be made freely available via } \\
\text { ORA for copyright reasons. }\end{array}$ \\
\hline
\end{tabular}

\section{Part II: the Nanyang Basin}

\begin{tabular}{|l|l|l|l|l|l|l|}
\hline Name of Tomb & Location & \multicolumn{1}{|c|}{ Dating } & $\begin{array}{c}\text { Construction } \\
\text { Material }\end{array}$ & Yoof Type & \multicolumn{1}{c|}{$\begin{array}{c}\text { Source } \\
\text { Excavation }\end{array}$} \\
\hline $\begin{array}{l}\text { Qilingang 麒麟崗 } \\
\text { tomb }\end{array}$ & $\begin{array}{l}\text { Nanyang, } \\
\text { Henan } \\
\text { Eastern Han }\end{array}$ & $\begin{array}{l}\text { Early to middle } \\
\text { Stone and brick }\end{array}$ & $\begin{array}{l}\text { Barrel vault; } \\
\text { flat roof }\end{array}$ & $\begin{array}{l}\text { The figure originally presented here } \\
\text { cannot be made freely available via } \\
\text { ORA for copyright reasons. }\end{array}$ \\
\hline
\end{tabular}




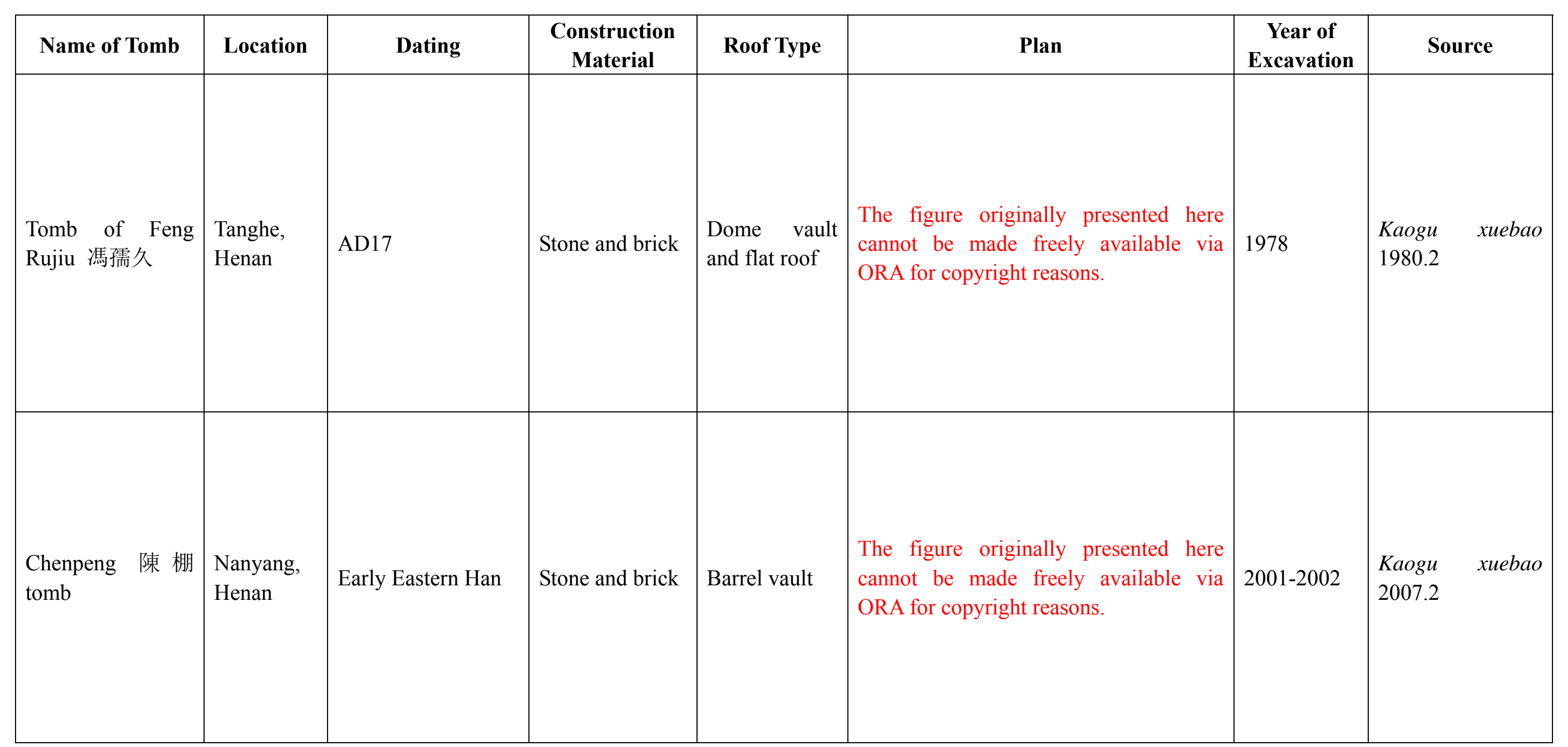




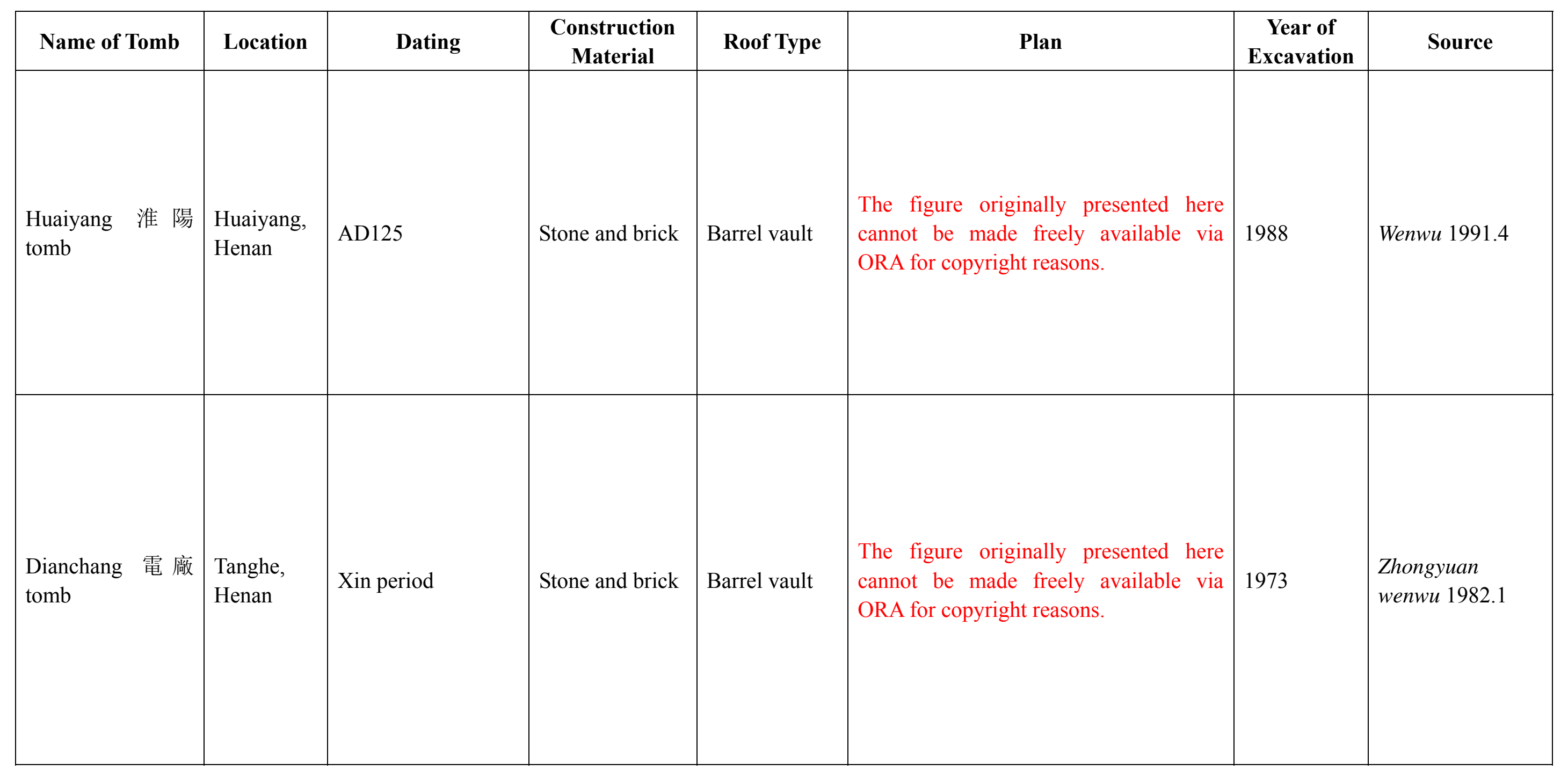




\section{Part III: the Capital Region}

\begin{tabular}{|c|c|c|c|c|c|c|c|}
\hline Name of Tomb & Location & Dating & $\begin{array}{c}\text { Construction } \\
\text { Material } \\
\end{array}$ & Roof Type & Plan & $\begin{array}{c}\text { Year of } \\
\text { Excavation } \\
\end{array}$ & Source \\
\hline $\begin{array}{l}\text { Dahuting 打虎 } \\
\text { 亭 tomb No. } 1\end{array}$ & $\begin{array}{l}\text { Xinmi, } \\
\text { Henan }\end{array}$ & Late Eastern Han & Stone and brick & Barrel vault & $\begin{array}{l}\text { The figure originally presented here cannot be } \\
\text { made freely available via ORA for copyright } \\
\text { reasons. }\end{array}$ & 1960 & $\begin{array}{l}\text { Wenwu } \\
\text { 1972.10; } \\
\text { Mixian } 1993\end{array}$ \\
\hline $\begin{array}{l}\text { Dahuting tomb } \\
\text { No. } 2\end{array}$ & $\begin{array}{l}\text { Xinmi, } \\
\text { Henan }\end{array}$ & Late Eastern Han & Stone and brick & Barrel vault & $\begin{array}{l}\text { The figure originally presented here cannot be } \\
\text { made freely available via ORA for copyright } \\
\text { reasons. }\end{array}$ & 1960 & $\begin{array}{l}\text { Wenwu } \\
\text { 1972.10; } \\
\text { Mixian } 1993\end{array}$ \\
\hline
\end{tabular}




\begin{tabular}{|c|c|c|c|c|c|c|c|}
\hline Name of Tomb & Location & Dating & $\begin{array}{c}\text { Construction } \\
\text { Material }\end{array}$ & Roof Type & Plan & $\begin{array}{c}\text { Year of } \\
\text { Excavation }\end{array}$ & Source \\
\hline $\begin{array}{l}\text { Zhucun 朱 村 } \\
\text { tomb }\end{array}$ & $\begin{array}{l}\text { Luoyang, } \\
\text { Henan }\end{array}$ & Late Eastern Han & Stone and brick & Barrel vault & $\begin{array}{c}\text { The figure originally presented here cannot be } \\
\text { made freely available via ORA for copyright } \\
\text { reasons. }\end{array}$ & 1991 & $\begin{array}{l}\text { Wenwu } \\
\text { 1992.12: 15-20. }\end{array}$ \\
\hline
\end{tabular}

\section{Part IV: Other Regions}

\begin{tabular}{|l|l|l|l|l|l|l|}
\hline \multicolumn{1}{|c|}{ Name of Tomb } & \multicolumn{1}{|c|}{ Location } & \multicolumn{1}{|c|}{ Dating } & \multicolumn{1}{c|}{$\begin{array}{c}\text { Construction } \\
\text { Material }\end{array}$} & \multicolumn{1}{c|}{ Roof Type } & Year of Discovery & \multicolumn{1}{c|}{ Source } \\
\hline $\begin{array}{l}\text { Tomb of Qin Jun } \\
\text { 秦君 }\end{array}$ & Beijing & AD105 & Unknown & Unknown & 1964 & Wenwu 1964.11 \\
\hline $\begin{array}{l}\text { Xiamaozhuang } \\
\text { 小莊 tomb }\end{array}$ & Jixian, Tianjin & Late Eastern Han & Stone and brick & Barrel vault & 2004 & Jixian 2005 \\
\hline $\begin{array}{l}\text { Fengtaizi 丰台子 } \\
\text { tomb }\end{array}$ & Beijing & Late Eastern Han & $\begin{array}{l}\text { Stone and } \\
\text { probably brick }\end{array}$ & Unknown & 1957 & Wenwu 1966.4 \\
\hline $\begin{array}{l}\text { Chang'an zhen 長 } \\
\text { 安鎮 tomb }\end{array}$ & Haining, Zhejiang & Late Eastern Han & Stone and brick & Barrel vault & 1973 & $\begin{array}{l}\text { Wenwu } \\
\text { Huang } \\
2009\end{array}$ \\
\hline $\begin{array}{l}\text { Fenghuangshan } \\
\text { 鳳凰山 tomb }\end{array}$ & Deqing, Zhejiang & Late Eastern Han & Stone and brick & Barrel vault & 1963 & Zhejiang 2005 \\
\hline
\end{tabular}




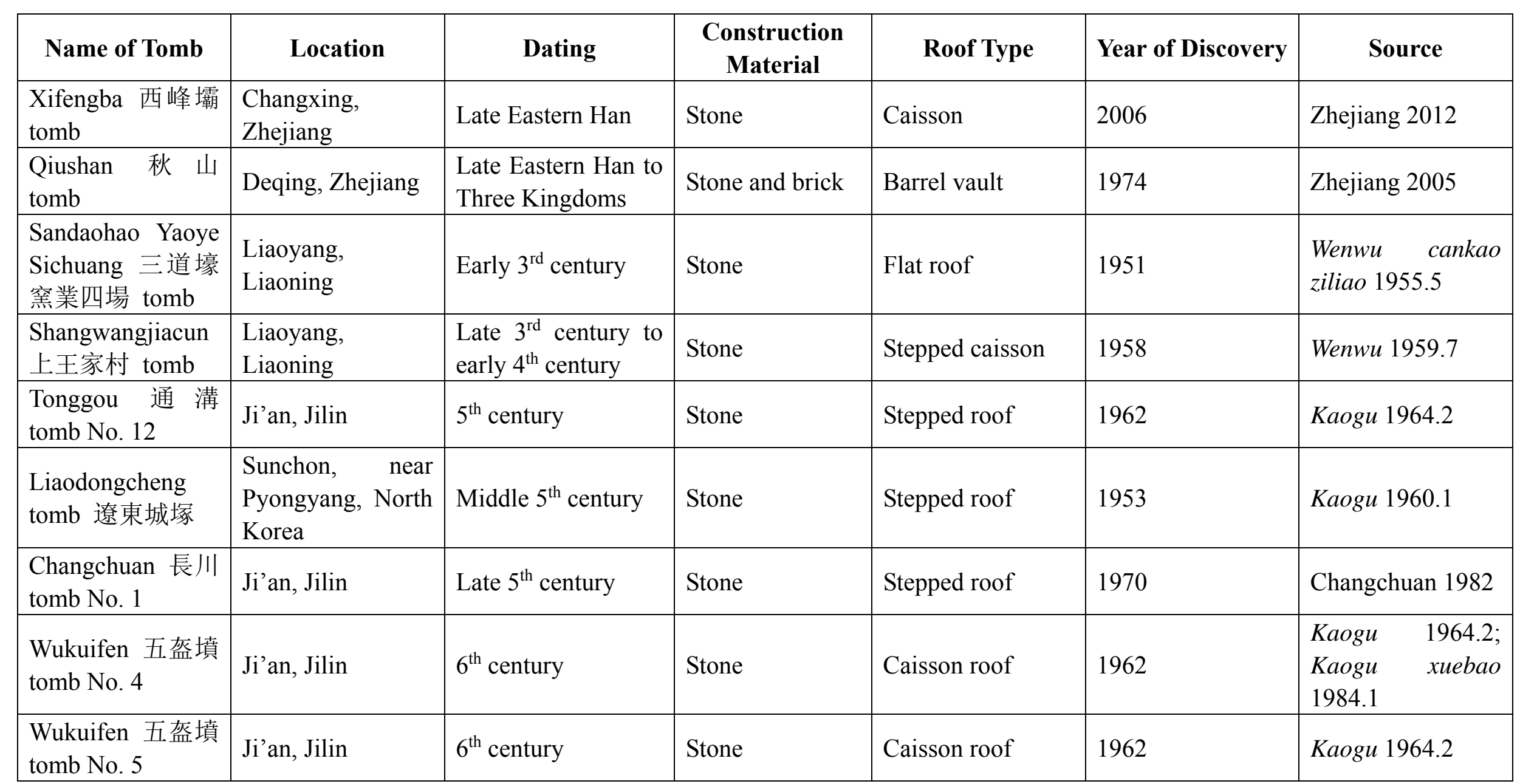




\section{Appendix II: Description of the Shilipu tomb in Xuzhou (Qi-Lu region)}

The Shilipu 十里鋪 tomb was found in the southern suburbs of Xuzhou, Jiangsu Province in 1964. Though it was excavated and published in the 1960s, the archaeological report is surprisingly detailed and of high quality. ${ }^{1}$

The whole tomb structure is semi-subterranean, buried within un-rammed earth. It consists of a rear chamber, a middle chamber, and a front chamber with two side chambers, as well as a entrance chamber accessed by a ramped passage way. The plan of the tomb resembles a cross facing south, and is about 15 meters long, and 5.5 meters wide at its widest point (Fig. 7-10). It is a multi-chamber tomb constructed from a combination of stone slabs and small moulded bricks. There are 18 stone slabs, all carrying relief images; and they are distributed in every chamber of the tomb, serving as columns, lintels, or doors. Three types of moulded bricks have been used. Cuboid bricks, sized $35 \mathrm{~cm} \times 17.5 \mathrm{~cm} \times 7.3 \mathrm{~cm}$, were mainly used for building tomb walls and paving floors of the two side chambers. Two types of voussoir bricks were used for constructing the vaulted roofs and for paving floors of the front, middle and rear chambers.

The tomb doors of the Shilipu tomb have been moved when it was disturbed in early years. And most of the chamber roofs have collapsed, possibly because of tomb looting activities. However, a great majority of the stone carvings were preserved in situ, and a total number of 196 pottery, bronze, stone, glass and lead objects were

\footnotetext{
${ }^{1}$ For the archaeological report see Kaogu 1966.2: 66-83 and 91.
} 
excavated from the silt sediments. Many intact objects were found in the eastern side chamber and the middle chamber. These surviving relief carvings and burial objects have not only helped date the tomb from AD167 to AD189, namely late Eastern Han, but also make it possible for the sets of images and objects to be examined together.

The ramped passage way of the tomb is lined with small bricks, and supplies access to the entrance chamber, the entrance of which includes two stone columns, a stone lintel, and two stone doors (marked as I on Fig. 7-10). Both of the two lintels are 1.15 metres high, 0.43-45 metres wide, and 0.12-13 metres thick. The broken eastern door is 0.54 metres high, 0.47 metres wide and 0.07 metres thick, and the intact western door is 0.8 metres high, 0.47 metres wide and 0.07 metres thick. The columns and doors carry simple geometrical patterns only (Fig. 7-11a).

The lintel has been broken, with only the lower left corner survived, but has relief images on both sides. The front side of the fragment depicts three standing figures in robes, and even more figures may have been carved on the original stone surface, which is framed by decorated borders (Fig. 7-11b). On its rear is a frame and further decoration. On the surviving lower right corner is a figure sitting on a small low bed, with a servant standing to one side. A bird stands above cloud or plant scrolls, below which is a winged rabbit-like figure pestling (Fig. 7-11c), presumably the jade hare in the Guanghan Palace 廣寒宮 of the moon. No burial objects, apart from vault bricks, were found in the entrance chamber. This foremost chamber is not really a part of the tomb yet, but marks the boundary between the living and the dead. Figures on the front side of the lintel are either welcoming guests, or guarding the tomb chambers 
behind them. Images on the rear side of the lintel should be understood as part of the pictorial programme of the entrance chamber, as it indicates an auspicious space.

The front chamber next to the entrance chamber to the north is 3.31 metres long, 1.5 metres wide, and its brick vault is 1.5 metres high. Most of the chamber walls are constructed from small bricks, but where the front chamber adjoins the entrance, the middle and the side chambers, stone elements were used. The entrance of the front chamber includes two columns, a lintel, and two doors (marked as II on Fig. 7-10). The western column is 1.16 metres high, 0.45 metres wide, and 0.13 metres thick, while the eastern column is 1.16 metres high, $0.39-42$ metres wide, and 0.13 metres thick. Both columns carry simple consecutive diamond patterns only (Fig. 7-12a). The two stone doors are both 1.15 metres high, 0.53 metres wide, and 0.08 metres thick, and are decorated with consecutive semicircular pattern framing a beast head holding a string in its mouth (Fig. 7-12b), a motif that is most common for Han period stone tomb doors. Their functions should be 'warding off evil' as mentioned in the Cangshan text.

Carved images on the lintel, which is 1.52 metres long, 0.42 metres wide, and 0.21 metres thick, are much more complicated. The composition of its front side can be divided into two groups. The left group includes two warriors and two servants or spectators, each standing on one side. The first warrior is dressed in robe and armour holding a long $j i$ halbert pointing at the second warrior, whose twisted body is half naked. A dao sword, a gouxiang 钩镶 weapon and an armour, probably belong to the second warrior, are placed aside. The right group of the composition includes a master 
sitting on a low bed holding a dao 刀 sword, and three figures kowtowing to him, each holds an information tablet (Fig. 7-12c). The rear side of the lintel is divided by three trees with monkeys climbing and birds standing in them. Between the left tree and the middle tree stand two winged beasts heading backwards to each other, with their tails scrolled / tied together, pointing upwards. Between the middle and the right tree is another similar winged beast seems jumping, also facing backwards. At the edges of the whole composition, many birds' heads are carved (Fig. 7-12d). Images on the rear side of the lintel should be understood as part of the pictorial programme of the front chamber.

Apart from some pottery vessel fragments, several intact pottery objects have also been excavated from the front chamber: a handled vessel in the shape of a crouching animal, which is widely believed to be a urinal vessel (Fig. 7-13a); a lamp seat that has nine branches with animal heads (Fig. 7-13b); and a plate copying lacquer plates' shape and has red pigment remains inside. The front chamber might not be the original places for these objects, as similar ones have been found in other chambers. But the nine-branched lamp might have been used to light the occupant's afterlife, and might be related to a kind of Daoist ritual. ${ }^{2}$

At the western and eastern sides of the front chamber, there are two smaller chambers. The western chamber is constructed from small moulded bricks and is 2.7 metres long, 0.92 metres wide. Its brick barrel vault is 1.08 metres high. At the junction of the western niche and the front chamber, two stone columns and a stone

${ }^{2}$ For an intensive study on the styles and functions on different types of lamps excavated from Eastern Han tombs and their possible relations to Daoist lamp ritual, see Lin Sheng-chih 2012: 265-179. 
lintel is used (marked as III on Fig. 7-10). The lintel is 2.2 metres long, 0.44 metres high, 0.34 metres thick, only the front side facing the front chamber is decorated. A winged dragon and a winged tiger are carved at the left and right part respectively, facing each other with their mouths open. A dog-like small mammal stands between them, looking backwards at the tiger. Beneath the three animals are mountains, or floating clouds. At the left most part of the lintel there is a bird sitting on top of a small tree. The whole composition is framed by scrolled decorative patterns (Fig. 7-14). The lintel is longer than the width of the chamber door, so that its north end penetrates the western wall of the front chamber (Fig. 7-10). The archaeological report does not mention any carved images on the door posts, so presumably they do not carry any decorations. The stone structure here sunk a bit when it was excavated.

The western chamber was found empty during its excavation. However, five lead objects were discovered in the gaps between the floor bricks. These small objects are believed to be parts of chariot accessories, and include three bow caps that are 2.3-2.8 centimetres long, a U-shaped $y i$ 轙 accessory that is 3.2 centimetres long and 1.5 centimetres wide, and a rectangular lead patch 4.5 centimetres long and 2.2 centimetres wide (Fig. 7-15). It is very likely that the tomb raiders took the chariots away, leaving these accessories behind. Obviously the chariots are much smaller than real chariots judging from the accessories' sizes. They are lead models specifically made for the burial. ${ }^{3}$ Obviously the west chamber was designed as the chariot

\footnotetext{
${ }^{3}$ Models of chariots and horses have been mentioned in Han texts as '偶車馬 model chariots and horses'. See Hanshu and Qianfu lun.
} 
storage, ${ }^{4}$ and model chariots were as functional as real chariots and would be ready for the tomb occupant's excursions in the afterlife when needed.

The eastern side chamber has a nearly identical structure as the western niche, with brick walls supporting a brick barrel vault, as well as two stone posts and one stone crossbeam (marked as IV on the plan), except that it is slightly smaller, 1.94 metres long, 0.86 metres wide, and 1.06 metres high. The stone lintel is 1.74 metres long, 0.44 metres high and 0.34 metres thick, with relief carvings on the front side. Within semicircular border patterns, two dragons are depicted. Their bodies are intertwisted together in opposite directions, each going through the circular holes of three discs (presumably jade bi discs) in a well organised pattern, and they are biting each other's tails. This motif is common enough for Han stone carvings, and is commonly called erlong chuanbi 二龙穿壁 (literally two dragons crossing bi discs) by Chinese scholars. To the left of the dragons stands an unidentified beast heading backwards. At the right end there is a tree with a flying bird and a climbing monkey (Fig. 7-16).

Large numbers of pottery burial objects have been excavated from the east chamber. Nearly all objects are intact, and their original positions can be identified (Fig. 7-10). These include three plates that are similar to the one excavated from the front chamber; a round basin (Fig. 7-17a) and a handled basin (Fig. 7-17b); four pottery cups (Fig. 7-17c) copying lacquer cups' shapes with red pigment remains, all

\footnotetext{
${ }^{4}$ In Feng Rujiu's tomb near Nanyang, chariot accessories have also been found in one of the side chambers. Moreover, on stone surfaces of the chamber inscriptions were found and reads ‘車庫 chariot storage'. See Kaogu xиebao 1980.2: 239-262. This further indicates that, west chamber of the Shilipu tomb should be a chariot storage chamber as well.
} 
placed in a shallow plate (Fig. 7-17d); a shallow plate with three legs in the appearance of bears (Fig. 7-17e); a pottery model of a stove (Fig. 7-17f); a millstones (Fig. 7-17g); a building model that is around 60 centimetres high (Fig. 7-17h). It is very likely that, the east chamber was the kitchen and storage room of the house. The stove and other devices were to prepare food for the tomb occupant in the afterlife, and the utensils would be used to serve food. On the other hand, the building model would be a symbol of fortune. Although all devices and utensils are pottery models, they are all functional.

The middle chamber neighbours the front chamber to the north. It is 3.16 metres long, 2.3 metres wide, and its floor is lined with Type I bricks (Fig. 7-10). The walls are constructed from cuboid bricks, supporting a 2.44-metre-high barrel vault, which is highest among all the tomb chambers. At the junction of the front chamber and the middle chamber, there are two stone columns and a stone crossbeam (marked as $\mathrm{V}$ on Fig. 7-10) but no doors or doorsills. The western post is 1.2 metres high, 0.43 metres wide and 0.2 metres thick. On its front surface the scene of two intertwisted dragons crossing two bi discs is depicted, but both dragons are heading upwards with their tails wound together (Fig. 7-18a), which is slightly different from the other erlong chuanbi scene mentioned above. The side of the western post carries simple consecutive diamond patterns. The eastern post is 1.2 metres high, 0.44 metres wide and 0.28 metres thick. Its front face carries a similar scene of erlong chuanbi to the western post, except that the dragons' tails are not intertwisted.

A stone crossbeam that is 2.78 metres long, 0.48 metres high and 0.4 metres 
thick is placed upon the two stone posts. Both the front and the rear faces of the beam carry carved images. The front face depicts two intertwisted dragons crossing three $b i$ discs, similar to that of the beam of the eastern chamber, but is more complicated. The whole composition is framed with scroll decorative borders. In the space between the dragons and the borders, there are six crested birds with long tails, all seem flying from the right to the left of the composition. In the space between the two dragons, there are two mythical creatures each with the body of a fish and a human head (Fig. $7-18 b)$.

The rear face of this beam faces the rear chamber of the tomb, and carries even more complicated relief images. Scroll decorative patterns frame the composition, where there are three trees, one at the left edge the other at the right edge, and the third one right in the middle, dividing the scene into two parts. Near the left tree and the right tree, there are running or jumping winged beasts and crested long-tail birds. Between the left tree and the middle tree, two beasts are facing each other. The left one has a feline body with two human heads with hats, and the right winged beast has one human face, with a crest that has nine branches. Between the middle tree and the right tree there is a big bird with erecting crest and long tail, presumably a feng phoenix. A winged figure stands in front of the feng, holding its beak. Both the figure and the feng are surrounded by flying birds and cloud scrolls (Fig. 7-18c). Images on the rear side of this lintel should be understood as part of the pictorial programme of the rear chamber.

Many intact objects as well as fragments have been excavated from the middle 
chamber. A large proportion of these are pottery models of buildings, animals, servants and daily objects. However, their original positions are unknown, and many of them may have been moved from other chambers, as the tomb has been disturbed. Buildings include a stove that is similar to the one from the eastern chamber, two water wells, and a pigpen with a pottery pig in it (Fig. 7-19a). All the pottery animals are slightly smaller than life-sized, and include a rooster, two ducks, and a dog with red pigment remains (Fig. 7-19b). The sitting male servant is 24.8 centimetres high and is painted all over in red (Fig. 7-19c). The 23.4-centimetre-high crouching female figure is also painted in red, and wears a peaked cap (Fig. 7-19d). The clothing and facial characteristics indicate that she might be a foreigner. Pottery vessels include an intact handled basin, a pottery imitation of bronze incense burner as well as fragments of five handled cups placed on a bigger plate, three small cups and some other unidentified pieces. A very complicated sculpture in the shape of a pedestal or a vessel is probably the most impressive object of the middle chamber. It is 35.5 metres high, and its diameter is 41 centimetres (base) and 29 centimetres (top) respectively. Among its mountain-like knobs, there are many smaller figures including winged horses, sheep, fourteen dancing figures and musicians many of which might be foreigners, and the siling animals. A pottery millstone was placed in its top opening (Fig. 7-19e). The excavators believe that this sculpture depicts a ceremony praying for a bumper harvest of crops. Dozens of bronze coins were found in the middle chamber, but it is very likely that they were moved from the rear chamber by the tomb looters. In total 141 coins were found in this tomb, one huoquan 貨泉, one moguo wuzhu 磨郭五銖, 
and 139 wuzhu 五銖 coins. Most of them were found in the rear chamber. Three stone pigs were also found, and they are 10.5-10.9 centimetres long, 2.2-2.3 centimetres wide, and 2.6-2.8 centimetres high (Fig. 7-19f). Such stone pigs are often found being held by tomb occupants in other Han period tombs. This indicates that the Shilipu very likely belonged to a couple, each had two stone pigs, although the fourth one is missing. The low tables and incense burners suggests that the middle chamber might have served as the sitting room. 'Barbarian' servants have been employed to show off the occupants' links to exotica.

The rear chamber is 3.16 metres long, 2.3 metres wide, and is constructed from small bricks, with a floor paved with Type I bricks (Fig. 7-10). Its brick barrel vault was penetrated by a looters' tunnel, and is 1.96 metres high. At the junction of the middle chamber and the rear chamber, there are two stone posts and a stone crossbeam (marked as VI on Fig. 7-10) but no doors or doorsills, similar to the junction between the front and the middle chambers. The western post is 1.17 metres high, 0.31 metres wide and 0.21 metres thick. On the front surface of the post carves a figure in robes with human head but the tail of a snake, raising his hands holding a circle, presumably the sun (Fig. 7-20a). One side of the post is also decorated with two rows of consecutive diamond patterns. The eastern post is 1.17 metres high, 0.68 metres wide and 0.26 metres thick. Its front face carries relief images which are framed by semicircular and triangle patterns and is divided into two parts. The lower part depicts two que tower gates, each with a bird standing on top. Within the gate stands two servants each holding a broom, which is a sign of welcoming guests by 
sweeping the ground. The upper part is a house with two birds standing on the roof, and two persons sitting on a couch with wine vessels. Between the upper and the lower parts there are two handled vessels (Fig. 7-20b). A stone crossbeam that is 3.2 metres long, 0.47 metres high and 0.37 metres thick is placed upon the two stone posts at the entrance of the rear chamber. The front surface of the lintel faces the middle chamber, and carries carved images of supernatural animals including winged beasts, birds, dragon and two mammals intertwisting their necks (Fig. 7-20c).

Many broken potteries, including small cups, vessel handle, broken plates and other vessels, have been excavated from the sediments of the rear chamber. An intact low table which is 64.4 centimetres long and 43.6 centimetres wide is also found, with four removable legs in the appearance of mammal hoofs (Fig. 7-21). Other intact objects include a pottery liubo 六博 chess board 36 centimetres wide and 6.5 centimetres high (Fig. 7-21), a pottery building model that is similar to the one in the eastern chamber, and more than a hundred bronze coins as mentioned above. Fourteen coloured glazed beads of different shapes have also been excavated. These beads range in size from 0.6 to 2.5 centimetres in diameter, and are all pierced for threading or stringing (Fig. 7-21). Moreover, at the left and right sides of the chamber floor, many lacquerwork remains, human teeth and iron coffin nails were found. This indicates that the rear chamber was where the tomb occupants were buried, in lacquered wooden coffins. Images at the east post of the side chamber, symbolises the entrance to the occupants' dwellings, and the images of two mammals intertwisting their necks carved on the lintel of the rear chamber further indicates that this tomb 
belongs to husband and wife. 


\section{Maps and Figures of Chapter One}

The map originally presented here cannot be made freely available via ORA for copyright reasons.

Map 1-1, distribution of Han stone tombs. after Xin Lixiang 2000, Figure 1, with English notations. 
The map originally presented here cannot be made freely available via ORA for copyright reasons.

Map 1-5, population map of Han China (AD2), after Powers 1992, Map 1. 
The figure originally presented here cannot be made freely available via ORA for copyright reasons.

Figure 1-1a, plan and elevation of Baiji Tomb, after Kaogu 1981, Figure 2, with English notations.

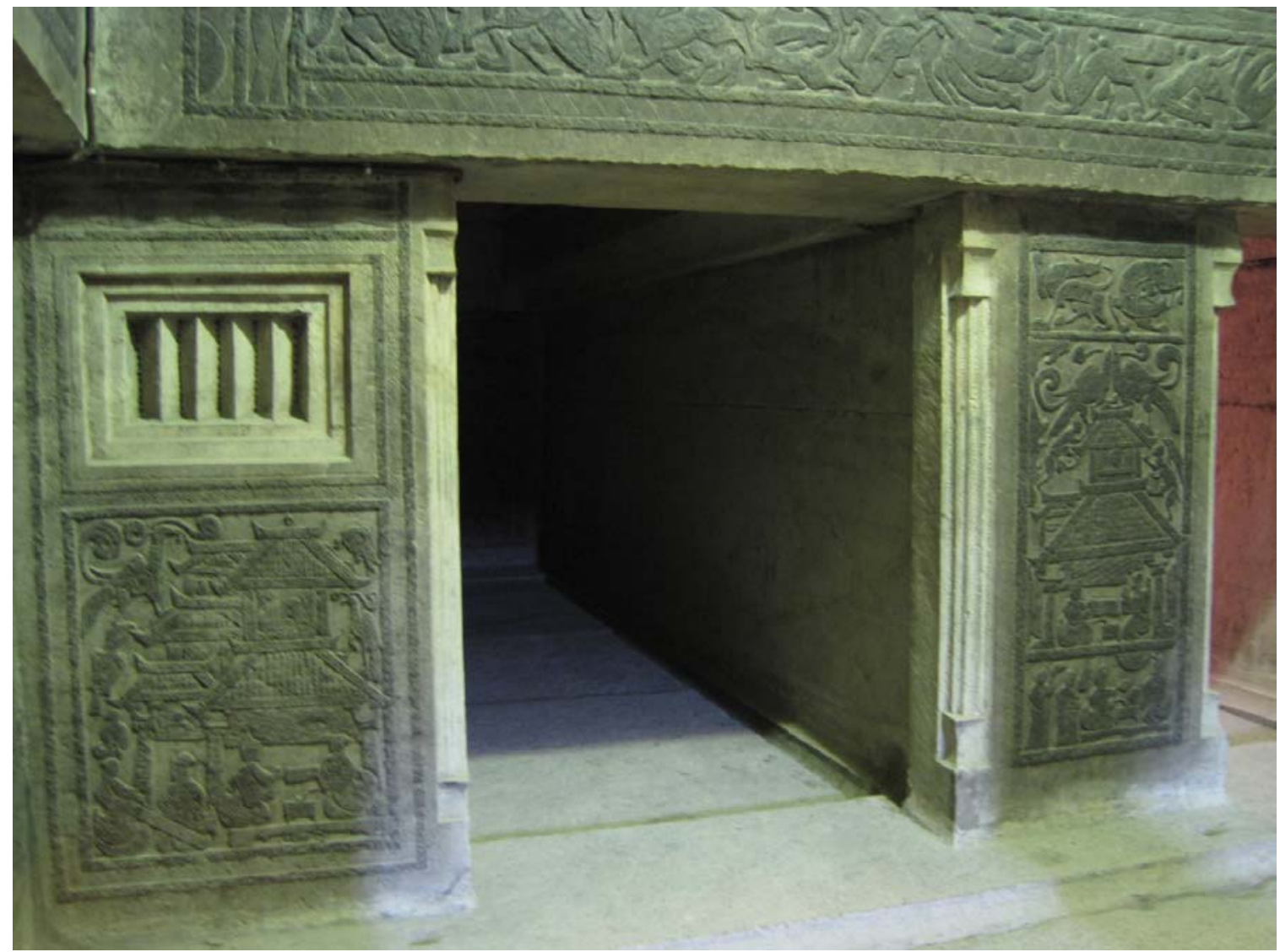

Figure 1-1b, View of the interior of Baiji Tomb. Photograph by the author. - 269 - 
The figure originally presented here cannot be made freely available via ORA for copyright reasons.

Figure 1-1c, Front view of Baiji Tomb and shrine during excavation, after Kaogu 1981, Plate 10.

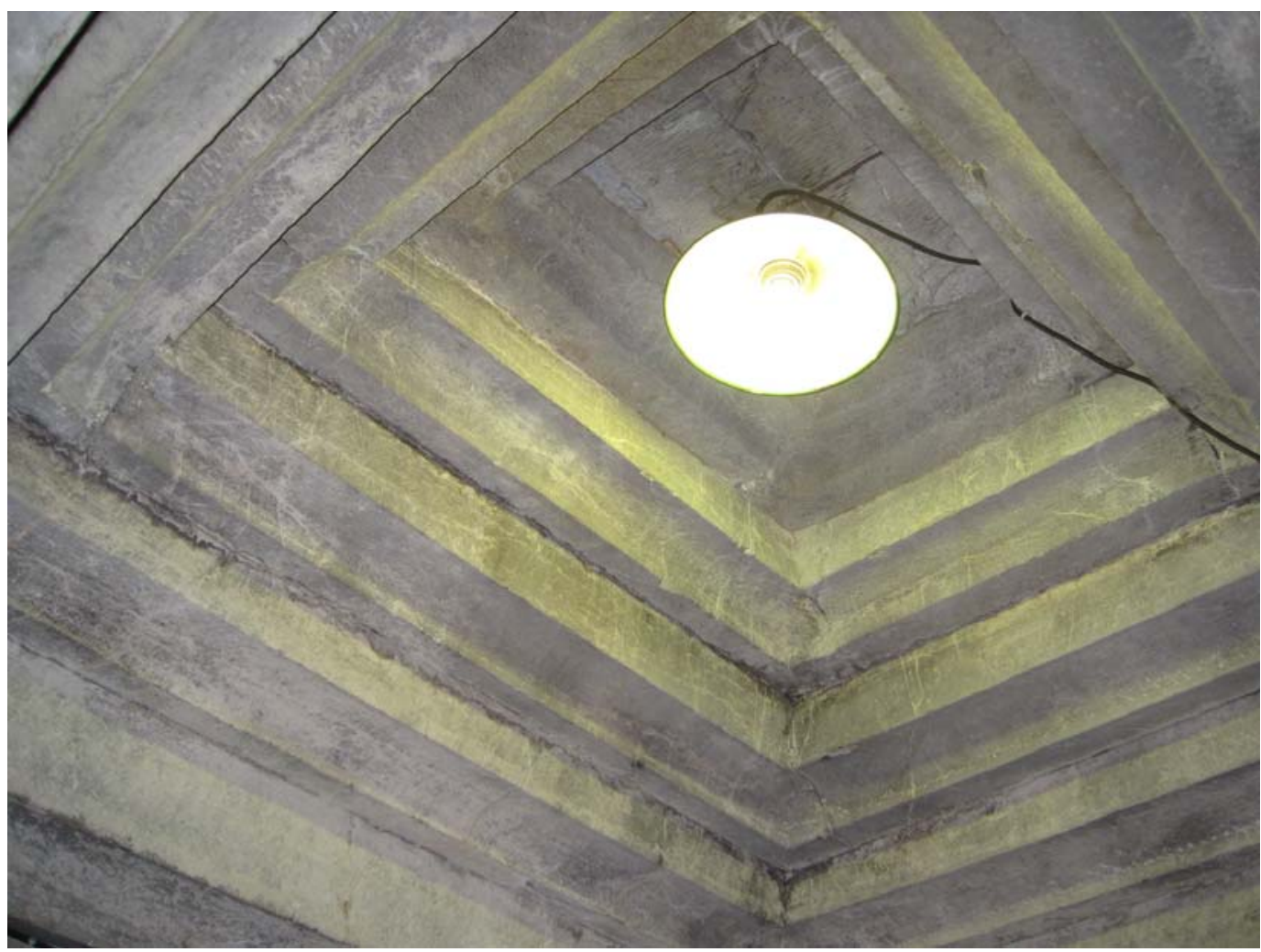

Figure 1-1d, Stepped caisson roof of the main chamber in Baiji Tomb. Photograph by the author. 
The figure originally presented here cannot be made freely available via ORA for copyright reasons.

Figure 1-2, typical stone tomb planning in the Qi-Lu region.

The figure originally presented here cannot be made freely available via ORA for copyright reasons.

Figure 1-3, typical stone tomb planning in the Nanyang Basin.

The figure originally presented here cannot be made freely available via ORA for copyright reasons

Figure 1-4, front view of the Nanyang Chenpeng Tomb during excavation, after Kaogu xuebao 2007.2 Plate 5. 
The figure originally presented here cannot be made freely available via ORA for copyright reasons.

Figure 1-5, drawing of Dahuting Tomb M2 at Mixian in Henan, after Mixian 1993, Figure 161.

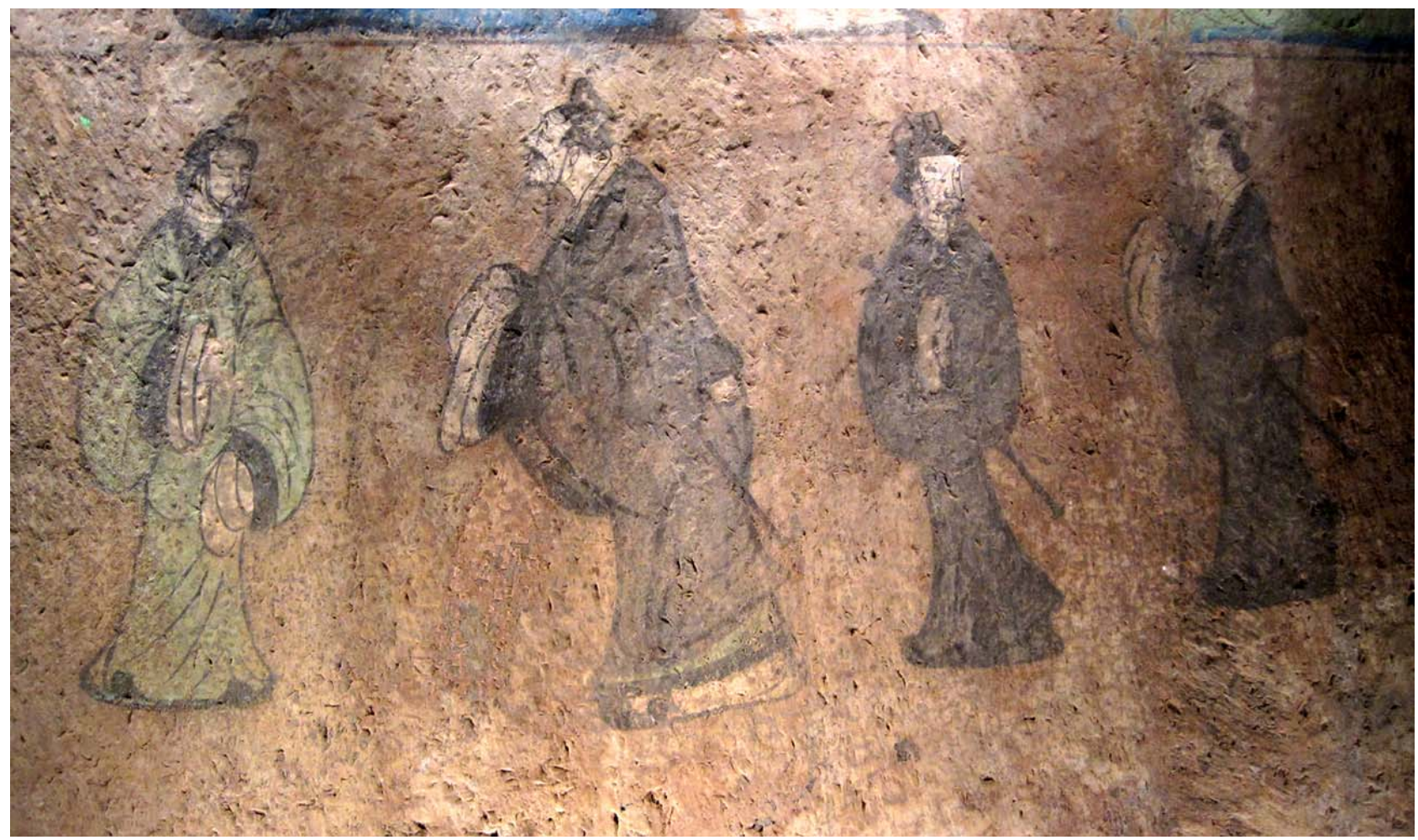

Figure 1-6, coloured mural painting from the Dongping Tomb in Shandong. Photograph by the author. 
The figure originally presented here cannot be made freely available via ORA for copyright reasons.

Figure 1-7, two pages of Jinshi Suo.

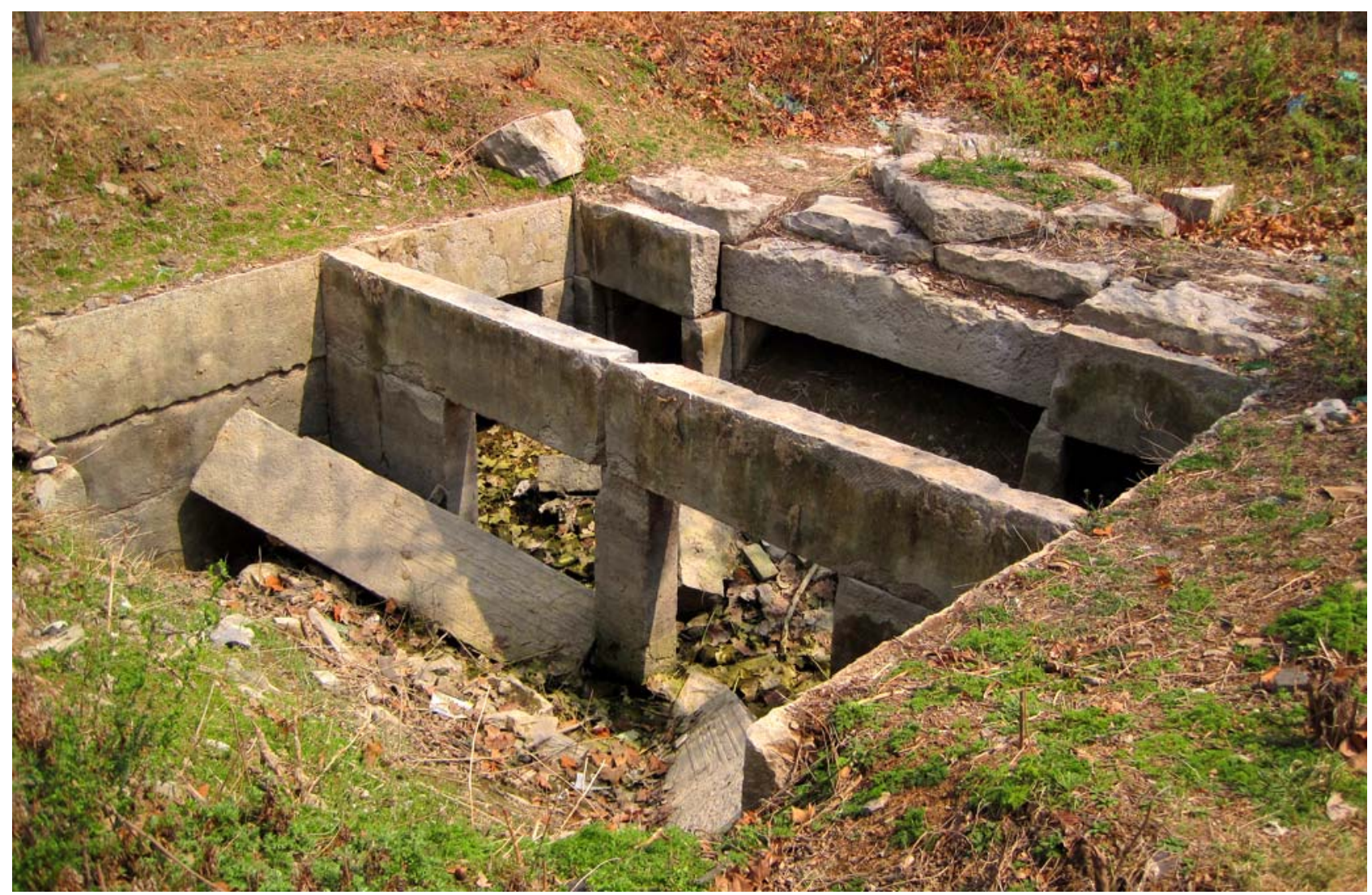

Figure 1-9, stone tomb ruins in the courtyard of Wu Family Shrines Museum in Jiaxiang, Shandong. Photograph by the author. 
Figures of Chapter Two

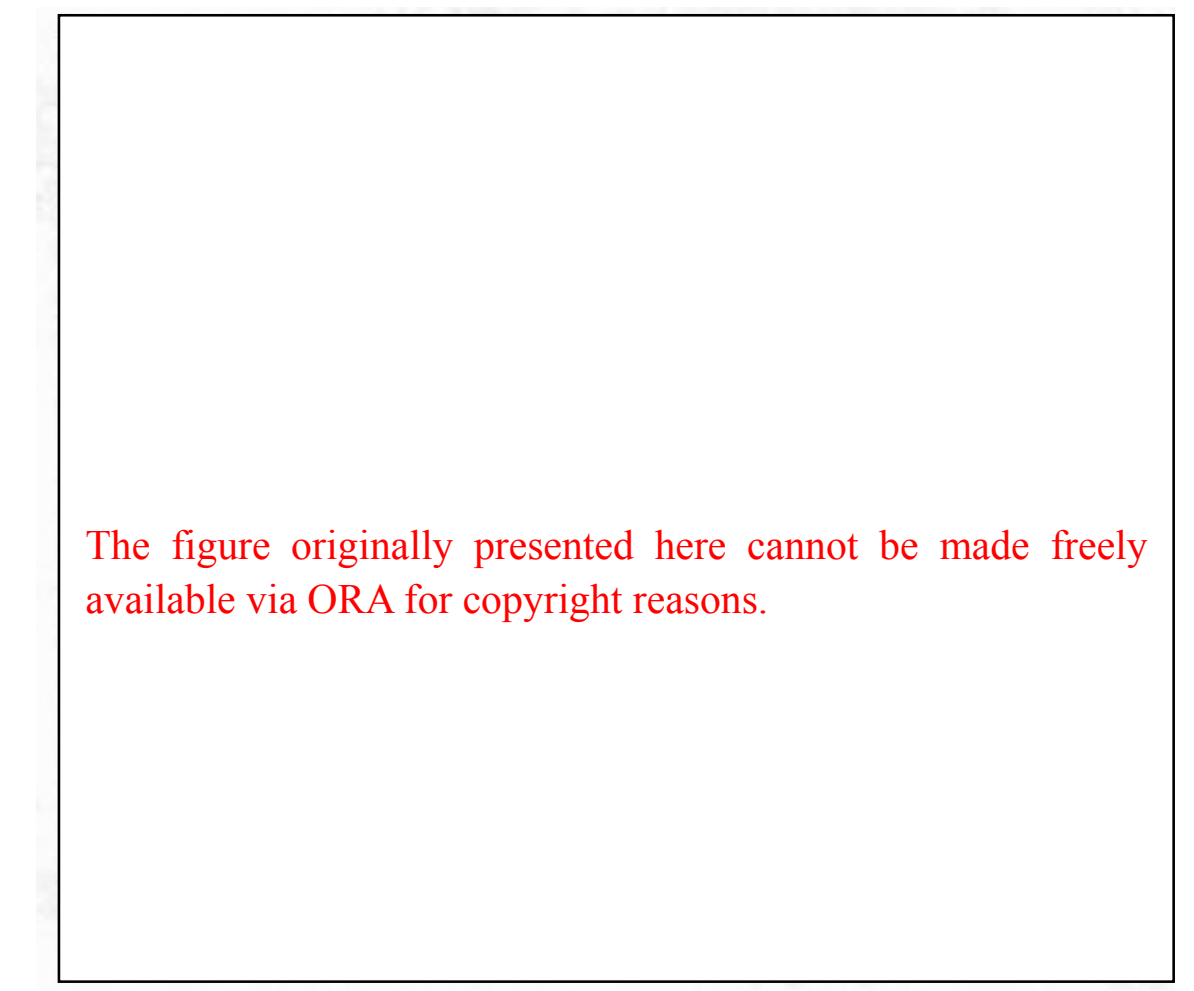

Figure 2-1a, plan of the Qilingang tomb. After Nanyang 2008, Figure 4.

The figure originally presented here cannot be made freely available via ORA for copyright reasons.

Figure 2-1b, view of the Qilingang tomb during excavation. After Nanyang 2008, Plate 11. 
The figure originally presented here cannot be made freely available via ORA for copyright reasons.

Figure 2-2a, plan of the Feng Rujiu tomb. After Kaogu хиebao 1980.2: 240, Figure 2.

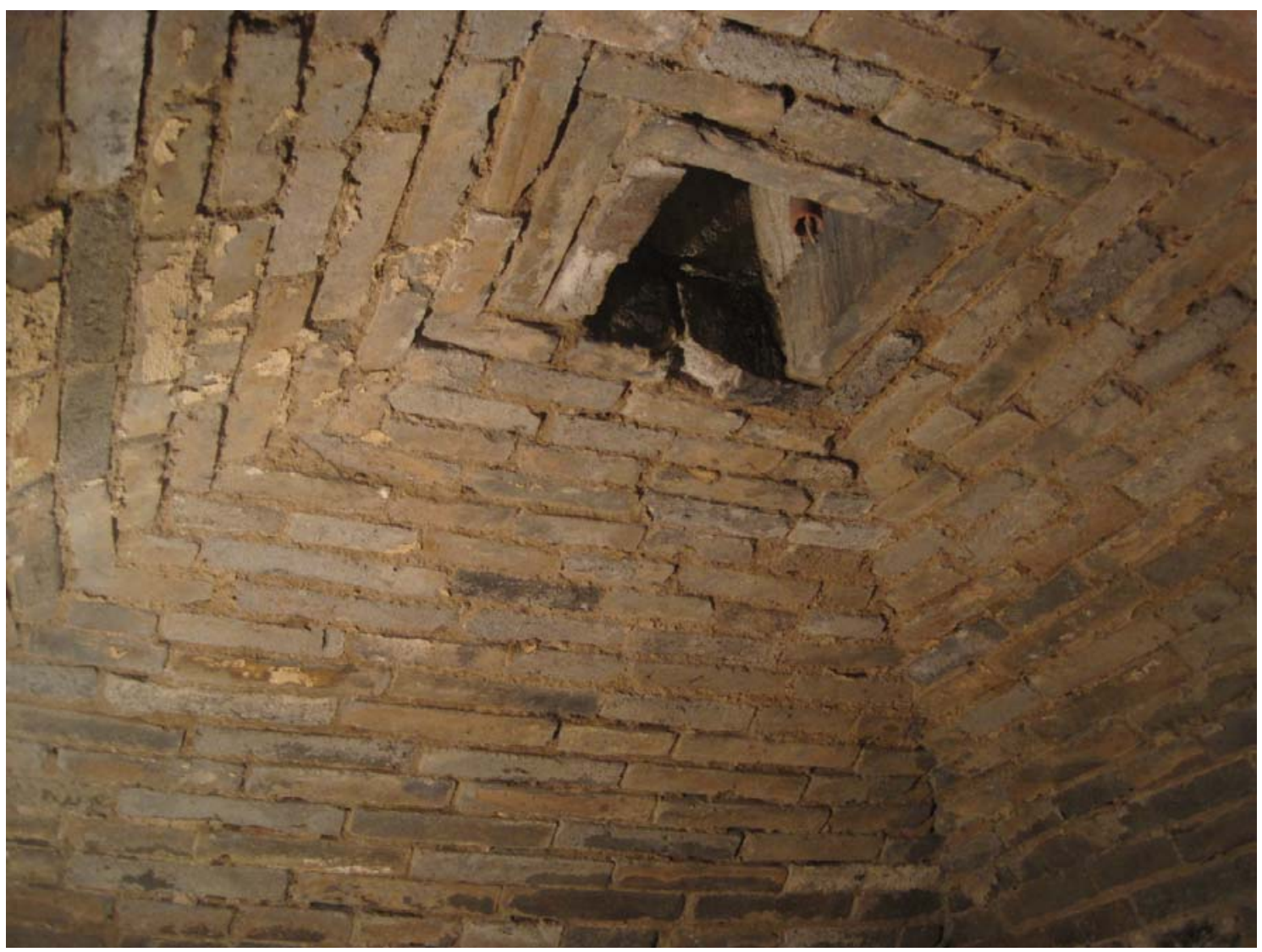

Figure $2-2 b$, domed ceiling of the Feng Rujiu tomb. Photograph by the author. 
The figure originally presented here cannot be made freely available via ORA for copyright reasons.

Figure 2-3a, plan of Mixian tomb M1. After Mixian 1993, Figure 4.

The figure originally presented here cannot be made freely available via ORA for copyright reasons.

Figure 2-3b, façade of Mixian tomb M1. After Mixian 1993, Figure 7. 
The figure originally presented here cannot be made freely available via ORA for copyright reasons.

Figure 2-3c, detail of stone wall of Mixian tomb M1. After Mixian 1993, Plate IX.

The figure originally presented here cannot be made freely available via ORA for copyright reasons.

Figure 2-4, plan of the Mengzhuang tomb. After Wenwu 2002.2: 39, Figure 1. 
The figure originally presented here cannot be made freely available via ORA for copyright reasons.

Figure 2-5a, mural painting of Han architecture. After Helinge'er 1978: 88.

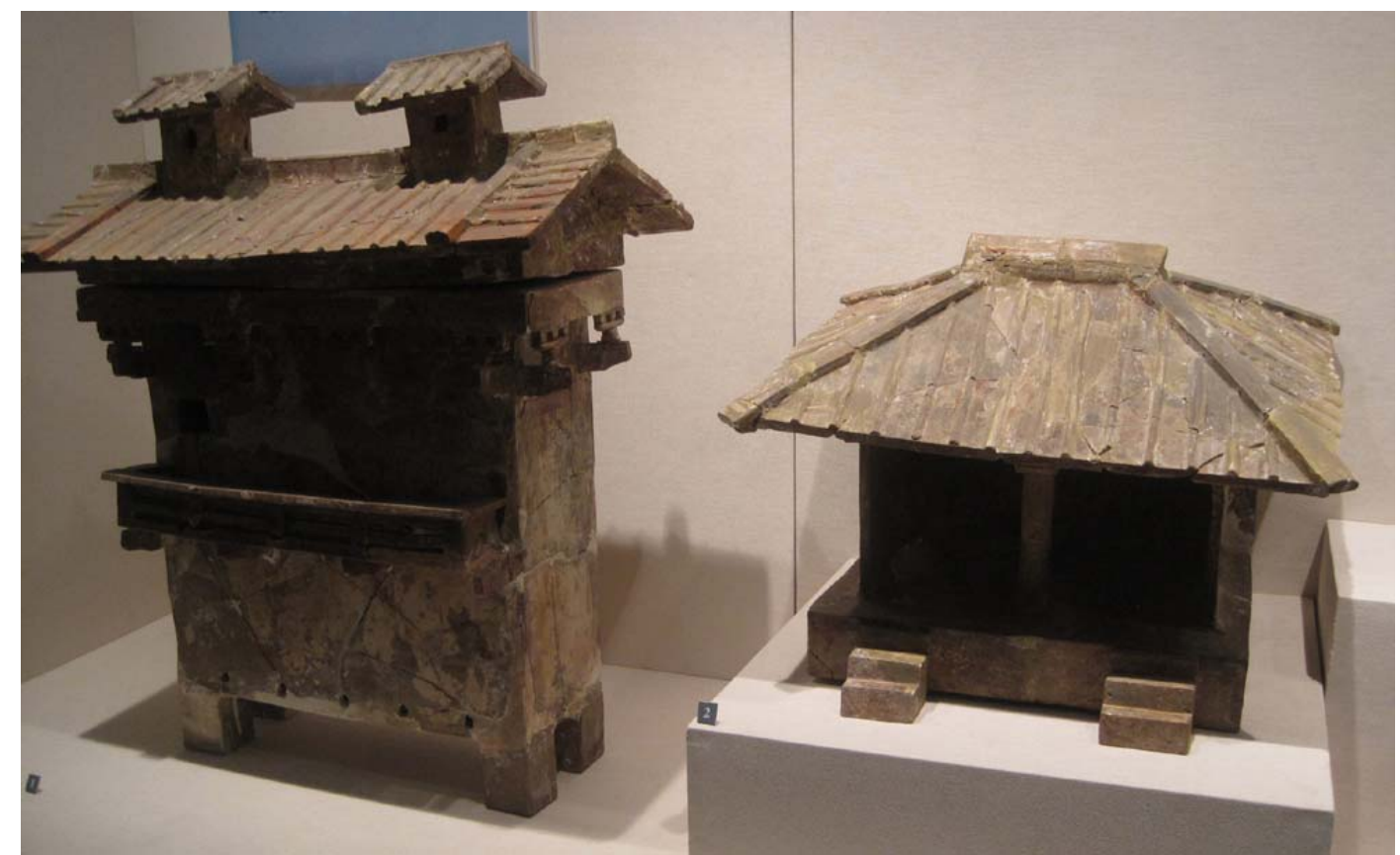

Figure 2-5b, Pottery granary and pottery shrine excavated near Linyi, Shandong. Photograph by the author. 
The figure originally presented here cannot be made freely available via ORA for copyright reasons.

Figure 2-6a, b, mortise and tenon of Mawangdui tomb M1. After Changsha 1973, vol. 1, Figure 8 and 7.

The figure originally presented here cannot be made freely available via ORA for copyright reasons. 
The figure originally presented here cannot be made freely available via ORA for copyright reasons.

Figure 2-7, structure of the Dabaotai tomb M1. After Beijing 1989, Figure 13.

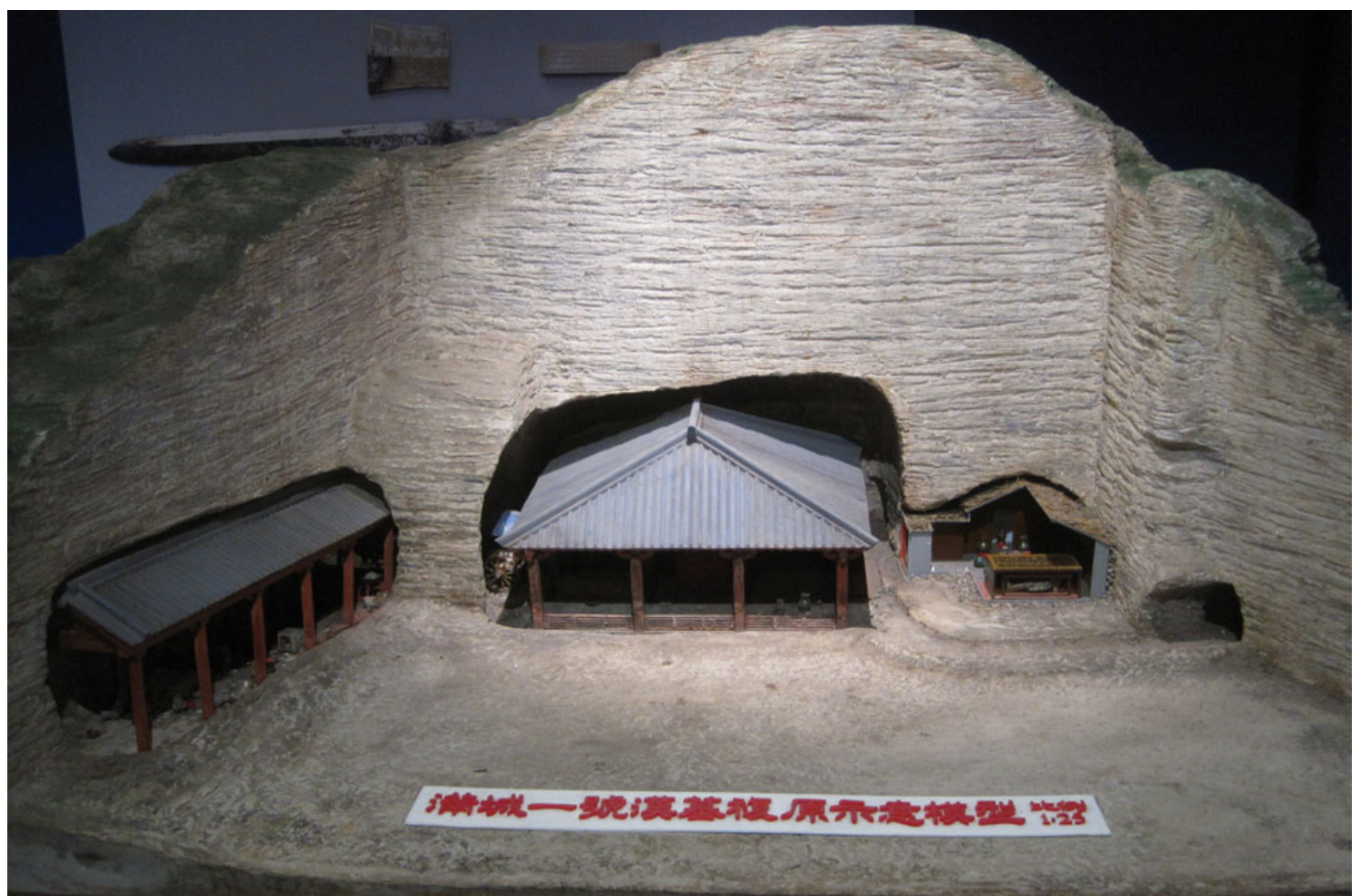

Figure 2-8a, model of the tomb of Liu Sheng showing the structure. Photograph by the author. 
The figure originally presented here cannot be made freely available via ORA for copyright reasons.

Figure 2-8b, stone house in the tomb of Liu Sheng. After Mancheng 1980, vol. 1, Figure 14.

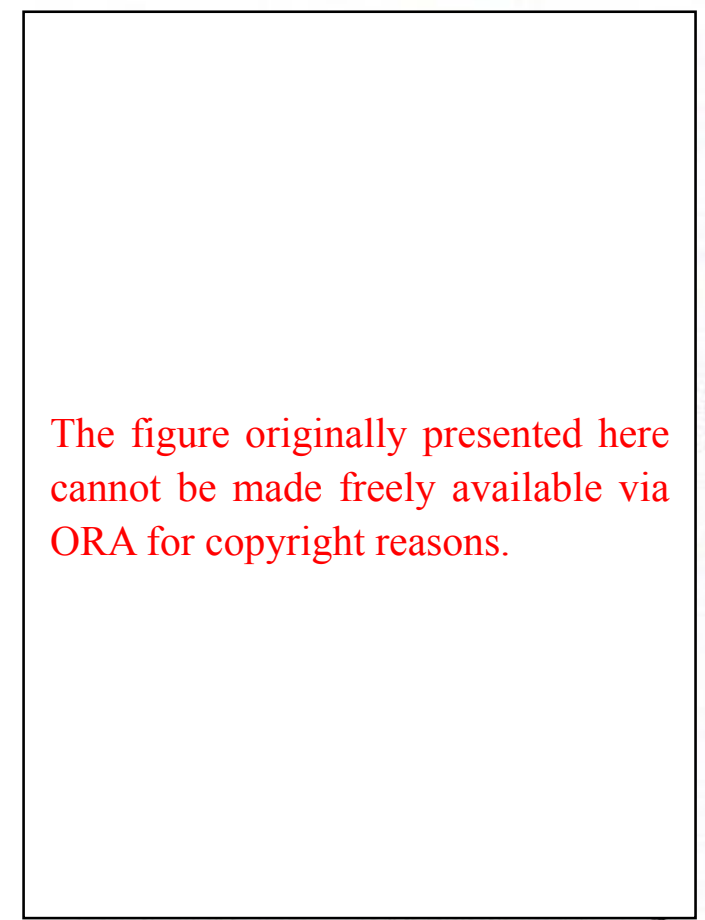

Figure 2-9b, inscriptions from the Beizhuang tomb of Dingxian, Hebei Province. After Kaogu хиеbao 1964.2: 189, Rubbing 155. 
The figure originally presented here cannot be made freely available via ORA for copyright reasons.

Figure 2-10a, dougong brackets represented on stone carvings. After Jiaxiang 1992: Fig. 63.

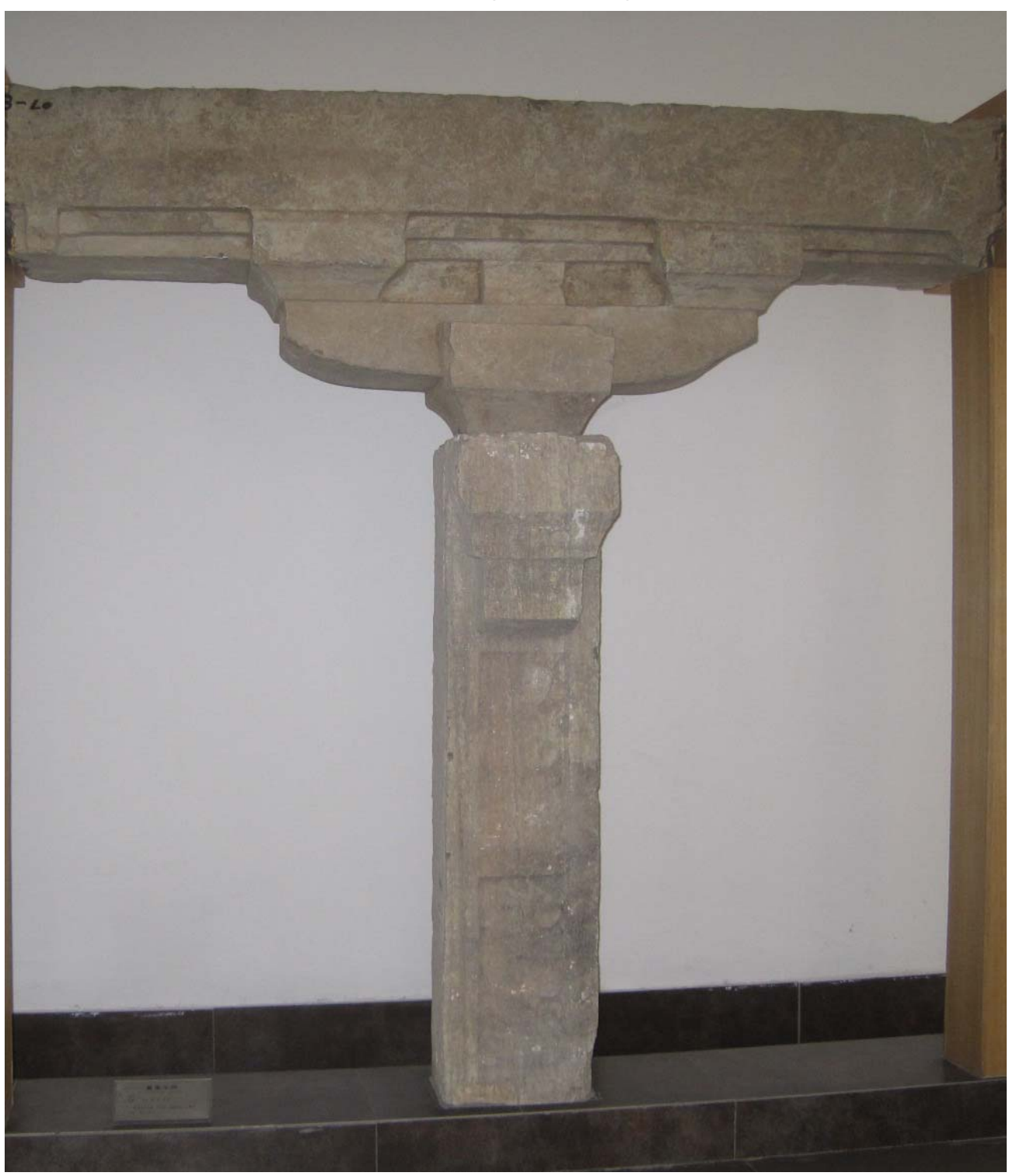

Figure 2-10b, a stone dougong bracket in a stone tomb. Photograph by the author. 


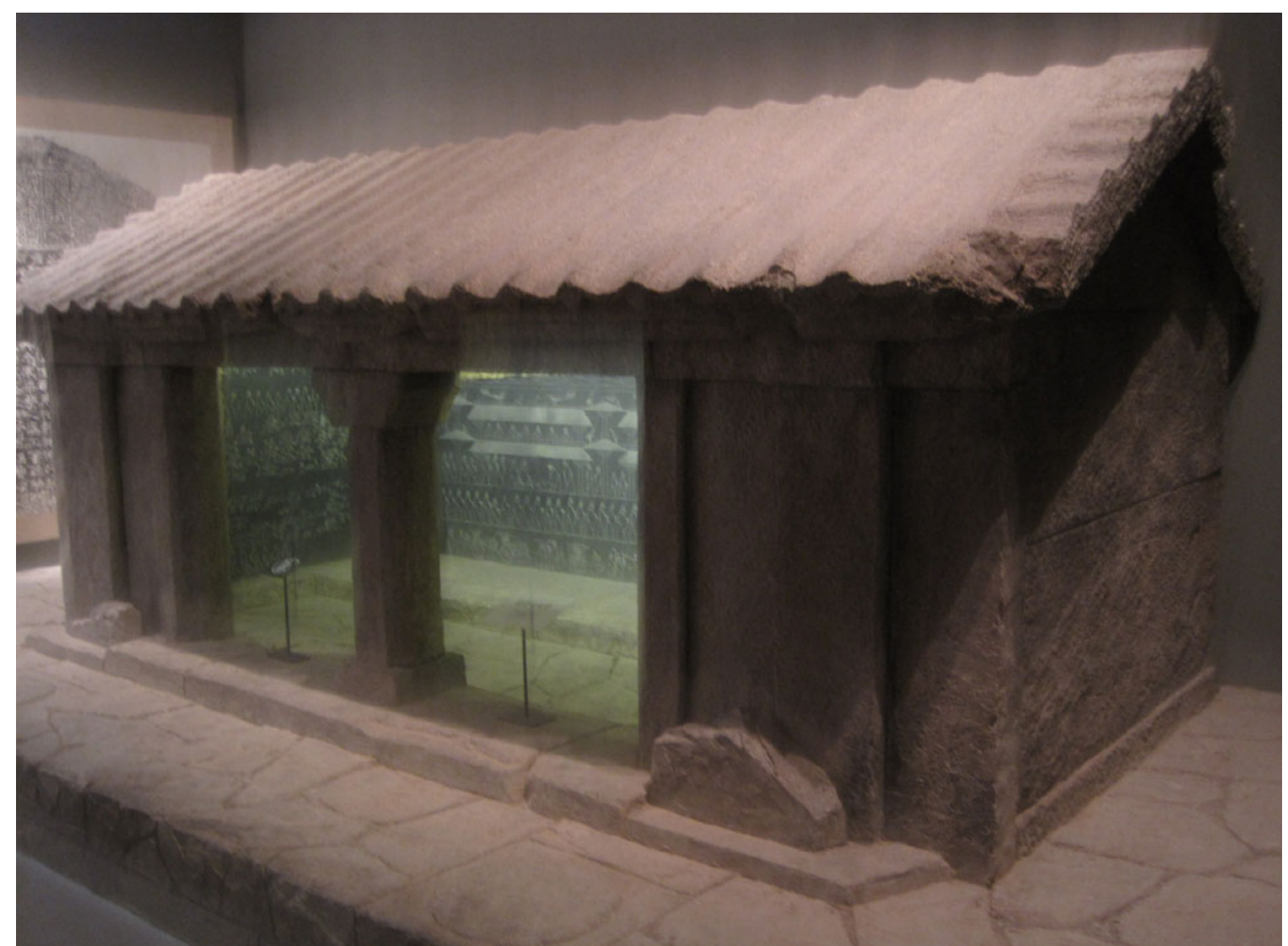

Figure 2-11a, reconstruction of the Xiaotangshan shrine. Photograph by the author.

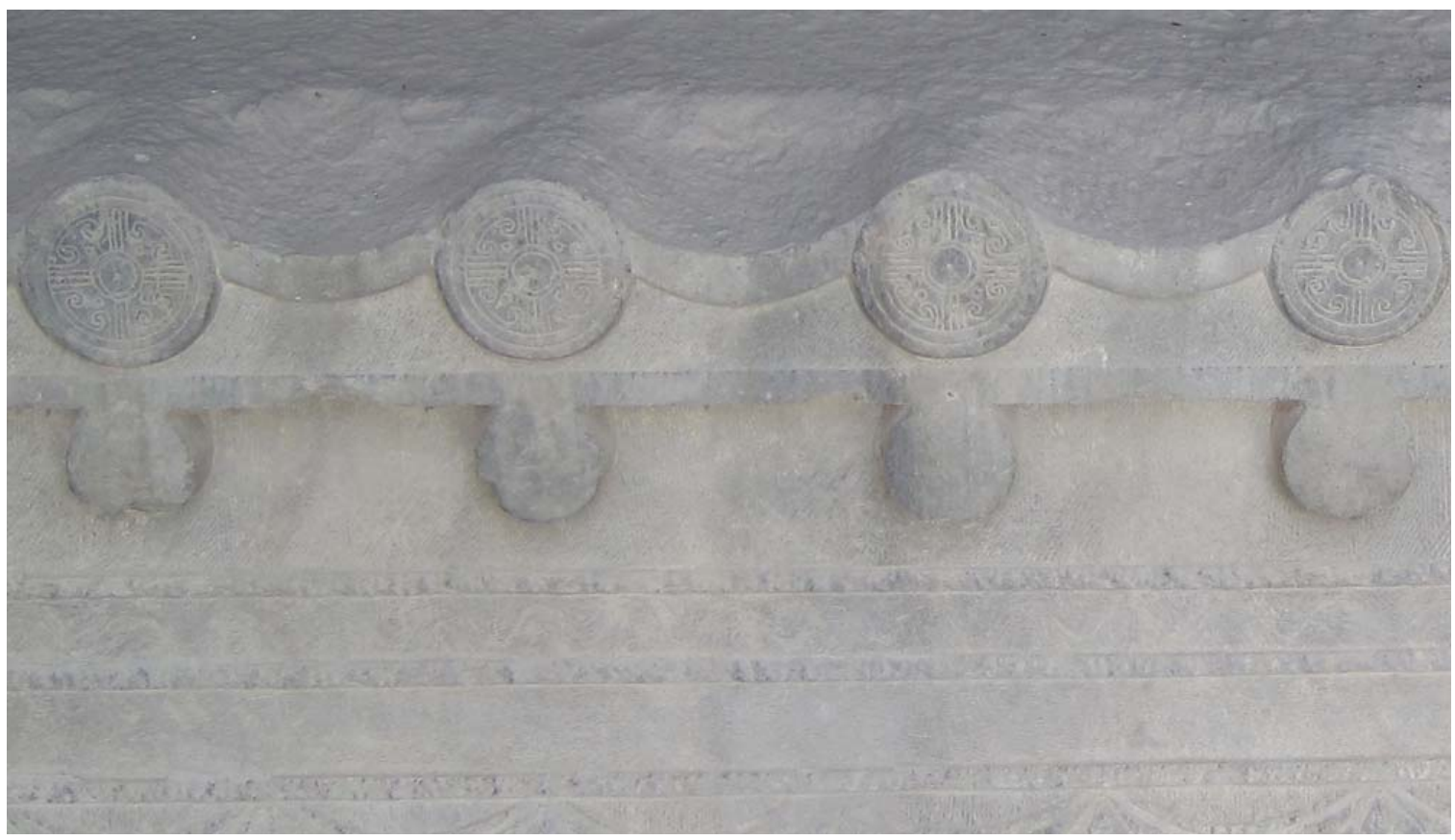

Figure 2-11b, tiled eaves of an unnamed shrine in Jiaxiang, Shandong. Photograph by the author. 
The figure originally presented here cannot be made freely available via ORA for copyright reasons.

Figure 2-12a, drawings of pillar gates carved on stones of the Yinan tomb. After Yinan 1956: Plate 105 (3), (4).

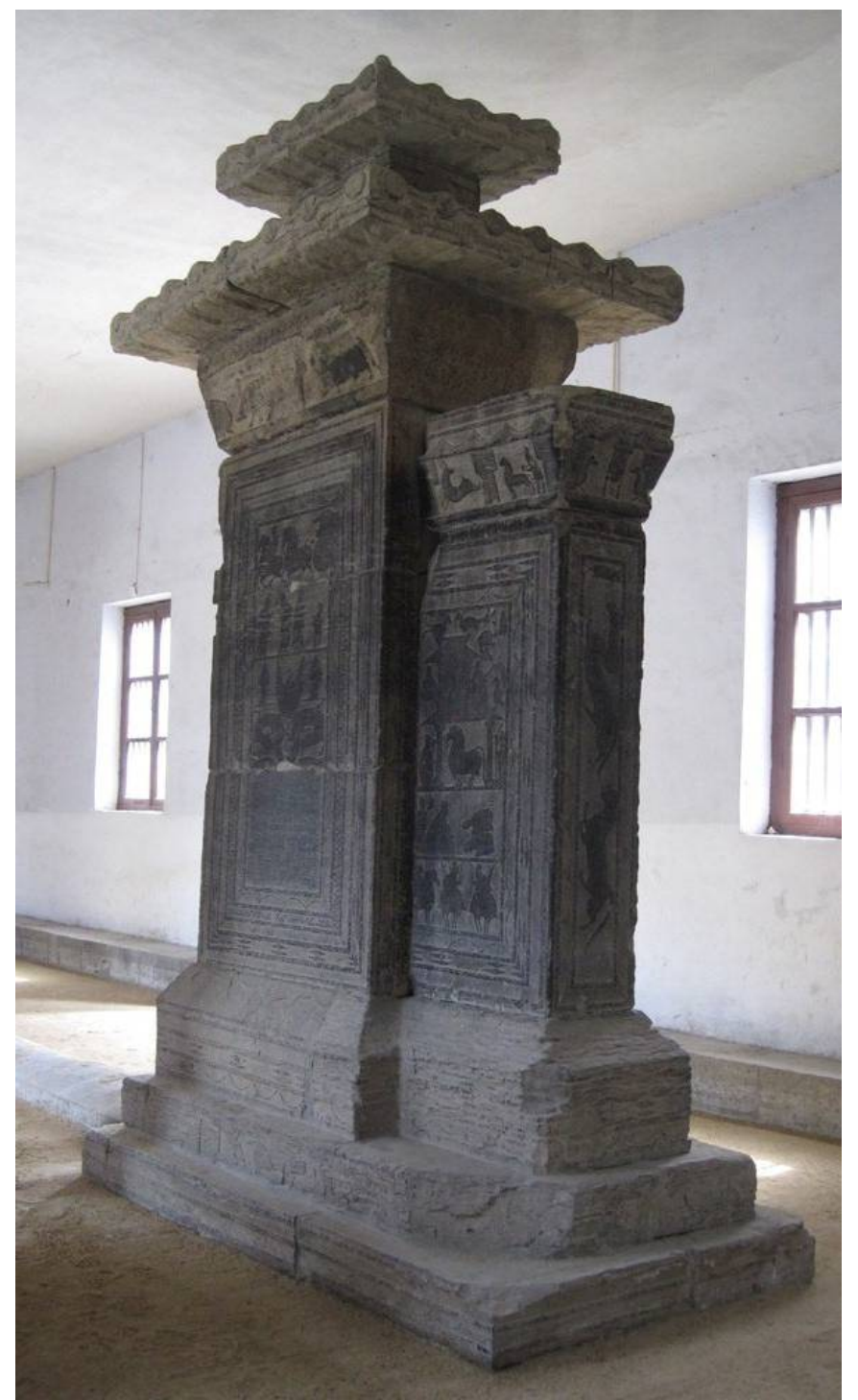

Figure 2-12b, one of the pillar gates of the Wu Family cemetery.

Photograph by the author. 

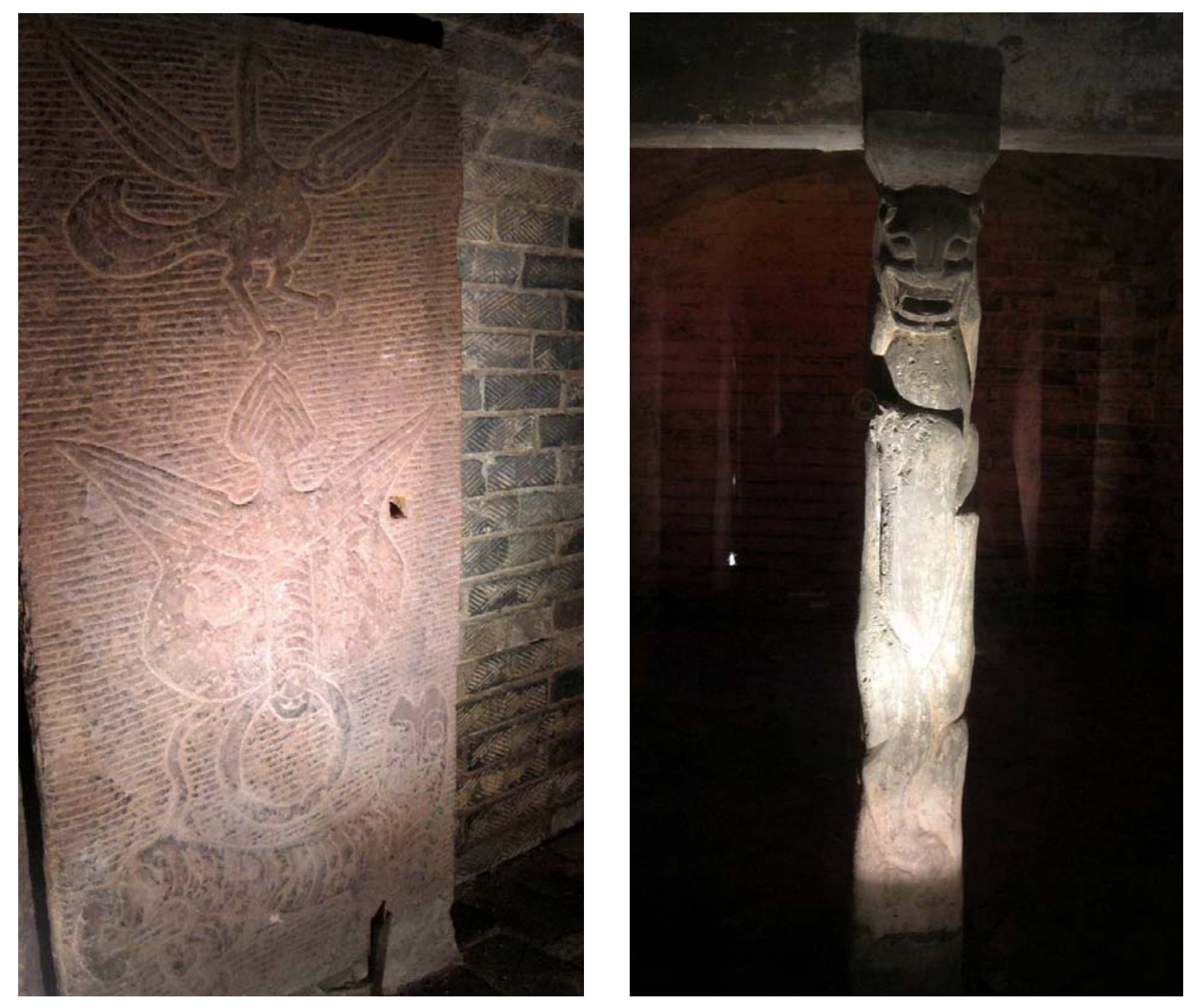

Figure 2-13a, (left) stone door and brick wall of the Jianhe tomb near Luoyang. Photograph by the author.

Figure 2-13b, (right) terracotta column in the Jianhe tomb near Luoyang. Photograph by the author. 


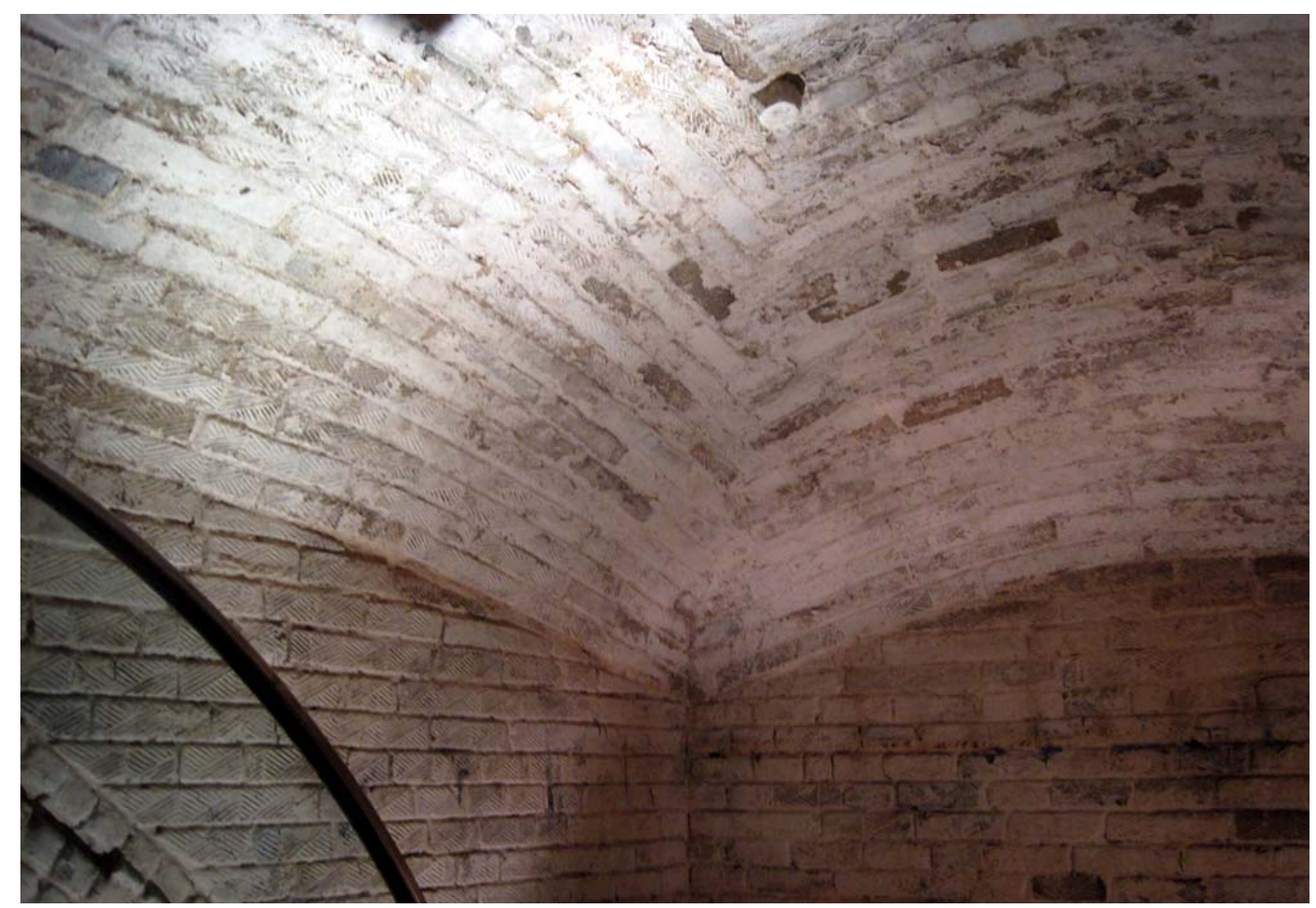

Figure 2-14a, round dome vault of the Jianhe tomb near Luoyang. Photograph by the author.

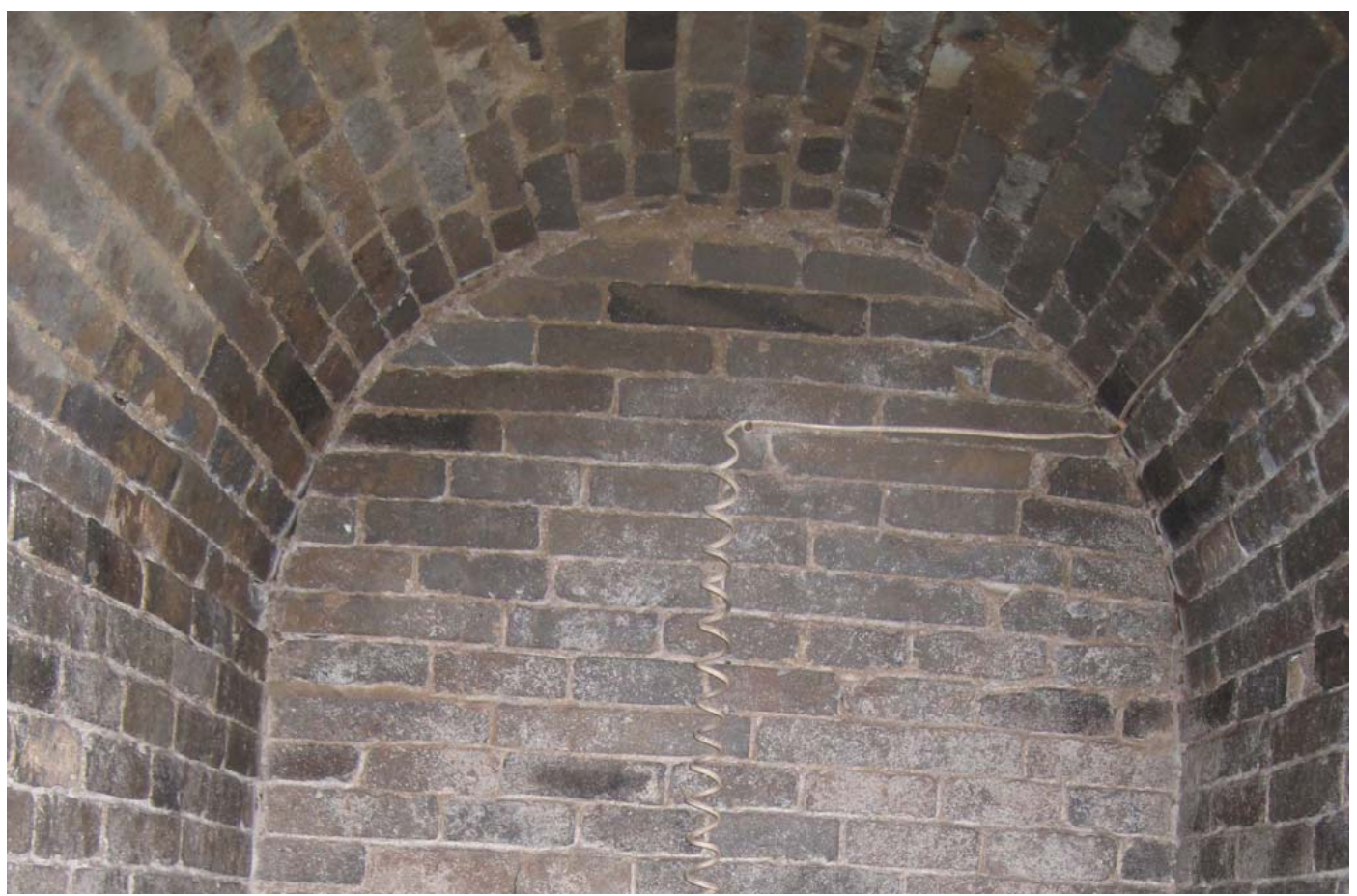

Figure 2-14b, barrel vault of the Feng Rujiu tomb. Photograph by the author. 


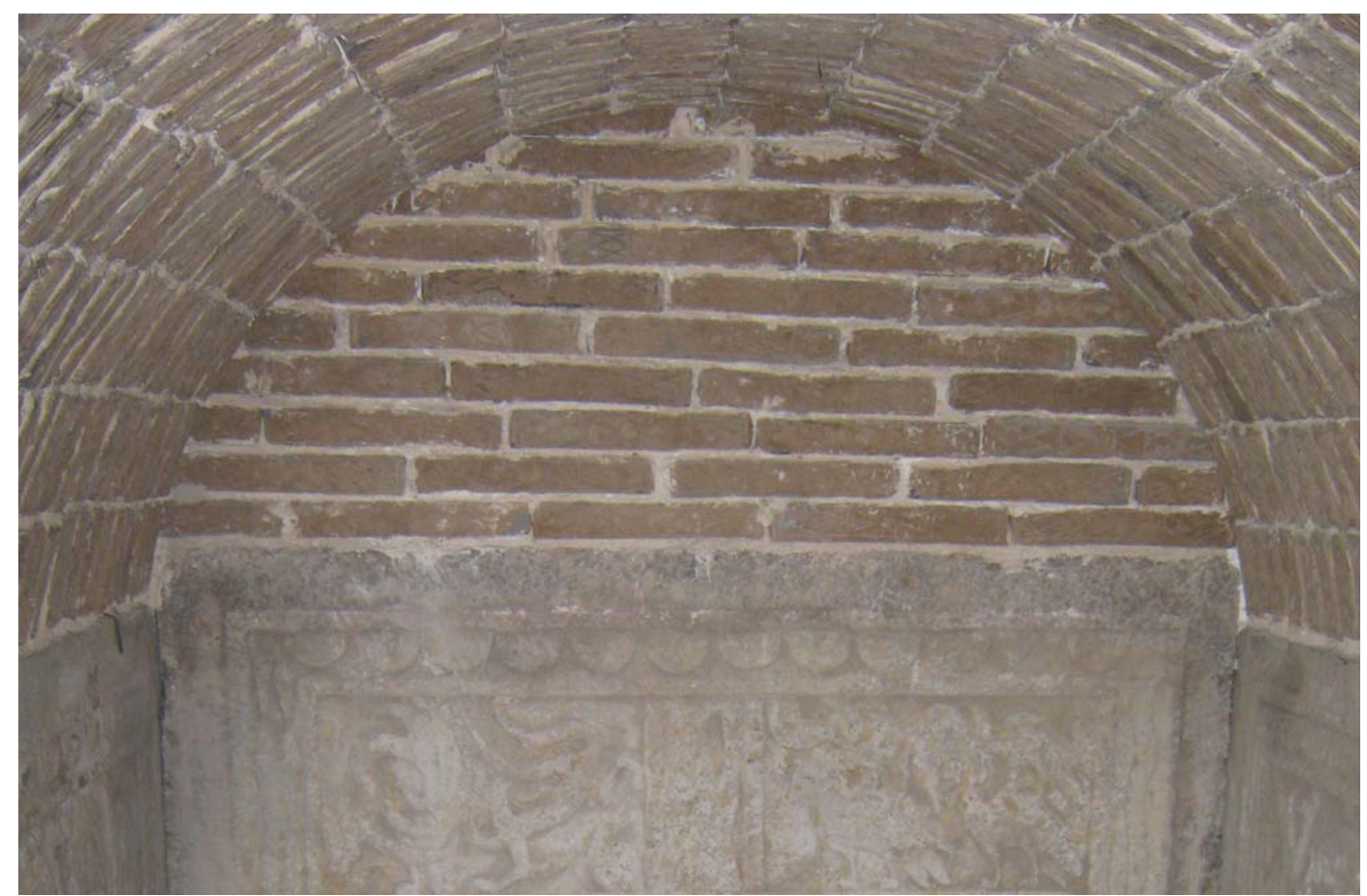

Figure 2-14c, barrel vault of the Chefushan tomb. Photograph by the author.

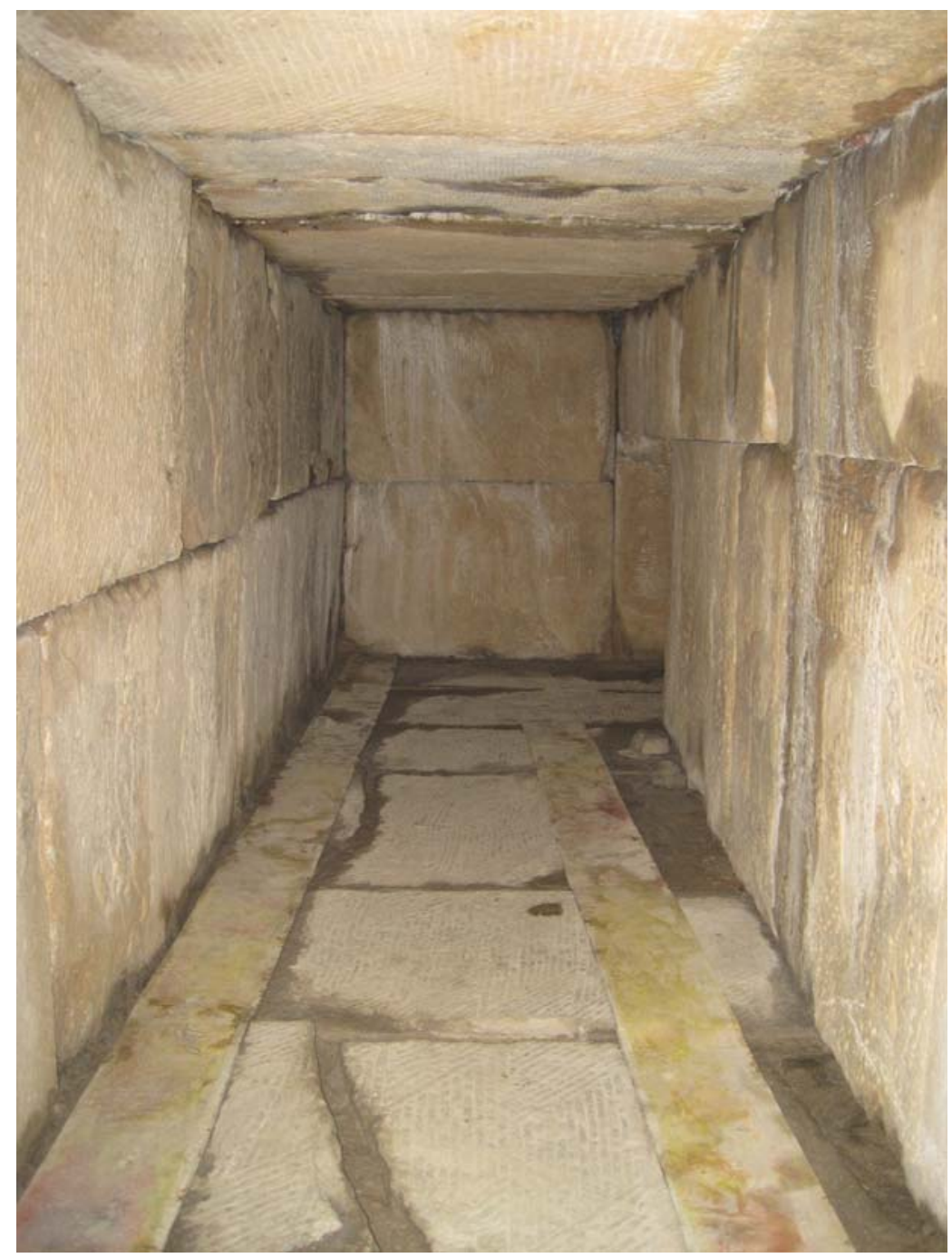

Figure 2-15a, flat roof of the Feng Rujiu tomb. Photograph by the author. 


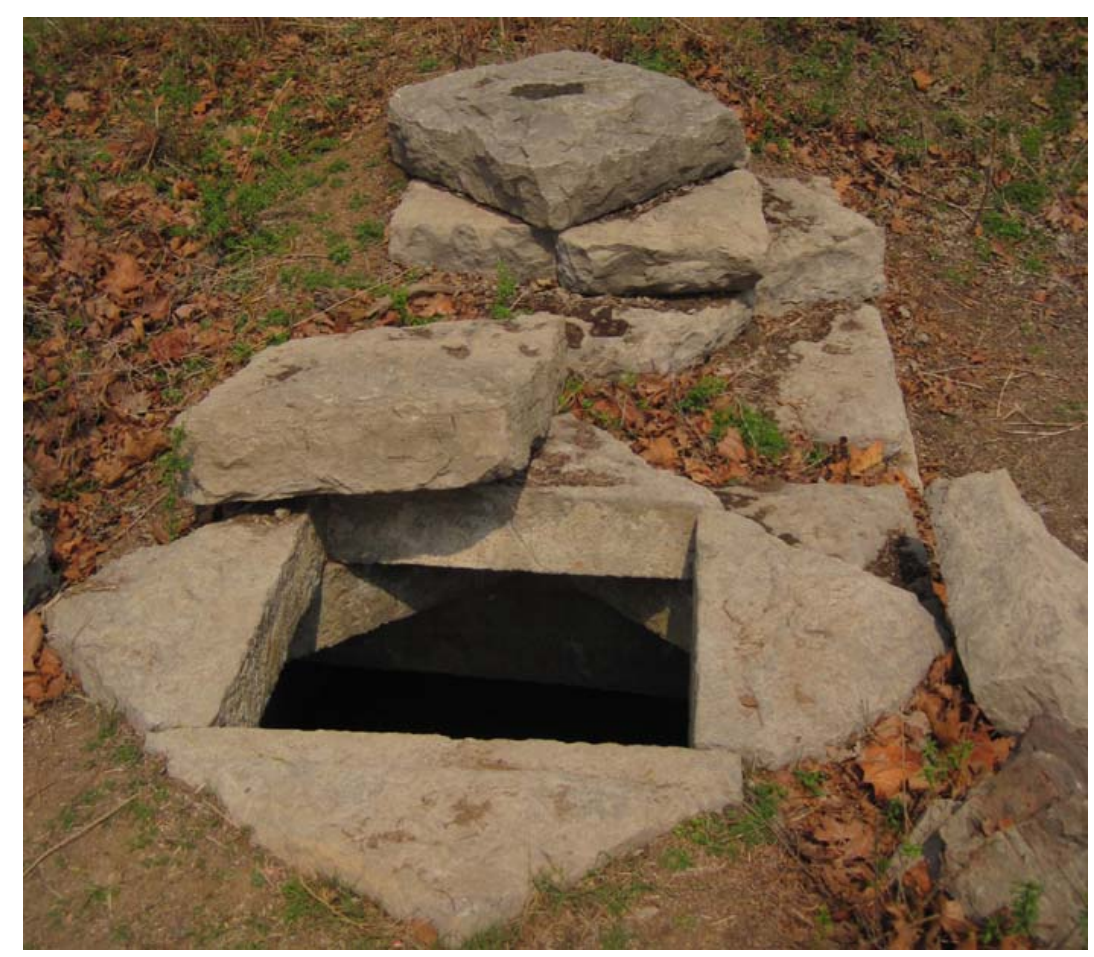

Figure 2-15b, overlaid diamond roof of one the Wu Family tombs. Photograph by the author.

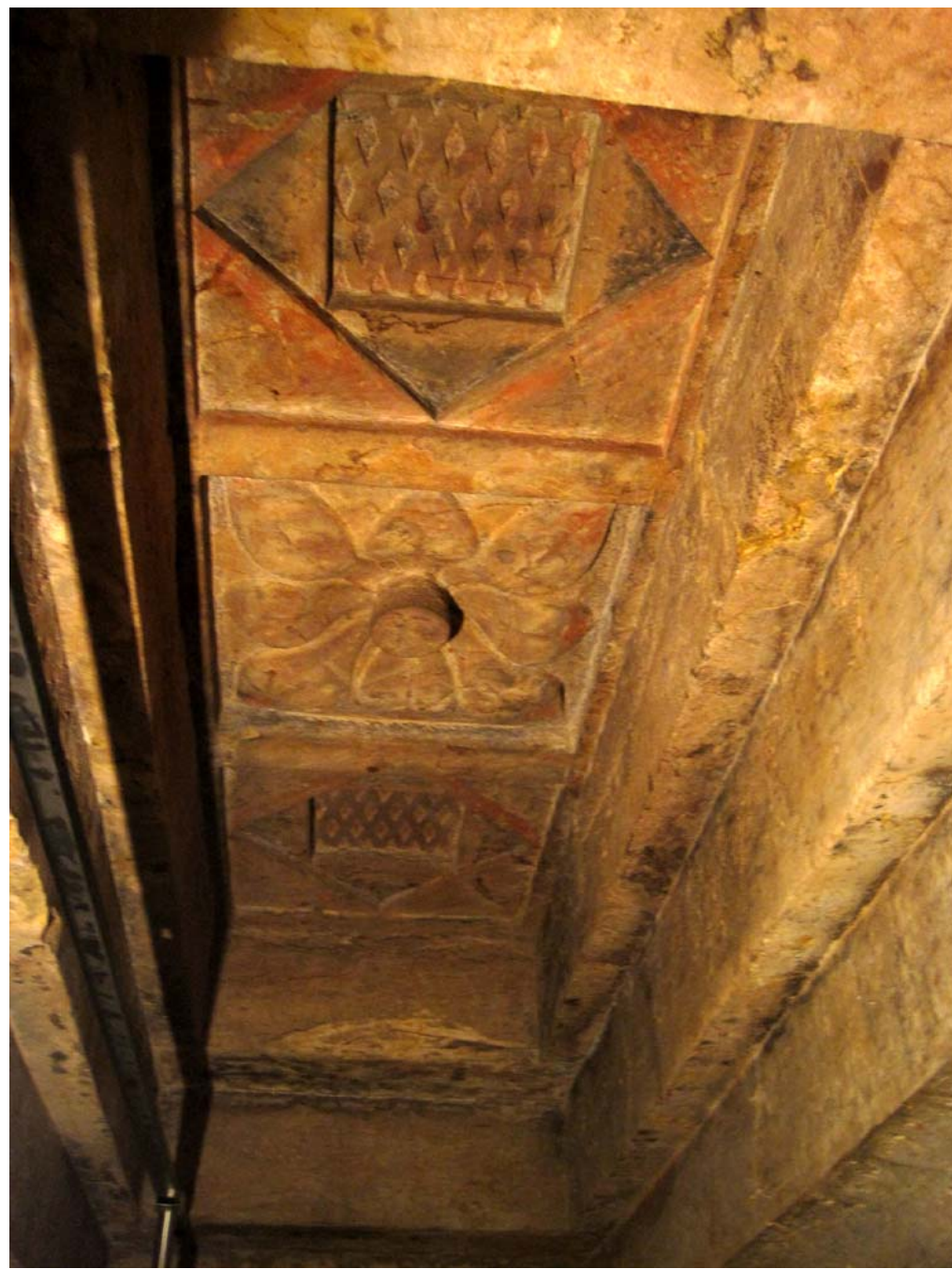

Figure 2-15c, stepped roof of the Yi'nan tomb. Photograph by the author. 
The figure originally presented here cannot be made freely available via ORA for copyright reasons.

Figure 2-15d, structure of the Dengmiao tomb showing the truncated pyramid roofs. After Kaogu 2007.3: 35, Figure 3.

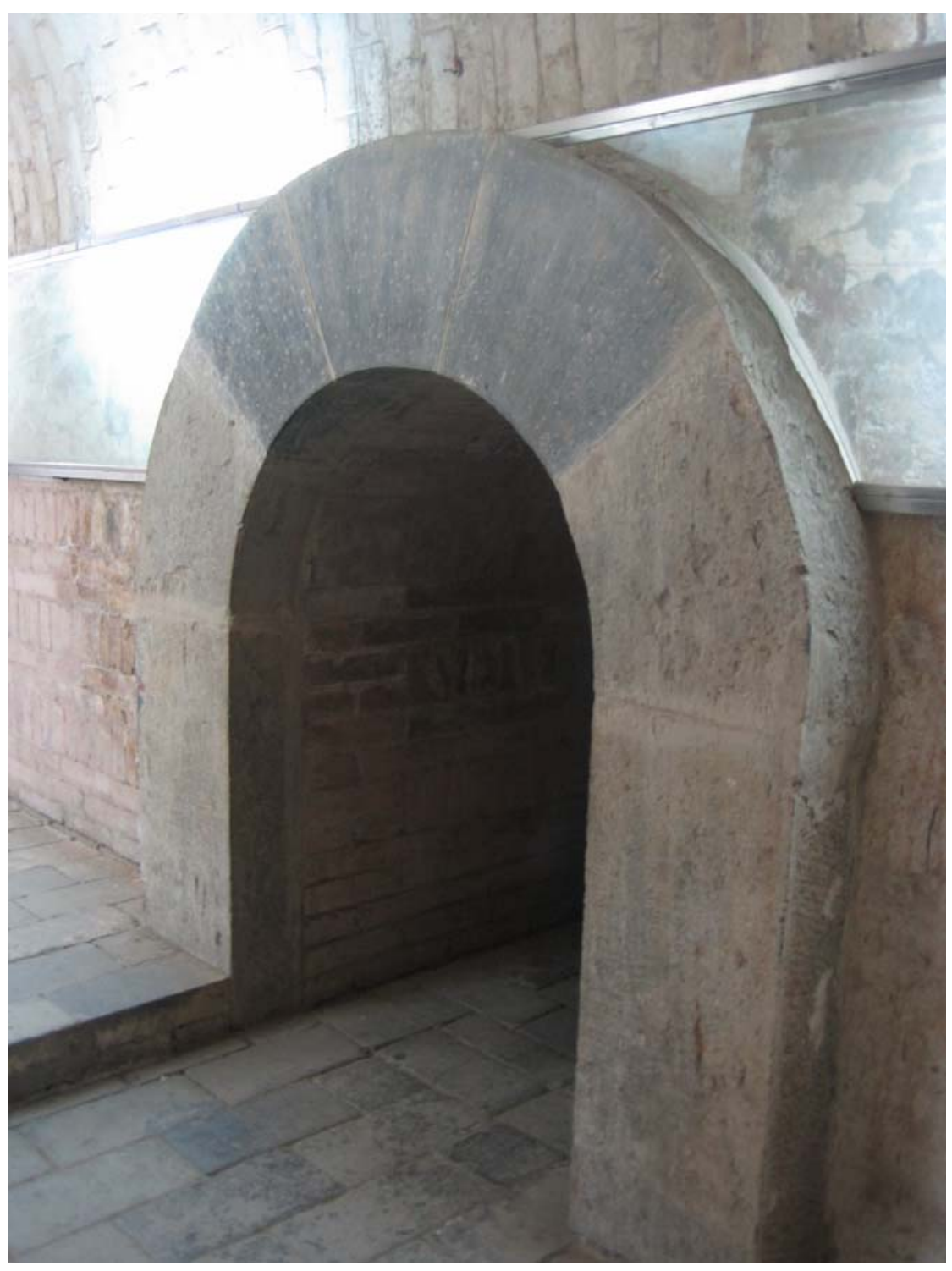

Figure 2-15e, barrel vault of the Xingyuan tomb. Photograph by the author. 
The figure originally presented here cannot be made freely available via ORA for copyright reasons.

Figure 2-16, iron tools excavated from a Han quarry site at Xuzhou. After Kaogu 2010.11: 36, Figure 15.

The figures originally presented here cannot be made freely available via ORA for copyright reasons.

Figure 2-17a, (left) mason tools of late Imperial China. After Mao Yisheng 1986, Figure 6-1.

Figure 2-17b, (right) principal stone tools of the $20^{\text {th }}$ c. After Adam 1994: fig. 46. 


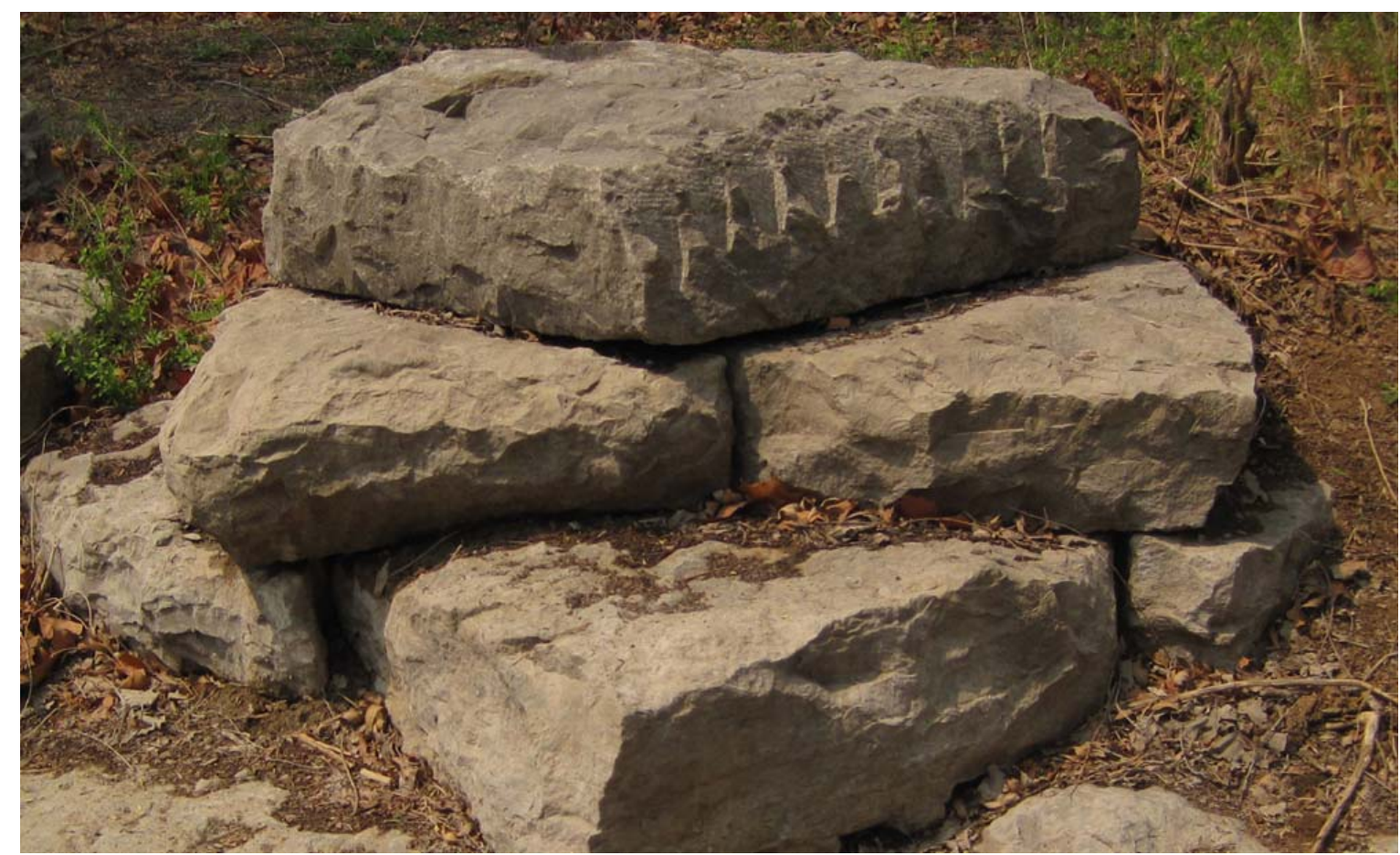

Figure 2-18, roof of one of the Wu Family tombs showing wedged sockets.

Photograph by the author.

The figure originally presented here cannot be made freely available via ORA for copyright reasons.

Figure 2-19, modern wedged quarrying. Photo Courtesy of Reiner Flassig. 


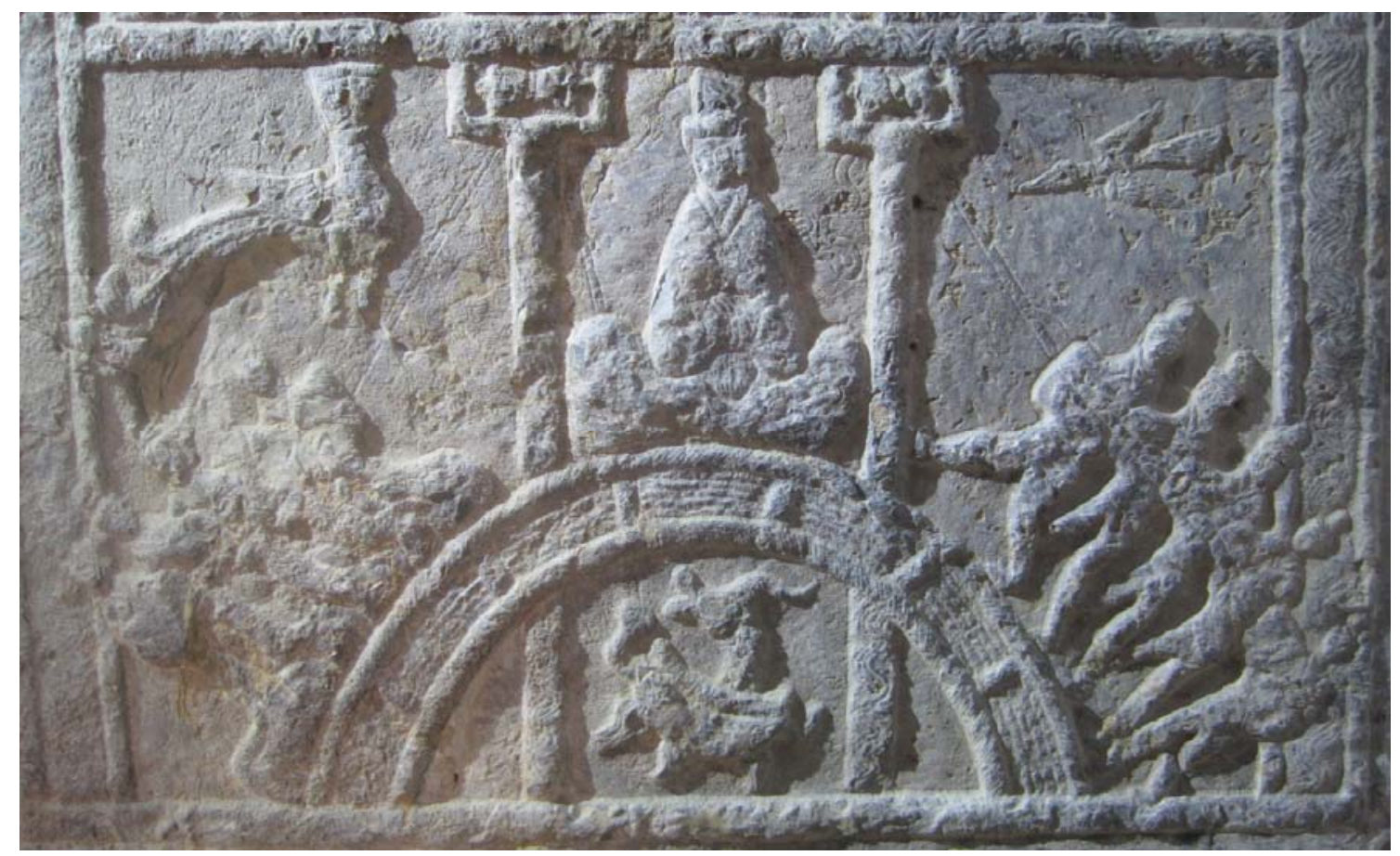

Figure 2-20a, stone carvings of the tripod lifting scene. Photograph by the author.

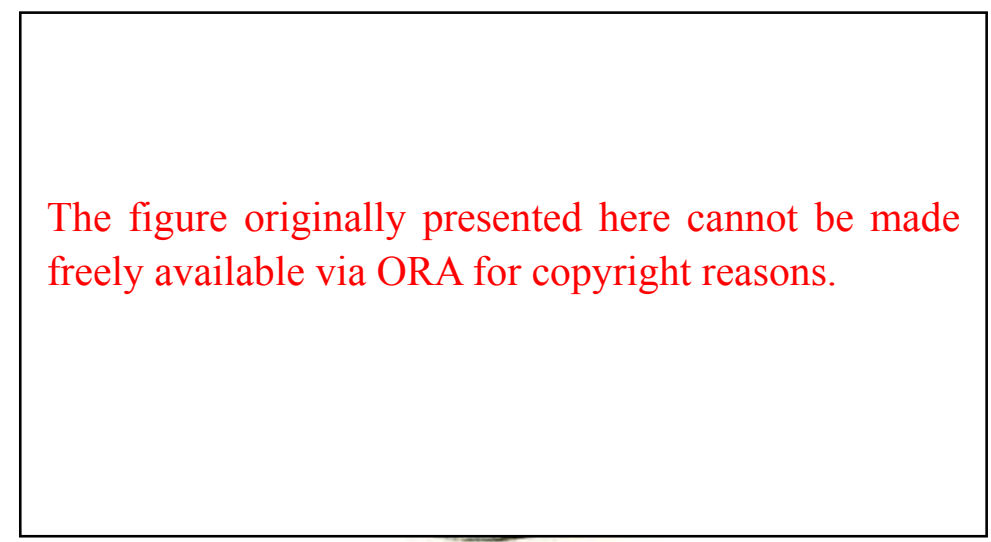

Figure 2-20b, pottery model of a well with a pulley. After Xiaoxian 2008, Plate VIII-3.

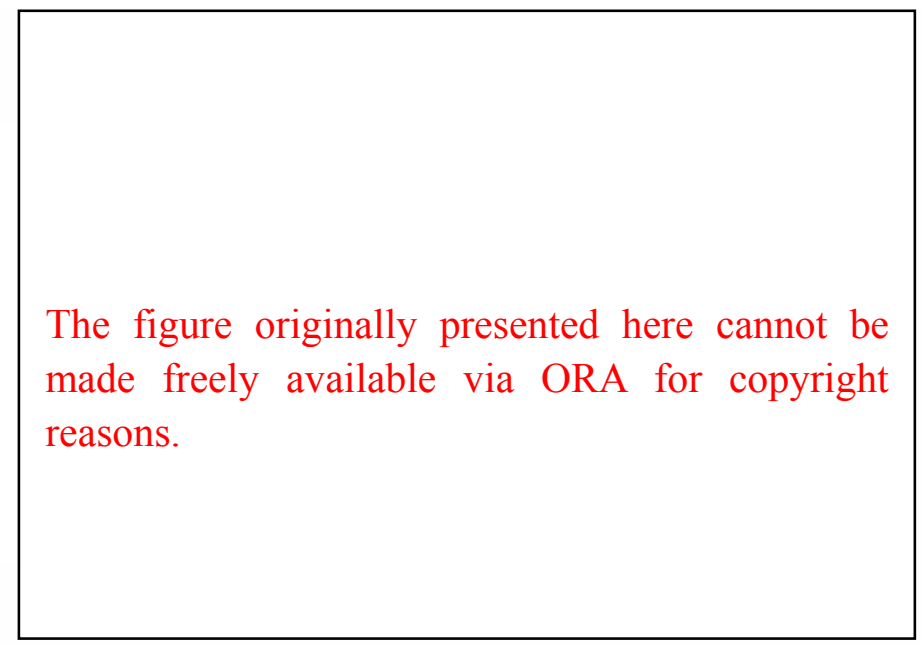

Figure 2-20c, drawing of a bronze pulley from Mancheng tomb M1. After Mancheng 1980, vol. 1, Figure 21. 
The figure originally presented here cannot be made freely available via ORA for copyright reasons.

Figure 2-21a, pulley system of late Imperial China.

After Mao Yisheng 1986, Figure 6-22.

The figure originally presented here cannot be made freely available via ORA for copyright reasons.

Figure 2-21b, levers and ropes used for stone transportation in late Imperial China. After Mao Yisheng 1986, Figure 6-21. 
The figure originally presented here cannot be made freely available via ORA for copyright reasons.

Figure 2-22a, plan of the Yang Family cemetery. After Wenwu 1961.1: 56, Figure 1.

The figure originally presented here cannot be made freely available via ORA for copyright reasons.

Figure 2-22b, arrangement of the Changli tombs. After Wenwu cankao ziliao 1957.12: 35.

The figure originally presented here cannot be made freely available via ORA for copyright reasons.

Figure 2-22c, plan of the Wu Family cemetery. After Jiang Yingju and Wu Wenqi 1995, Figure 2. 


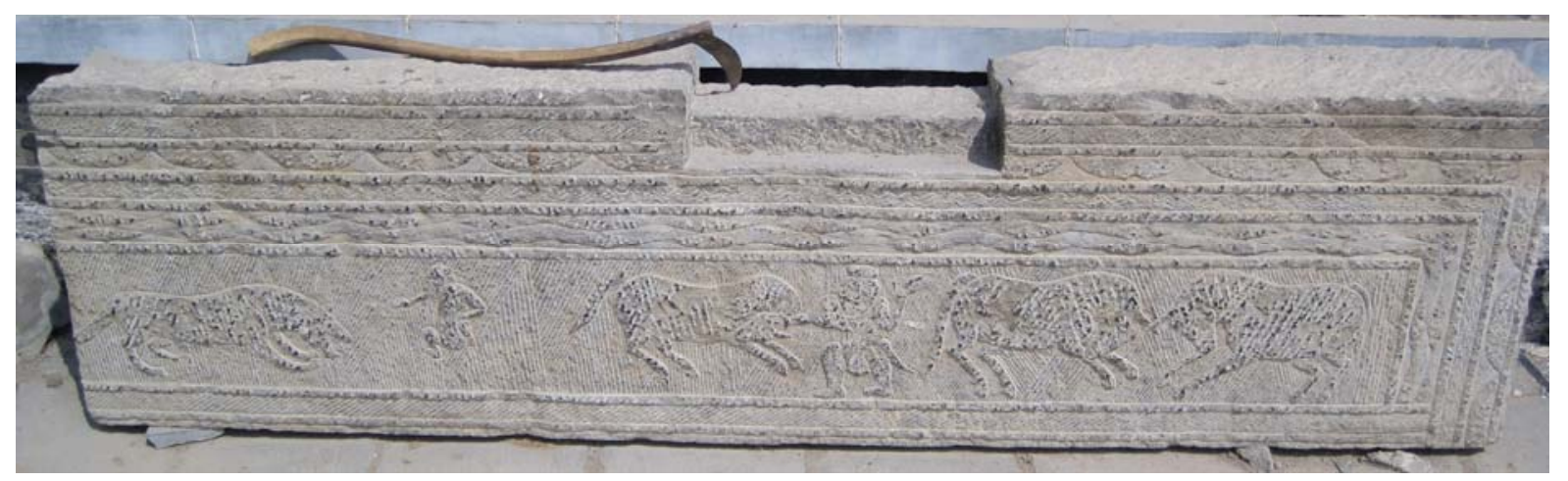

Figure 2-23, a carved stone slab with a notch from Jiaxiang, Shandong. Photograph by the author.

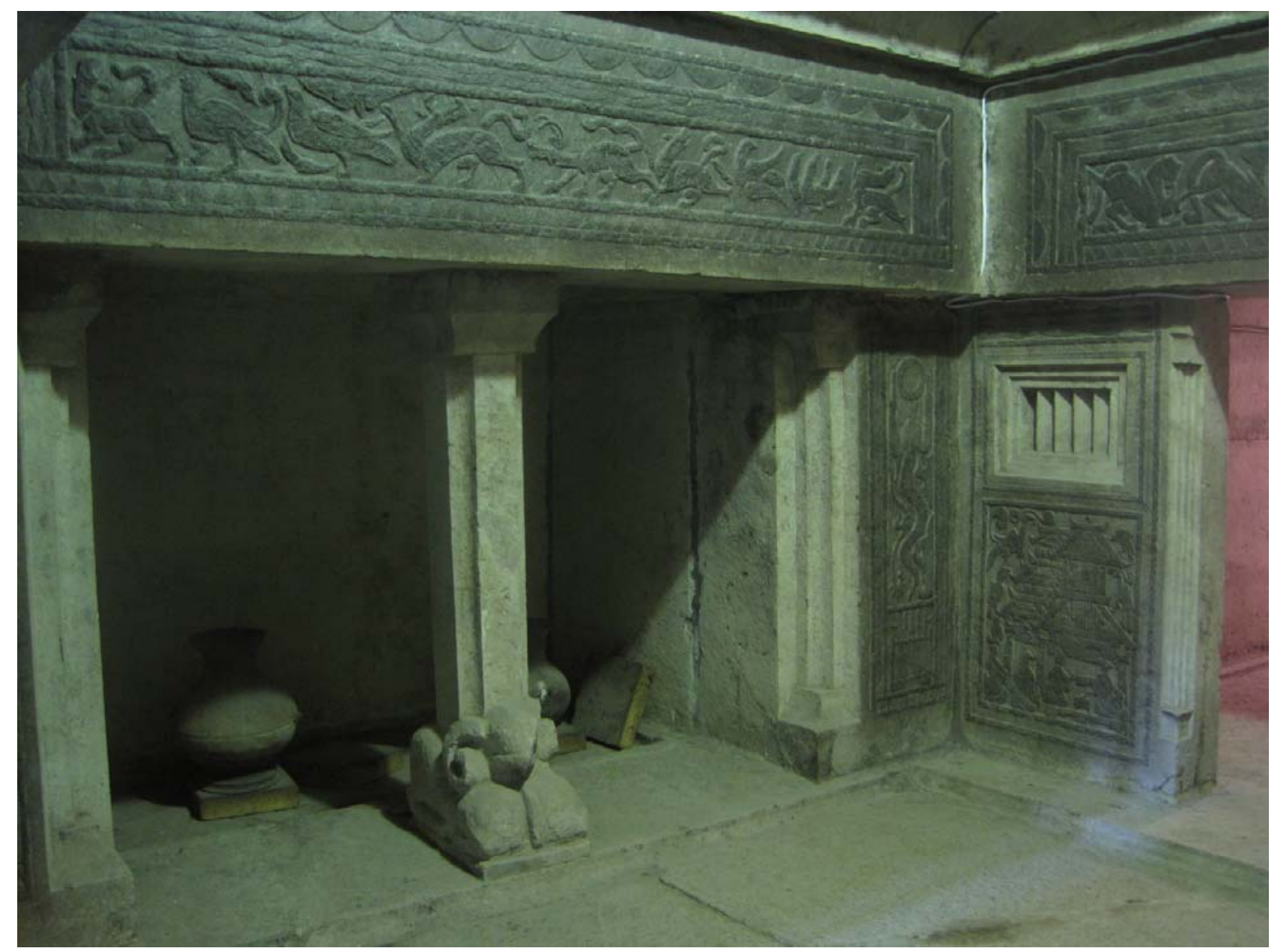

Figure 2-24, view of middle chamber in the Baiji Tomb. Photograph by the author. 


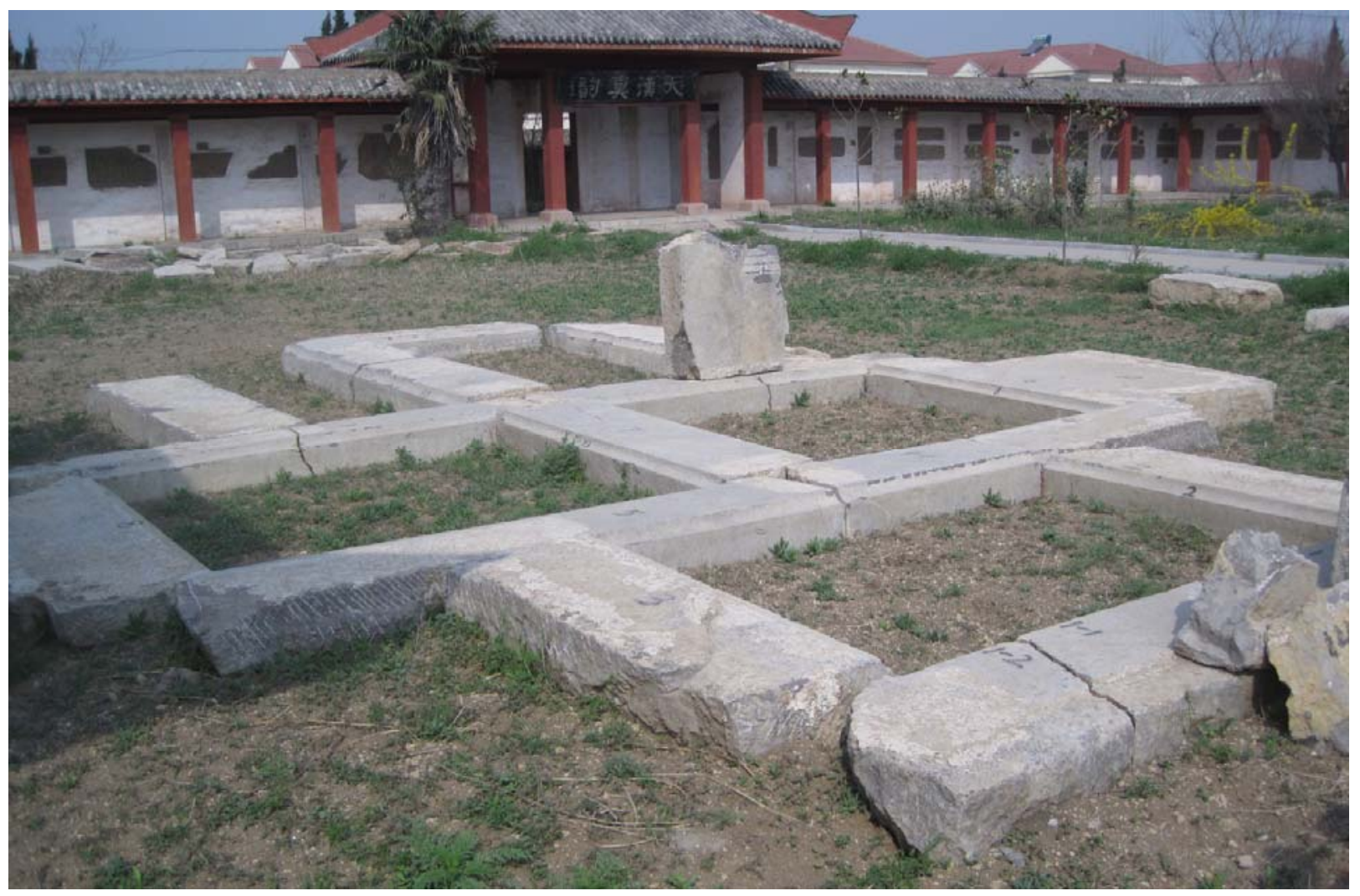

Figure 2-26, footing stones excavated near Baiji, Xuzhou. Photograph by the author.

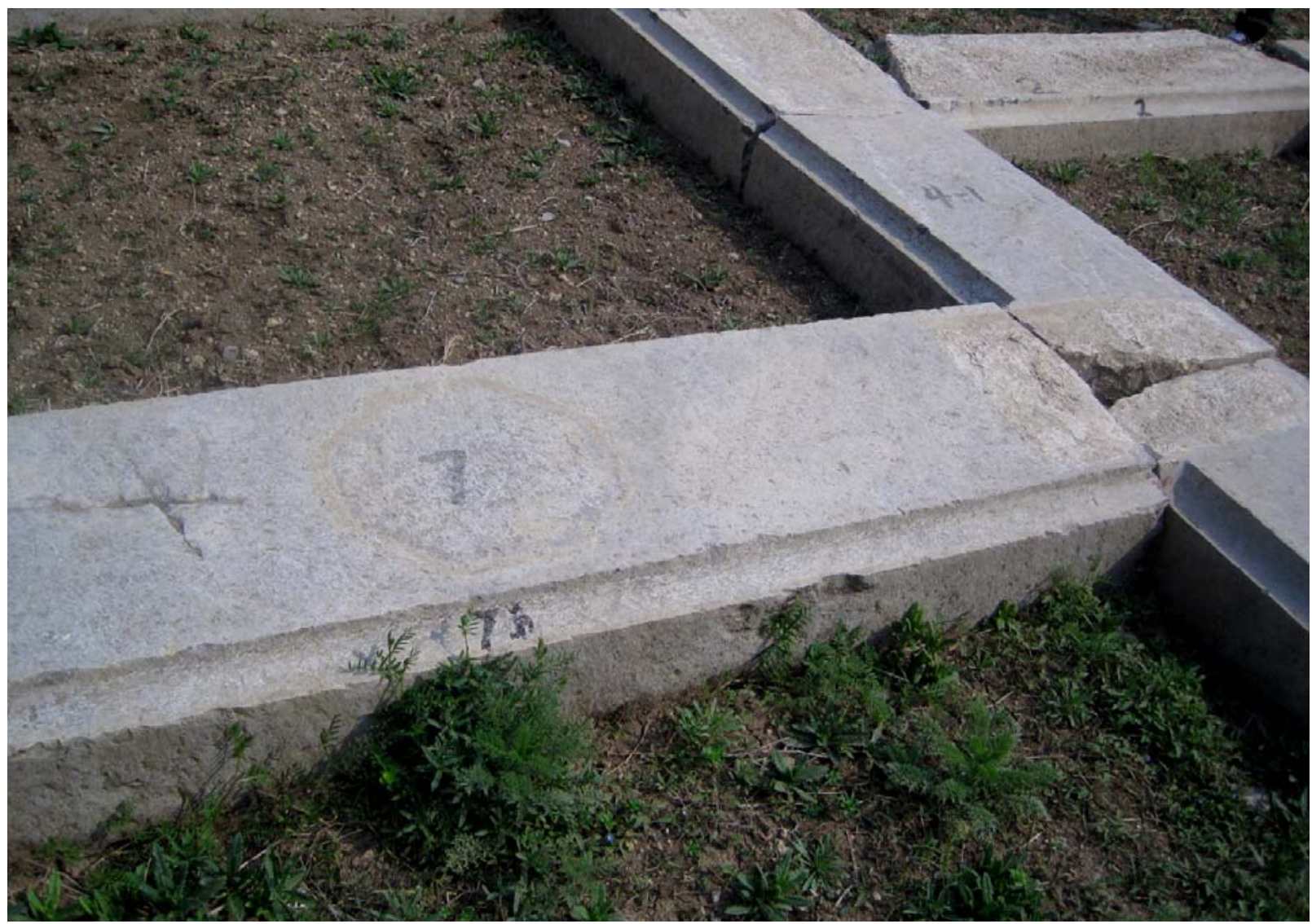

Figure 2-27, footing stones excavated near Baiji, Xuzhou, note the imprint of a column. Photograph by the author. 
The figure originally presented here cannot be made freely available via ORA for copyright reasons.

Figure 2-28, wooden frameworks for the construction of vaults, late Imperial China. After Mao Yisheng 1986, Figure 6-23 and 6-24.

The figure originally presented here cannot be made freely available via ORA for copyright reasons.

Figure 2-29, Roman centerings for arches and vaults. After Adam 1994, Figure 417.

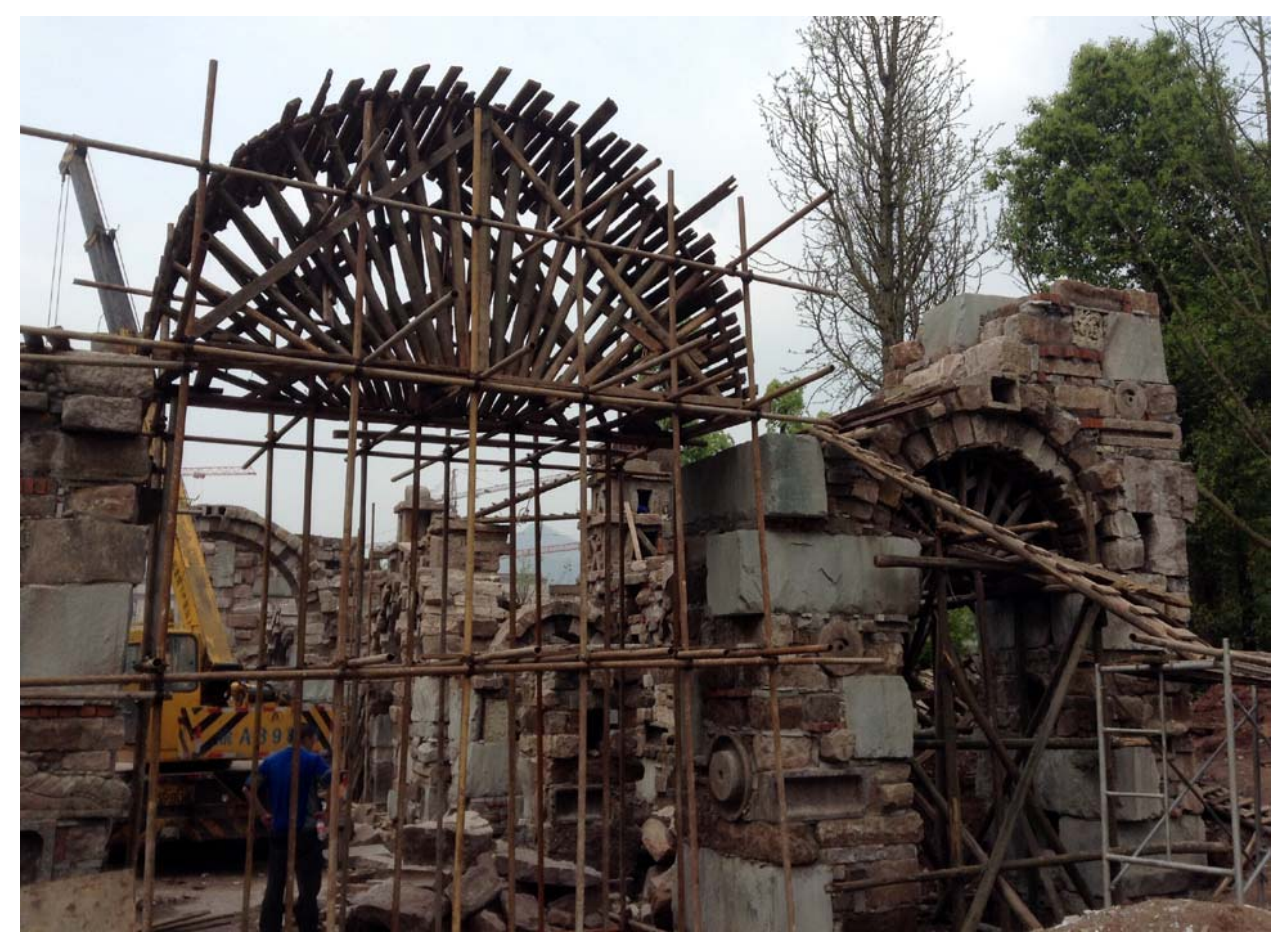

Figure 2-30, centrings for the construction site of the gate of Sichuan Fine Arts Institute, Chongqing, China. Photograph by the author. 


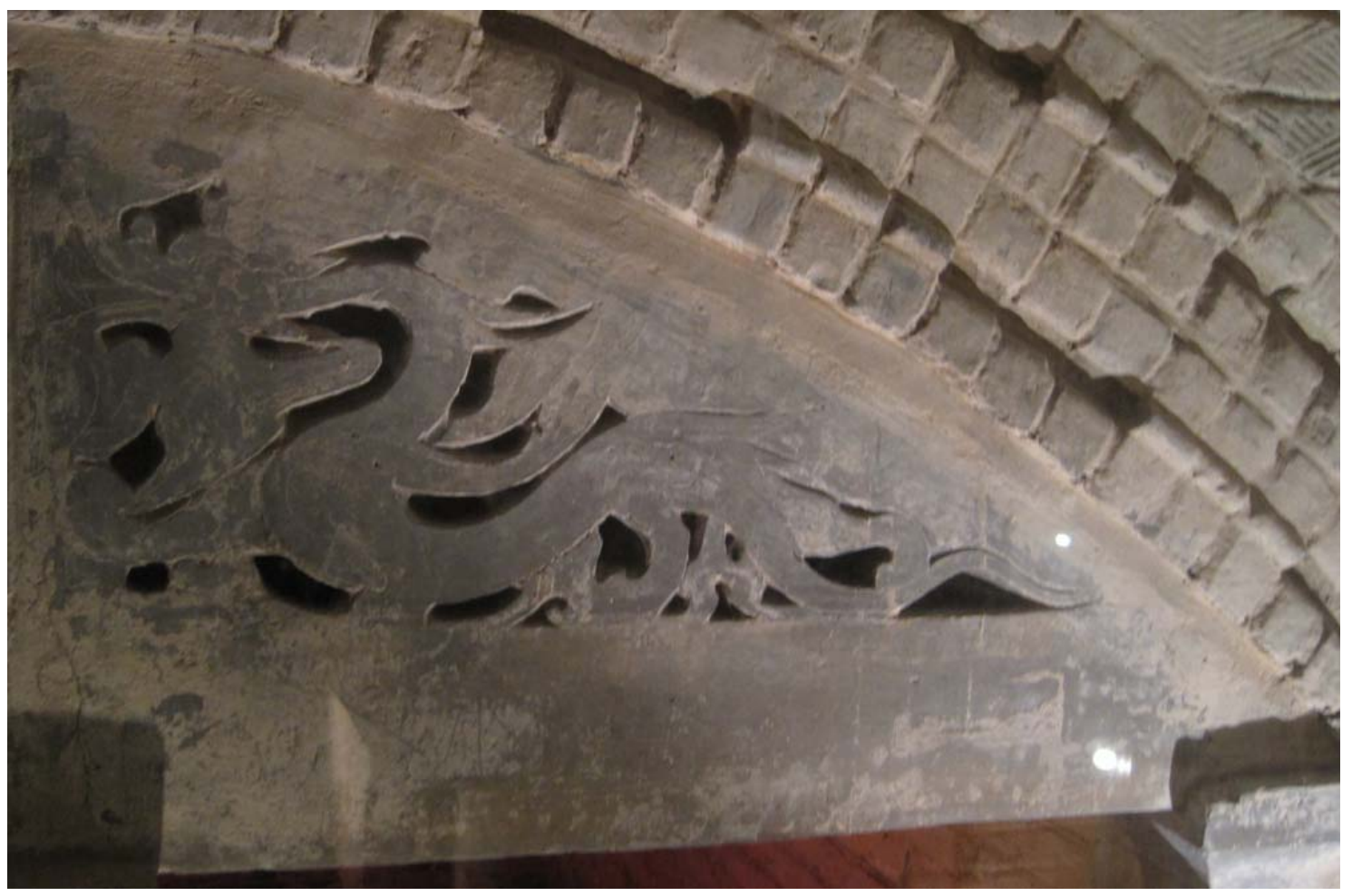

Figure 2-31, an arch of layers of bricks, Jianhe tomb of Luoyang. Photograph by the author.

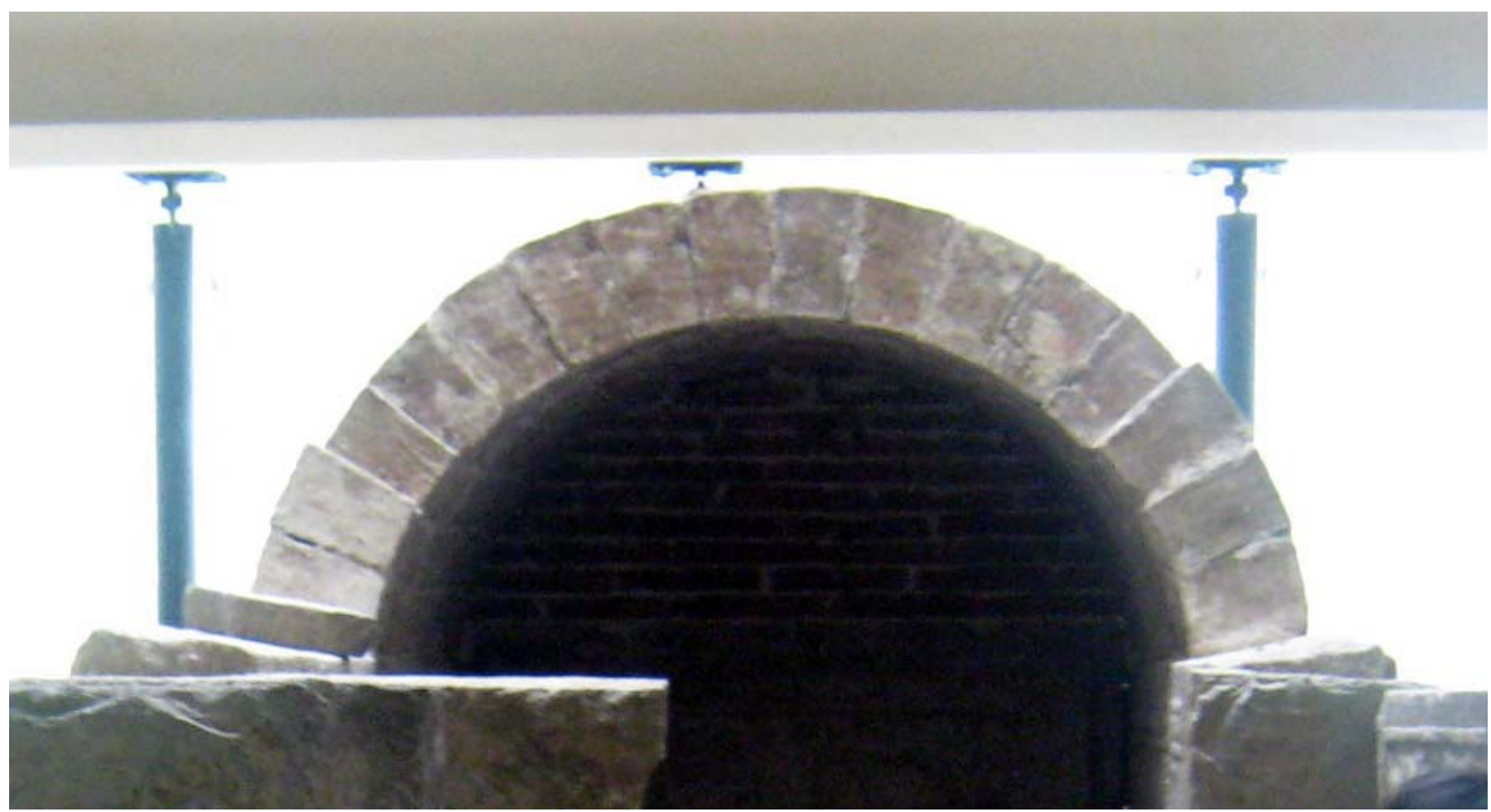

Figure 2-32, roof of the Chefushan tomb. Photograph by the author. 
The figure originally presented here cannot be made freely available via ORA for copyright reasons.

Figure 2-35a, lined stone protection of Dahuting tomb M1. After Mixian 1993, Plate I-2.

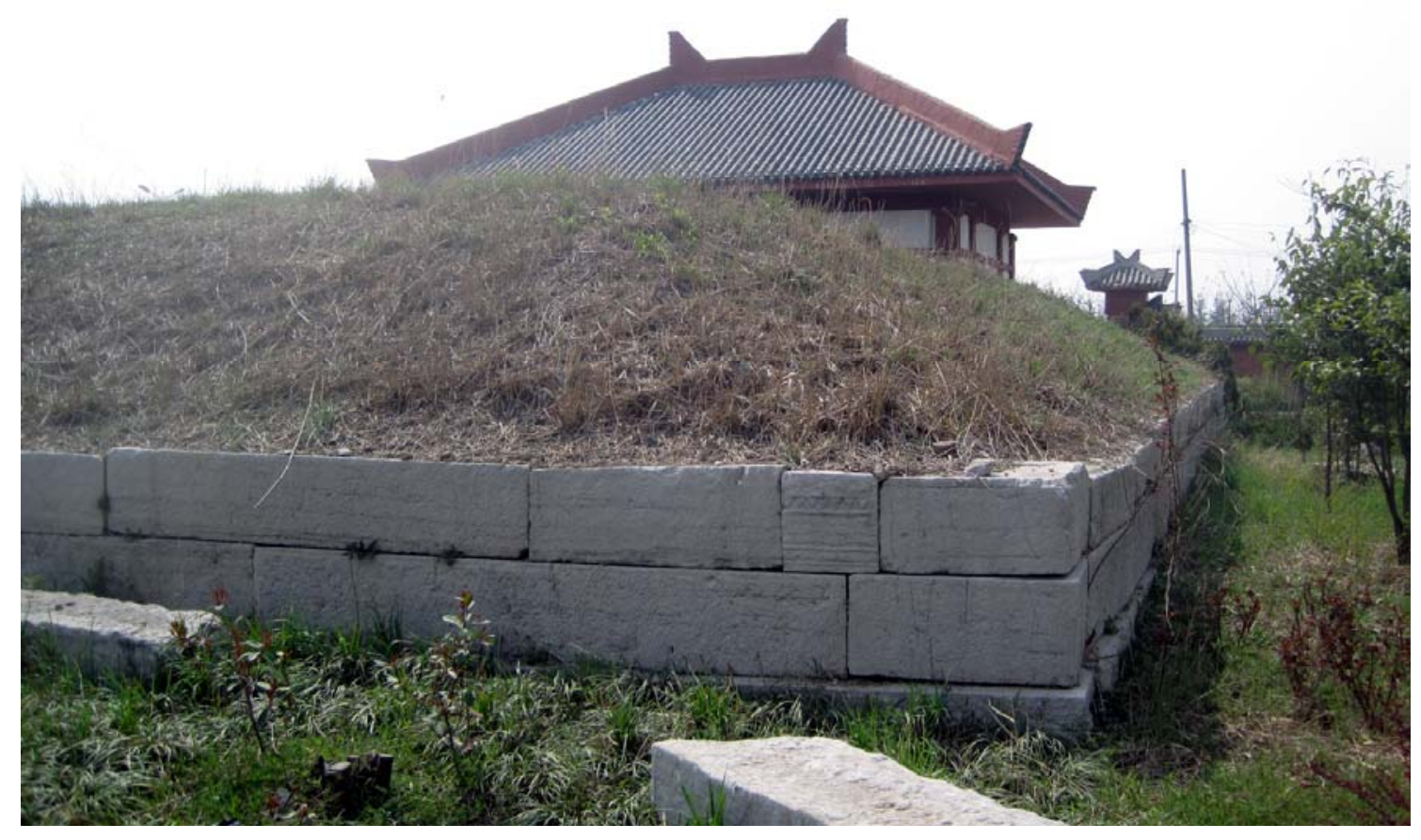

Figure 2-35b, lined stone protection of the Baiji tomb. Photograph by the author. 


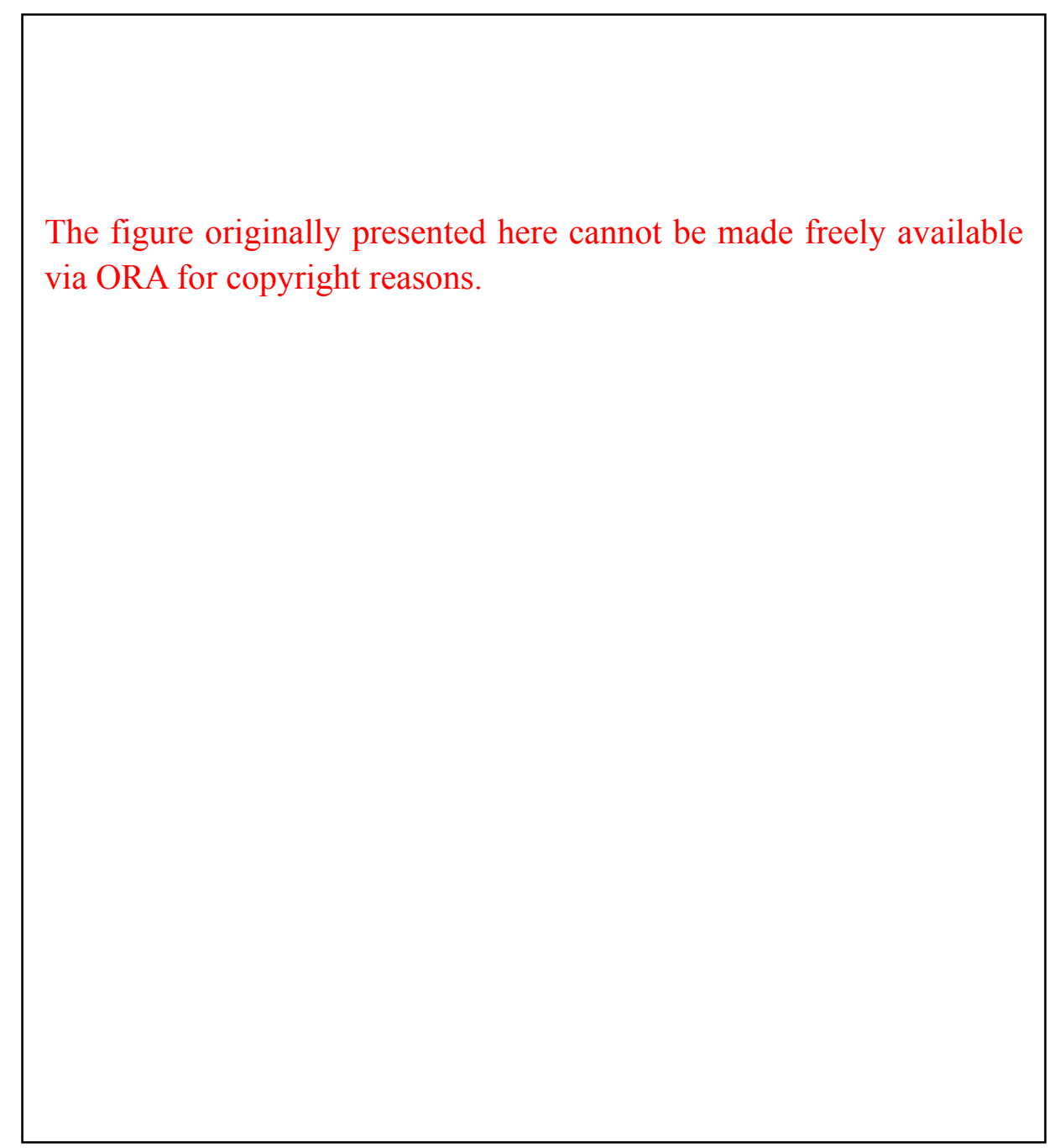

Figure 2-36, Plan and elevation of Miao Yu's graveyard. After Wenwu 1984.8: p. 22, Fig. 1. 
The figure originally presented here cannot be made freely available via ORA for copyright reasons.

Figure 2-40, Plan of Chefushan tomb No. 2.

After Dongnan wenhua 2006.2: p. 26, Fig. 1.

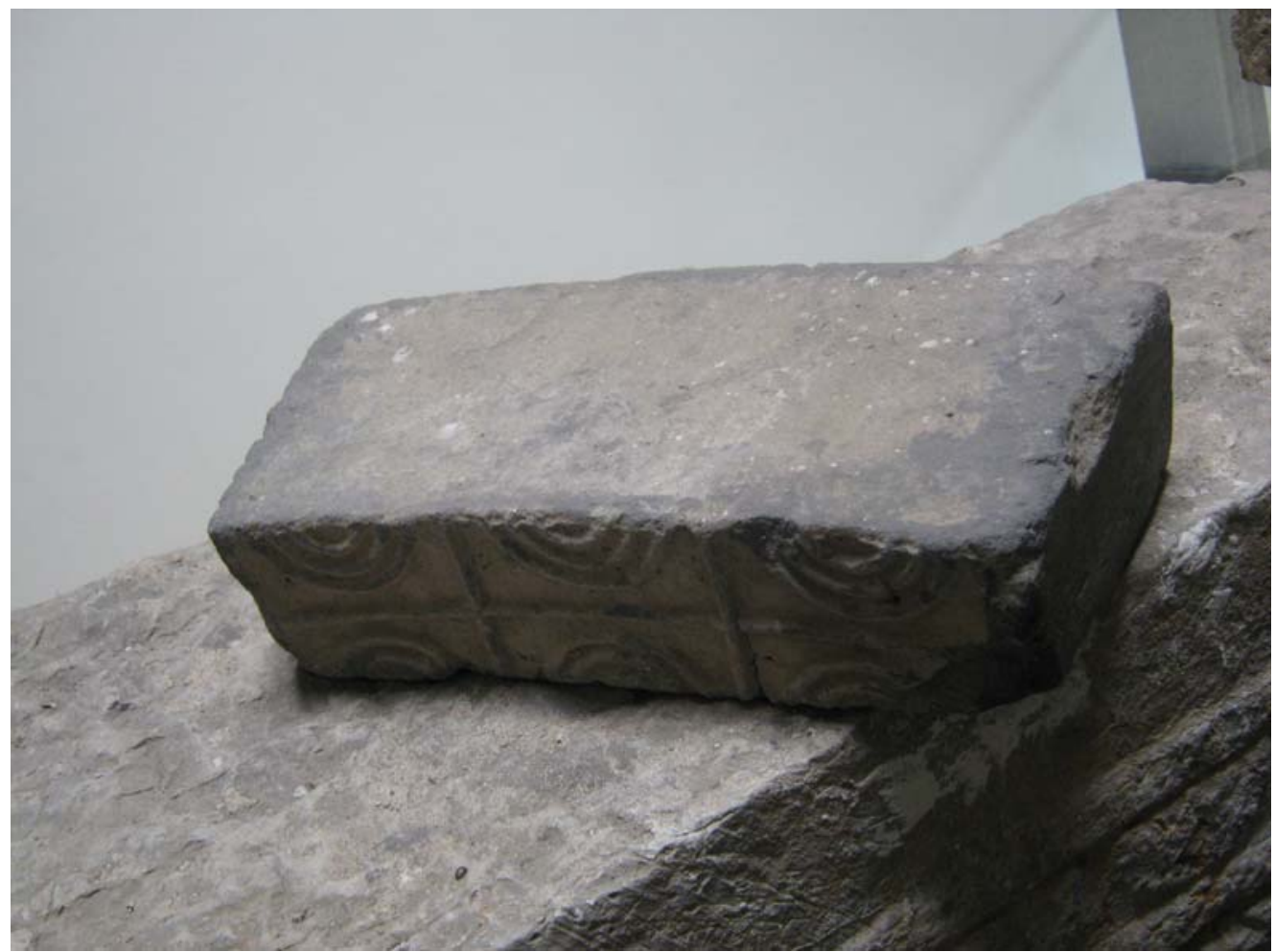

Figure 2-41, voussoir brick of Chefushan tomb No. 2. Photograph by the author. 


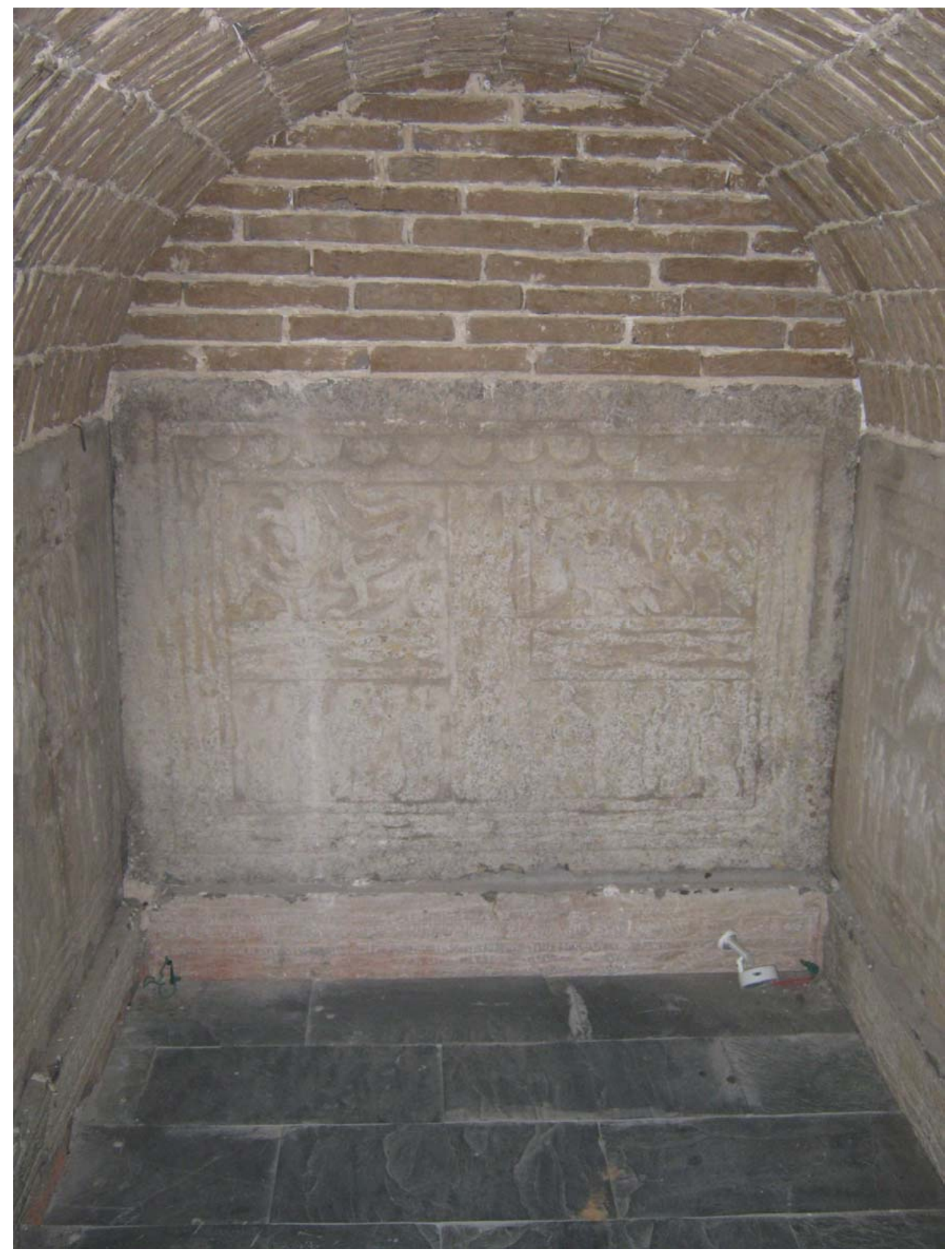

Figure 2-42, rear chamber of Chefushan tomb No. 2. Photograph by the author. 
Figures of Chapter Three

The figure originally presented here cannot be made freely available via ORA for copyright reasons.

Fig 3-1a, rubbing of inscriptions in the Cangshan tomb. After Kaogu 1975.2: 124-134, Fig 5. -305 - 


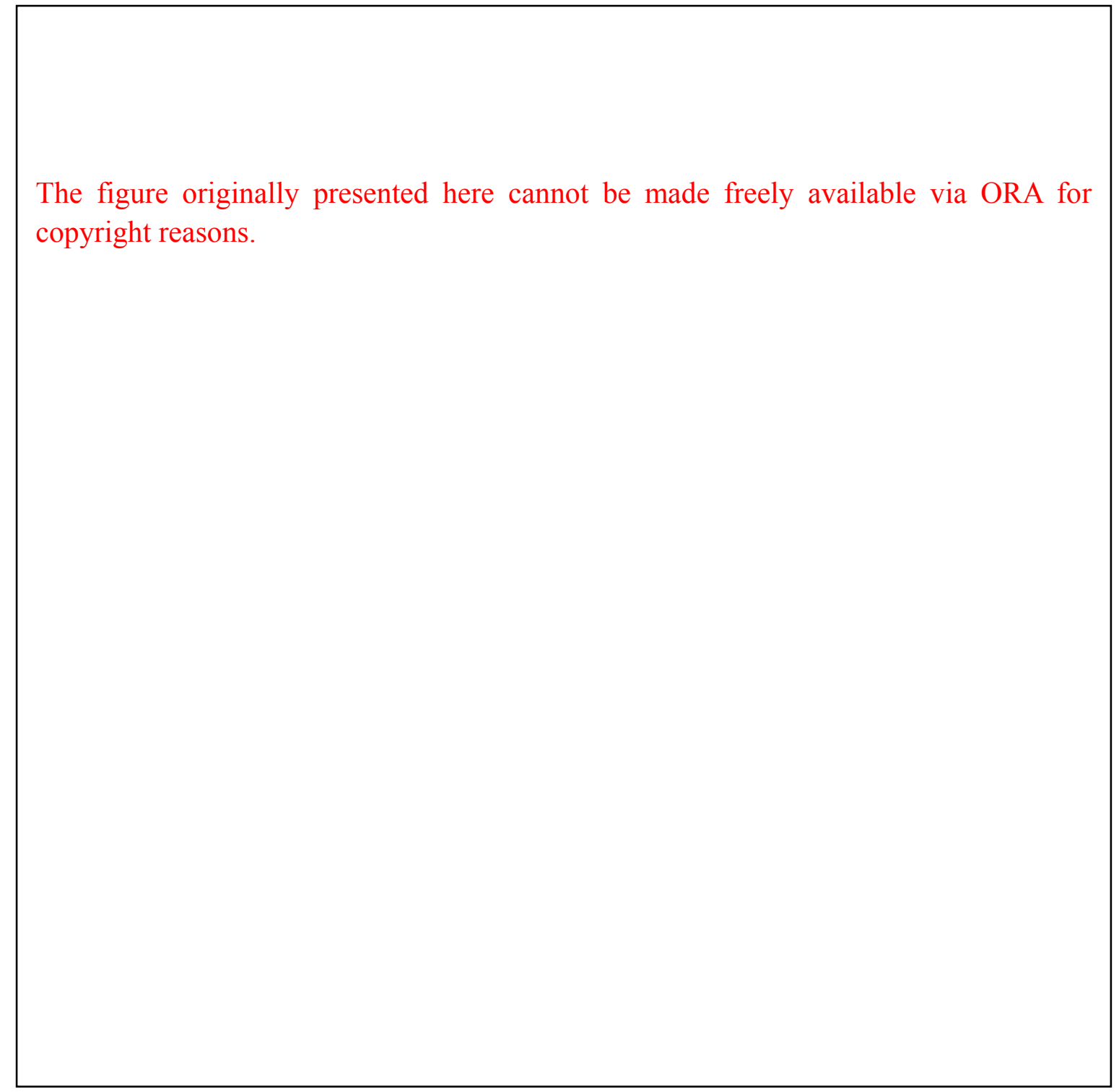

Fig. 3-1b, plan and elevation of the Cangshan tomb. After Kaogu 1975.2: 124-134, Fig. 1. 
The figure originally presented here cannot be made freely available via ORA for copyright reasons.

Fig. 3-2, inner coffin of the tomb of the Marquis Yi of Zeng. After Suizhou 1989, Plate X.

The figure originally presented here cannot be made freely available via ORA for copyright reasons.

Fig. 3-3a, coffins of Mawangdui tomb No. 1. After Changsha 1973, Plate 26. 
The figure originally presented here cannot be made freely available via ORA for copyright reasons.

Fig. 3-3b, silk banner excavated from the Mawangdui tomb No. 1. After Changsha 1973, Plate 71. 
The figure originally presented here cannot be made freely available via ORA for copyright reasons.

Fig. 3-4, mural painted on the ceiling of the main chamber in the Shiyuan tomb. After Yongcheng 2001: Plate I.

The figure originally presented here cannot be made freely available via ORA for copyright reasons.

Fig. 3-5, mural painted on the front chamber ceiling in the tomb of Zhaomo, King Wen of Nanyue. After Guangzhou 1991, Plate I. 
The figure originally presented here cannot be made freely available via ORA for copyright reasons.

Fig. 3-10a, rubbing of tomb doors of the Anqiu tomb. After Anqiu 1992: Plate 1.
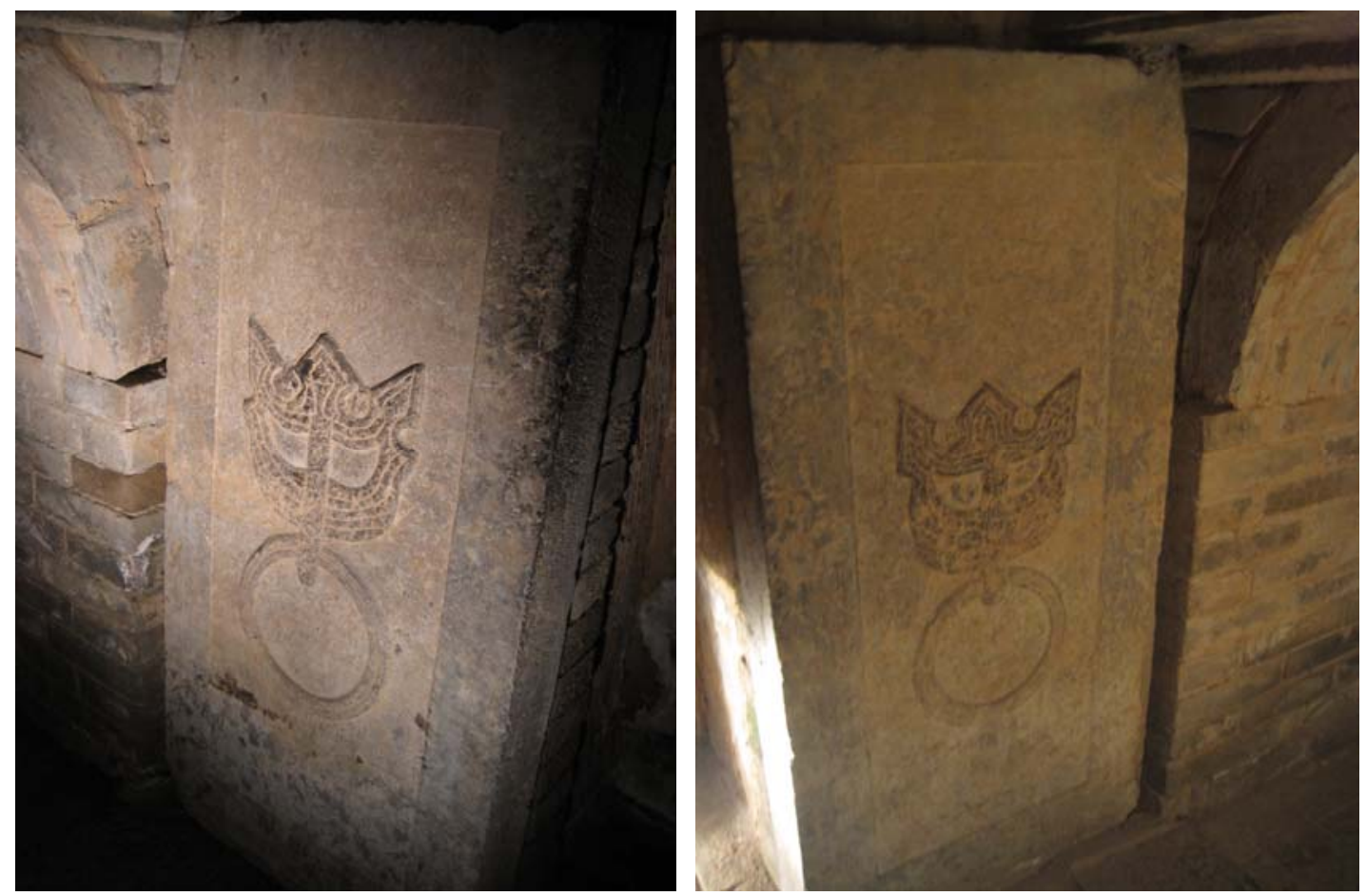

Fig. 3-10b, tomb doors of the Tangsimen tomb. Photograph by the author. 
The figure originally presented here cannot be made freely available via ORA for copyright reasons.

Fig. 3-10c, line drawing of tomb doors of the Chenpeng tomb. After Kaogu xuebao 2007.2: 233-266: fig. 5.

The figure originally presented here cannot be made freely available via ORA for copyright reasons.

Fig. 3-11, images at the rear chamber door of Miao Yu's tomb. After Wenwu 1984.8: 22-29. 
The figures originally presented here cannot be made freely available via ORA for copyright reasons.

Figs. 3-12 (a-c), 'shuixietu 水榭圖 Image of waterside pavilions' scenes.

a, excavated in Huanglutun, Zoucheng, Shandong, after Shandong 1982: fig. 56.

b, excavated in Xiazhentou, Zoucheng, Shandong, after Zoucheng 2008: fig. 69.

c, excavated in Xiazhentou, Zoucheng, Shandong, after Zoucheng 2008: fig. 68. 
The figures originally presented here cannot be made freely available via ORA for copyright reasons.

Figs. 3-12 (d-f), 'shuixietu 水榭圖 Image of waterside pavilions' scenes. d, excavated in Liangcheng, Weishan, Shandong, after Shandong 1982: fig. 40.

e, excavated in Liangcheng, Weishan, Shandong, after Shandong 1982: fig. 38. f, excavated in Shanting, Tengzhou, Shandong, after Shandong 1982: fig. 239. 


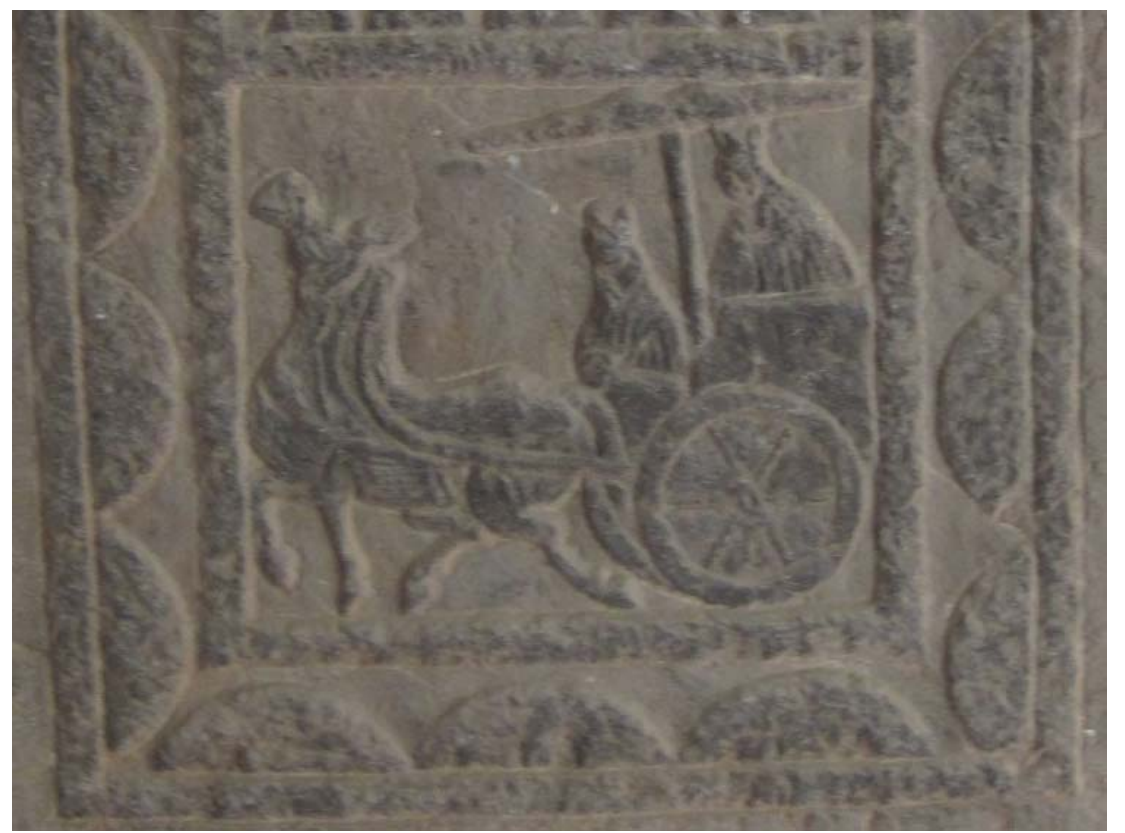

Fig. 3-20, a stone slab from Xuzhou, Jiangsu. Photograph by the author.
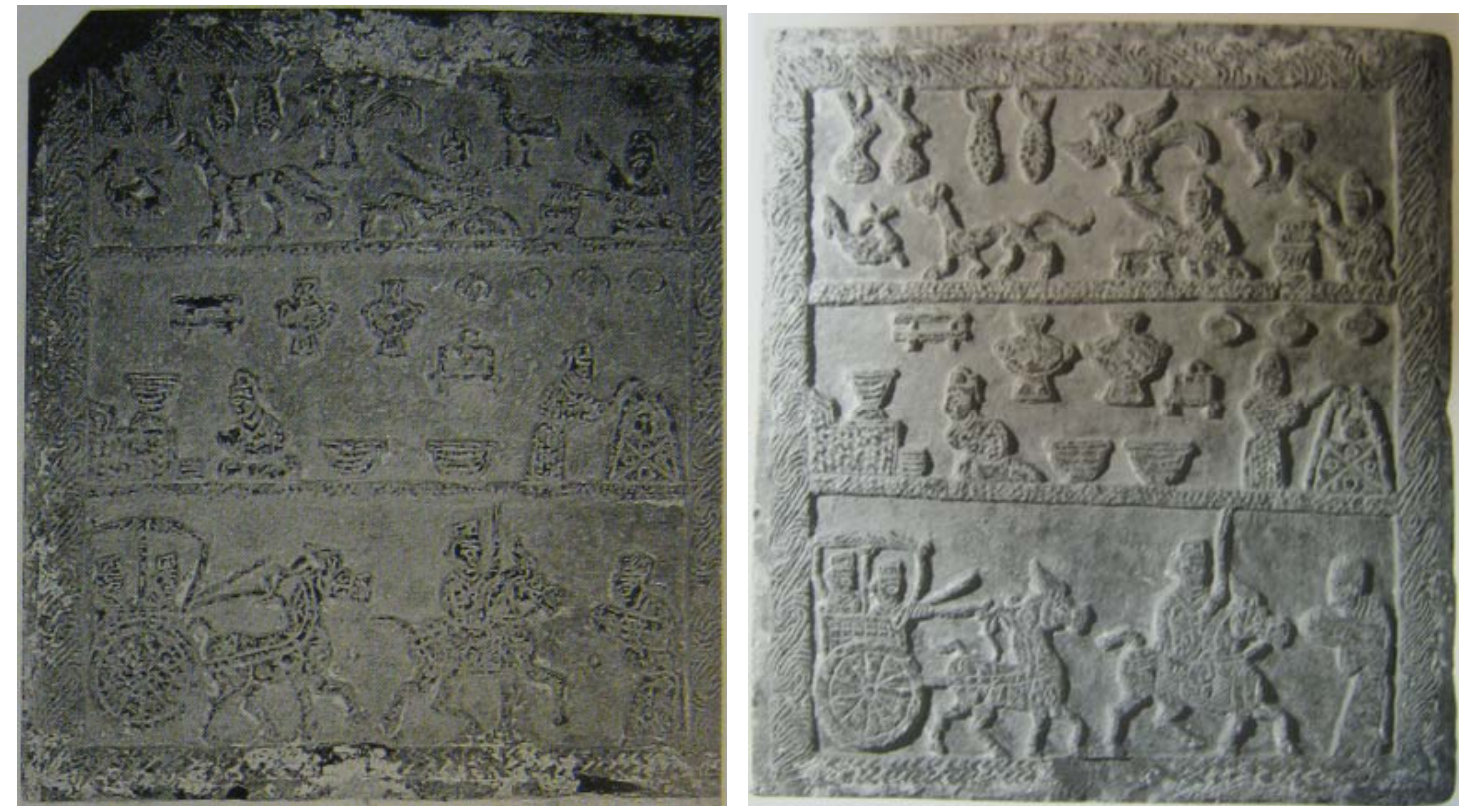

Fig. 3-21, stone slabs from Xuzhou, Jiangsu. Photograph by the author. 
The figure originally presented here cannot be made freely available via ORA for copyright reasons.

Fig. 3-22, images on stone doors excavated from Suide, Shaanxi. After Shandong and Henan 2000 vol. 5: figs. 145 and 146. 
The figure originally presented here cannot be made freely available via ORA for copyright reasons.

Fig. 3-23, Homage scenes from stone offering halls in Shandong.

After Barbieri-Low 2007: fig. 3.17. 
The figure originally presented here cannot be made freely available via ORA for copyright reasons.

Fig. 3-24, inscribed bamboo tablet from Fenghuangshan tomb No. 168. After Kaogu хиеbao 1993.4: 455-513. 
The figure originally presented here cannot be made freely available via ORA for copyright reasons.

Fig. 3-30, plan and structure of the Shizishan tomb. After After Lin 2012: p. 322.

The figure originally presented here cannot be made freely available via ORA for copyright reasons.

Fig. 3-31, plan and elevation of the Woniushan tomb.

After Zhou Xueying 2001: Fig. 2-49. 
The map originally presented here cannot be made freely available via ORA for copyright reasons.

Map 4-1, kingdoms and commanderies of the Western Han Empire in 108BC. After Lin 2012: Map 3. 
The map originally presented here cannot be made freely available via ORA for copyright reasons.

Map 4-2, kingdoms and commanderies in Eastern China of the Eastern Han Empire in c. AD140. After Barbieri-low 2007: Map 4-2. 


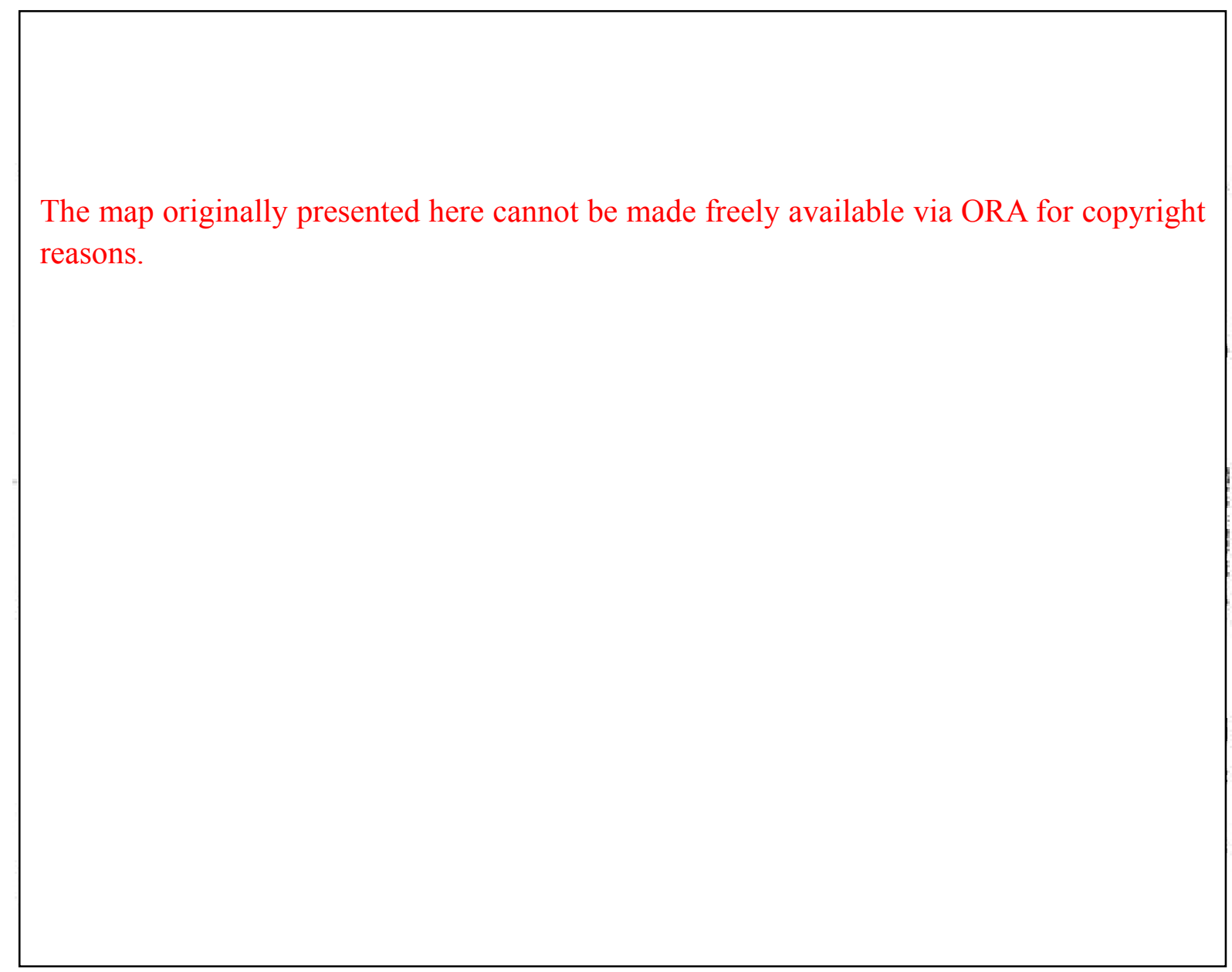

Map 4-3, distribution of Western Han kingly rock-cut tombs.

After Rawson 2005: Figure 3. 
The map originally presented here cannot be made freely available via ORA for copyright reasons. 
The figure originally presented here cannot be made freely available via ORA for copyright reasons.

Figure 4-1, plan and elevation of the Guishan tombs. Adapted from Liu Zunzhi 2011: fig. 9.

The figure originally presented here cannot be made freely available via ORA for copyright reasons.

Figure 4-2 elevation of the Mawangdui tomb M1. Adapted from Guo 2004: Fig. 1. 
The figure originally presented here cannot be made freely available via ORA for copyright reasons.

Figure 4-3, Huang's theory of tomb structure evolution. After Huang Xiaofen 2003: Fig. 39.

The figure originally presented here cannot be made freely available via ORA for copyright reasons.

Figure 4-4a, plan of the Mancheng tomb. After Wu Hung 1995: Fig. 2.44.

Figure 4-4b, plan of one of the Vat Bhaja Caves in India. After Wu Hung 1995: Fig. 2.47. 
The figure originally presented here cannot be made freely available via ORA for copyright reasons.

Figure 4-5, plan and elevation of tomb 1, locality 5 of Niuheliang site. After Wenwu 1997.8: pp. 4-8, Figure 1.

The figure originally presented here cannot be made freely available via ORA for copyright reasons. 
The figure originally presented here cannot be made freely available via ORA for copyright reasons.

Figure 4-7, elevation of Jing Gong of Qi's tomb. After Wenwu 1984.9: 14-19.

The figure originally presented here cannot be made freely available via ORA for copyright reasons.

Figure 4-10, columns at the Xerxes Palace. Photo courtesy of Georgios Giannopoulos.

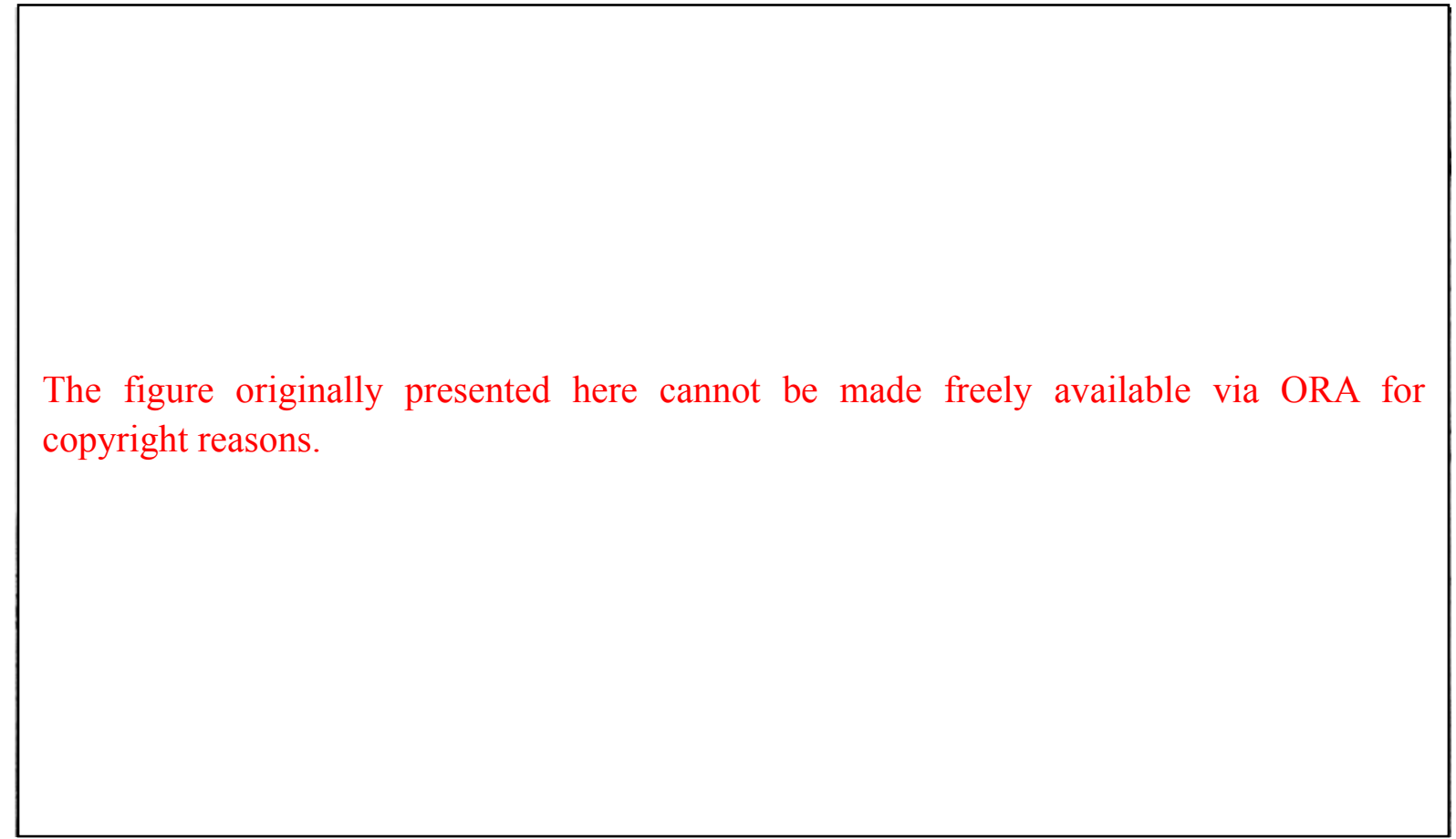

Figure 4-11a, rock-cut tombs near Persepolis. After Schmidt 1941: Plate XI. 
The figure originally presented here cannot be made freely available via ORA for copyright reasons.

Figure 4-11b, facade of rock-cut tombs belonged to Darius I. After Schmidt 1970: Plate I. 
The figure originally presented here cannot be made freely available via ORA for copyright reasons.

Figure 4-12, plan and elevation of tomb of Xerxes I. After Schmidt 1970: fig. 33.

The figure originally presented here cannot be made freely available via ORA for copyright reasons.

Fig 4-13, Ashoka column at Vaishali, Bihar, India. Photo courtesy of Rajeev Kumar. 
The figure originally presented here cannot be made freely available via ORA for copyright reasons.

Fig 4-14, the capital of four lions of the stone column erected by Ashoka. c. 250BC. After Craven 1997: Fig 16.

The figure originally presented here cannot be made freely available via ORA for copyright reasons.

Fig 4-15a, façade of the Lomas Rishi grotto. Photo courtesy of Alexander Cunningham. 
The figure originally presented here cannot be made freely available via ORA for copyright reasons.

Fig 4-15b, plan of the Lomas Rishi grotto, Baraba, India. After Gupta 1980: Fig 2.

The figure originally presented here cannot be made freely available via ORA for copyright reasons.

Figure 4-16, plan of tomb of Darius I. After Schmidt 1970: fig. 31. 


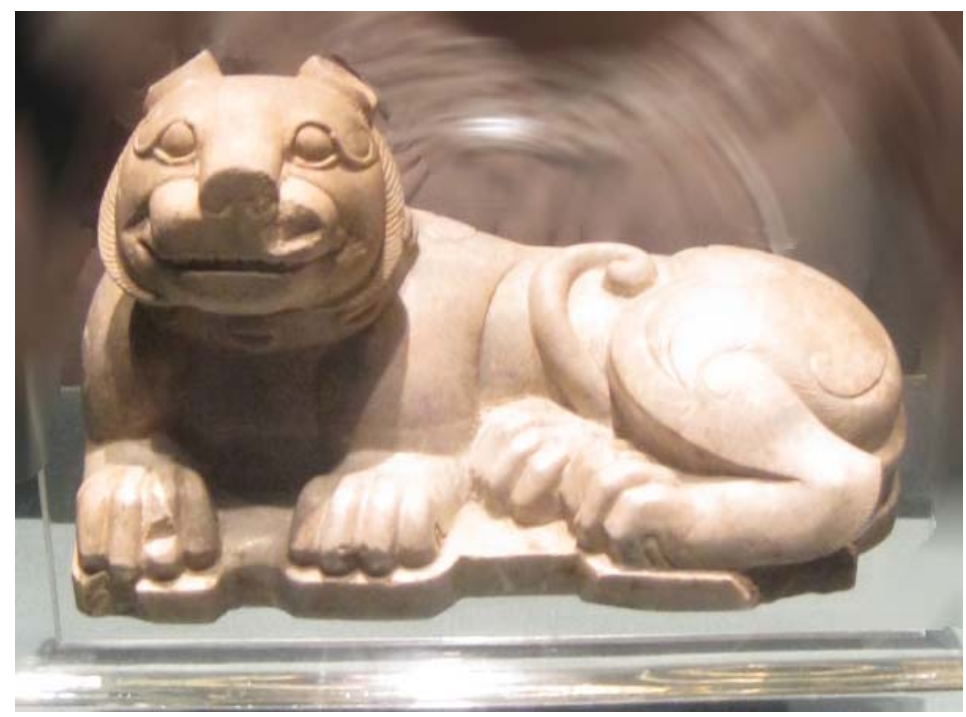

Figure 4-17a, stone carving of a feline, from Shizishan tomb, Xuzhou. 2nd century BC Photograph by the author.

The figure originally presented here cannot be made freely available via ORA for copyright reasons.

Figure 4-17b, gold weight in the shape of a crouching feline, excavated at Xuyi, Jiangsu Photo courtesy of Nanjing Museum.

The figure originally presented here cannot be made freely available via ORA for copyright reasons.

Figure 4-17c, bronze weight in the shape of a crouching lion. Iran, 6th-5th century BC After Rawson 1999: fig. 30. 
The figure originally presented here cannot be made freely available via ORA for copyright reasons.

Figure 4-20a, structure of the Tuolanshan tomb. After Kaogu xuebao 2011.1: 57-98: Fig. 6.

The figure originally presented here cannot be made freely available via ORA for copyright reasons.

Figure 4-20c, structure of the Dengmiao tomb. After Kaogu 2007.3: 35, Figure 3. 
The figure originally presented here cannot be made freely available via ORA for copyright reasons.

Figure 4-21, structure of the Shiyuan tomb chambers. After Yongcheng 2001: fig. 33.

The figure originally presented here cannot be made freely available via ORA for copyright reasons.

Figure 4-22a, stone carved images in the Shiyuan tomb. After Yongcheng 2001: fig. 40. 
The figure originally presented here cannot be made freely available via ORA for copyright reasons.

Figure 4-22b, images on sarcophagus from Qingyunshan, Linyi. After Wenwu 1988.10: 68-75, fig. 13.

The figure originally presented here cannot be made freely available via ORA for copyright reasons.

Figure 4-22c, images on sarcophagus from Fanshan, Xuzhou. After Xin 2000: fig. 108.

The figure originally presented here cannot be made freely available via ORA for copyright reasons.

Figure 4-22d, images on sarcophagus from Xiayi, Henan. After Xin 2000: fig. 107.

The figure originally presented here cannot be made freely available via ORA for copyright reasons.

Figure 4-23, inscription found on stone block from tomb of Liu Shang, After Jining 1998. 


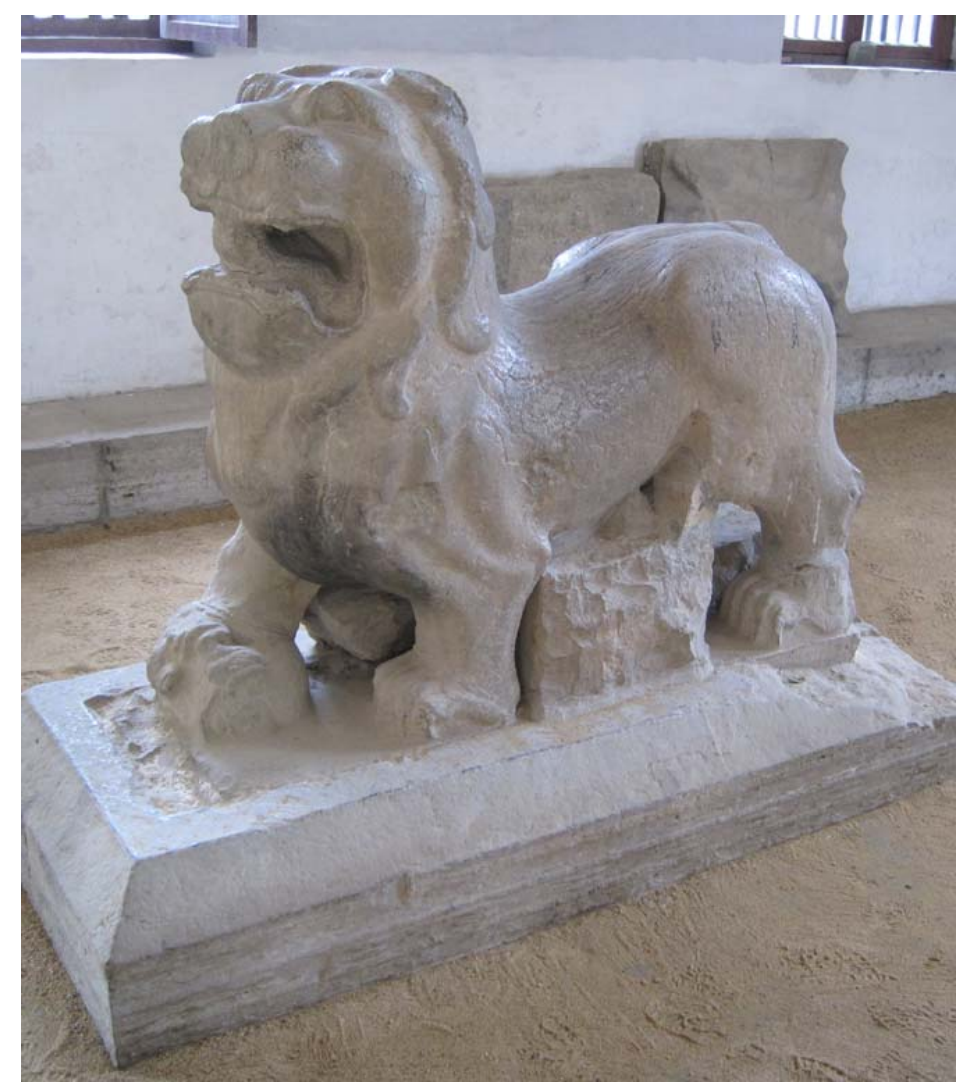

Figure 4-24a, stone lion of the Wu Family cemetery. Photograph by the author.

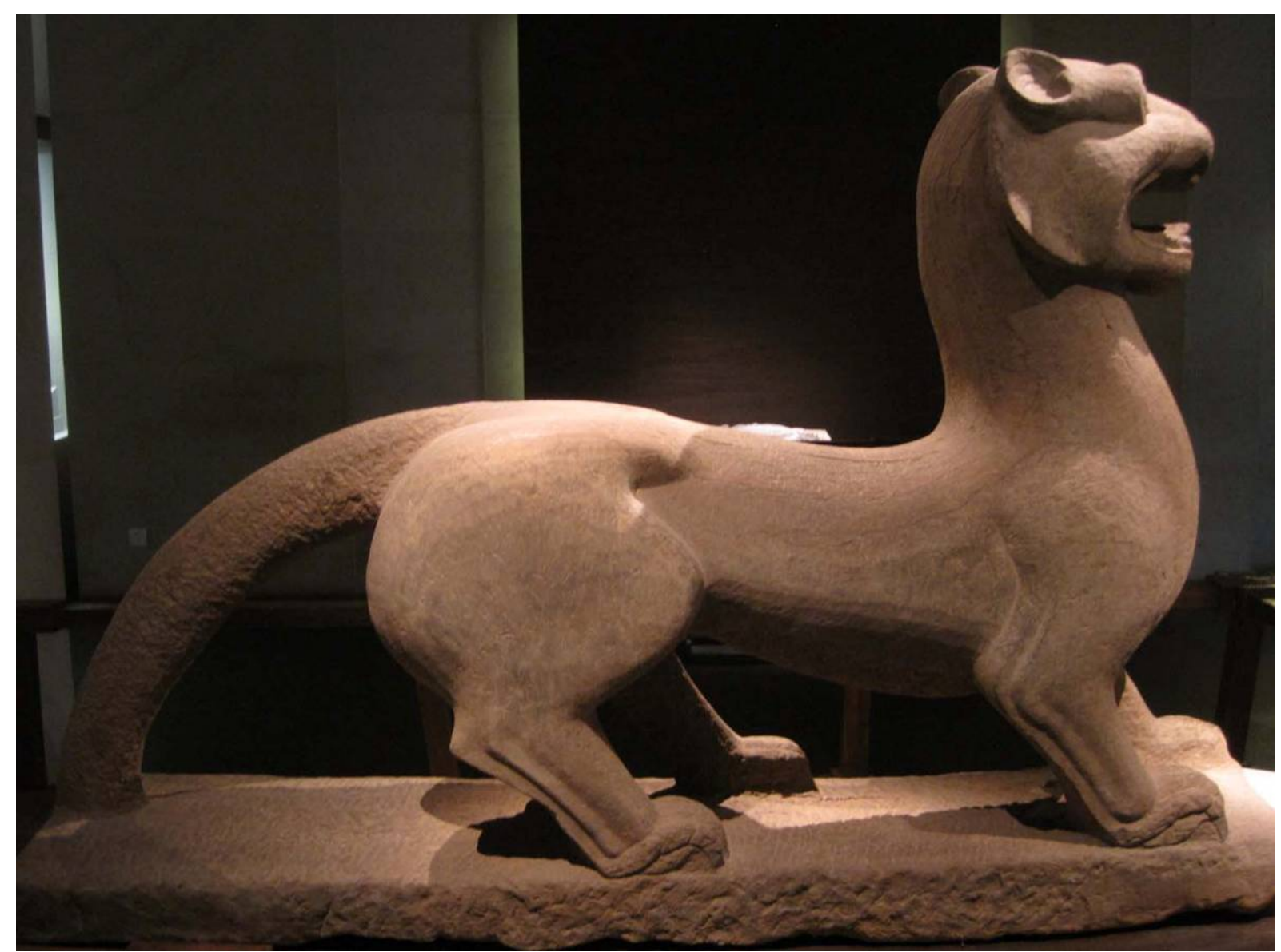

Figure 4-24b, Stone feline excavated near Xuchang, Henan Province Eastern Han. Photograph by the author. 
The figure originally presented here cannot be made freely available via ORA for copyright reasons.

Figure 4-24c, small jade sculpture of a winged lion excavated from site of the Weiling, Mausoleum of Emperor Yuan (r. 76-33BC). After Lin Meicun 2000: Plate 11.

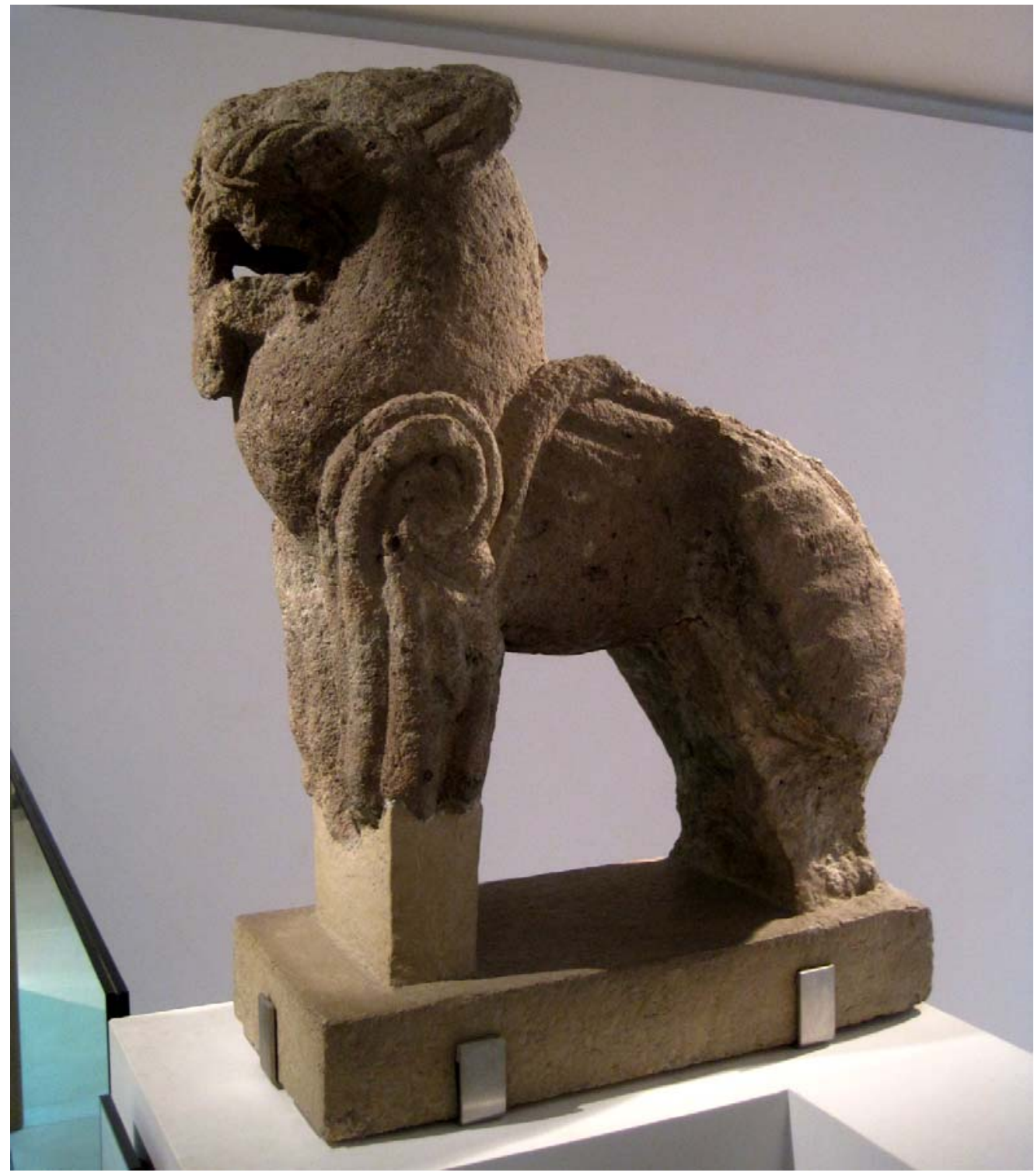

Figure 4-24d, stone lion found at Vulci, 6th century BC, Ashmolean Museum. Photograph by the author. 
The figure originally presented here cannot be made freely available via ORA for copyright reasons.

Figure 4-25a, spiritual road of Qin Jun's tomb. Photo courtesy of Chen Xuan.

The figure originally presented here cannot be made freely available via ORA for copyright reasons.

Figure 4-25b, line drawing of the stone columns in front of Qin Jun's tomb. After Wenwu 1964.11: 13-22, fig. 3. 
The figure originally presented here cannot be made freely available via ORA for copyright reasons.

Figure 4-26, joinery system of stone roof in the Beidongshan tomb. After Xuzhou 2003.

The figure originally presented here cannot be made freely available via ORA for copyright reasons.

Figure 4-27, stone house in the tomb of Liu Sheng. After Mancheng 1980, vol. 1, Figure 14. 
The figures originally presented here cannot be made freely available via ORA for copyright reasons.

Figure 4-28a (left), the Gümüşkesen Monument, Milas Province, Turkey. Photo courtesy of Mehmet Yasa.

Figure 4-28b (right), structure of the Yinan tomb. After Yinan 1956.

The figure originally presented here cannot be made freely available via ORA for copyright reasons.

Figure 4-28c (left), ceiling of the Gümüşkesen Monument. Photo courtesy of Mehmet Yasa. Figure 4-28d, ceiling of the Yinan tomb. After Yinan 1956. 


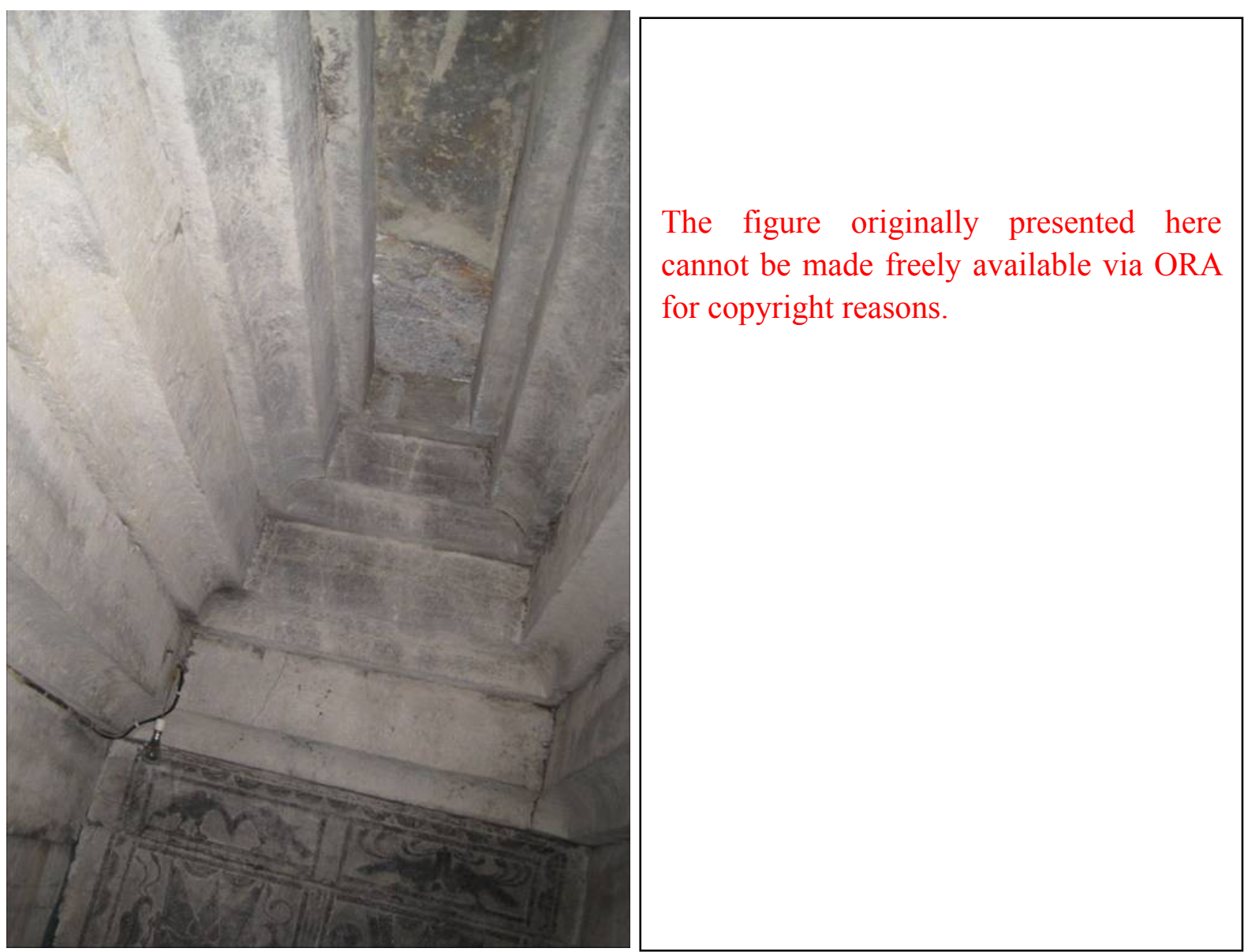

Figure 4-30a, roof the Baiji tomb. Photograph by the author.

Figure 4-30b, elevation of the Scythian tomb at Koul Oba. After Minns 1913, Fig. 89.

The figure originally presented here cannot be made freely available via ORA for copyright reasons.

Figure 4-31, columns and pilasters in the Baiji tomb. After Kaogu 1981.2: 137-150, Fig. 3. 
The figure originally presented here cannot be made freely available via ORA for copyright reasons.

Figure 4-32a, columns in the Changli tomb. After Wenwu cankao ziliao 1957.12: p. 39.

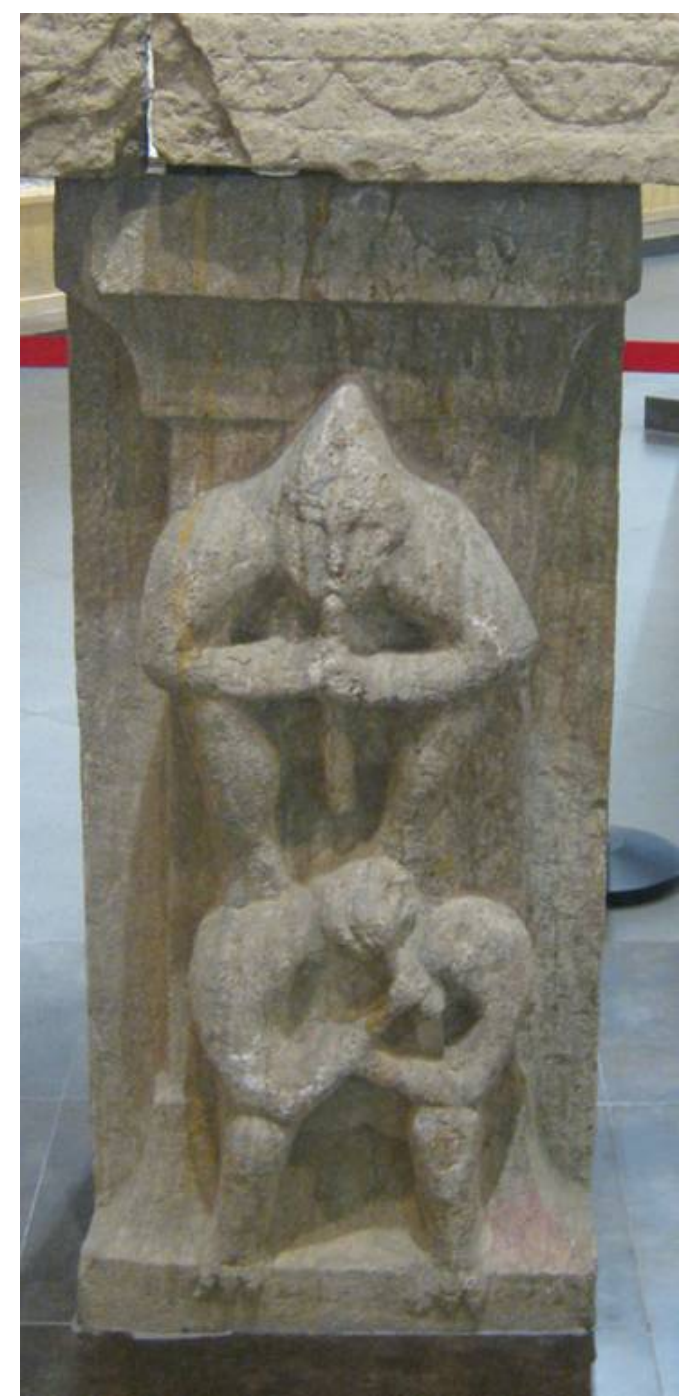

Figure 4-32b, column from an unknown tomb near Xuzhou. Photograph by the author. 
The figure originally presented here cannot be made freely available via ORA for copyright reasons.

Figure 4-33a, rubbing of Column No. 10 of the Mengzhuang tomb.

After Wenwu 2002.2: 38-52, Fig. 23.

The figure originally presented here cannot be made freely available via ORA for copyright reasons.

Figure 4-33b, rubbing of Column No. 2 of the Mengzhuang tomb After Wenwu 2002.2: 38-52, Fig. 14. 
The figure originally presented here cannot be made freely available via ORA for copyright reasons.

Figure 4-34, façade of the rock-cut tomb belonged to Darius I. After Koch 2001: fig. 130.

The figure originally presented here cannot be made freely available via ORA for copyright reasons.

Figure 4-35, line drawing of images on a cylinder seal excavated in Persepolis. After Garrison et al. 2001: fig. 172.

The figure originally presented here cannot be made freely available via ORA for copyright reasons.

Figure 4-36, erotic scene in Classical art. Photo courtesy of Sir Mortimer Wheeler. 
The figure originally presented here cannot be made freely available via ORA for copyright reasons.

Figure 4-37a, double headed sculpture excavated from the Huaiyang tomb.

After Wenwu 1991.4: 34-46, fig. 9.

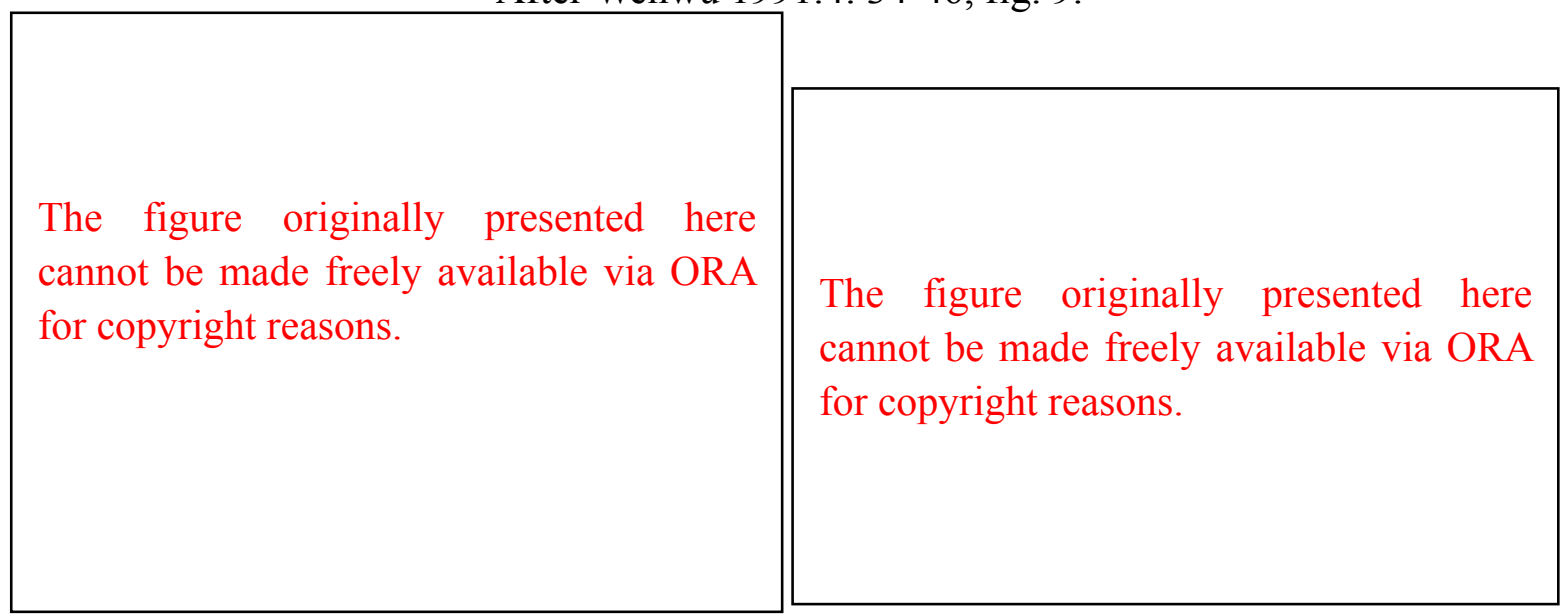

Figure 4-37b, double headed sculptures as capitals at Persepolis. After Koch 2001: fig. 62.

The figures originally presented here cannot be made freely available via ORA for copyright reasons.

Figure 4-38a, Queen Mother of the West on Han stone carving. After Li 2009: fig. 2-8. Figure 4-38b, wooden deity from a coffin near the Caucasus. After Minns 1913: fig. 237.

The figures originally presented here cannot be made freely available via ORA for copyright reasons.

Figure 4-38c, Roman bronze, c. 350BC. After Hinks 1938: fig. a.

Figure 4-38d, drawing of a Roman coin. After Knauer 2006: fig. 3.44. 
The figure originally presented here cannot be made freely available via ORA for copyright reasons.

Figure 4-40, structure of the Beidongshan tomb. After Lin 2012, Fig. 29.

The figure originally presented here cannot be made freely available via ORA for copyright reasons.

Figure 4-41, elevation and plan of Miao Yu's tomb. After Wenwu 1984.8: 22-29, Fig. 3. 
The figures originally presented here cannot be made freely available via ORA for copyright reasons.

Figure 4-42a (left), silk excavated from the Pazyryk burials.

After Chen Jianwen 2010: 921-964, fig. 1.

Figure 4-42b (right), silk excavated from Mashan tomb No. 1, Jiangling, Hubei Province.

After Chen Jianwen 2010: 921-964, fig. 2.

The figure originally presented here cannot be made freely available via ORA for copyright reasons.

Figure 4-43, bronze mirror excavated from Pazyryk burial No. 6.

After Chen Jianwen 2010: 921-964, fig. 4. 
The figure originally presented here cannot be made freely available via ORA for copyright reasons.

Figure 4-44, brocade arm-band excavated from tomb M8 at Niya, Xinjiang.

After Wenwu tiandi 1999.6: inside back cover.

The figure originally presented here cannot be made freely available via ORA for copyright reasons.

Figure 4-45, Han style damasks found at Kerch in Crimea.

After Xia Nai 1961: 52-54, figures 4. 
The figures originally presented here cannot be made freely available via ORA for copyright reasons.

Figure 4-46, Han style damasks found at Palmyra in Syria. After Xia Nai 1961: 52-54, figures 7 and 8. 


\section{Maps and Figures of Chapter Five}

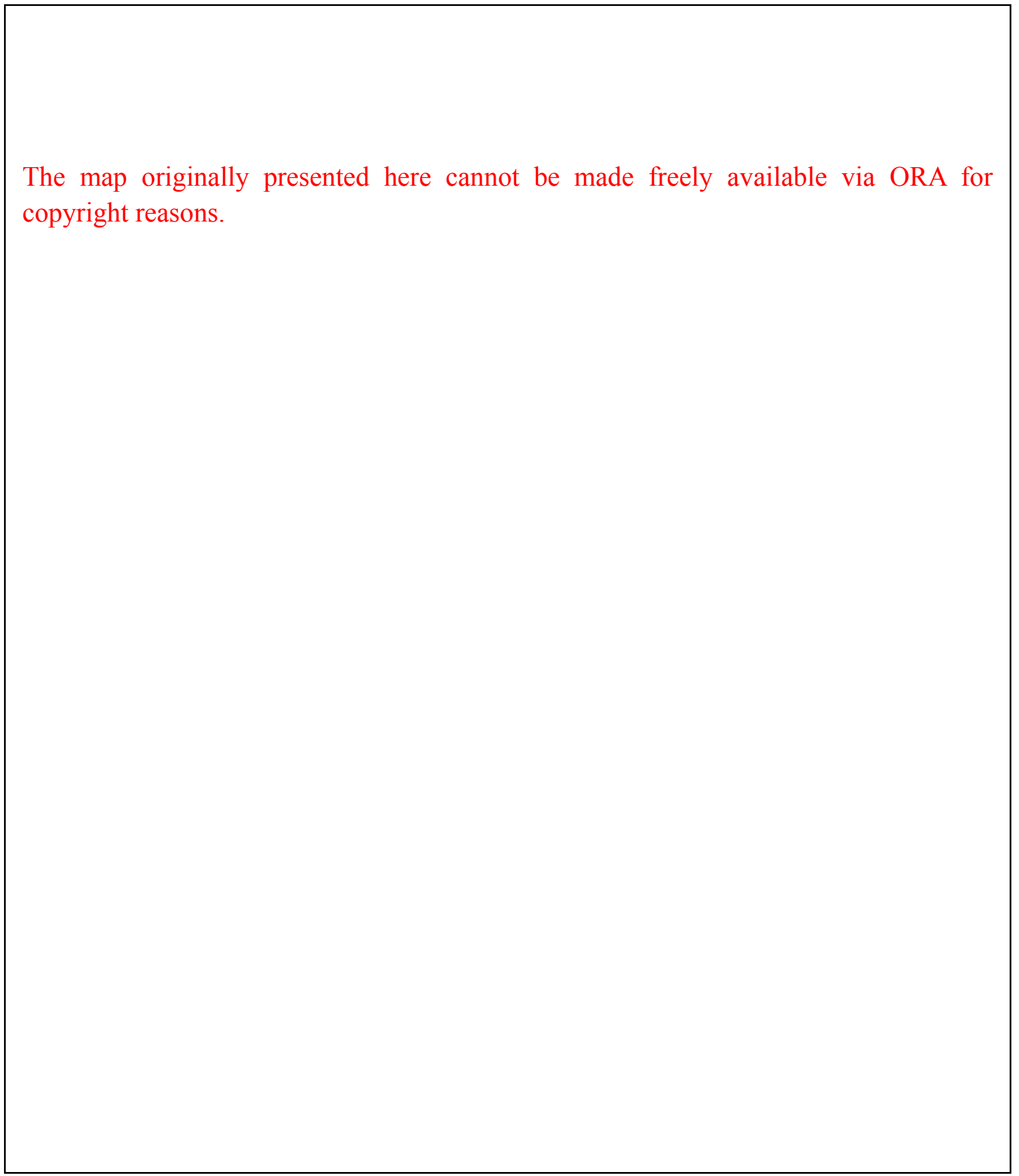

Map 5-2, distribution of stone carved tombs in Northern Shaanxi and Western Shanxi. Adapted from Shandong and Henan 2000: vol. 5, p. 2. 


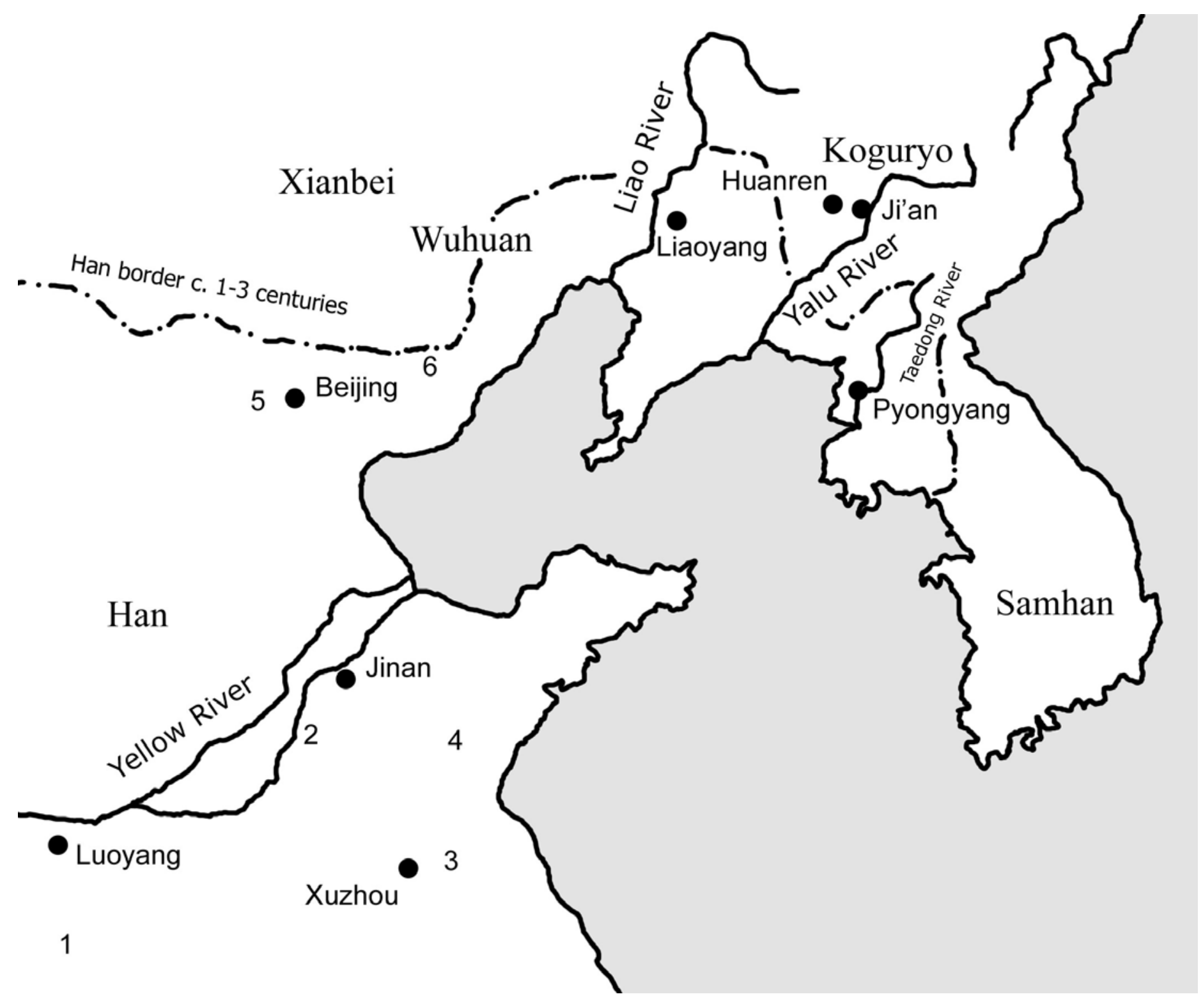

Map 5-4, map of Northeast China and the Korean Peninsula, showing modern towns and major tomb sites discussed: 1, Feng Rujiu' tomb; 2, Houtun tombs; 3, Miao Yu's tomb; 4, Yinan tomb No. 1; 5, Qin Jun's tomb; 6, Jixian tomb.

Borders, coastlines and river courses are based on Tan 1982. 
The figure originally presented here cannot be made freely available via ORA for copyright reasons.

Map 5-5a, Koguryo and neighbouring areas, c. AD300. Adapted from Wikimedia

Commons file (http://commons.wikimedia.org/wiki/File:History of Korea-300.png)

The figure originally presented here cannot be made freely available via ORA for copyright reasons. 
The figure originally presented here cannot be made freely available via ORA for copyright reasons.

Fig. 5-1, structure of Mamaozhuang tomb No. 3 at Lishi.

After Shandong and Henan 2000: vol. 5, p. 7.

The figure originally presented here cannot be made freely available via ORA for copyright reasons.

Fig. 5-2, doors of the Shipan tomb at Lishi. After Wenwu 2005.2: 42-51, Fig. 12. 
The figure originally presented here cannot be made freely available via ORA for copyright reasons.

Fig. 5-3, rubbing of the left column of Niu Chan's tomb door near Lishi After Shandong and Henan 2000: vol. 5, p. 201: plates 272, 273. 
The figure originally presented here cannot be made freely available via ORA for copyright reasons.

Fig. 5-4a, stone structure of the Chang'an tomb, Zhejiang.

After Huang Yafeng 2009, Fig. 7.

The figure originally presented here cannot be made freely available via ORA for copyright reasons.

Fig. 5-4b, overall structure of the Chang'an tomb, Zhejiang

After Huang Yafeng 2009, Fig. 8. 
The figures originally presented here cannot be made freely available via ORA for copyright reasons.

Fig. 5-4c, (left) stone carving in the front chamber of the Chang'an tomb, Zhejiang. After Huang Yafeng 2009, Fig. 70.

Fig. 5-4d, (right) stone carving in the middle chamber of the Yinan tomb, Shandong. After Yinan 1956, Plate 59. 
The figures originally presented here cannot be made freely available via ORA for copyright reasons.

Fig. 5-5d, e, plan of the Fenghuangshan tombs M1 and M2, Zhejiang. After Zhejiang 2005a: Fig. 3. 
The figure originally presented here cannot be made freely available via ORA for copyright reasons.

Fig. 5-5a, b, c, stone furniture set from Fenghuangshan tomb M1.

After Zhejiang 2005a: Figs. 5, 12 and 13

Upper: 2, couch; 3, screen; 4, basement; 5, lion; 7, low table

Lower: carved images on the stone screens

The figure originally presented here cannot be made freely available via ORA for copyright reasons. 
The figure originally presented here cannot be made freely available via ORA for copyright reasons.

Fig. 5-6 stone furniture set from the Qiushan tomb. After Zhejiang 2005b: Fig. 2.

a, stone low table

b, stone couch 
The figure originally presented here cannot be made freely available via ORA for copyright reasons.

Fig. 5-7a, roof of the Xifengba tomb in Changxin, Zhejiang. Photo courtesy of Shen Yan.

The figure originally presented here cannot be made freely available via ORA for copyright reasons.

Fig. 5-7b, front view of the Xifengba tomb. Photo courtesy of Shen Yan. 
The figure originally presented here cannot be made freely available via ORA for copyright reasons.

Fig. 5-8 stone sculptures of the Huaiyang tomb. After Wenwu 1991.4: 34-46: Figs. 7, 16. Upper: line drawing of stone tiger, lion and table Lower: line drawing of stone screen

The figure originally presented here cannot be made freely available via ORA for copyright reasons. 
The figure originally presented here cannot be made freely available via ORA for copyright reasons.

Fig. 5-9a, stone furniture set in the Wangdu tomb No. 2. After Wangdu 1959, Fig. 15.

The figure originally presented here cannot be made freely available via ORA for copyright reasons.

Fig. 5-9b, close view of the couch and low table from the Wangdu tomb No. 2. After Wangdu 1959, Fig. 41, Fig. 42. 
The figure originally presented here cannot be made freely available via ORA for copyright reasons.

Fig. 5-15a, rubbing of Xianyu Huang's stele.

After Kaogu хиеbao 1982.3: 351-365: Plate 22. 
The figures originally presented here cannot be made freely available via ORA for copyright reasons.

Fig. 5-15b, (left) stone box excavated from Xianyu Huang's tomb

Fig. 5-15d, (right) roof of a que pillar gate found near Xianyu Huang's tomb site After Kaogu xиebao 1982.3: 351-365: Plate 21.

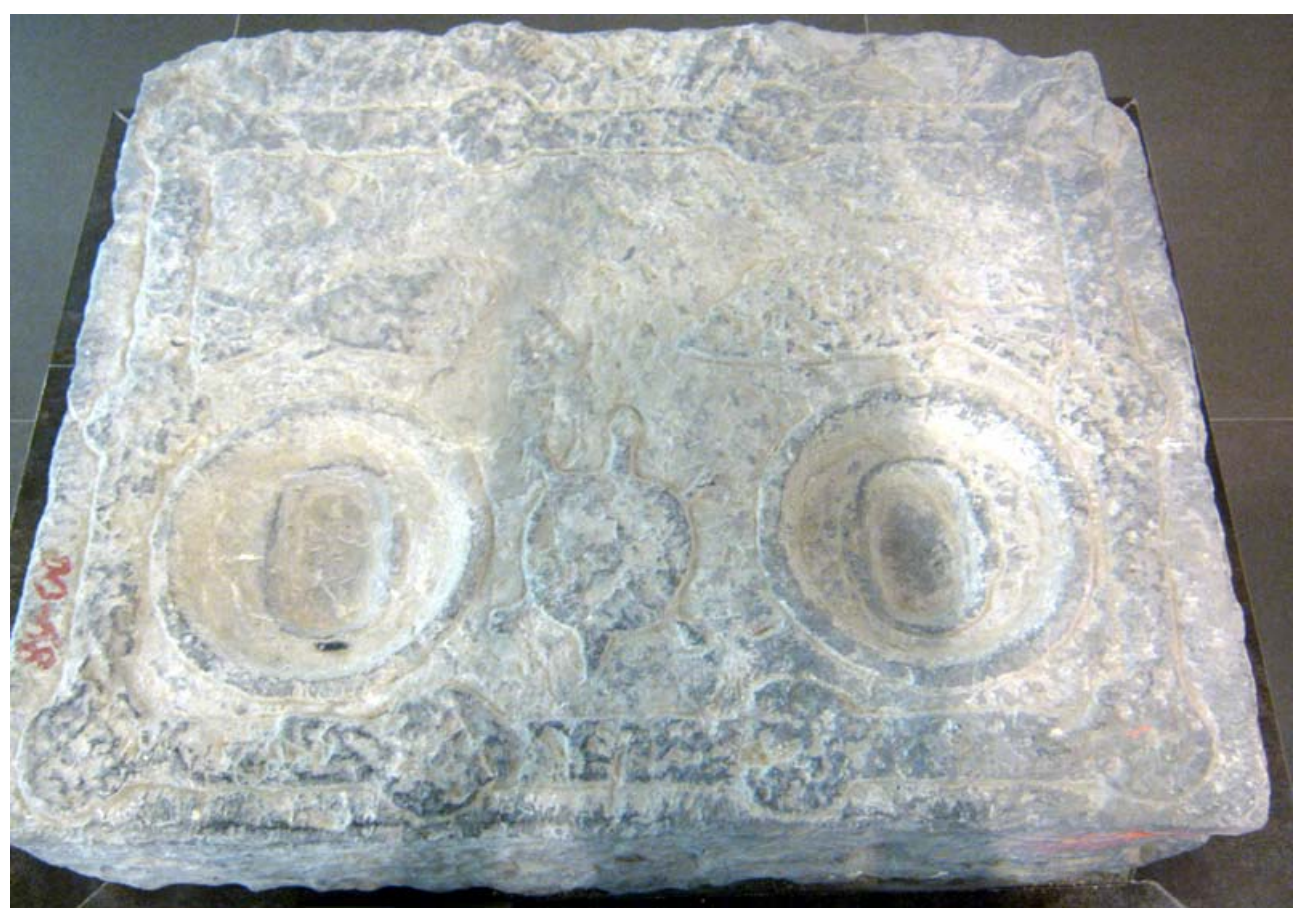

Fig. 5-15c, stone carving excavated in Xuzhou. Photograph by the author. 
The figure originally presented here cannot be made freely available via ORA for copyright reasons.

Fig. 5-16a, structure of the Xiaomaozhuang tomb, Jixian, Tianjin. After Liang Hongfeng 2004: fig. 2, with English notations.

The figure originally presented here cannot be made freely available via ORA for copyright reasons.

Fig. 5-16b, view of the Xiaomaozhuang tomb, Jixian, Tianjin.

After Liang Hongfeng 2004: fig. 1. 
The figure originally presented here cannot be made freely available via ORA for copyright reasons.

Fig. 5-17, stone tomb doors excavated from Santaizi, Beijing.

After Wenwu 1966.4: 53-54, Fig. 1.

The figure originally presented here cannot be made freely available via ORA for copyright reasons.

Fig. 5-18, plan of the Wangdu tomb No. 2. After Wangdu 1959, Fig. 2. 
The figures originally presented here cannot be made freely available via ORA for copyright reasons.

Fig. 5-21, plans of Han period tombs of the Central Plains:

a, plan of Yinan tomb No. 1. After Yinan 1956: Fig. 2.

b, plan of Miao Yu's tomb. After Wenwu 1984.8: p. 23, Fig. 3.

c, plan of Houtun tomb M13. After Dongping 2010: Fig. 55.

The figures originally presented here cannot be made freely available via ORA for copyright reasons.

Fig. 5-22, plans of stone chamber tombs in Liaodong:

a, plan of Bangtaizi tomb No. 1. After Wenwu cankao ziliao 1955.5: p. 16, Fig. 2.

b, plan of Sandaohao Yaoye Sichang tomb. After Wenwu cankao ziliao 1955.5: p. 28, Fig. 17.

c, plan of the Yingshuisi tomb. After Fairbank and Kitano 1954: p. 261, Fig. 13b.

d, plan of the Shangwangjiacun tomb. After Wenwu 1959.7: p. 60, Fig. 3. 
The figures originally presented here cannot be made freely available via ORA for copyright reasons.

Fig. 5-23, plans of Koguryo tombs near Ji'an:

a, plan of the Wukuifen tombs No. 4. After Kaogu xuebao 1984.1: p. 123, Fig. 2.

b, plan of the Tonggou tomb No. 12, south chamber. After Kaogu 1964.2: p. 68, Fig. 1.

c. plan of Ran Mu's tomb. After Wei 1995: Fig. 91-4.

The figures originally presented here cannot be made freely available via ORA for copyright reasons.

Fig. 5-24, plans of Koguryo tombs near Pyongyang:

a, plan of the Anak tomb No. 3. After Wei 1995: Fig. 124-1.

b, plan of the Liaodong Cheng tomb. After Kaogu 1960.1: p. 56, Fig. 1-2.

c, plan of the Tokhwa-ri tomb. After Zhao 2009: Fig 3-13. 
The figure originally presented here cannot be made freely available via ORA for copyright reasons.

Fig. 5-25, front view of Houtun tomb M12. After Dongping 2010: Plate X.

The figure originally presented here cannot be made freely available via ORA for copyright reasons.

Fig. 5-26a, ceiling of the Wukuifen tomb No. 4. After Ji'an 2007: p. 57. 
The figure originally presented here cannot be made freely available via ORA for copyright reasons.

Fig. 5-26b, south wall of the main chamber of Wukuifen tomb No. 4. After Ji'an 2007: p. 56.

The figure originally presented here cannot be made freely available via ORA for copyright reasons.

Fig. 5-27, plan and elevation of Yushan tomb No. 3241 near Ji'an. After Wei Cuncheng 1995: Fig. 20. 
The figure originally presented here cannot be made freely available via ORA for copyright reasons.

Fig. 5-28a, plan and elevation of the Jiangjunfen tomb near Ji'an.

After Wei Cuncheng 1995: Fig. 23.

The figure originally presented here cannot be made freely available via ORA for copyright reasons.

Fig. 5-28b, the Jiangjunfen tomb near Ji'an. After Wei Cuncheng 1995: Plate 1. 
The figure originally presented here cannot be made freely available via ORA for copyright reasons.

Fig. 5-30, the Koguryo elite cemetery at Shanchengxia near Ji'an. After Ji'an 2007: p. 17.

The figure originally presented here cannot be made freely available via ORA for copyright reasons.

Fig. 5-31, ceiling of the front chamber of Changchuan tomb No. 1. After Ji'an 2007: p. 50. 
-372 - 


\section{Figures of Appendix II}

The figure originally presented here cannot be made freely available via ORA for copyright reasons.

Fig. 7-10, plan and elevation of the Shilipu tomb.

All figs. in this section after Kaogu 1966.2: 66-83 and 91. 
The figures originally presented here cannot be made freely available via ORA for copyright reasons.

Fig. 7-11, images at the entrance of the foremost chamber

a, west door

$b$, front side of the lintel

c, rear side of the lintel 
The figures originally presented here cannot be made freely available via ORA for copyright reasons.

Fig. 7-12, images at the entrance of the front chamber a, (left) east column

b, (right) doors 


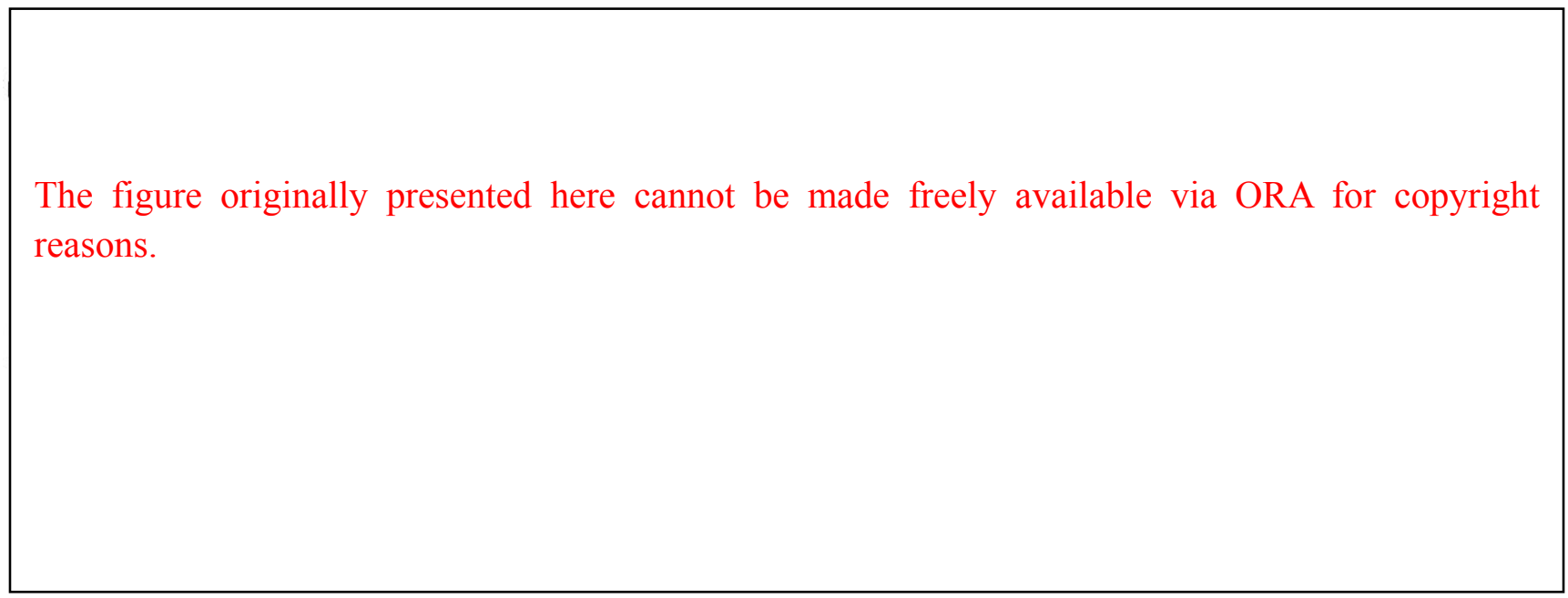

Fig. 7-12, images at the entrance of the front chamber

c, front side of the lintel

The figure originally presented here cannot be made freely available via ORA for copyright reasons.

Fig. 7-12, images at the entrance of the front chamber

$\mathrm{d}$, rear side of the lintel 
The figures originally presented here cannot be made freely available via ORA for copyright reasons.

Fig. 7-13, objects excavated from the front chamber

a, (left) urinal vessel

b, (right) lamp

The figure originally presented here cannot be made freely available via ORA for copyright reasons.

Fig. 7-14, images at the entrance of the west chamber (front side of the lintel)

The figure originally presented here cannot be made freely available via ORA for copyright reasons.

Fig. 7-16, images at the entrance of the east chamber (front side of the lintel) 
The figure originally presented here cannot be made freely available via ORA for copyright reasons.

Fig. 7-15, chariot accessories excavated from the west chamber

The figure originally presented here cannot be made freely available via ORA for copyright reasons.

Fig. 7-17, objects excavated from the east chamber

$\mathrm{h}$, pottery model of building complex 
The figure originally presented here cannot be made freely available via ORA for copyright reasons.

Fig. 7-18, images at the entrance of the middle chamber a, western post 
The figure originally presented here cannot be made freely available via ORA for copyright reasons.

Fig. 7-18, images at the entrance of the middle chamber $b$, front side of the lintel

The figure originally presented here cannot be made freely available via ORA for copyright reasons.

Fig. 7-18, images at the entrance of the middle chamber c, rear side of the lintel

The figures originally presented here cannot be made freely available via ORA for copyright reasons.

Fig. 7-19, objects excavated from the middle chamber a, (left) pigpen; $b$, dog

The figures originally presented here cannot be made freely available via ORA for copyright reasons.

Fig. 7-19, objects excavated from the middle chamber: c, male figure; $d$, female figure 
The figures originally presented here cannot be made freely available via ORA for copyright reasons.

Fig. 7-19, objects excavated from the middle chamber

e, (left) pottery sculpture

f, (right) stone pig

The figure originally presented here cannot be made freely available via ORA for copyright reasons.

Fig. 7-20, images at the entrance of the rear chamber

c, front surface of the lintel 
The figure originally presented here cannot be made freely available via ORA for copyright reasons.

Fig. 7-20, images at the entrance of the rear chamber a, (left) front surface of western post

$\mathrm{b}$, (right) front surface of eastern post 


\section{Bibliography}

\section{Archaeological Reports}

\section{1 Monographs}

\section{2 Articles}

II. Catalogues

III. Chinese Language Primary Sources

IV. Chinese, Japanese and Korean Secondary Sources

V. Western Language Secondary Sources

VI. Maps

\section{Archaeological Reports}

\section{1 Monographs}

\section{Anqiu 1992}

Anqiu xian wenhuaju 安丘县文化局 and Anqiu xian bowuguan 安丘县博物馆. Anqiu Dongjiazhuang Han huaxiangshi mu 安丘董家庄汉画像石墓. Ji'nan: Ji'nan chubanshe, 1992.

\section{Beijing 1981}

Wenwu bianji weiyuanhui 文物编辑委员会. Zhongguo changcheng yiji diaocha baogao ji 中国长城遗迹调查报告集. Beijing: wenwu chubanshe, 1981.

\section{Beijing 1989}

Dabaotai Han mu fajuezu 大葆台汉墓发掘组 and Zhongguo shekeyuan kaogu yanjiusuo 中国社科院考古研究所. Beijing Dabaotai Han $m u$ 北京大葆台汉墓, 2 vols. Beijing: wenwu chubanshe, 1989.

\section{Changsha 1973}

Hunan sheng bowuguan 湖南省博物馆 and Zhongguo shekeyuan kaogu yanjiusuo 中国社科院考古研究所. Changsha Mawangdui yihao Han mu 长沙马王堆一号汉 
墓, 2 vols. Beijing: wenwu chubanshe, 1973.

\section{Dongping 2010}

Shandong sheng wenwu kaogu yanjiusuo 山东省文物考古研究所 and Dongping xian wenwu guanlisuo 东平县文物管理所. Dongping Houtun Han dai bihua mu 东 平后屯汉代壁画墓. Beijing: wenwu chubanshe, 2010.

\section{Guangzhou 1991}

Guangzhou shi wenwu guanli weiyuanhui 广州市文物管理委员会, Zhongguo shehui kexueyuan kaogu yanjiusuo 中国社会科学院考古研究所, and Guangdong sheng bowuguan 广东省博物馆. Xi Han Nan Yue wang mu 西汉南越王墓, 2 vols. Beijing: wenwu chubanshe, 1991.

\section{Ji’an 2007}

Jilin sheng Ji'an shi wenwuju 吉林省集安市文物局. Gaogouli wangcheng wangling ji guizu muzang 高句丽王城王陵及贵族墓葬, Shanghai: Shanghai shijie tushu chuban gongsi, 2007.

\section{Luoyang 1995}

Zhongguo shehui kexueyuan kaogu yanjiusuo 中國社会科學院考古研究所. Xingyuan Dong Han mu bihua 杏園東漢墓壁畫. Shenyang: Liaoning meishu chubanshe, 1995.

\section{Mancheng 1980}

Zhongguo shehui kexueyuan kaogu yanjiusuo 中国社会科学院考古研究所 and Hebei sheng wenwu guanlichu 河北省文物管理处. Mancheng Han mu fajue baogao 满城汉墓发掘报告, 2 vols. Beijing: wenwu chubanshe, 1980.

\section{Mixian 1993}

Henan sheng wenwu yanjiusuo 河南省文物研究所. Mixian Dahuting Han mu 密县 打虎亭汉墓. Beijing: Wenwu chubanshe, 1993.

\section{Nanyang 2008}

Huang Yafeng 黄雅峰 eds., Nanyang Qilingang huaxiangshi mu 南阳麒麟岗画像 石墓. Xi'an: San Qin chubanshe, 2008.

\section{Suizhou 1989}

Hubei sheng bowuguan 湖北省博物馆, Zeng Hou Yi mu 曾侯乙墓. Beijing: Wenwu chubanshe, 1989.

\section{Wangdu 1959}

Hebei sheng wenhuaju wenwu gongzuodui 河北省文化局文物工作队，Wangdu erhao Han mu 望都二号汉墓. Beijing: Wenwu chubanshe, 1959. 


\section{Xiaoxian 2008}

Anhuisheng wenwu kaogu yanjiusuo 安徽省文物考古研究所 and Anhuisheng Xiaoxian bowuguan 安徽省萧县博物馆. Xiaoxian Han $m u$ 萧县汉墓. Beijing: Wenwu chubanshe, 2008.

\section{Xuzhou 2003}

Xuzhou bowuguan 徐州博物馆 and Nanjing daxue lishixuexi kaoguzhuanye 南京 大学历史学系考古专业. Xuzhou beidongshan Xi Han Chu wang mu 徐州北洞山西 汉楚王墓. Beijing: Wenwu chubanshe, 2003.

\section{Yinan 1956}

Shandongsheng wenwu guanlichu 山東省文物管理處. Yinan gu huaxiangshi $m u$ fajue baogao 沂南古畫像石墓發掘報告. Beijing: Wenhuabu wenwu guanliju, 1956.

\section{Yongcheng 1996}

Henan sheng wenwu kaogu yanjiusuo 河南省文物考古研究所. Yongcheng Xi Han Liangguo wangling yu qinyuan 永城西汉梁国王陵与寝园. Zhengzhou: zhongzhou guji chubanshe, 2001.

\section{Yongcheng 2001}

Yan Genqi 阎根齐 eds., Mangdangshan Xi Han Liangwang mudi 芒砀山西汉梁王 墓地. Beijing: wenwu chubanshe, 2001.

\section{2 Articles}

\section{Changchuan 1982}

Jilin sheng wenwu gongzuodui 吉林省文物工作队 and Ji'an xian wenwu baoguansuo 集安县文物保管所. 'Ji' an Changchuan yihao bihua mu 集安长川一号 壁画墓', in Dongbei kaogu yu lishi bianji weiyuanhui 东北考古与历史编辑委员会. Dongbei kaogu yu lishi diyiji 东北考古与历史 第一辑, Beijing: Wenwu chubanshe, 1982: 154-173.

\section{Dongnan wenhua 1999}

Yao Jingzhou 姚景洲 and Jia Qinghua 贾庆华. 'Pizhou Chefushan Han huaxiangshi 邳州车夫山汉画像石', Dongnan wenhua 1999.2: 18-21.

\section{Dongnan wenhua 2006}

Hao Lirong 郝利荣. 'Pizhou Chefushan Han huaxiangshi mu chubu yanjiu 㳪州车 夫山汉画像石墓初步研究', Dongnan wenhua 2006.2: 26-32.

\section{Huaxia kaogu 1987}

Henan sheng wenwu yanjiusuo 河南省文物研究所. 'Mixian Houshiguo Han huaxiangshi mu fajue baogao 密县后士郭汉画像石墓发掘报告, , Huaxia kaogu 1987.2: 96-240. 


\section{Huaxia kaogu 2003}

Li Jun 李军, Meng Qiang 孟强 and Geng Jianjun 耿建军. 'Jiangsu Pizhou Chefushan Qianbu Han huaxiangshi mu de fuyuan yu yanjiu 江苏丕州车夫山前埠汉 画像石墓的复原与研究, Huaxia kaogu 2003.3: 87-95.

\section{Jixian 2005}

'Tianjian Jixian Xiaomaozhuang Dong Han huaxiangshi mu 天津䔡县小毛庄东汉画 像石墓, in Guojia wenwuju 国家文物局. 2004 Zhongguo zhongyao kaogu faxian 2004 中国重要考古发现, Beijing: Wenwu chubanshe, 2005: 118-122.

\section{Kaogu 1960}

Daosheng 道生 trans., 'Chaoxian Ping'an Nan Dao Shunchuan Jun Longfengli Liaodong Cheng zhong diaocha baogao 朝鮮平安南道順川郡龍鳳里遼東城塚調查 報告', Kaogu 1960.1: 54-58.

\section{Kaogu 1964a}

Jilin sheng bowuguan 吉林省博物館. 'Jilin Ji'an Wukuifen sihao he wuhao mu qingli lueji 吉林輯安五盔坟四号和五号墓清理略記’, Kaogu 1964.2: 59-66.

\section{Kaogu 1964b}

Wang Chengli 王承礼 and Han Shuhua 韓淑华. 'Jilin Ji'an Tonggou di shi'er hao bihua mu 吉林輯安通沟第十二号高句丽壁画墓’, Kaogu 1964.2: 67-72.

\section{Kaogu 1966}

Jiangsu sheng wenwu guanli weiyuanhui 江苏省文物管理委員会 and Nanjing bowuyuan 南京博物院. 'Jiangsu Xuzhou Shilipu Han huaxiangshi mu 江苏徐州十 里鋪汉画象石墓’, Kaogu 1966.2: 66-83 and 91.

\section{Kaogu 1975}

Shandong sheng bowuguan 山东省博物馆 and Cangshan xian wenhuaguan 苍山县 文化馆. 'Shandong Cangshan Yuanjia yuannian huaxiangshi mu 山东苍山元嘉元年 画象石墓', Kaogu 1975.2: 124-134.

\section{Kaogu 1979}

Ji'an xian wenwu baoguansuo 集安县文物保管所. 'Ji'an xian liangzuo Gaogouli jishimu de qingli 集安县两座高句丽积石墓的清理', Kaogu 1979.1: 27-32 and 50.

\section{Kaogu 1981}

Nanjing bowuyuan 南京博物院. 'Xuzhou Qingshanquan Baiji Dong Han huaxiangshi mu 徐州青山泉白集东汉画象石墓', Kaogu 1981.2: 137-150.

\section{Kaogu 1985}

Zhongguo shehui kexueyuan kaogu yanjiusuo Henan di'er gongzuodui 中國社会科 
學院考古研究所河南第二工作队. 'Henan Yanshi Xingyuan cun Dong Han bihuamu 河南偃师杏园村东汉壁画墓, Kaogu 1985.1: 18-22.

\section{Kaogu 1987}

Liu Boqin 刘伯勤 and Liu Shanyi 刘善沂. 'Shandong Pingying Xintun Han huaxiangshi mu 山东平阴新屯汉画像石墓', Kaogu 1988.11: 961-974.

\section{Kaogu 1991}

Zhang Xueyan 张雪岩. 'Jilin Ji'an Dongdapo Gaogouli muzang fajue jianbao 吉林 集安东大坡高句丽墓葬发掘简报’, Kaogu 1991.7: 600-607.

\section{Kaogu 1997}

Xuzhou bowuguan 徐州博物馆. 'Jiangsu Tongshan xian guishan erhao Xi Han yadongmu cailiao de zaibuchong 江苏铜山县龟山二号西汉崖洞墓材料的再补充, Kaogu 1997.2: 36-46.

\section{Kaogu 1998}

Wei Zheng 韦正, Li Huren 李虎仁 and Zou Houben 邹厚本. 'Jiangsu Xuzhou shi shizishan Xi Han mu de fajue yu shouhuo 江苏徐州市狮子山西汉墓的发掘与收获, Kaogu 1998.8: 1-20.

\section{Kaogu 2007}

Chen Kunlin 陈昆麟 et al. 'Shandong Dong'e xian Dengmiao Han huaxiangshi mu 山东东阿县邓庙汉画像石墓', Kaogu 2007.3: 32-51.

\section{Kaogu 2010}

Xuzhou bowuguan 徐州博物馆. 'Jiangsu Xuzhou shi Han dai caishichang yizhi fajue jianbao 江苏徐州市汉代采石场遗址发掘简报’, Kaogu 2010.11: 28-39.

\section{Kaogu tongxun 1955}

Li Jianzhao 李鑑昭. 'Jiangsu Suining Jiunüdun Han mu qingli jianbao 江蘇睢寧九 女墩漢墓清理簡報’, Kaogu tongxun 1955.2: 31-33.

\section{Kaogu xuebao 1964}

Hebei sheng wenhuaju wenwu gongzuodui 河北省文化局文物工作队. 'Hebei sheng Dingxian Beizhuang Han mu fajue baogao 河北定县北庄汉墓发掘报告', Kaogu xuebao 1964.2: 127-194.

\section{Kaogu xuebao 1980}

Nanyang diqu wenwudui 南阳地区文物队 and Nanyang bowuguan 南阳博物馆. 'Tanghe Han Yuping dayin Fengjunruren huaxiangshi mu 唐河汉郁平大尹冯君孺人 画象石墓', Kaogu xuebao 1980.2: 239-262.

\section{Kaogu xuebao 1982}


Tianjin shi wenwu guanlichu kaogudui 天津市文物管理处考古队. 'Wuqing Dong Han Xianyu Huang mu 武清东汉鲜于璜墓’, Kaogu xuebao 1982.3: 351-365.

\section{Kaogu xuebao 1984}

Jilin sheng wenwu gongzuodui 吉林省文物工作队. 'Jilin Ji'an Wukuifen sihao mu 吉林集安五盔坟四号墓, Kaogu xuebao 1984.1: pp. 121-136.

\section{Kaogu xuebao 1985}

Nanjing bowuyuan 南京博物院 and Tongshan xian wenhuaguan 铜山县文化馆. 'Tongshan guishan erhao Xi Han yadongmu 铜山龟山二号西汉崖洞墓', Kaogu xuebao 1985.1: 119-137.

\section{Kaogu xuebao 1993}

Hubei sheng wenwu kaogu yanjiusuo 湖北省文物考古研究所. 'Jiangling fenghuangshan yiliuba hao Han mu 江陵凤凰山一六八号汉墓', Kaogu xuebao 1993.4: 455-513.

\section{Kaogu xuebao 2007}

Henan Nanyang shi wenwu kaogu yanjiusuo 河南南阳市文物考古研究所, 'Henan Nanyang Chenpeng Han dai caihui huaxiangshi mu 河南南阳陈棚汉代彩绘画像石 墓', Kaogu xuebao 2007.2: 233-266.

\section{Kaogu yu wenwu 1982}

Jilin sheng Ji'an xian wenwu baoguansuo 吉林省集安县文物保管所. 'Ji'an Wanbaoting muqu 242 hao gumu qingli jianbao 集安万宝汀墓区 242 号古墓清理简 报', Kaogu yu wenwu 1982.6: 16-19 and 28.

\section{Wenwu 1959}

Li Qingfa 李庆发. 'Liaoyang Shangwangjiacun Jin dai bihua mu qingli jianbao 辽阳 上王家村晉代壁画墓清理簡报’,Wenwu 1959.7: 60-62.

\section{Wenwu 1960}

Yin Ruzhang 殷汝章. 'Shandong Anqiu Mushan shuiku faxian daxing shike Han mu 山东安邱牟山水庫发現大型石刻汉墓, Wenwu 1960.5: 55-59.

\section{Wenwu 1961}

Shaanxi sheng wenwu guanli weiyuanhui 陝西省文物管理委員会. 'Tongguan Diaoqiao Han dai Yang shi muqun fajue jianji 潼关吊桥汉代楊氏墓群发掘簡記', Wenwu 1961.1: 56-66.

\section{Wenwu 1964a}

Shandong sheng bowuguan 山东省博物馆. 'Shandong Anqiu Han huaxiangshi mu fajue jianbao 山东安丘汉画象石墓发掘簡报’, Wenwu 1964.4: 30-40. 


\section{Wenwu 1964b}

Beijing shi wenwu gongzuodui 北京市文物工作队. 'Beijing xijiao faxian Han dai shique qingli jianbao 北京西郊发現汉代石䦣清理簡报, Wenwu 1964.11: 13-22.

\section{Wenwu 1964c}

Hebei sheng wenhuaju wenwu gongzuodui 河北省文化局文物工作队. 'Dingxian Beizhuang Han mu chutu wenwu jianbao 定县北庄汉墓出土文物簡报’, Wenwu 1964.12: 26-40.

\section{Wenwu 1966}

Beijing shi wenwu gongzuodui 北京市文物工作队. 'Fengtai qu Santaizi chutu Han huaxiangshi 丰台区三台子出土汉画像石', Wenwu 1966.4: 53-54.

\section{Wenwu 1972}

An Jinhuai 安金槐 and Wang Yugang 王与刚. 'Mixian Dahuting Han dai huaxiangshi mu he bihua mu 密县打虎亭汉代画象石墓和壁画墓, Wenwu 1972.10: 49-62.

\section{Wenwu 1973}

Zhou Dao 周到 and Li Jinghua 李京华. 'Tanghe zhenzhichang Han huaxiangshi mu de fajue 唐河针织厂汉画像石墓的发掘, Wenwu 1973.6: 26-40.

\section{Wenwu 1979}

Jiaxiang xian $\mathrm{Wu}$ Shi Ci wenguansuo 嘉祥县武氏祠文管所. 'Shandong Jiaxiang Songshan faxian Han huaxiangshi 山东嘉祥宋山发现汉画像石’, Wenwu 1979.9: $1-6$.

\section{Wenwu 1982}

Ji'ning diqu wenwuzu 济宁地区文物组 and Jiaxiang xian wenguansuo 嘉祥县文 管所. 'Shandong Jiaxiang Songshan 1980 nian chutu de Han huaxiangshi 山东嘉祥 宋山 1980 年出土的汉画像石’, Wenwu 1982.5: 60-70.

\section{Wenwu 1983}

Jiaxiang diqu wenguanhui 嘉兴地区文管会 and Haining xian bowuguan 海宁县博 物馆. 'Zhejiang Haining Dong Han huaxiangshi mu fajue jianbao 浙江海宁东汉画 像石墓发掘简报', Wenwu 1983.5: 1-20.

\section{Wenwu 1984}

Nanjing bowuyuan 南京博物院 and Pixian wenhuaguan 䂙县文化馆. 'Dong Han Pengcheng xiang Miao Yu mu 东汉彭城相缪宇墓, Wenwu 1984.8: 22-29.

\section{Wenwu 1988}

Xuzhou bowuguan 徐州博物馆 and Nanjing daxue lishixi kaoguzhuanye 南京大学 历史系考古专业. 'Xuzhou beidongshan Xi Han mu fajue jianbao 徐州北洞山西汉 
墓发掘简报', Wenwu 1988.2: 4-33.

\section{Wenwu 1989}

Tai'an shi wenwuju 泰安市文物局. ‘Tai'an Dawenkou Han huaxiangshi mu 泰安大 汶口汉画像石墓’, Wenwu 1989.1: 48-58.

\section{Wenwu 1991}

Zhoukou diqu wenwu gongzuodui 周口地区文物工作队 and Huaiyang xian bowuguan 淮阳县博物馆. 'Henan Huaiyang Beiguan yihao Han mu fajue jianbao 河南淮阳北关一号汉墓发掘简报’,Wenwu 1991.4: 34-46.

\section{Wenwu 1992}

Luoyang shi di'er wenwu gongzuodui 洛阳市第二文物工作队. 'Luoyang shi Zhucun Dong Han bihua mu fajue jianbao 洛阳市朱村东汉壁画墓发掘简报', Wenwu 1992.12: 15-20.

\section{Wenwu 1998}

Shizishan Chu Wang ling kaogufajuedui 狮子山楚王陵考古发掘队。'Xuzhou shizishan Xi Han Chu Wang ling fajue jianbao 徐州狮子山西汉楚王陵发掘简报', Wenwu 1998.8: 2-18 and 68.

\section{Wenwu 2002}

Ji'nan shi wenhuaju wenwuchu 济南市文化局文物处 and Pingyin xian bowuguan 平阴县博物馆. 'Shandong Pingyin Mengzhuang Dong Han huaxiangshi mu 山东平 阴孟庄东汉画像石墓', Wenwu 2002.2: 38-52.

\section{Wenwu 2005}

Wang Jinyuan 王金元. 'Shanxi Lishi Shipan Han dai huaxiangshi mu 山西离石石 盘汉代画像石墓', Wenwu 2005.2: 42-51.

\section{Wenwu cankao ziliao 1955a}

Li Wenxin 李文信. 'Liaoyang faxian de sanzuo bihua gumu 遼陽發現的三座壁畫 古墓', Wenwu cankao ziliao 1955.5: 15-42.

\section{Wenwu cankao ziliao 1955b}

Henan wenwu gongzuo dui diyi dui 河南文物工作隊第一隊, 'Zhengzhou Gangdu fujin gu muzang fajue jianbao 鄭州崗杜附近古墓葬發掘簡報', Wenwu cankao ziliao 1955.10: 3-24.

\section{Wenwu cankao ziliao 1955c}

Dongbei bowuguan 东北博物館, 'Liaoyang sandaohao liangzuo bihuamu de qingli fongzuo jianbao 遼陽三道壕兩座壁畫墓的清理工作簡報', Wenwu cankao ziliao 1955.12: 49-58. 


\section{Wenwu cankao ziliao 1957}

Nanjing bowuyuan 南京博物院, “Changli shuiku Han muqun fajue jianbao 昌梨水 庫汉墓㾕發掘簡报', Wenwu cankao ziliao 1957.12: 29-44.

\section{Xuzhou 1986}

Li Yinde 李银德, 'Xuzhou shi Tunli lalishan Dong Han shishimu 徐州市屯里拉犁 山东汉石室墓', in Zhongguo kaoguxue nianjian 1986: 123-124.

\section{Xuzhou 1990}

Geng Jianjun 耿建军, 'Xuzhou shi lalishan erhao Dong Han shishimu 徐州市拉犁 山二号东汉石室墓', in Zhongguo kaoguxue nianjian 1990: 208-209.

\section{Xuzhou 1991}

Qiu Yongsheng 邱永生 and Xu Xu 徐旭, 'Xuzhou shi tuolanshan Xi Han mu 徐州 市驮篮山西汉墓', in Zhongguo kaoguxue nianjian 1991: 173-174.

\section{Zhejiang 2005a}

Zhejiang sheng wenwu guanli weiyuanhui 浙江省文物管理委员会. 'Zhejiang sheng Deqing xian Fenghuangshan huaxiangshi mu fajue jianbao 浙江省德清县凤凰山画 像石墓发掘简报, , in Zhejiang sheng wenwu kaogu yanjiusuo 浙江省文物考古研究 所 eds., Zhejiang sheng wenwu kaogu yanjiusuo xuekan diqiji 浙江省文物考古研 究所学刊第 7 辑. Hangzhou: Hangzhou chubanshe, 2005: 439-457.

\section{Zhejiang 2005b}

Zhejiang sheng bowuguan 浙江省博物馆. 'Zhejiang sheng Deqing xian Qiushan huaxiangshi mu de fajue 浙江省德清县秋山画像石墓的发掘', in Zhejiang sheng wenwu kaogu yanjiusuo 浙江省文物考古研究所 eds., Zhejiang sheng wenwu kaogu yanjiusuo xuekan diqiji 浙江省文物考古研究所学刊第 7 辑. Hangzhou: Hangzhou chubanshe, 2005: 458-462.

\section{Zhejiang 2012}

Changxing xian bowuguan 长兴县博物馆. 'Changxing Xifengba Han huaxiangshi mu qingli jianbao 长兴西峰坝汉画像石墓清理简报', in Zhejiang Han Liu Chao mu baogao ji 浙江汉六朝墓报告集. Beijing: Kexue chubanshe, 2012.

\section{Zhongyuan wenwu 1982a}

Nanyang shi bowuguan 南阳市博物馆. 'Nanyang xian Zhaozhai zhuanwachang Han huaxiangshi mu 南阳县赵寨砖瓦厂汉画像石墓, Zhongyuan wenwu 1982.1: 1-4.

\section{Zhongyuan wenwu 1982b}

Nanyang huaxiangshi bianweihui 《南阳画像石》编委会. 'Tanghe dianchang Han huaxiangshi mu 唐河电厂汉画像石墓, Zhongyuan wenwu 1982.1: 5-11.

\section{Catalogues}




\section{Beijing 1996}

Feng Yunpeng 馮雲鵬 and Feng Yunyuan 馮雲鵷. Jinshi suo 金石索. Beijing: Shumu wenxian chubanshe, 1996.

\section{Finsterbusch 1966, 1971, 2000 and 2004}

Finsterbusch, Käte. Verzeichnis und Motivindex der Han-Darstellungen. 4 vols, Wisebaden: O. Harrassowitz, 1966, 1971, 2000 and 2004.

\section{Helinge'er 1978}

Neimenggu zizhiqu bowuguan wenwu gongzuodui 内蒙古自治区博物馆文物工作 队. Helinge'er Han mu bihua 和林格尔汉墓壁画. Beijing: wenwu chubanshe, 1978.

\section{Huaibei 2002}

Gao Shulin 高书林 eds., Huaibei Han huaxiangshi 淮北汉画像石, Tianjin: Tianjin renmin meishu chubanshe, 2002.

\section{Jiaxiang 1996}

Zhu Xilu 朱锡禄. Jiaxiang Han huaxiangshi 嘉祥汉画像石, Ji'nan: Shandong meishu chubanshe, 1996.

\section{Linyi 2002}

Linyi shi bowuguan 临沂市博物馆. Linyi Han huaxiangshi 临沂汉画像石, Ji'nan: Shandong meishu chubanshe, 2002.

\section{Nanyang 1981}

Nanyang shi bowuguan 南阳市博物馆. Nanyang Han dai huaxiang shike 南阳汉代 画像石刻, Shanghai: Shanghai renmin meishu chubanshe, 1981.

\section{Nanyang 1985}

Nanyang Han huaxiangshi bianji weiyuanhui 南阳汉画像石编辑委员会. Nanyang Han huaxiangshi 南阳汉画像石, Beijing: Wenwu chubanshe, 1985.

\section{Nanyang 1988}

Nanyang Hanhuaguan 南阳汉画馆. Nanyang Han dai huaxiang shike xubian 南阳 汉代画像石刻续编, Shanghai: Shanghai renmin meishu chubanshe, 1988.

\section{Nanyang 1990}

Wang Jianzhong 王建中 and Shan Xiushan 閃修山 eds., Nanyang liang Han huaxiangshi 南阳两汉画像石, Beijing: Wenwu chubanshe, 1990.

\section{Qingzhou 2003}

Qingzhou bowuguan eds., Qingzhou bowuguan 青州博物馆, Beijing: wenwu chubanshe, 2003. 


\section{Shandong 1982}

Shandong sheng bowuguan 山东省博物馆 and Shandong sheng wenwu kaogu yanjiusuo 山东省文物考古研究所. Shandong Han huaxiangsh xuanjii 山东汉画像 石选集, Ji’nan: Qi Lu shushe, 1982.

\section{Shandong and Henan 2000}

Zhongguo huaxiangshi quanji bianji weiyuanhui 中國畫像石全集編輯委員會. Zhongguo meishu fenlei quanji, Zhongguo huaxiangshi quanji 中國美術分類全集, 中國畫像石全集, 8 vols., Ji'nan: Shandong meishu chubanshe, Zhengzhou: Henan meishu chubanshe, 2000.

\section{Shangqiu 1991}

Yan Genqi 阎根齐, Mi Jingzhou 米景周 and Li Junshan 李俊山 eds., Shangqiu Han huaxiangshi 商丘汉画像石, Zhengzhou: Henan meishu chubanshe, 1991.

\section{Weishan 2003}

Ma Hanguo 马汉国. Weishan Han huaxiangshi xuanji 微山汉画像石选集, Beijing: Wenwu chubanshe, 2003.

\section{Xuzhou 1959}

Zhongguo kexueyuan kaogu yanjiusuo 中國科學院考古研究所. Jiangsu Xuzhou Han huaxiangshi 江蘇徐州漢畫像石, Beijing: Kexue chubanshe, 1959.

\section{Xuzhou 1985}

Xuzhou bowuguan 徐州博物馆. Xuzhou Han huaxiangshi 徐州汉画像石, Nanjing: Jiangsu meishu chubanshe, 1985.

\section{Xuzhou 1995}

Xuzhou duiwai jiaoliu xiehui 徐州对外交流协会. Xuzhou Han huaxiangshi 徐州汉 画像石, Beijing: Zhongguo shijieyu chubanshe, 1995.

\section{Zoucheng 2008}

$\mathrm{Hu}$ Xinli 胡新立. Zoucheng Han huaxiangshi 邹城汉画像石, Beijing: Wenwu chubanshe, 2008.

\section{Lin Ronghua 1957, 1979, 1982 and 1986}

Lin Ronghua 林榮華 eds., Shike shiliao xinbian 石刻史料新編. Taipei: Xinwenfeng chuban gongsi, 1957, 1979, 1982 and 1986.

\section{Chinese Language Primary Sources}

\section{Baihu tong}

Baihu tong shuzheng 白虎通疏證 by Ban $\mathrm{Gu}$ 班固, edited by Chen Li 陳立, 
Beijing: Zhonghua shuju, 1994.

Fengsu Tongyi

Fengsu Tongyi jiaoshi 風俗通義校釋 by Ying Shao 應劭, annotated by Wu Shuping 吳樹平, Tianjin: Tianjin renmin chubanshe, 1980.

Hanshu

Hanshu 漢書 by Ban Gu 班固, Beijing: Zhonghua shuju, 1962.

Hou Hanshu

Hou Hanshu 後漢書 by Fan Ye 范曄, Beijing: Zhonghua shuju, 1965.

Liji

Liji jijie 禮記集解 by Sun Xidan 孫希旦, Beijing: Zhonghua shuju, 1989.

Lunheng

Lunheng 論衡 by Wang Chong 王充, Shanghai: Shanghai renmin chubanshe, 1974.

Mozi

Mozi jiaozhu 墨子校注 by Mo Di 墨翟, annotated by Wu Yujiang 吳毓江, Beijing: Zhonghua shuju, 1993.

Qianfulun

Qianfu lun jian jiaozheng 潛夫論箋校正 by Wang $\mathrm{Fu}$ 王符, annotated by Wang Jipei 汪繼培, amended by Peng Duo 彭鐸, Beijing: Zhonghua shuju, 1985.

Quan Han fu

Quan Han fu 全漢賦 annotated by Fei Zhengang 費振剛, Hu Shuangbao 胡雙寶 and Zong Minghua 宗明華, Beijing: Beijing daxue chubanshe, 1993.

Samguk sagi

Sanguo shiji (Korean: Samguk sagi) 三國史記 by Kim Bu-sik 金富軾 [AD1075-1151], annonated by Sun Wenfan 孫文範, Changchun: Jilin wenshi chubanshe, 2003.

Sanguo zhi

Sanguo zhi 三國志 by Chen Shou 陳壽 [AD233-297], Beijing: Zhonghua shuju, 1971.

Shiji

Shiji 史記 by Sima Qian 司馬遷, Beijing: Zhonghua shuju, 1982.

Shuijing zhu

Shuijing zhu 水經注 by Li Daoyuan 麗道元, Shanghai: Renmin chubanshe, 1984. 
Yili

Yili zhushu 儀禮注疏 by Zheng Xuan 鄭玄, Shanghai: Shanghai guji chubanshe, 2008.

Zhouli

Zhouli zhengyi 周禮正義 by 孫詒讓, Beijing: Zhonghua shuju, 1987.

\section{Chinese, Japanese and Korean Secondary Sources}

\section{Chang Qing 1991}

Chang Qing 常青. 'Liang Han zhuan shi gongding jianzhu tanyuan 两汉砖石拱顶 建筑探源', Ziran kexueshi yanjiu 自然科学史研究, vol. 10, No. 3, 1991: 288-295.

\section{Chen Zhi 1988}

Chen Zhi 陈直. 'Han Xiangtajun shicitang tizi tongkao 汉芕他君石祠堂题字通考', in Chen Zhi, Wenshi kaogu luncong 文史考古论丛, Tianjin: Tianjin guji chubanshe 1988: 411-415.

\section{Doi Yoshiko 1986}

Doi Yoshiko 土居淑子. Kodai Chugoku no gazoseki 古代中国の画象石, Kyoto 1986.

\section{Geng Tiehua 2008}

Geng Tiehua 耿铁华. Gaogouli gumu bihua yanjiu 高句丽古墓壁画研究, Changchun: Jilin Daxue chubanshe, 2008.

\section{Guo Xiaochuan 1997}

Guo Xiaochuan 郭晓川. 'Su Lu Yu Wan qu Han huaxiang shijue xingshi yanbian de fenqi yanjiu 苏鲁豫皖区汉画像视觉形式演变的分期研究, Kaogu xuebao 1997.2: 171-195.

\section{Han Yuxiang 1995}

Han Yuxiang 韩玉祥 eds., Nanyang Han dai tianwen huaxiangshi yanjiu 南阳汉代 天文画像石研究, Beijing: Minzu chubanshe, 1995.

\section{Hayashi Minao 1974}

Hayashi Minao 林巳奈夫. 'Kandai kishin no sekai 漢代鬼神の世界', the Toho Gakuho Journal of Oriental Studies 東方學報, no. 46: 223-306.

\section{Hayashi Minao 1992}

Hayashi Minao 林巳奈夫. Ishi ni kizamareta sekai 石に刻まれた世界, Tokyo 1992.

\section{Huang Xiaofen 2003}


Huang Xiaofen 黄晓芬. Han mu de kaoguxue yanjiu 汉墓的考古学研究, Changsha: Yuelu shushe, 2003.

\section{Huang Yafeng 2009}

Huang Yafeng 黄雅峰. Haining Han huaxiangshi mu yanjiu 海宁汉画像石墓研究, Hangzhou: Zhejiang daxue chubanshe, 2009.

\section{Hsing I-Tien 1996}

Hsing I-Tien 邢義田. 'Han bei, Han hua he shigong de guanxi 漢碑、漢畫和石工的 關係’, Gugong wenwu yuekan 故宮文物月刊, vol 14, 1996.4: 44-59.

\section{Hsing I-Tien 2011}

Hsing I-Tien 邢義田. Hua wei xinsheng 画为心声: 画像石、画像砖与壁画, Beijing: Zhonghua shuju, 2011.

\section{Jiang Yingju 1983}

Jiang Yingju 蒋英炬. 'Han dai de xiaocitang: Jiaxiang Songshan Han huaxiangshi de jianzhu fuyuan 汉代的小祠堂: 嘉祥宋山汉画像石的建筑复原, Kaogu 1983.8: 741-751.

\section{Jiang Yingju and Wu Wenqi 1980}

Jiang Yingju 蒋英炬 and Wu Wenqi 吴文祺. 'Shilun Shandong Han huaxiangshi de fenbu kefa yu fenqi 试论山东汉画像石的分布、刻法与分期'. Kaogu yu wenwu 1980.4: 108-114.

\section{Jiang Yingju and Wu Wenqi 1995}

Jiang Yingju 蒋英炬 and Wu Wenqi 吴文祺. Han dai Wu shi muqun shike yanjiu 汉代武氏墓群石刻研究. Ji’nan: Shandong meishu chubanshe, 1995.

\section{Kim Byong-mo 1976}

Kim Byong-mo 金秉模. 'The Origin of Cut-stone Tomb in China and its Influence on Korea', Journal of Korean Archaeological Studies, vol.1, 1976.11: 1-25.

\section{Li Dianfu 1980}

Li Dianfu 李殿福. 'Ji'an Gaogouli mu yanjiu 集安高句丽墓研究', Kaogu xuebao 1980.2: 163-185.

\section{Li Falin 1982}

Li Falin 李发林. Shandong Han huaxiangshi yanjiu 山东汉画像石研究. Ji'nan: Qi Lu shushe, 1982.

\section{Li Falin 2000}

Li Falin 李发林. Hanhua kaoshi he yanjiu 汉画考释和研究. Beijing: Zhongguo wenlian chubanshe, 2000. 


\section{Li Weiran 1958}

Li Weiran 李蔚然. 'Jiangsu Suining jiunüdun Han mu chutu yupai yongtu de tuice 江蘇睢寧九女墩漢墓出土玉牌用途的推測’, Kaogu tongxun 1958.2: 57-59.

\section{Liang Yong 2000}

Liang Yong 梁勇. 'Cong Xi Han Chu Wang mu de jianzhu jiegou kan Chu Wang mu de pailie shunxu 从西汉楚王墓的建筑结构看楚王墓的排列顺序', Wenwu 2001.10: 71-84.

\section{Lin Meicun 2000}

Lin Meicun 林梅村. Gudao xifeng: kaogu xinfaxian suojian Zhong Xi wenhua jiaoliu 古道西风: 考古新发现所见中西文化交流, Beijing: Sanlian shudian, 2000.

\section{Liu Dake 1993}

Liu Dake 刘大可. Zhongguo gujianzhu washi yingfa 中国古建筑瓦石营法, Beijing: Zhongguo jianzhu gongye chubanshe, 1993.

\section{Liu Dunyuan 1994}

Liu Dunyuan 劉敦願. 'Han huaxiangshi shang de “yinshi nannü” - Pingyin Mengzhuang Han mu shizhu jisi gewu tuxiang fenxi 漢畫像石上的“飲食男女”一平陰孟莊漢墓石柱祭祀歌舞圖像分析, Gugong wenwu yuekan 故宮文物月刊, vol 141, 1994.12.

\section{Liu Fengming 2010}

Liu Fengming 刘凤鸣. Shandong bandao yu gudai Zhong Han guanxi 山东半岛与 古代中韩关系, Beijing: Zhonghua shuju, 2010.

\section{Liu Wei 2004}

Liu Wei 刘未. 'Liaoyang Han Wei Jin bihuamu yanjiu 辽阳汉魏晋壁画墓研究', in Jilin Daxue bianjiang kaogu yanjiu zhongxin 吉林大学边疆考古研究中心. Bianjiang kaogu yanjiu 边疆考古研究, vol. 2, Beijing: Kexue chubanshe, 2004: 232-257.

\section{Liu Wei 2008}

Liu Wei 刘未. 'Gaogouli shishimu de qiyuan yu fazhan jieduan 高句丽石室墓的起 源与发展阶段, Nanfang wenwu 2008.4: 74-83.

\section{Luo Fuyi 1960}

Luo Fuyi 罗福頣. 'Xiangtajun shicitang tizi jieshi 薌他君石祠堂題字解釋', Gugong bowuyuan yuankan 故宮博物院院刊 1960.2: 178-181.

\section{Miao Zhe 2007}

Miao Zhe 缪哲. Han Dai yishu zhong wailai muti juli - yi huaxiangshi wei zhongxin 
汉代艺术中外来母题举例——以画像石为中心, $\mathrm{PhD}$ thesis, Nanjing: Nanjing Normal University, 2007.

\section{Mao Yisheng 1986}

Mao Yisheng 茅以升 eds., Zhongguo guqiao jishu shi 中国古桥技术史. Beijing: Beijing chubanshe, 1986.

\section{Segalen 1930}

Segalen, Victor. Feng Chengjun 馮承鈞. trans., Zhongguo xibu kaogu ji 中國西部考 古記 (Premier Exposé des Résultats Archéologiques Obtenus dans la Chine Occidentale par la Mission Gilbert de Voisins Jean Latirgue et Victor Segalen). Shanghai: Shangwu yinshuguan, 1930.

\section{Su Bai 1952}

Su Bai 宿白. 'Chaoxian Anyue faxian de Dong Shou mu 朝鮮安岳所發現的冬壽 墓, Wenwu cankao ziliao 1952.1: 101-104.

\section{Sun Guanwen 2006}

Sun Guanwen 孙贯文. 'Xiangtajun shicitang kaoshi 薌他君石祠堂考释', in Beijing daxue kaogu wenbo xueyuan 北京大学考古文博学院, Kaoguxue yanjiu (liu) 考古 学研究 (六), Beijing: kexue chubanshe, 2006: 503-513.

\section{Sun Ji 1991}

Sun Ji 孙机, Han dai wuzhi wenhua ziliao tushuo 汉代物质文化资料图说, Beijing: Wenwu chubanshe, 1991.

\section{Tseng 2000}

Tseng, Lan-ying. 'Workshops, Repertoires and Regional Visual Traditions: Traces of the Han Carved Tomb at Anqiu in Shandong,' Taida Journal of Art History, 2000.8: 33-86.

\section{Wang Jianzhong 2001}

Wang Jianzhong 王建中, Han dai huaxiangshi tonglun 汉代画像石通论. Beijing: Zijincheng chubanshe, 2001.

\section{Wei Cuncheng 1995}

Wei Cuncheng 魏存成. Gaogouli kaogu 高句丽考古, Changchun: Jilin Daxue chubanshe, 1995.

\section{Wei Cuncheng 2002}

Wei Cuncheng 魏存成. Gaogouli yiji 高句丽遗迹, Beijing: Wenwu chubanshe, 2002.

\section{Wenwu 1973}


Henan sheng bowuguan 河南省博物馆. 'Nanyang Han huaxiangshi gaishu 南阳汉 画像石概述', Wenwu 1973.6: 16-25.

\section{Wenwu 1980}

Xuzhou bowuguan 徐州博物馆. 'Lun Xuzhou Han huaxiangshi 论徐州汉画像石', Wenwu 1980.2: 44-55.

\section{Wu Hung 1994a}

Wu Hung 巫鸿. 'Guowai bainian Han huaxiang yanjiu zhi huigu 国外百年汉画像研 究之回顾, Zhongyuan wenwu 1994.1: 45-50.

\section{Wenwu 2006}

Luan Fengshi 奕丰实. 'Shiqian guanguo de chansheng fazhan he guanguo zhidu de xingcheng 史前棺楟的产生、发展和棺楟制度的形成', Wenwu 2006.6: 49-55.

\section{Xia Nai 1961}

Xia Nai 夏叟. 'Xinjiang xinfaxian de gudai sizhipin: qi, jin he cixiu 新疆新发現的 古代絲織品——綺、錦和刺綉’, Kaogu xuebao 1963.1: 45-76.

\section{Xin Lixiang 1982}

Xin Lixiang 信立祥, Han huaxiangshi de fenqu yu fenqi yanjiu 汉画像石的分区与 分期研究, Master thesis, Peking University, 1982. Published in Yu Weichao 俞伟超 ed., Kaogu leixingxue de lilun yu shijian 考古类型学的理论与实践, Beijing: Wenwu chubanshe, 1989: 234-306.

\section{Xin Lixiang 2000}

Xin Lixiang 信立祥, Han dai huaxiangshi zonghe yanjiu 汉代画像石综合研究, Beijing: Wenwu chubanshe, 2000.

\section{Yang Hong 1958}

Yang Hong 杨泓, 'Gaogouli bihua shimu 高句丽壁画石墓', Wenwu cankao ziliao 1958.4: 12-21.

\section{Yang Shuda 1933}

Yang Shuda 楊樹達. Han dai hunsang lisu kao 漢代婚喪禮俗考 (new edition). Shanghai: Shanghai guji chubanshe, 2000.

\section{You Yifei 2009}

You Yifei 游逸飛, Han Dai ‘niaoyutu’ de duochong yuyi 漢代 “鳥魚圖” 的多重寓 意, in 2009 nian Taida Yishushi Yanjiusuo xuesheng yantaohui huiyi lunwenji 2009 年 臺大藝術史研究所學生研討會會議論文集, Taipei 2009: 150-175.

\section{Yu Weichao 1960}

Yu Weichao 俞偉超. 'Ba Chaoxian Ping'an Nan Dao Shunchuan Jun Longfengli 
Liaodong Cheng zhong diaocha baogao 跋朝鮮平安南道順川郡龍鳳里遼東城塚調 查報告, Kaogu 1960.1: 59-60.

\section{Zhao Junjie 2009}

Zhao Junjie 赵俊杰. 4-7 shiji Datong Jiang, Zaining Jiang liuyu fengtu shishimu yanjiu 4-7 世纪大同江、载宁江流域封土石室墓研究, PhD thesis, Changchun: Jilin University, 2009.

\section{Zheng Yan 2006}

Zheng Yan 郑岩. 'Guanyu Han dai sangzang huaxiang guanzhe wenti de sikao 关于 汉代丧葬画像观者问题的思考', in Zhongguo Hanhua yanjiu 中国汉画研究, vol. 2, 2006: 39-55.

\section{Zhou Xueying 2001}

Zhou Xueying 周学鹰. Xuzhou Han mu jianzhu, Zhongguo Han dai Chu guo (Pengcheng) muzang jianzhu kao, 徐州汉墓建筑一一国汉代楚国（彭城）墓葬 建筑考, Beijing: Zhongguo jianzhu gongye chubanshe, 2001.

\section{Zhou Xueying 2006a}

Zhou Xueying 周学鹰. 'Han dai jianzhu damuzuo jishu tezheng (zhiyi), dougong 汉 代建筑大木作技术特征 (之一) ——斗拱', Huazhong jianzhu, 2006.9: 124-128.

\section{Zhou Xueying 2006b}

Zhou Xueying 周学鹰. 'Han dai jianzhu damuzuo jishu tezheng (zhi'er), dougong zhi fenlei: zhutou puzuo, zhuanjiao puzuo, bujian puzuo 汉代建筑大木作技术特征 (之二) ——斗拱之分类: 柱头铺作、转角铺作、补间铺作', Huazhong jianzhu, 2006.7: 133-136.

\section{Western Language Secondary Sources}

\section{Adam 1994}

Adam, Jean Pierre. Mathews, Anthony. trans., Roman building: materials and techniques. London: Batsford, 1994.

\section{Barbieri-low 2007}

Barbieri-low, Anthony. Artisans in Early Imperial China. Seattle: University of Washington Press, 2007.

\section{Barfield 1989}

Barfield, Thomas. The Perilous Frontier: Nomadic Empires and China. Oxford and Cambridge, MA: Basil Blackwell, 1989.

\section{Barker and Russell 2012}

Barker, Simon and Russell, Ben. 'Labour Figures for Roman Stone-working: Pitfalls 
and Potential', in S. Camporeale, H. Dessales, and A. Pizzo eds., Arqueología de la Construcción III. Los procesos constructivos en el mundo Romano: la economía de las obras (Anejos de Archivo Español de Arqueologa 64), Madrid and Merida 2012: 83-94.

\section{Berger 1976}

Berger, Patricia. 'The Battle at the Bridge at Wu Liang Tz'u: A Problem in Method', Early China vol. 2 (Fall):3-8.

\section{Brashier 1996}

Brashier, K.E. 'Han Thanatology and the Division of "Souls", Early China vol. 21, 1996, 125-158.

\section{Bushell 1910}

Bushell, Stephan. Chinese Art, 2 vols. London: H. M. S. O, 1910.

\section{Campbell 2010}

Campbell, Aurelia. 'The Form and Function of Western Han Dynasty Ticou Tombs', Artibus Asiae, Vol. LXX, No. 2, 2010: 227-258.

\section{Chen Xuan 2014}

Chen, Xuan. Eastern Han (AD25-220) Tombs in Sichuan. PhD thesis, University of Oxford, 2014.

\section{Craven 1997}

Craven, Roy. Indian Art: A Concise History. London: Thames and Hudson, 1997.

\section{Dien 1987}

Dien, Albert. 'Chinese Beliefs in the Afterworld', in The Quest for Eternity: Chinese Ceramic Sculptures from the People's Republic of China. Los Angeles: Los Angeles County Museum of Art, 1987:1-16.

\section{DeLaine 1997}

DeLaine, Janet. The baths of Caracalla: a study in the design, construction, and economics of large-scale building projects in imperial Rome. Portsmouth: Journal of Roman Archaeology, 1997.

\section{Dramer 2002}

Dramer, Kim Irene Nedra. Between the Living and the Dead: Han Dynasty Stone Carved Tomb Doors (China). PhD thesis, Columbia University, 2002.

\section{Erickson et al. 2010}

Erickson, Susan., Yi Song-mi, and Nylan, Michael. 'The Archaeology of the Outlying Lands', in Nylan, Michael and Loewe, Michael eds., China's Early Empires: A 
Re-appraisal, Cambridge: Cambridge University Press, 2010: 135-168.

\section{Fairbank 1941}

Fairbank, Wilma. 'The Offering Shrines of Wu Liang Tzu', Harvard Journal of Asiatic Studies, vol. 6 no. 1, 1941: 1-36.

\section{Fairbank 1942}

Fairbank, Wilma. 'A Structural Key to Han Mural Art', Harvard Journal of Asiatic Studies, vol. 7 no. 1, 1942: 52-88.

\section{Fairbank et al. 1954}

Fairbank, Wilma., and Kitano Masao. 'Han Mural Paintings in the Pei-Yuan Tomb at Liao-yang, South Manchuria', Artibus Asiae, vol. 17, no. 3, 1954: 238-264. Reprinted in Fairbank, Wilma. Adventures in Retrieval, Cambridge, MA: Harvard University Press, 1972: 141-180.

\section{Gell 1998}

Gell, Alfred. Art and Agency: an Anthropological Theory. Oxford: Clarendon Press, 1998.

\section{Gombrich 1961}

Gombrich, E. H. Art and Illusion (second edition). London: Phaidon Press, 1961.

\section{Guo Qinghua 2004}

Guo Qinghua. 'Tomb Architecture of Dynastic China: Old and New Question', Architectural History, vol. 47 no. 1, 2004: 1-24.

\section{Guo Qinghua 2010}

Guo Qinghua. The Mingqi Pottery Buildings of Han Dynasty China: 206 BC - AD 220. Brighton: Sussex Academic Press, 2010.

\section{Gupta 1980}

Gupta, Swarajya. The Roots of Indian Art: A detailed Study of the Formative Period of Indian Art and Architecture (Third and Second Centuries B.C. - Mauryan and Late Mauryan). Delhi: BR Publ., 1980.

\section{Harper 1985}

Harper, Donald. 'A Chinese Demonography of the Third Century B.C.', Harvard Journal of Asiatic Studies, vol. 45. no. 2, 1985: 459-498.

\section{Holt 1988}

Holt, Frank. Alexander the Great and Bactria: The Formation of a Greek Frontier in Central Asia. Leiden: Brill, 1988 


\section{Horlyck 2002}

Horlyck, Charlotte. 'Korean Bronze Mirrors and Their Chinese and Japanese Influences', Orientations, vol. 33, no. 9, November 2002: 48-53.

\section{Ingold 2007}

Ingold, Timothy. Materials against Materiality (and comments and response). Cambridge Archaeological Journal 14 (1), 2007: 1-38.

\section{James 1982}

James, Jean. 'Bridges and Cavalcades in Eastern Han Funerary Art', Oriental Art, vol. 28, no. 2: 165-171.

\section{James 1983}

James, Jean. An Iconographic Study of Two Late Han Funerary Monuments: The Offering Shrines of the Wu Family and the Multichamber Tomb at Holingor. $\mathrm{PhD}$ Thesis, Iowa University, 1983.

\section{James 1985}

James, Jean. 'Interpreting Han Funerary Art: The Importance of Context', Oriental Art, vol. 31: 283-292.

\section{James 1988}

James, Jean. 'The Iconographic Program of the Wu Family Offering Shrines (A.D.151-ca.170)', Artibus Asiae, XLIX:1/2, 1988/89: 39-72.

\section{James 1998}

James, Jean. 'The Han Offering Shrines: A Functional Study', Archives of Asian Art, vol.51, 1998: 16-29

\section{Jeon 2006}

Jeon, Ho-Tae. 'Artistic Creation, Borrowing, Adaptation, and Assimilation in Koguryo Tomb Murals of the Fourth to Seventh Century', Archives of Asian Art, Vol. 56, 2006: 81-104.

\section{Jeppesen et al. 2003}

Jeppesen, Kristian et al. The Maussolleion at Halikarnassos, 6 vols. Aarhus: Aarhus University Press, 2003.

\section{Johnston 2010}

Johnston, Ian. The Mozi: a complete translation. Hong Kong: Chinese University Press, 2010.

\section{Kleeman 1984}

Kleeman, Terry. 'Land Contracts and Related Documents', in Makio Ryokai Hakase 
Shoju Kinen Ronshu: Chugoku no shukyo, shiso to kagaku, Tokyo: Kokusho Kankokai, 1984: 1-34.

\section{Kristiansen and Larsson 2005}

Kristiansen, Kristian and Larsson, Thomas. The Rise of Bronze Age Society: travels, transmissions and transformations. Cambridge and New York: Cambridge University Press, 2005.

\section{Kuz'mina 2007}

Kuz'mina, Elena E. The Origin of the Indo-Iranians. Leiden: Brill, 2007.

\section{Ledderose 1998}

Ledderose, Lothar. Ten Thousand Things: Module and Mass Production in Chinese Art. Princeton, N.J.: Princeton University Press, 1998.

\section{Lin 2012}

Lin, James C. S. The Search for Immortality: Tomb Treasures of Han China. New Haven: Yale University Press, 2012.

\section{Litvinskij and Pičikjan 2002}

Boris Litvinskij and Igor R. Picikjan. Taxt-i Sangīn, der Oxus-Tempel:

Grabungsbefund, Statigraphie und Architektur. Mainz am Rhein: P. von Zabern, 2002.

\section{Loewe 1979}

Loewe, Michael. Ways to paradise: the Chinese quest for immortality. London: Allen \& Unwin, 1979.

\section{Loewe 1982}

Loewe, Michael. Chinese Ideas of Life and Death: Faith, Myth and Reason in the Han Period. London, Boston: Allen \& Unwin, 1982.

\section{Loewe 1992}

Loewe, Michael. eds., Early Chinese Texts: A bibliographical Guide. Berkeley: University of Californian and the Society for the Study of Early China, 1993.

\section{Miller 2005}

Miller, Daniel. 'Materiality: An Introduction', in Daniel Miller, ed., Materiality:

Politics, History, and Culture. Durham, N.C.: Duke University Press, 2005: 1-50.

\section{Miller 2011}

Miller, Allison. Patronage, Politics, and the Emergence of Rock-cut Tombs in Early Han China. PhD thesis, Harvard University, 2011. 


\section{Minns 1913}

Minns, Ellis. Scythians and Greeks: A Survey of Ancient History and Archaeology on the North Coast of the Euxine from the Danube to the Caucusus, Cambridge, 1913.

\section{Mitter 2001}

Mitter, Partha. Indian Art. Oxford: Oxford University Press, 2001.

\section{Nickel 2010}

Nickel, Lukas. Gräber der Han-Zeit in Luoyang. Stuttgart: Franz Steiner Verlag, 2010 .

\section{Nickel 2012}

Nickel, Lukas. 'The Nanyue Silver Box', Arts of Asia, vol. 42, no. 3, 2012: 98-107.

\section{Nickel 2012}

Nickel, Lukas. 'Brick Built Heavens - Cosmic Symbolism in Tomb Architecture and Painting of the Han Period', in Jungmann, Burglind and Schlombs, Adele and Trede, Melanie, eds., Shifting Paradigms in East Asian Visual Culture: A Festschrift in Honour of Lothar Ledderose / Grenzverschiebungen in der visuellen Kultur Ostasiens: eine Festschrift für Lothar Ledderose, Berlin: Reimer Publishers, 2012: 43-58.

\section{Nylan 2001}

Nylan, Michael. The Five "Confucian" Classics. New Haven \& London: Yale University Press, 2001.

\section{Nylan and Loewe 2010}

Nylan, Michael and Loewe, Michael eds. China's Early Empires: A Re-appraisal. Cambridge: Cambridge University Press, 2010.

\section{Okauchi 1986}

Okauchi, Mitsuzane. 'Mounded Tombs in East Asia from the 3rd to 7th Centuries A.D.' In Pearson, Richard., Barnes, Gina., and Hutterer, Karl (eds) Windows on the Japanese Past: Studies in Archaeology and Prehistory, Ann Arbor, MI: The Center for Japanese Studies, the University of Michigan, 1986: 127-148

\section{Ozgen et al. 1996}

Ilknur Özgen, Jean Öztürk, and Machteld J. Mellink. The Lydian Treasure: Heritage Recovered. Istanbul: Ugur Okman for Republic of Turkey, Ministry of Culture, General Directorate of Monuments and Museums, 1996.

\section{Paludan 1991}

Paludan, Ann. The Chinese Spirit Road: The Classical Tradition of Stone Tomb Statuary. New Haven and London: Yale University Press, 1991. 


\section{Paludan 1994}

Paludan, Ann. Chinese Tomb Figurines. Oxford: Oxford University Press, 1994.

\section{Powers 1992}

Powers, Martin. Art and Political Expression in Early China. New Haven and London: Yale University Press, 1992.

\section{Rawson 1996}

Rawson, Jessica. 'From Ritual Vessels to Pottery Tomb Figures: Changes in Ancient Chinese Burial Practice', Orientations, vol. 27. no. 9, 1996: 42-49.

\section{Rawson 1998}

Rawson, Jessica. 'Chinese Burial Patterns: Sources of Information on Thought and Belief', in Colin Renfrew and Chris Scarre, eds., Cognition and Material Culture: The Archaeology of Symbolic Storage. Cambridge: McDonald Institute for Archaeological Research, 1998: 107-133.

\section{Rawson 1999a}

Rawson, Jessica. 'The Eternal Palaces of the Western Han: A New View of the Universe', Artibus Asiae, vol. 59, no.1-2, 1999: 5-58.

\section{Rawson 2000}

Rawson, Jessica. 'Cosmological Systems as Sources of Art, Ornament and Design', Bulletin of the Museum of Far Eastern Antiquities, 72, 2000: 133-189.

\section{Rawson 2001a}

Rawson, Jessica. 'Creating Universes: Cultural Exchange as Seen in Tombs in Northern China between the Han and Tang Periods', in Wu Hung, ed., Between Han and Tang: Cultural and Artistic Interaction in a Transformative Period. Beijing: Wenwu chubanshe, 2001: 113-152.

\section{Rawson 2001b}

Rawson, Jessica. 'The Many Meanings of the Past in China', in Dieter Kuhn and Helga Stahl, eds., Die Gegenwart des Altertums: Formen and Funktionen des Altertumsbezugs in den Hochkulturen der Alten Welt. Heidelberg: Edition Forum, 2001: 397-422.

\section{Rawson 2001c}

Rawson, Jessica. 'Tombs and Tomb Furnishings of the Eastern Han Period (AD 25-220)', in Robert Bagley ed., Ancient Sichuan: Treasures from a Lost Civilisation, Princeton 2001: 253-267

\section{Rawson 2002}

Rawson, Jessica. 'The Power of Images: the Model Universe of the First Emperor and 
Its Legacy', Historical Research, vol. 75, no. 188, 2002: 123-154.

\section{Rawson 2005}

Rawson, Jessica. 'Han Dynasty Tomb Planning and design', in Christelle Marechal 麥里䈗 and Yau Shun-chiu 游順釗 eds., Proceedings of the International Symposiums: the Visual World of China, Paris 2005: 103-116.

\section{Rawson 2006a}

Rawson, Jessica. 'The Chinese Hill Censer, boshan lu: a Note on Origins, Influences and Meanings', Arts Asiatiques, Volume en homage á Madame Michéle Pirazzoli t' Serstevens, vol.61, 2006: 75-86.

\section{Rawson 2006b}

Rawson, Jessica. 'Ornament as System: The Case of Chinese Bird and Flower Designs', Burlington Magazine, July 2006: 380-389.

\section{Rawson 2007}

Rawson, Jessica. 'The Agency of, and the Agency for, the Wanli Emperor', in Robin Osborne and Jeremy Tanner, eds., Art's Agency and Art History. Malden, MA; Oxford: Blackwell Publishing, 2007: 95-113.

\section{Rawson 2010a}

Rawson, Jessica. 'Tombs of the Han Dynasty', in Kristian Göransson and Jessica Rawson eds. China's Terracotta Army, Sockholm: The Museum of Far Eastern Antiquities, 2010: 79-88.

\section{Rawson 2010b}

Rawson, Jessica. 'Reviving Ancient Ornament and the Presence of the Past: Examples from Shang and Zhou Bronze Vessels', in Wu Hung eds. Reinventing the Past: Archaism, Antiquarianism in Chinese Art and Visual Culture. Chicago: Center for the Art of East Asia, University of Chicago, 2010: 47-76.

\section{Rawson 2010c}

Rawson, Jessica. 'Carnelian Beads, Animal Figures and Exotic Vessels: traces of contact between the Chinese States and the Inner Asia, ca. 1000-650BC', Archaeologie in China, vol.1, Bridging Eurasia, 2010: 1-42.

\section{Rawson 2012}

Rawson, Jessica. 'China and Northern neighbours', in Lin, James C. S. The Search for Immortality: Tomb Treasures of Han China. New Haven: Yale University Press, 2012.

\section{Renfrew and Bahn 2005}

Renfrew, Colin and Bahn, Paul. eds., Archaeology: the Key Concepts. London and New York: Routledge, 2005. 


\section{Richard 2005}

Richard, Naomi. ed., Recarving China's Past: Art, Archaeology and Architecture of the Wu Family Shrines. Princeton, N.J.: Princeton University Art Museum, 2005

\section{Richard 2008}

Richard, Naomi. ed., Rethinking Recarving: Ideals, Practices, and Problems of the 'Wu Family Shrines' and Han China. New Haven, Conn.; London: Yale University Press, 2008

\section{Rockwell 1993}

Rockwell, Peter. The Art of Stoneworking: A Reference Guide. Cambridge: Cambridge University Press, 1993.

\section{Russell 2013}

Russell, Ben. The Economics of Roman Stone Trade. Oxford: Oxford University Press, 2013.

\section{Schmidt 1953}

Schmidt, Erich. Persepolis I: Structures, Reliefs, Inscriptions. Chicago: The University of Chicago Press, 1953.

\section{Schmidt 1970}

Schmidt, Erich. Persepolis III: The Royal Tombs and other Monuments. Chicago: The University of Chicago Press, 1953.

\section{Sear 1983}

Sear, Frank. Roman Architecture. Cornel University Press, 1983.

\section{Seidel 1982}

Seidel, Anna. 'Tokens of Immortality in Han Graves', Numen, vol. 39 no. 1, 1982: 79-114.

\section{Seidel 1987}

Seidel, Anna. 'Traces of Han Religion in Funerary Texts Found in Tombs', in Akizuki Kan'ei ed., Dokyo to Shokyo bunka, Tokyo, 1987: 678-714.

\section{Shih Hsio-yen 1961}

Shih Hsio-yen. Early Chinese Pictorial Style: From the Later Han to the Six Dynasties. PhD thesis, Bryn Mawr College, 1961.

\section{Skinner 1977}

Skinner, G. William. eds., The City in Late Imperial China: Studies in Chinese Society. Stanford: Stanford University Press, 1977. 


\section{Steinhardt 2001}

Steinhardt, Nancy. 'From Koguryo to Gansu and Xinjiang: Funerary and Worship Space in North Asia 4th - 7th Centuries', in Wu Hung eds., Between Han and Tang: Artistic and Cultural Interactions in a Transformative Period. Beijing: Wenwu chubanshe, 2001: 153-203.

\section{Steinhardt 2002}

Steinhardt, Nancy. 'Changchuan Tomb No. 1 and Its North Asian Context', Journal of East Asian Archaeology, vol. 4, no.1-4, 2002: 225-292.

\section{Thompson 1998}

Thompson, Lydia. The Yi'nan Tomb: Narrative and Ritual in Pictorial Art of the Eastern Han (25-220 C.E.). PhD thesis, New York University, 1998.

\section{Twitchett and Fairbank 1987}

Twitchett, Denis and Fairbank, John. eds., The Cambridge History of China, Volume 1: The The Ch'in and Han Empires, 221 B.C.-A.D. 220. Cambridge: Cambridge University Press 1987.

\section{von Falkenhausen 1993}

von Falkenhausen, Lothar. 'On the Historiographical Orientation of Chinese Archaeology,' Antiquity, vol. 67, 1993: 839-849.

\section{von Falkenhausen 1995}

von Falkenhausen, Lothar. 'The Regionalist Paradigm in Chinese Archaeology,' in Kohl, Philip and Fawcet, Clare. eds., Nationalism, Politics and the Practice of Archaeology. Cambridge: Cambridge University Press, 1995: 198-217.

\section{Wagner 1993}

Wagner, Donald. Iron and steel in ancient China. Leiden: Brill, 1993.

\section{Wallace 2010}

Wallace, Leslie. Chasing the Beyong: Depictions of Hunting in Eastern Han Dynasty Tomb Reliefs (25-220 CE) from Shaanxi and Shanxi. PhD thesis, University of Pittsburgh, 2010.

\section{Wu Hung 1986}

Wu Hung. 'Buddhist Elements in Early Chinese Art (2nd and 3rd Centuries A.D.)', Artibus Asiae, , no. 3/4, 1986: 263-352.

\section{Wu Hung 1992a}

Wu Hung. The Wu Liang Shrine: The Ideology of Early Chinese Pictorial Art. Stanford: Stanford University Press, 1992. 


\section{Wu Hung 1994b}

Wu Hung. 'Beyond the "Great Boundary": Funerary Narrative in the Cangshan Tomb', in John Hay, ed., Boundaries in China. London: Reaktion Press: 81-104

\section{Wu Hung 1995}

Wu Hung. Monumentality in Early Chinese Art and Architecture. Stanford: Stanford University Press, 1995.

\section{Wu Hung 2003}

Wu Hung. 'On Rubbings: Their Materiality and Historicity'. In J. Zeitlin and L. Liu eds., Writing and materiality in China: essays in honor of Patrick Hanan. Harvard University Press, 2003.

\section{Yü Ying-shih 1967}

Yü Ying-shih. Trade and Expansion in Han China: A Study in the Structure of Sino-Barbarian Economic Relations. Berkeley: California University Press, 1967.

\section{Maps}

\section{Zhongguo dizhi tuji}

Zhongguo dizhi tuji bianweihui 《中国地质图集》编委会. Zhongguo dizhi tuji 中国 地质图集. Beijing: Dizhi chubanshe, 2002.

\section{Zhongguo lishi dituji}

Tan Qixiang 谭其骧. Zhongguo lishi dituji 中国历史地图集, 8 vols. Beijing: Zhongguo ditu chubanshe, 1982-1988. 